\title{
Global Initiative for Chronic Obstructive
}

\section{L ung \\ Disease}

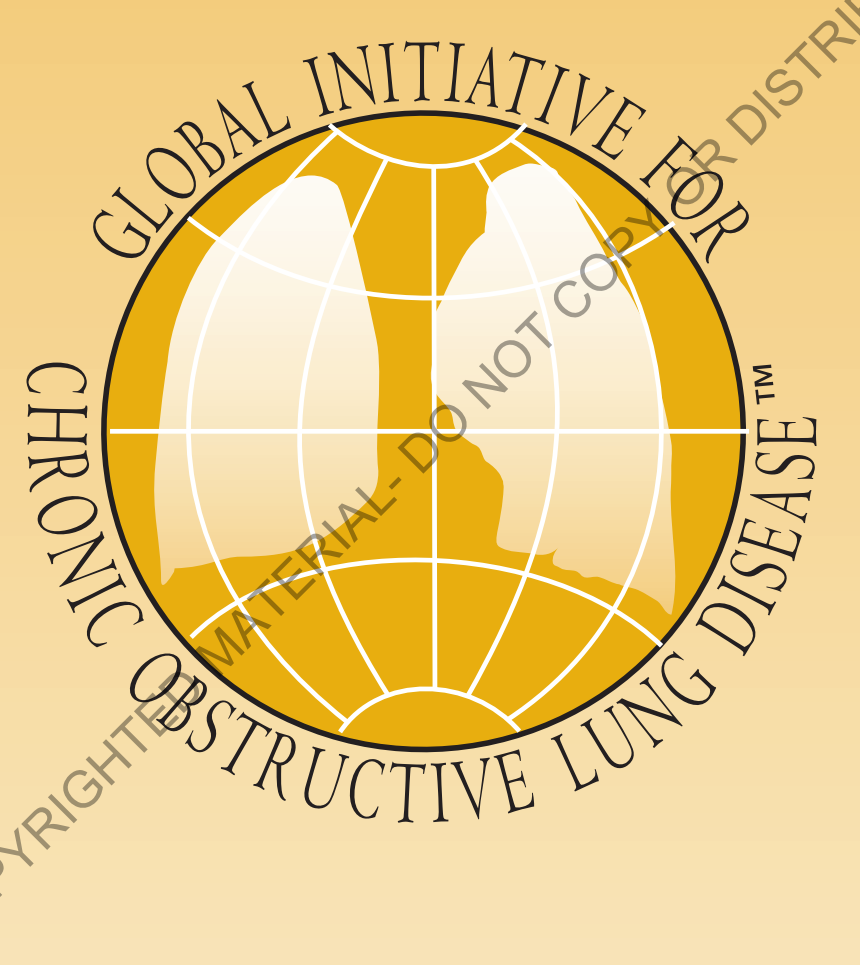

GLOBAL STRATEGY FOR THE DIAGNOSIS, MANAGEMENT, AND PREVENTION OF CHRONIC OBSTRUCTIVE PULMONARY DISEASE 


\section{GLOBAL INITIATIVE FOR CHRONIC OBSTRUCTIVE LUNG DISEASE}

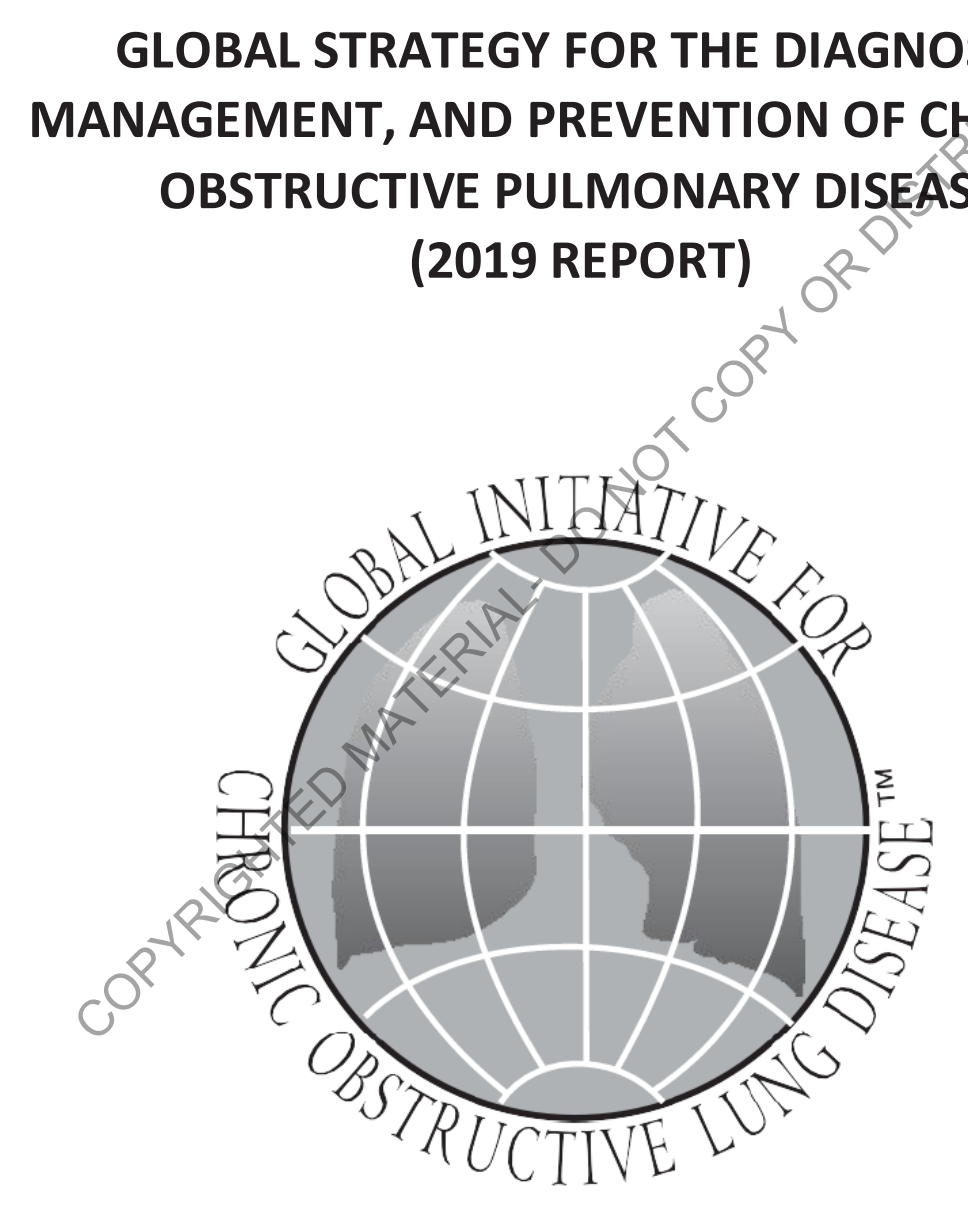

(C) 2019 Global Initiative for Chronic Obstructive Lung Disease, Inc. 
GOLD BOARD OF DIRECTORS (2018)

Alvar Agusti, MD, Chair

Respiratory Institute,

Hospital Clinic, IDIBAPS

Univ. Barcelona and Ciberes

Barcelona, Spain

Bartolome R. Celli, MD

Brigham and Women's Hospital

Boston, Massachusetts, USA

Rongchang Chen, MD

Guangzhou Institute of Respiratory

Disease

Guangzhou, PRC

Gerard Criner, MD

Temple University School of Medicine

Philadelphia, Pennsylvania, USA

Peter Frith, MD

Flinders University

Adelaide, Australia

David Halpin, MD

Royal Devon and Exeter Hospital

Devon, UK

M. Victorina López Varela, MD

Universidad de la República

Montevideo, Uruguay

Masaharu Nishimura, MD

(retired May, 2018)

Hokkaido University School of Medicine

Sapporo, Japan

Sundeep Salvi, MD

Chest Research Foundation

Pune, India

Claus Vogelmeier, MDO

University of Marburg

Marburg, Germany

\section{GOLD PROGRAM DIRECTOR}

Rebecca Decker, MSJ

Fontana, Wisconsin, USA

\section{EDITORIAL ASSISTANCE}

Ruth Hadfield, PhD, Sydney, Australia

Michael Hess, RRT RPFT, Michigan, USA

\section{GOLD SCIENCE COMMITTEE}

(2018)

Claus Vogelmeier, MD, Chair

University of Marburg

Marburg, Germany

Alvar Agusti, MD

Respiratory Institute, Hospital

Clinic, IDIBAPS

Univ. Barcelona and Ciberes

Barcelona, Spain

Antonio Anzueto, MD

University of Texas

Health Science Center

San Antonio, Texas, USA

Peter Barnes, MD

National Heart and Lung Institute

London, United Kingdom

Jean Bourbeau, MD

McGill University Health Centre

Montreal, Canada

Gerard Criner, MD

Temple University Sehool of Medicine

Philadelphia, Pennsylvania, USA

Maria Montes de Oca, MD

Hospital Universitario de Caracas

Caracás, Venezuela

Beter Frith, MD

Repatriation General Hospital

Adelaide, Australia

David Halpin, MD

Royal Devon and Exeter Hospital

Devon, United Kingdom

MeiLan Han, MD MS

University of Michigan

Ann Arbor, MI, USA
Fernando J. Martinez, MD MS

New York-Presbyterian Hospital/

Weill Cornell Medical Center

New York, NY, USA

Alberto Papi, MD

University of Ferrara

Ferrara, Italy

lan Pavord, MA DM

University of Oxford

Oxford, UK

Nicolas Roche, MD

University Paris Descartes

Hôpital Cochin APHP

Paris, France

Donald Sin, MD

St. Paul's Hospital, University of British Columbia

Vancouver, Canada

Dave Singh, MD

University of Manchester

Manchester, UK

Robert Stockley, MD

University Hospital

Birmingham, UK

Jørgen Vestbo, MD

University of Manchester

Manchester, England, UK

Jadwiga A. Wedzicha, MD

Imperial College London

London, UK

M. Victorina López Varela, MD Universidad de la República

Hospital Maciel

Montevideo, Uruguay

* Disclosure forms for GOLD Committees are posted on the GOLD Website, www.goldcopd.org 


\section{GLOBAL STRATEGY FOR THE DIAGNOSIS, MANAGEMENT, AND PREVENTION OF COPD}

(2019)

GOLD ASSEMBLY

\section{ARGENTINA}

Dr Eduardo A. Schiavi

Buenos Aires, Argentina

AUSTRALIA

Peter Frith, MD

Adelaide, South Australia, Australia AUSTRIA

Dr Otto Chris Burghuber

BANGLADESH

Prof Md Mostafizur Rahman

Dhaka, Bangladesh

Dr Kazi S. Bennoor

Dhaka, Bangladesh

BRAZIL

Aquiles Camelier, MD

Sao Paulo, Brazil

Fernando Lundgren, MD

CANADA

Dr Dennis E. O'Donnell

Kingston, Ontario, Canada

CHILE

Dr Manuel Barros

CHINA

Jiangtao Lin, MD

Beijing, China

Fu-Qiang Wen, MD, PhD

Chengdu, Sichuan, China

Nan-Shan Zhong, MD

Guangzhou, China

COLOMBIA

Alejandro Casas, MD

Vice-Director, COPD Department

Latin American Thoracic Society

\section{CROATIA}

Neven Miculinic, MD

Zagreb, Croatia

\section{CZECH REPUBLIC}

Stanislav Kos, MD, PhD, FCCP

Czech Civic Association Against tung

Diseases

Pilsen, Czech Republic

DOMINICAN REPUBLIC

Dr Eduardo Gautreau de Windt

Provincia Santo Domingo,

Dominican Republic

EGYPT

Hisham Tarraf, MD

Cairo, Egypt

EL SALVADOR

Dr Victor Castro Gòmez

San Salvador, El Salvador

FRANCE

Gaetan Deslée, MD

Hôpital Maison Blanche

Reims, France

GEORGIA

Maia Gotua, MD, PhD

Tbilisi, Georgia

\section{HONG KONG CHINA}

David S.C. Hui, MD

Shatin, N.T. Hong Kong

INDONESIA

Professor Faisal Yunus

\section{IRAN}

Dr Masjedi Mohammad Reza

Tehran, Iran

Mohammad Ashkan Moslehi, MD

Shiraz, Iran

IRELAND

Timothy J. McDonnell, MD

Dublin, Ireland

ISRAEL

Zvi G. Fridlender, MD, MSC

Jerusalem, Israel

ITALY

Professor Lorenzo Corbetta

Florence, Italy

JAPAN

Takahide Nagase, MD

Tokyo, Japan

Michiaki Mishima, MD

Kyoto, Japan

JORDAN

Haytham El-Khushman

Amman, Jordan

\section{KAZAKHSTAN}

Damilya Nugmanova, MD, PhD, DSci

Almaty, Kazakhstan

KOREA

Yeon-Mok Oh, MD

Seoul, South Korea

KUWAIT

Professor Mousa Khadadah

Kuwait University

\section{KYRGYZSTAN}

Talant Sooronbaev, MD

Bishkek, Kyrgyzstan

\section{MALTA}

Prof Joseph M Cacciottolo

Pieta, Malta

LEBANON

Mirna Waked, MD

Beirut, Lebanon

MOLDOVA

Alexandru Corlateanu, MD, PhD

ERS National Delegate

Republic of Moldova

\section{MONGOLIA}

Dr Oyunchimeg

Chair of International Cooperation

\section{NORWAY}

Rune Nielsen, MD

Bergen, Norway

\section{PAKISTAN}

Professor Javaid Khan

Karachi, Pakistan

Dr Mohammad Osman Yusuf Islamabad, Pakistan

\section{PHILIPPINES}

Teresita S. deGuia, MD

Quezon City, Philippines

\section{POLAND}

Ewa Nizankowska-

Mogilnicka,MD,PhD,

Krakow, Poland

Pawel Śliwiński

Warsaw, Poland

Paul Kuca, MD

Warsaw, Roland

ROMANIA

Florin Mihaltan, MD

Bucharest, Romania

Ruxandra Ulmeanu, MD

Bucharest, Romania

\section{RUSSIA}

Alexander Chuchalin, MD

Moscow, Russia

\section{SINGAPORE}

Kian-Chung Ong, MD

Wan-Cheng Tan, MD,

Chair, Asian Pacific COPD

Roundtable

SLOVAK REPUBLIC

Ruzena Tkacova, MD PhD

Kosice, Slovakia

SPAIN

Dr Patricia Sobradillo

SYRIA

Yousser Mohammad, MD

Lattakia, Syria

TURKEY

Prof Dr. Hakan Gunen

Malatya, Turkey

Nurdan Kokturk, MD

Ankara, Turkey

URUGUAY

Mará Victorina López, MD

Montevideo, Uruguay

\section{VENEZUELA}

Maria Montes de Oca, MD

Caracas, Venezuela

\section{VIETNAM}

Sy Duong-Quy, MD, PhD, FCCP Lam Dong Medical College, Vietnam Ngo Quy Chau, MD, PhD

Hanoi, Vietnam

Le Thi Tuyet Lan, MD, PhD

Ho Chi Minh City, Vietnam 


\section{PREFACE}

In 2011, the Global Initiative for Chronic Obstructive Lung Disease (GOLD) released a consensus report, Global Strategy for the Diagnosis, Management, and Prevention of COPD. It recommended a major revision in the management strategy for COPD that was first presented in the original 2001 document. Reports released in January 2013, January 2014, January 2015, January 2016, January 2017 and January 2018 were based on updated scientific literature published since the completion of the 2011 document but maintain the same treatment paradigm. The 2015 update added an Appendix on Asthma COPD Overlap Syndrome, material prepared jointly by the GOLD and GINA Science Committees.

The assessment of COPD proposed by GOLD has been based on the patient's level of symptoms, future risk of exacerbations, the extent of airflow limitation, the spirometric abnormality, and the identification of comorbidities. The "ABCD" assessment tool of the 2011 GOLD úpdate was a major advance from the simple spirometric grading system of the earlier versions of GOLD because it incorporated multimodality assessment, symptom burden and hightighted the importance of exacerbation prevention in the management of COPD. Howeventhere were some important limitations to this scheme. The ABCD assessment tool performed ho better than spirometric grades for mortality prediction or other important health outcomes. to address these and other concerns (while at the same time maintaining consistency and simplicity for the practicing clinician), a refinement of the $A B C D$ assessment tool was proposed in the 2017 GOLD Report that separates spirometric grades from the "ABCD" groups. Thus, $A B C D$ groups and their associated implications for pharmacotherapy recommendations will be derived exclusively from patient symptoms and their history of exacerbations. The separation of airflow limitation from clinical parameters makes it clearer what is being evaluated and ranked. This revised assessment tool acknowledges the limitations of FEV in influencing some therapeutic decisions for individualized patient care and highlights the importance of patient symptoms and exacerbation risks in patients with COPD. Spirometry remains key in the diagnosis, prognostication and treatment with non-pharmacological therapies.

The GOLD report has been used worldwide as a "strategy document" for healthcare professionals to use as a tool to implement effective management programs based on local healthcare systems. The $A B C D$ assessment tool has been used by many to structure their assessment of COPD symptom burden and create treatment plans. The 2017 revision introduced a refinement of the $A B C D$ system by separating spirometric evaluation from analysis of symptoms/exacerbation history with the recommendations for pharmacotherapy being based primarily on the patient needs (symptom reduction and/or exacerbation prevention). Following feedback from GOLD report users, the committee identified there was some misinterpretation regarding the use of the $A B C D$ system. Therefore, in the 2019 revision initial treatment (based on $A B C D$ ) is separated from follow-up treatment (based on the patient's major treatable trait(s) and the currently used drug(s)). In addition, we introduce the blood eosinophil count as a biomarker for estimating the efficacy of inhaled corticosteroids for the prevention of exacerbations.

GOLD has been fortunate to have a network of international distinguished health professionals from multiple disciplines. Many of these experts have initiated investigations of the causes and prevalence 
of COPD in their countries, and have developed innovative approaches for the dissemination and implementation of the GOLD management strategy. The GOLD initiative will continue to work with National Leaders and other interested healthcare professionals to bring COPD to the attention of governments, public health officials, healthcare workers, and the general public to raise awareness of the burden of COPD and to develop programs for early detection, prevention and approaches to management.

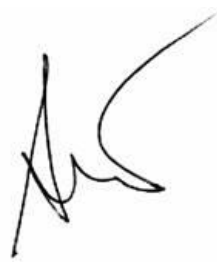

Alvar G. Agusti, MD

Chair, GOLD Board of Directors

Hospital Clínic,

Universitat de Barcelona,

Villarroel 170, 08036

Barcelona, Spain

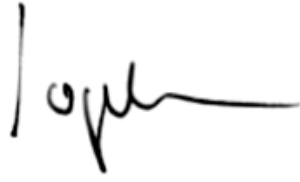

Claus Vogelmeier, MD

Chair, GOLD Science Committee

Department of Medicine,

Pulmonary and Critical Care Medicine

University-Medical Center Gießen and Marburg.

Philipps-Universität Marburg,

Bałdingerstraße

35043 Marburg, Germany 


\section{GLOBAL STRATEGY FOR DIAGNOSIS, MANAGEMENT AND PREVENTION OF COPD 2019 UPDATE $^{\dagger}$}

\section{METHODOLOGY}

When the Global Initiative for Chronic Obstructive Lung Disease (GOLD) program was initiated in 1998, a goal was to produce recommendations for management of COPD based on the best scientific information available. The first report, Global Strategy for Diagnosis, Management and Prevention of COPD was issued in 2001. In 2006 and again in 2011 a complete revision was prepared based on published research. These reports, and their companion documents, have been widely distributed and translated into many languages and can be found on the GOLD website (www.goldcopd.org).

The GOLD Science Committee ${ }^{\ddagger}$ was established in 2002 to review published research on COPD management and prevention, to evaluate the impact of this research on recommendations in the GOLD documents related to management and prevention, and to postyearly updates on the GOLD website. Its members are recognized leaders in COPD research and clinical practice with the scientific credentials to contribute to the task of the Committee and are invited to serve in a voluntary capacity.

Updates of the 2011-revised report were released in January 2013, 2014, 2015, and 2016. The 2017 GOLD Report, the 4th major revision of GOLD, incorporates an update of recent information that has been reviewed by the science committee from 2015 to 2016 and a comprehensive reassessment and revision of prior recommendations for the diagnosis, assessment and treatment of COPD.

Process: To produce the GOLD report, a PubMed (National Center for Biotechnology Information, U.S. National Library of Medicine, Bethesda MD, USA) search was completed using search fields established by the Committee: 1) COPD, All Fields, Adult: 19+ years, only items with abstracts, Clinical Trial, Meta-analysis, Human.

The literature included in this 2019 edition of the GOLD Report has been updated to include important literature in COPD research and care that was published from January 2017 to July 2018. Publications in peer reviewed journals not captured by PubMed may be submitted to the Chair, GOLD Science Committee, providing the full paper, including abstract, is submitted in (or translated into) English.

Members of the Committee receive a summary of citations and all abstracts. Each abstract is assigned to two Committee members, although all members are offered the opportunity to provide input on any abstract. Members evaluate the abstract or, subject to her/his judgment, the full publication, by answering four specific written questions from a short questionnaire, to indicate if the scientific data

\footnotetext{
† The Global Strategy for Diagnosis, Management and Prevention of COPD (updated 2019), the Pocket Guide (updated 2019) and the complete list of references examined by the Committee is available on the GOLD website: www.goldcopd.org.

$\ddagger$ GOLD Science Committee Members (2018-2019): C. Vogelmeier, Chair, A. Agusti, A. Anzueto, P. Barnes, J. Bourbeau, G. Criner, P. Frith, D. Halpin, M. Han, F. Martinez, A. Papi, I. Pavord, N. Roche, D. Sin, D. Singh, R. Stockley, J. Vestbo, J. Wedzicha, M. Victorina Lopez Varela.
} 
presented impacts on recommendations in the GOLD report. If so, the member is asked to specifically identify modifications that should be made.

The GOLD Science Committee meets twice yearly to discuss each publication that was considered by at least one member of the Committee to potentially have an impact on the management of COPD. The full Committee then reaches a consensus on whether to include it in the report, either as a reference supporting current recommendations, or to change the report. In the absence of consensus, disagreements are decided by an open vote of the full Committee.

Recommendations by the GOLD Committees for use of any medication are based on the best evidence available from the published literature and not on labeling directives from government regulators. The Committee does not make recommendations for therapies that have not been approved by at least one major regulatory agency.

\section{GOLD 2019 SUMMARY OF KEY CHANGES}

The GOLD 2019 report is a revision of the GOLD 2017 report. Following systematic literature searches and double-blind review by the GOLD Science committee, the GOLD report has been updated to include key peer-reviewed research publications from January 2017 to July 2018.

\section{Throughout}

Figures and Tables have been updated to improve appearance and clarity. Table 3.3 and Figure 4.1 have been revised. New figures have been inserted for Management cycle (Figure 4.2), Follow-up pharmacological treatment (Figure 4.3), and interventional bronchoscopic and surgical treatments for COPD (Figure 4.5).

\section{Chapter 1}

There is growing evidence that indoor biomass exposure to modern and traditional fuels used during cooking may predispose women to develop COPD in many developing countries. (Sana et al. 2018)

Poverty is consistently associated with airflow obstruction and lower socioeconomic status is associated with an increased risk of developing COPD. (Townend et al. 2017)

There is evidence that HIV patients are at increased risk of COPD compared to HIV negative controls (11 studies; pooled odds ratio for 1.14 (95\% Cl 1.05,1.25). (Bigna et al. 2018)

\section{Chapter 2}

A risk score based on routine data from electronic health records in primary care may facilitate casefinding. (Haroon et al. 2017)

Systematic active case-finding in a primary care setting via mail-out of a screening questionnaire was also found to be an effective way to identify undiagnosed COPD patients. (Jordan et al. 2016) 


\section{Chapter 3}

A new section on blood eosinophil count has been added to Chapter 3. The pulmonary rehabilitation and self-management sections have also been updated.

A systematic review of injectable vaccines in COPD patients identified twelve randomized studies for inclusion and observed injectable polyvalent pneumococcal vaccination provides significant protection against community-acquired pneumonia, although no evidence indicates that vaccination reduced the risk of confirmed pneumococcal pneumonia, which was a relatively rare event. Vaccination reduced the likelihood of a COPD exacerbation, and moderate-quality evidence suggests the benefits of pneumococcal vaccination in COPD patients. Evidence was insufficient for comparison of different pneumococcal vaccine types. (Walters et al. 2017)

Most studies with LABA/LAMA combinations have been performed in patients with a low rate of exacerbations. One study in patients with a history of exacerbations indicated that a combination of long-acting bronchodilators is more effective than long-acting bronchodilator monotherapy for preventing exacerbations. (Wedzicha et al. 2013) Another large study found that combining a LABA with a LAMA did not reduce exacerbation rate as much as expected compared with a LAMA alone. (Calverley et al. 2018) Another study in patients with a history of exacerbations confirmed that a combination LABA/LAMA decreased exacerbations to a greater extent than an ICS/LABA combination. (Wedzicha et al. 2014) However, another study in a population with high exacerbation risk ( $\geq 2$ exacerbations and/or 1 hospitalization in the previous year) reported that ICS/LABA decreased exacerbations to a greater extent than an LABA/LAAMA combination at higher blood eosinophil concentrations (see Chapter 2). (Lipson et al. 2018)

However, in moderate COPD, fluticasone furoate alone or in combination with vilanterol was associated with slower decline in FEV Cómpared with placebo or vilanterol alone by on average 9 $\mathrm{ml} /$ year.(Calverley et al., 2018)

\section{Chapter 4}

The algorithms for the initiation and follow-up management of pharmacological treatment have been revised. New diagrams (Figures 4.1, 4.2 and 4.3) have been developed to improve clarity and incorporate recent/advances in knowledge. The text has been updated to incorporate the latest evidence from RCTs.

A model for the INITIATION of pharmacological management of COPD according to the individualized assessment of symptoms and exacerbation risk following the $A B C D$ assessment scheme is shown in Figure 4.1. There is a lack of high quality evidence supporting initial pharmacological treatment strategies in newly diagnosed COPD patients. Figure 4.1 is an attempt to provide clinical guidance using the best available evidence.

Following implementation of therapy, patients should be reassessed for attainment of treatment goals and identification of any barriers for successful treatment (Figure 4.2). Following review of the patient response to treatment initiation, adjustments in pharmacological treatment may be needed. 
A separate algorithm is provided for FOLLOW-UP treatment, where the management is still based on symptoms and exacerbations, but the recommendations do not depend on the patient's GOLD group at diagnosis (Figure 4.3). These follow-up recommendations are designed to facilitate management of patients taking maintenance treatment(s), whether early after initial treatment or after years of follow-up. These recommendations incorporate recent evidence from clinical trials and the use of peripheral blood eosinophil counts as a biomarker to guide the use of ICS therapy for exacerbation prevention (see more detailed information regarding blood eosinophil counts as a predictor of ICS effects in Chapter 3).

Figure 4.3 suggests escalation and de-escalation strategies based on available efficacy as well as safety data. The response to treatment escalation should always be reviewed, and de-escalation should be considered if there is a lack of clinical benefit and/or side effects occur. De-escalation may also be considered in COPD patients receiving treatment who return with resolution of some symptoms that subsequently may require less therapy. Patients, in whom treatment modification is considered, in particular de-escalation, should be undertaken under close medical supervision. We are fully aware that treatment escalation has not been systematically tested; trials of defescalation are also limited and only include ICS.

Specific recommendations for treatment of GOLD groups $A, B, C$ and $D$ have been revised. Recommendations regarding the follow-up pharmacologioal management have also been updated and emphasizing the need to review, assess and adjust.

The non-pharmacological section has also been updated and revised.

The section on Interventional bronchoscopy and surgery has also been updated along with the corresponding Figure 4.5.

\section{Chapter 5}

Nebulized budesonide alone may be a suitable alternative for treatment of exacerbations in some patients,(Maltais et al., 2002, Gunen et al., 2007, Stallberg et al., 2009) and provides similar benefits to intravenous methyprednisolone, although the choice between these options may depend on local cost issues. (Ding et al., 2016) Intensified combination therapy with ICS/LABA for 10 days at URTI onset could be associated with a reduction of exacerbations, particularly in patients with severe disease.(Stolz et al., 2018)

In a recent $\mathrm{RCT}$, the addition of doxycycline to oral corticos teroid an outpatient setting did not prolong time to next exacerbation. (van Velzen et al., 2017)

A small pilot RCT $(n=29)$ reported that six weeks of high-flow nasal cannula oxygen therapy reduced hypercapnia and improved health-related quality of life in patients with stable hypercapnic COPD.(Nagata et al., 2018)

Once patients improve and can tolerate at least 4 hours of unassisted breathing, NIV can be directly discontinued without any need for a "weaning" period.(Sellares et al., 2017) 
One recent RCT showed that telemonitoring did not change hospitalization or exacerbation rates in patients with COPD. (Walker et al., 2018)

\section{GOLD 2019 NEW REFERENCES}

Alphabetical list of new references added to the GOLD 2019 edition:

Abdallah, SJ et al., Eur Respir J 2017, 50, 4, Epub.

Alison, JA et al., Respirology 2017, 22, 4, 800.

Bafadhel, M et al., Lancet Respir Med 2018, 6, 2, 117.

Bai, C et al., Int J Chron Obstruct Pulmon Dis 2017, 12, 3329.

Beaumont, M et al., Clin Resp J 2018, 12, 7, 2178.

Beaumont, M et al., Eur Respir J 2018, 51, 1, Epub.

Bekkat-Berkani, R et al., BMC Pulm Med 2017, 17, 1, 79.

Bigna, JJ et al., Lancet Glob Health 2018, 6, 2, e193.

Bourne, S et al., BMJ Open 2017, 7, 7, e014580.

Brook, RD et al., Heart 2017, 103, 19, 1536.

Calverley, PMA et al., Am J Respir Crit Care Med 2018, 197, 1,47.

Calverley, PMA et al., Lancet Respir Med 2018, 6, 5, 337.

Calverley, PMA et al., Am J Respir Crit Care Med 2017, 196, 9, 1219.

Cardim, AB et al., Respir Care 2016, 61, 11, 1552.

Casanova, C et al., Eur Respir J 2017, 50, 5, Epub.

Chapman, KR et al., Am J Respir Crit Care Med 2018, 198, 3, 329.

Charususin, N et al., Thorax 2018, 73, 10,942.

Chuang, HY et al., J Clin Nurs 2017, 26, 23-24, 4830.

Coultas, DB et al., Ann Am Thoracsoc 2018, 15, 4, 470.

Crim, C et al., Respir Med 2017, 131, 27.

Criner, GJ et al., Am J Respic Crit Care Med 2018, Epub.

Dal Negro, RW et al., EurRespir J 2017, 50, 4, Epub.

Daubin, C et al., Intensive Care Med 2018, 44, 4, 428.

Ding, Z et al., Clin Genet 2018, Epub doi: 10.1111/cge.13373.

Divo, MJ et al., PLoS One 2018, 13, 2, e0193143.

Dransfield, MT et al., Ann Am Thorac Soc 2018, 15, 5, 608.

Guerra, B et al., BMC Med 2018, 16, 1, 33.

Halpin, DMG et al., ERJ Open Res 2018, 4, 2, Epub.

Haroon, S et al., Eur Respir J 2017, 49, 6, Epub.

Herth, FJ et al., Lancet Respir Med 2016, 4, 3, 185.

Hohlfeld, JM et al., Lancet Respir Med 2018, 6, 5, 368.

Holland, AE et al., Thorax 2017, 72, 1, 57.

Horton, EJ et al., Thorax 2018, 73, 1, 29.

Jordan, RE et al., Lancet Respir Med 2016, 4, 9, 720.

Kemp, SV et al., Am J Respir Crit Care Med 2017, 196, 12, 1535.

Kessler, R et al., Eur Respir J 2018, 51, 1, Epub. 
Kopsaftis, Z et al., Cochrane Database Syst Rev 2018, 6, Cd002733.

Lahham, A et al., Int J Chron Obstruct Pulmon Dis 2016, 11, 3121.

Landis, SH et al., Copd 2017, 14, 4, 382.

Lenferink, A et al., Cochrane Database Syst Rev 2017, 8, Cd011682.

Lipson, DA et al., N Engl J Med 2018, 378, 18, 1671.

Liu, L et al., Eur Rev Med Pharmacol Sci 2018, 22, 3, 829.

Luckett, T et al., Eur Respir J 2017, 50, 2, Epub.

Martinez, FJ et al., Am J Respir Crit Care Med 2018, Epub doi: 10.1164/rccm.201712-24930C.

Martinez, FJ et al., Am J Respir Crit Care Med 2017, 195, 7, 881.

Mcelvaney, NG et al., Lancet Respir Med 2017, 5, 1, 51.

Miravitlles, M et al., Eur Respir J 2017, 50, 5, Epub.

Nagata, K et al., Ann Am Thorac Soc 2018, 15, 4, 432.

Osadnik, CR et al., Cochrane Database Syst Rev 2017, 7, Cd004104.

Oshagbemi, OA et al., Am J Respir Crit Care Med 2017, 195, 10, 1402.

Papi, A et al., Lancet 2018, 391, 10125, 1076.

Rose, L et al., Eur Respir J 2018, 51, 1, Epub.

Sana, A et al., BMJ Open Respir Res 2018, 5, 1, e000246.

Sellares, J et al., Eur Respir J 2017, 50, 1, Epub.

Southworth, T et al., Eur Respir J 2018, 52, 1, Epub.

Stolz, D et al., Am J Respir Crit Care Med 2018, 197, 9, 1136.

Stone, IS et al., Am J Respir Crit Care Med 2016, 193, 7, 717.

Townend, J et al., Eur Respir J 2017, 49, 6, Epub.

Van Velzen, P et al., Lancet Respir Med 2017, 5, 6, 492.

Walker, PP et al., Am J Respir Crit Care Med 2018, Epub doi: 10.1164/rccm.201712-2404OC.

Wang, JB et al., PLoS One 2018, 13, 7, e0198681.

Watz, H et al., Int J Chron Obstruct Pulmon Dis 2018, 13, 813.

Yun, JH et al., J Allergy Clin Immunol 2018, 141, 6, 2037.

Zhang, HL et al., Int J Chron Obstruct Pulmon Dis 2017, 12, 2333.

Zhou, Y et al., N Engl J Med 2017, 377, 10, 923.

Zhu, S et al., Complement Ther Med 2018, 39, 36. 


\section{TABLE OF CONTENTS}

PREFACE

GLOBAL STRATEGY FOR DIAGNOSIS, MANAGEMENT AND PREVENTION OFCOPD 2019 UPDATE..................................... I

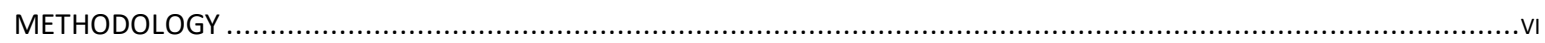

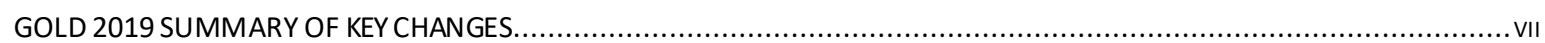

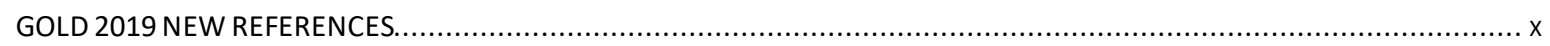

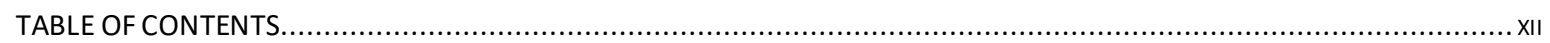

GLOBAL STRATEGY FOR THE DIAGNOSIS, MANAGEMENT, AND PREVENTION OF COPD............................................

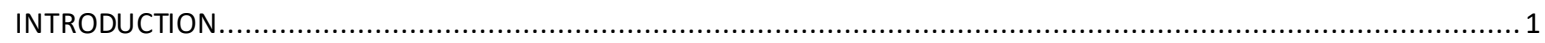

BACKGROUND

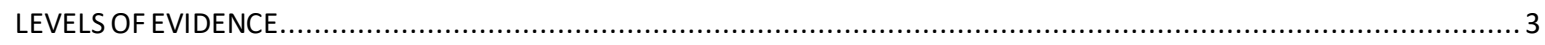

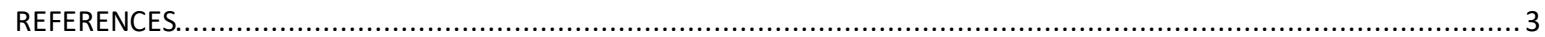

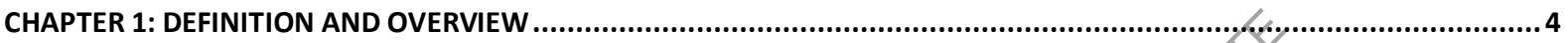

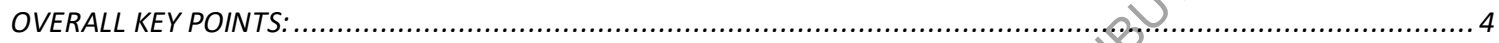

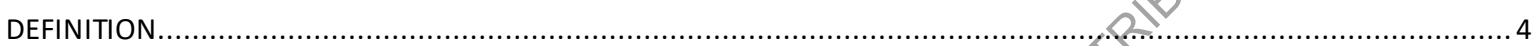

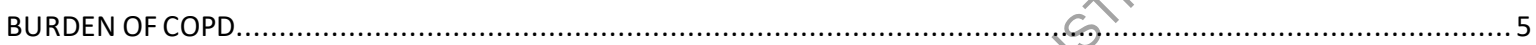

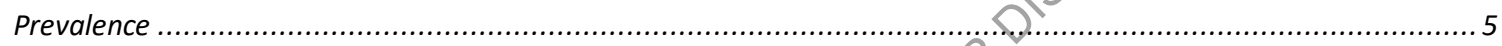

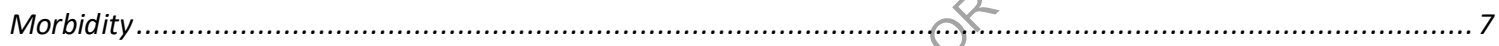

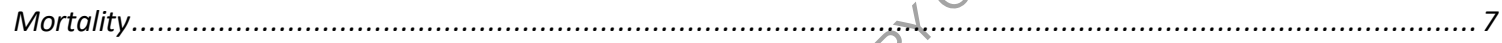

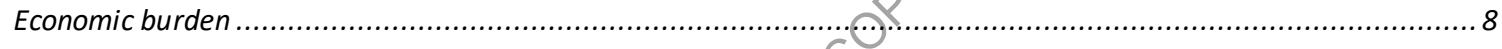

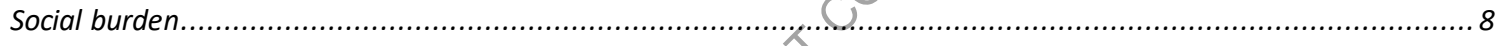

FACTORS THAT INFLUENCE DISEASE DEVELOPMENT AND PROGRESSION .....................................................

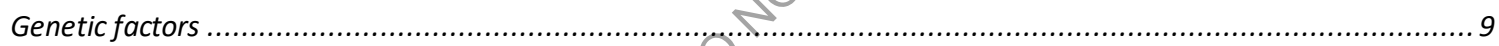

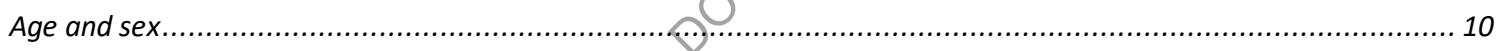

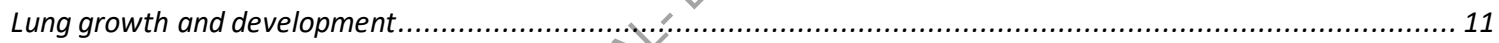

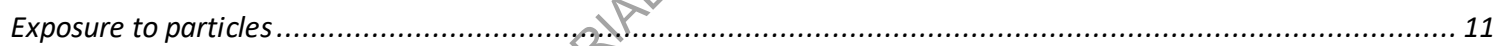

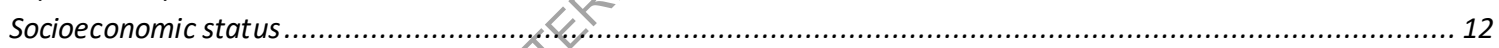

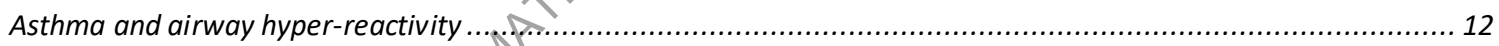

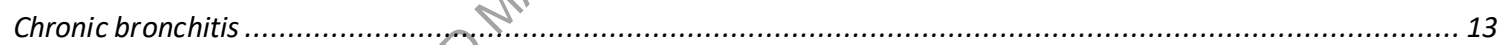

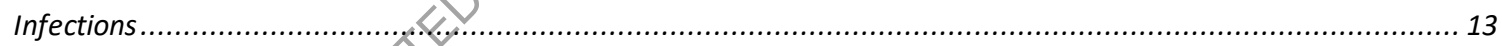

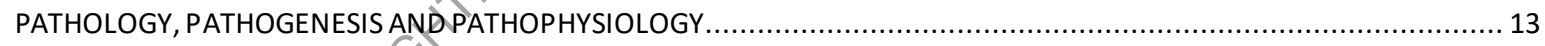

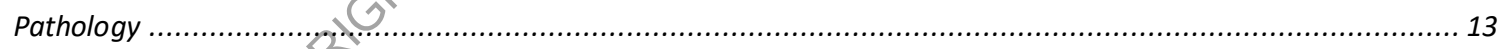

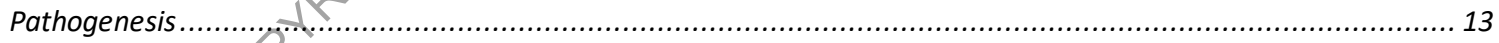

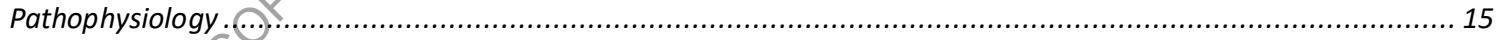

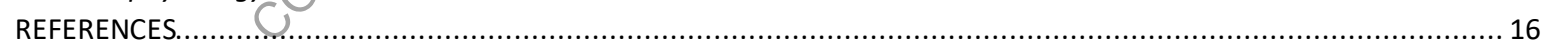

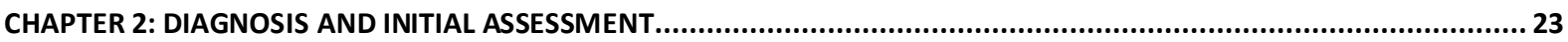

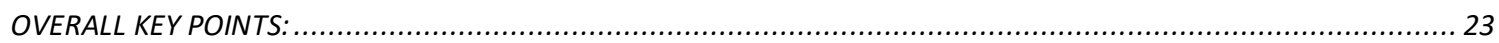

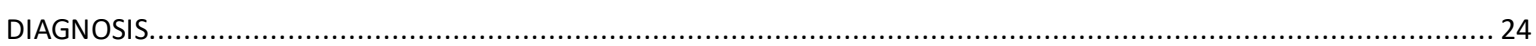

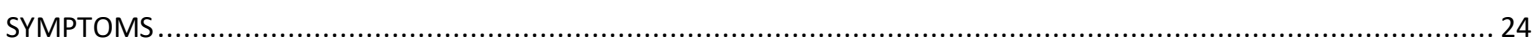

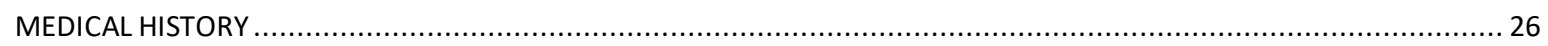

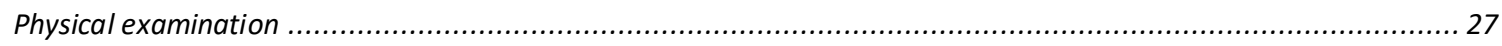

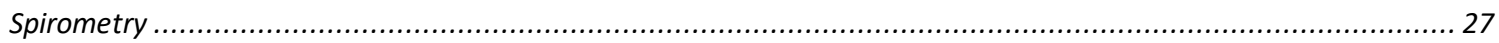

ASSESSMENT

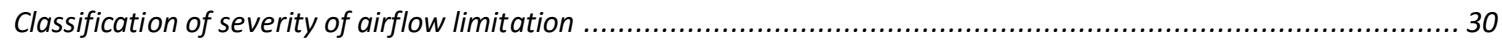

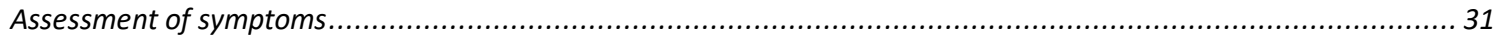

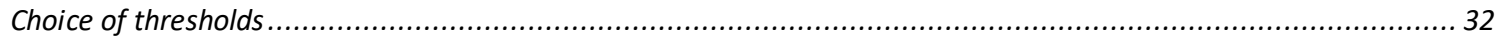

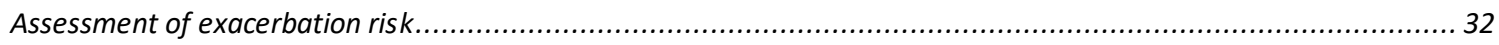

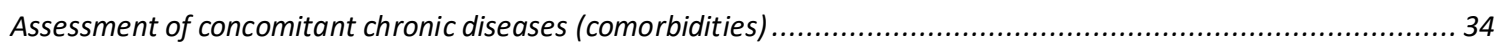

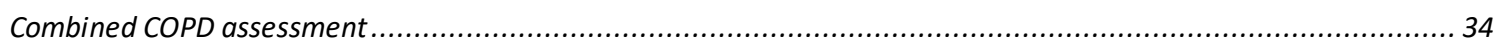

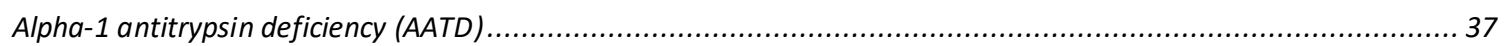




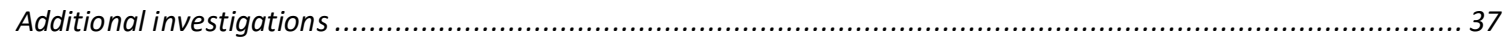

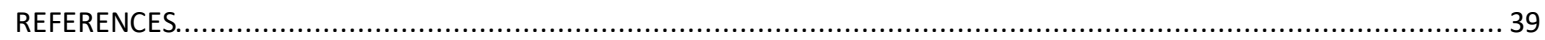

CHAPTER 3: EVIDENCE SUPPORTING PREVENTION AND MAINTENANCE THERAPY ................................................45

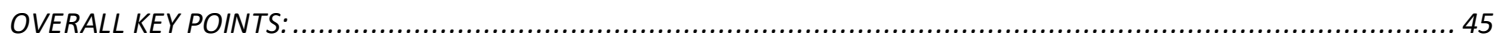

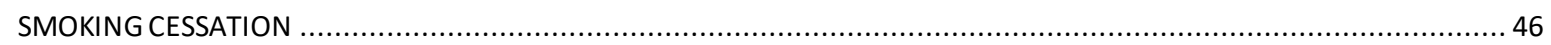

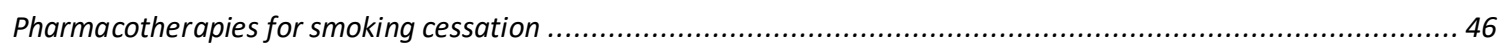

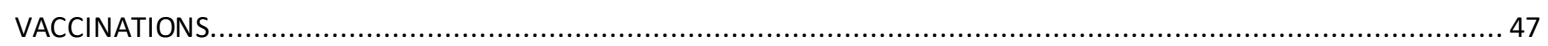

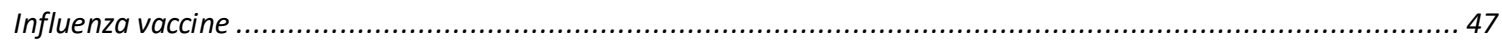

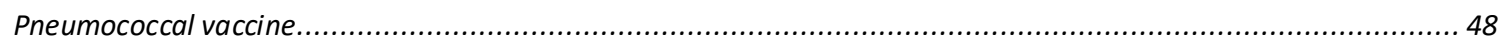

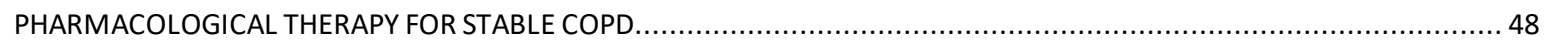

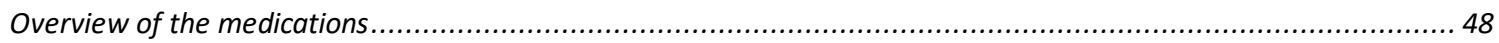

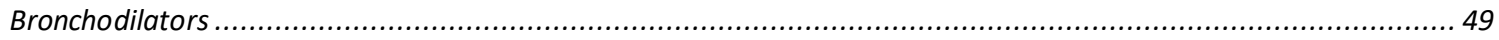

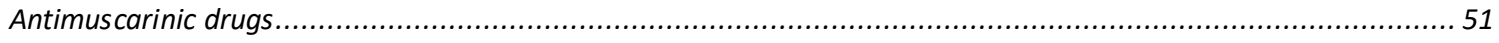

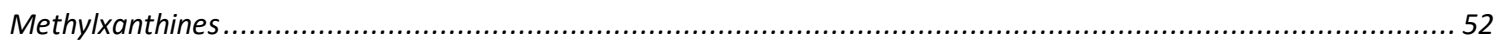

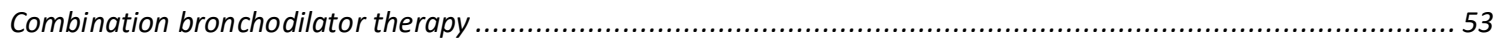

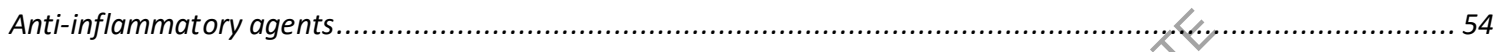

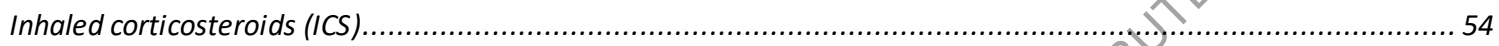

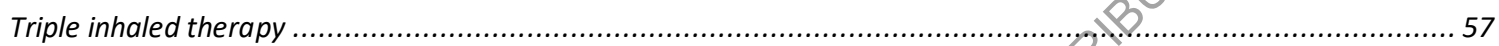

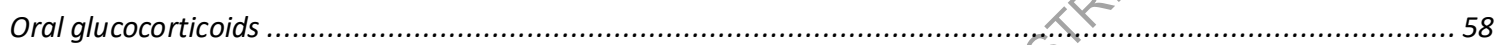

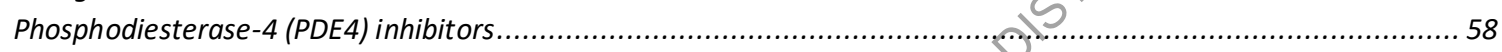

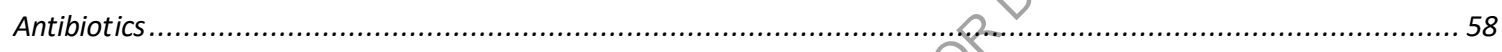

Mucolytic (mucokinetics, mucoregulators) and antioxidant agents (NAC, carbocysteine) .................................59

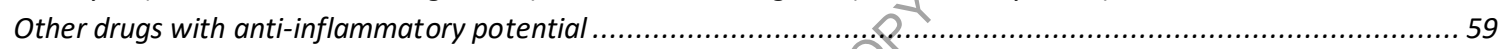

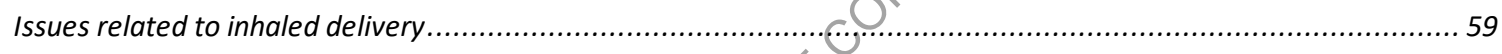

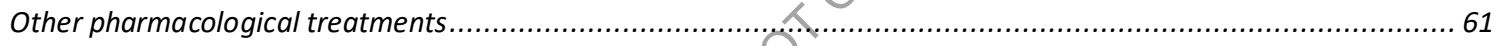

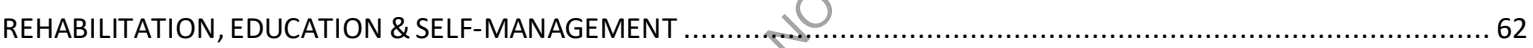

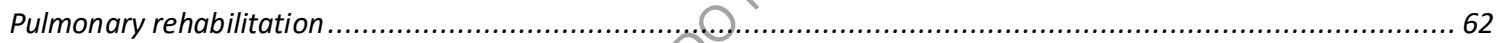

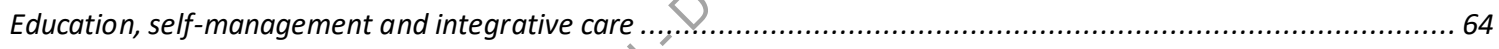

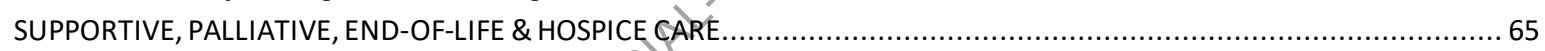

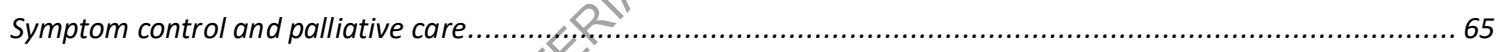

Therapy relevant to all patients with COPD

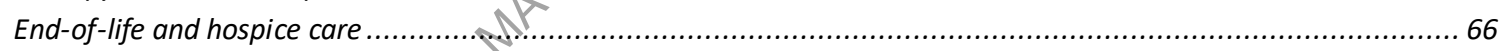

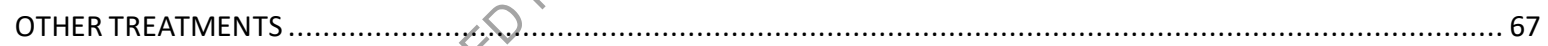

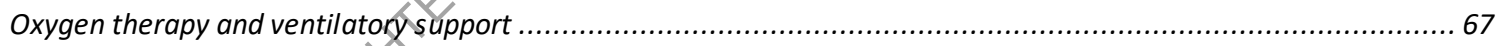

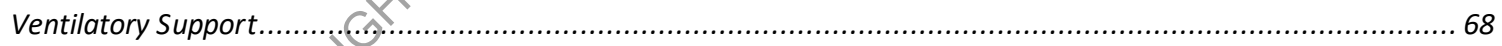

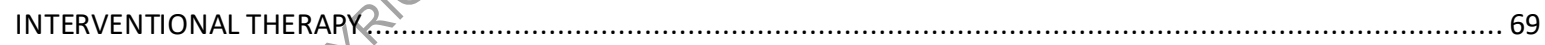

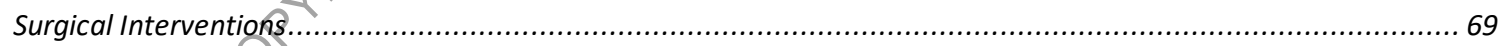

Bronchoscopic interventions to reduce hyperinflation in severe emphysema .............................................. 70

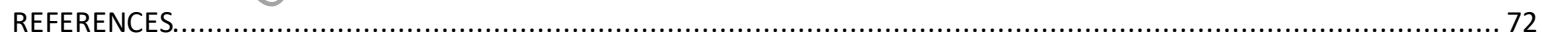

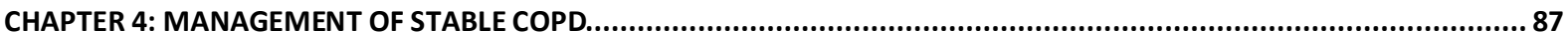

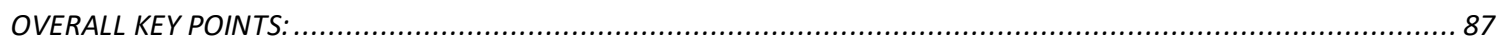

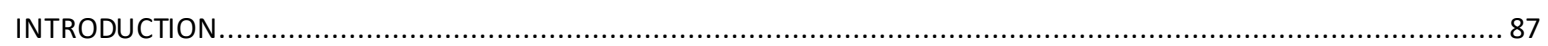

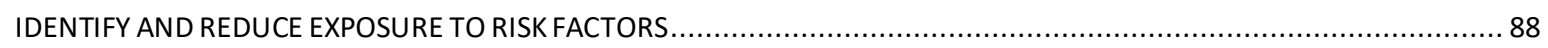

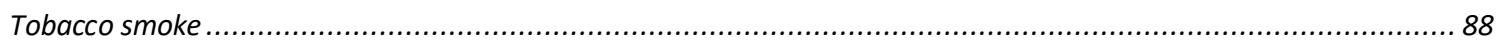

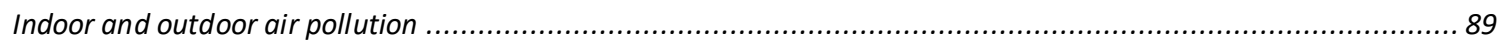

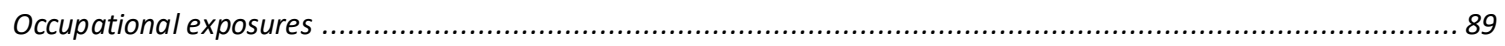

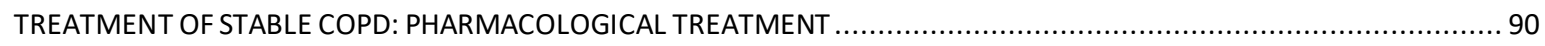

Algorithms for the assessment, initiation and follow-up management of pharmacological treatment ................... 91

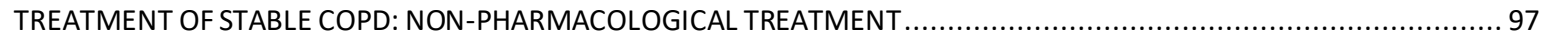

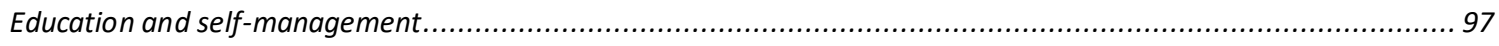

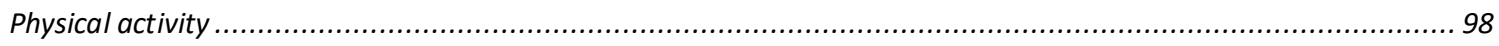

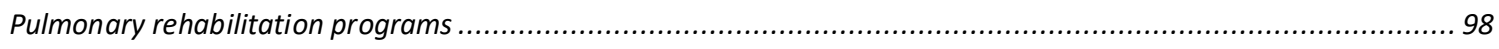

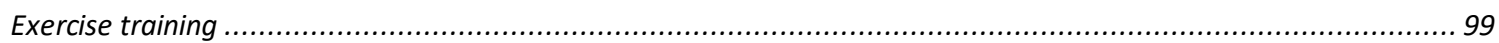




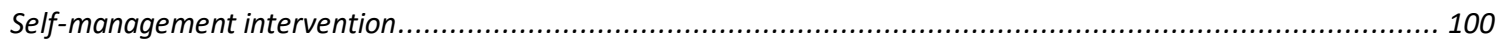

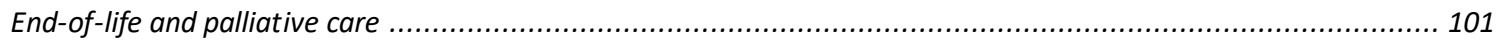

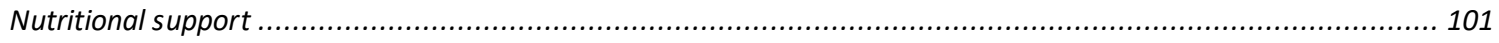

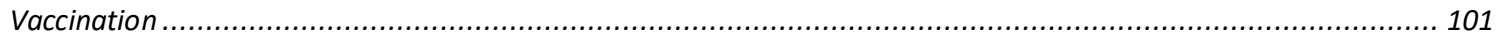

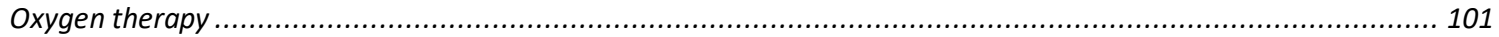

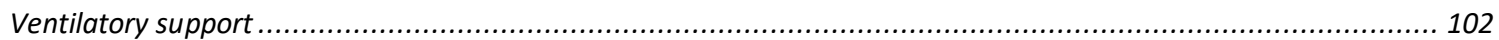

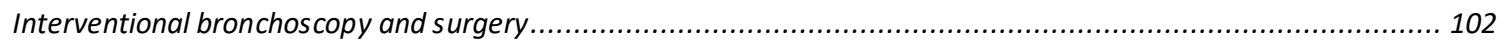

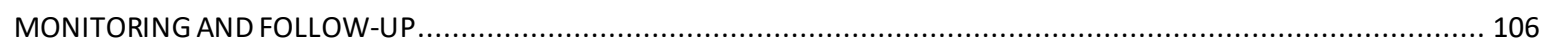

Monitoring disease progression and development of complications and/or comorbidities ................................. 106

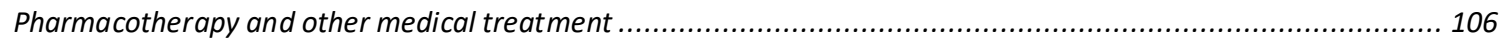

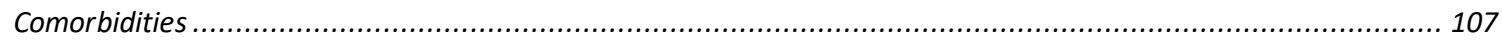

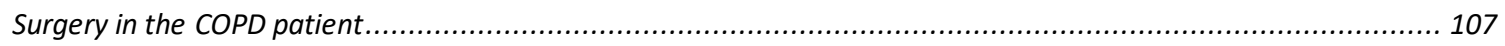

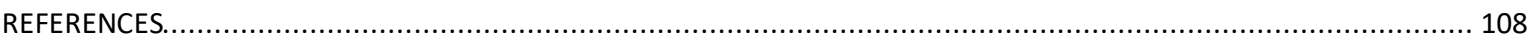

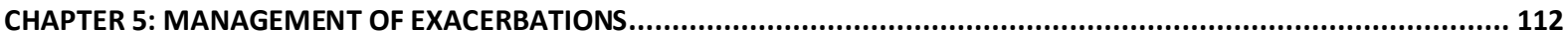

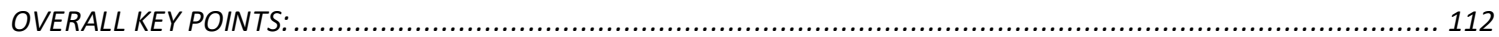

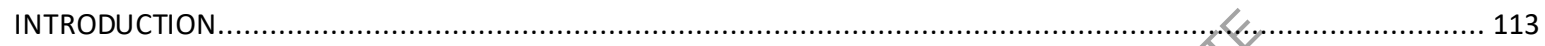

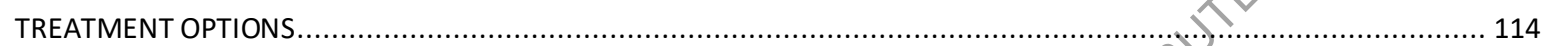

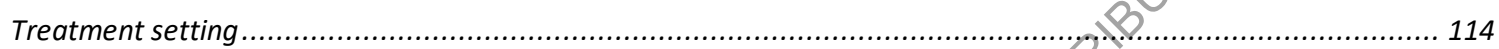

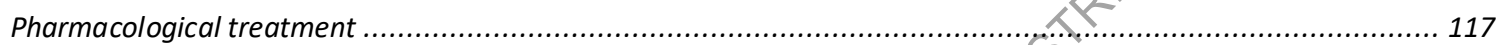

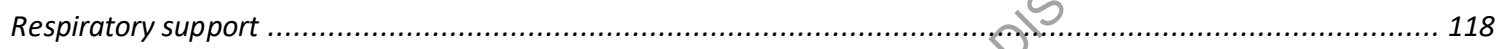

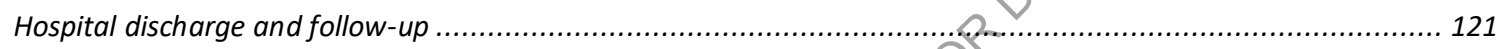

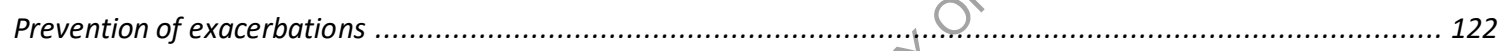

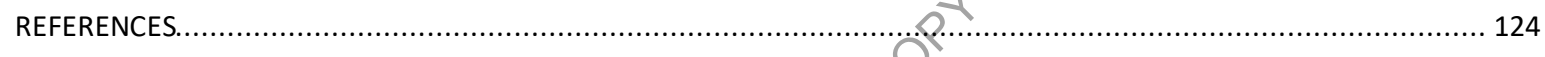

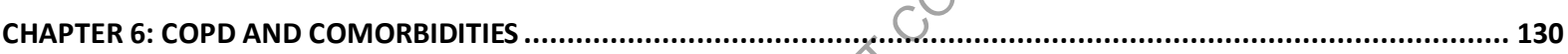

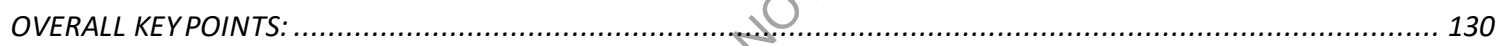

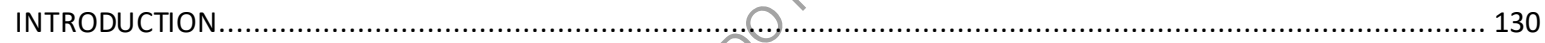

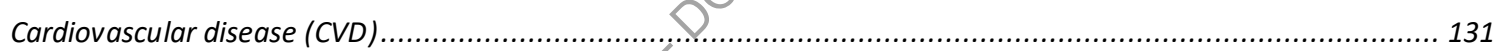

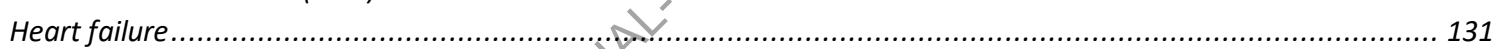

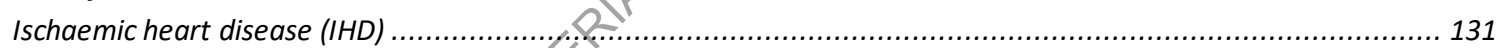

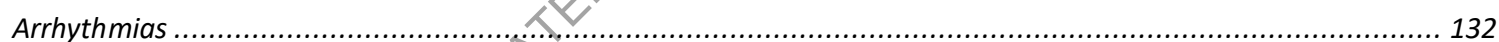

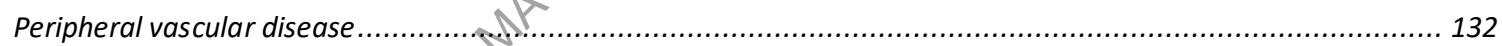

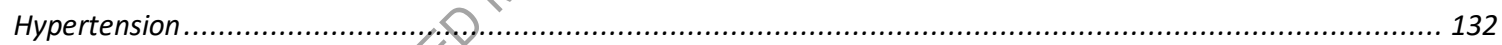

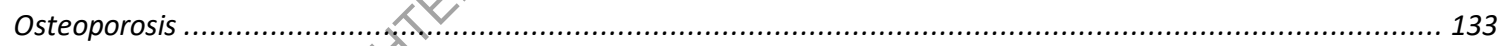

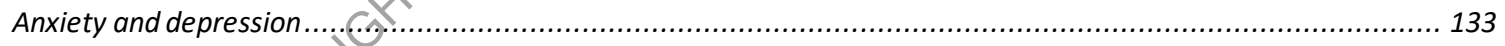

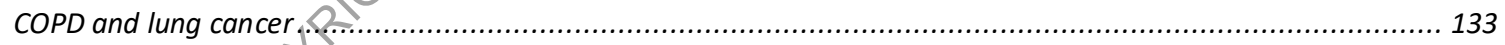

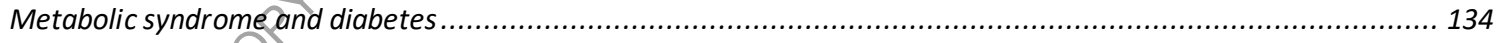

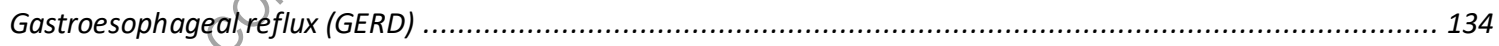

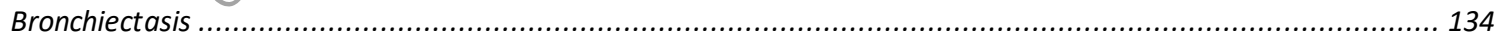

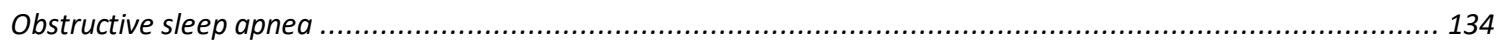

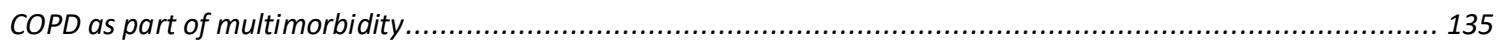

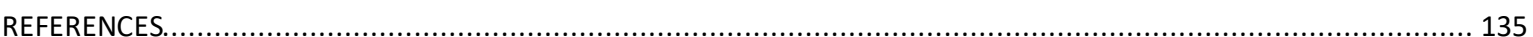




\section{GLOBAL STRATEGY FOR THE DIAGNOSIS, MANAGEMENT, AND PREVENTION OF COPD}

\section{INTRODUCTION}

The aim of the GOLD Report is to provide a non-biased review of the current evidence for the assessment, diagnosis and treatment of patients with COPD that can aid the clinician. One of the strengths of GOLD reports is the treatment objectives. These have stood the test of time, but are organized into two groups: objectives that are directed towards relieving and reducing the impact of symptoms, and objectives that reduce the risk of adverse health events that may affect the patient at some point in the future. (Exacerbations are an example of such events). This emphasizes the need for clinicians to focus on both the short-term and long-term impact of COPD on their patients.

A second strength of the original strategy was the simple, intuitive system for classifying COPD severity. This was based on FEV ${ }_{1}$ and was called a staging system because it was believed, at the time, that the majority of patients followed a path of disease progression in which theseverity of COPD tracked the severity of airflow limitation. Much is now known about the characteristics of patients in the different GOLD stages - for example, their risk of exacerbations, hospitalization, and death. However, at an individual patient level, $\mathrm{FEV}_{1}$ is an unreliable marker of the severity of breathlessness, exercise limitation, and health status impairment.

At the time of the original report, improvement in both symptoms and health status was a GOLD treatment objective, but symptoms assessment did not have a direct relation to the choice of management, and health status measurement was a complex process largely confined to clinical studies. Now, there are simple and reliable questionnaires designed for use in routine daily clinical practice. These are available in many languages. These developments have enabled an assessment system to be developed that draws together a measure of the impact of the patient's symptoms and an assessment of the patient's risk of having a serious adverse health event to the construction of a new approach to management - one that matches assessment to treatment objectives. This management approach can be used in any clinical setting anywhere in the world and moves COPD treatment towards individualized medicine - matching the patient's therapy more closely to his or her needs.

\section{BACKGROUND}

Chronic Obstructive Pulmonary Disease (COPD) is currently the fourth leading cause of death in the world 1 but is projected to be the $3^{\text {rd }}$ leading cause of death by 2020. More than 3 million people died of COPD in 2012 accounting for 6\% of all deaths globally. COPD represents an important public health challenge that is both preventable and treatable. COPD is a major cause of chronic morbidity and mortality throughout the world; many people suffer from this disease for years, and die prematurely from it or its complications. Globally, the COPD burden is projected to increase in coming decades because of continued exposure to COPD risk factors and aging of the population.?

In 1998, with the cooperation of the National Heart, Lung, and Blood Institute, National Institutes of 
Health and the World Health Organization the Global Initiative for Chronic Obstructive Lung Disease (GOLD) was implemented. Its goals were to increase awareness of the burden of COPD and to improve prevention and management of COPD through a concerted worldwide effort of people involved in all facets of healthcare and healthcare policy. An important and related goal was to encourage greater research interest in this highly prevalent disease.

In 2001, GOLD released its first report, Global Strategy for the Diagnosis, Management, and Prevention of COPD. This report was not intended to be a comprehensive textbook on COPD, but rather to summarize the current state of the field. It was developed by individuals with expertise in COPD research and patient care and was based on the best-validated concepts of COPD pathogenesis at that time, along with available evidence on the most appropriate management and prevention strategies. It provided state-of-the-art information about COPD for pulmonary specialists and other interested physicians and served as a source document for the production of various communications for other audiences, including an Executive Summary, a Pocket Guide for Healthcare Professionals, and a Patient Guide.

\begin{tabular}{|c|c|c|}
\hline $\begin{array}{l}\text { EVIDENCE } \\
\text { CATEGORY }\end{array}$ & SOURCES OF EVIDENCE & DEFINITION \\
\hline $\mathbf{A}$ & $\begin{array}{l}\text { Randomized controlled trials (RCTs) } \\
\text { Rich body of high quality evidence } \\
\text { without any significant limitation } \\
\text { or bias }\end{array}$ & $\begin{array}{l}\text { Evidence from endpoints of well-designed RCTs that } \\
\text { providedonsistent findings in the population for which the } \\
\text { reggmmendation is made without any important limitations. } \\
\text { Requires high quality evidence from } \geq 2 \text { clinical trials } \\
\text { involving a substantial number of subjects, or a single } \\
\text { high quality RCT involving substantial numbers of patient } \\
\text { without any bias. }\end{array}$ \\
\hline & $\begin{array}{l}\text { Randomized controlled trials (RCTs) } \\
\text { with important limatations } \\
\text { Limited Body of Evidence }\end{array}$ & $\begin{array}{l}\text { Evidence is from RCTs that include only a limited number } \\
\text { of patients, post hoc or subgroup analyses of RCTs or meta } \\
\text { analyses of RCTs. } \\
\text { Also pertains when few RCTs exist, or important limitations } \\
\text { are evident (methodologic flaws, small numbers, short } \\
\text { duration, undertaken in a population that differs from the } \\
\text { target population of the recommendation, or the results } \\
\text { are somewhat inconsistent). }\end{array}$ \\
\hline & $\begin{array}{l}\text { Non-randomized trials } \\
\text { Observational studies }\end{array}$ & $\begin{array}{l}\text { Evidence is from outcomes of uncontrolled or } \\
\text { non-randomized trials or from observational studies. }\end{array}$ \\
\hline D & Panel consensus judgment & $\begin{array}{l}\text { Provision of guidance is deemed valuable but clinical } \\
\text { literature addressing the subject is insufficient. } \\
\text { Panel consensus is based on clinical experience or } \\
\text { knowledge that does not meet the above stated criteria. }\end{array}$ \\
\hline
\end{tabular}

TABLE A. 
Immediately following the release of the first GOLD report in 2001, the GOLD Board of Directors appointed a Science Committee, charged with keeping the GOLD documents up-to-date by reviewing published research, evaluating the impact of this research on the management recommendations in the GOLD documents, and posting yearly updates of these documents on the GOLD website.

\section{LEVELS OF EVIDENCE}

Levels of evidence have been assigned to evidence-based recommendations where appropriate (Table A). Evidence levels are indicated in boldface type enclosed in parentheses after the relevant statement e.g., (Evidence A). The methodological issues concerning the use of evidence from meta-analyses were carefully considered when i) treatment effect (or effect size) was consistent from one study to the next, and we needed to identify the common effect; ii) the effect varied from one study to the next, and there was a need to identify the reason for the variation.

\section{REFERENCES}

1. Lozano R, Naghavi M, Foreman K, et al. Global and regional mortality from 235 causes of death for 20 age groups in 1990 and 2010: a systematic analysis for the Global Burden of Disease Study 2010. Lancet 2012; 380(9859): 2095-128.

2. Mathers CD, Loncar D. Projections of global mortality and-burden of disease from 2002 to 2030. PLoS Med 2006; 3(11): e442. 


\section{CHAPTER 1: DEFINITION AND OVERVIEW}

\section{OVERALL KEY POINTS:}

- Chronic Obstructive Pulmonary Disease (COPD) is a common, preventable and treatable disease that is characterized by persistent respiratory symptoms and airflow limitation that is due to airway and/or alveolar abnormalities usually caused by significant exposure to noxious particles or gases.

- The most common respiratory symptoms include dyspnea, cough and/or sputum production. These symptoms may be under-reported by patients.

- The main risk factor for COPD is tobacco smoking but other environmental exposures such as biomass fuel exposure and air pollution may contribute. Besides exposures, host factors predispose individuals to develop COPD. These include genetic abnormalities, abnormal lung development and acceleratedaging.

- COPD may be punctuated by periods of acute worsening of respiratory symptoms, called exacerbations.

- In most patients, COPD is associated with significant concomitant chronic diseases, which increase its morbidity and mortality.

\section{DEFINITION}

Chronic Obstructive Pulmonary Disease (COPD) is a common, preventable and treatable disease that is characterized by persistent respiratory symptoms and airflow limitation that is due to airway and/or alveolar abnormalities usuatly caused by significant exposure to noxious particles or gases.

The chronic airflow limitation that is characteristic of COPD is caused by a mixture of small airways disease (e.g., obstructive bronchiolitis) and parenchymal destruction (emphysema), the relative contributions of which vary from person to person (Figure 1.1). These changes do not always occur together, but evolve at different rates over time. Chronic inflammation causes structural changes, narrowing of the small airways and destruction of the lung parenchyma that leads to the loss of alveolar attachments to the small airways and decreases lung elastic recoil. In turn, these changes diminish the ability of the airways to remain open during expiration. A loss of small airways may also contribute to airflow limitation and mucociliary dysfunction is a characteristic feature of the disease. Airflow limitation is usually measured by spirometry as this is the most widely available and reproducible test of lung function. Many previous definitions of COPD have emphasized the terms "emphysema" and "chronic bronchitis", which are not included in the definition used in this or earlier GOLD reports. Emphysema, or destruction of the gas-exchanging surfaces of the lung (alveoli), is a pathological term that is often (but incorrectly) used clinically and describes only one of several structural abnormalities present in patients with COPD. Chronic bronchitis, or the presence of cough 
and sputum production for at least 3 months in each of two consecutive years, remains a clinically and epidemiologically useful term, but is present in only a minority of subjects when this definition is used. However, when alternative definitions are used to define chronic bronchitis, or older populations with greater levels of smoke or occupational inhalant exposure are queried, the prevalence of chronic bronchitis is greater. ${ }^{1,2} \mathrm{It}$ is important to recognize that chronic respiratory symptoms may precede the development of airflow limitation and may be associated with the development of acute respiratory events. $\frac{3}{-}$ Chronic respiratory symptoms also exist in individuals with normal spirometry 3,4 and a significant number of smokers without airflow limitation have structural evidence of lung disease manifested by the varying presence of emphysema, airway wall thickening and gas trapping. 3.4

\section{BURDEN OF COPD}

COPD is a leading cause of morbidity and mortality worldwide that induces an economic and social burden that is both substantial and increasing. ${ }^{5}, 6$ COPD prevalence, morbidity and mortality vary across countries and across different groups within countries. COPD is the result of a complex interplay of long-term cumulative exposure to noxious gases and particles, combined with a variety of host factors including genetics, airway hyper-responsiveness and poor lung growth during childhood. $\frac{7-9}{1}$ Often, the prevalence of COPD is directly related to the prevalence of tobacco smoking, although in many countries outdoor, occupational and indoor air pollution (resulting from the burning of wood and other biomass fuels) are major COPD risk factors. 10,11 The prevalence and burden of COPD are projected to increase over the coming decades due to Continued exposure to COPD risk factors and aging of the world's population; as longevity increases more people will express the long-term effects

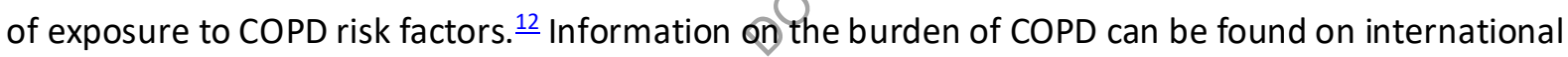
websites, for example the:

- World Health Organization (WHO) $\underline{13}$

- World Bank/WHO Global Burden of Disease Study 14

\section{Prevalence}

Existing COPD prevalence data vary widely due to differences in survey methods, diagnostic criteria, and analytical approaches. ${ }^{12}$ Importantly, all of the studies defined COPD by spirometry alone and not by the combination of symptoms and spirometry. The lowest estimates of prevalence are those based on self-reporting of a doctor's diagnosis of COPD, or equivalent condition. For example, most national data show that $<6 \%$ of the adult population have been told that they have COPD. $\frac{15}{}$ This is likely to be a reflection of the widespread under-recognition and under-diagnosis of COPD. $\underline{16}$

Despite the complexities, data are emerging that enable more accurate estimates of COPD prevalence. A systematic review and meta-analysis, including studies carried out in 28 countries between 1990 and $2004, \underline{\underline{15}}$ provided evidence that the prevalence of COPD is appreciably higher in smokers and exsmokers compared to non-smokers, in those $\geq 40$ years of age compared to those $<40$, and in men compared to women. The Latin American Project for the Investigation of Obstructive Lung Disease (PLATINO) ${ }^{17}$ examined the prevalence of post-bronchodilator airflow limitation among persons $>40$ years in one major city from each of five Latin American countries - Brazil, Chile, Mexico, Uruguay, and Venezuela. In each country, the prevalence of COPD increased steeply with age, with the highest 
prevalence among those $>60$ years. Prevalence in the total population ranged from a low of $7.8 \%$ in Mexico City, Mexico, to a high of $19.7 \%$ in Montevideo, Uruguay. In all five cities, the prevalence was appreciably higher in men than in women, $\underline{\underline{17}}$ which contrasts with findings from European cities such as Salzburg, Austria. $\underline{18}$

\section{ETIOLOGY}

- Smoking and pollutants

- Host factors

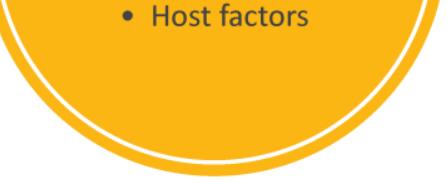

Impaired lunggrowth

- Accelerबted decline

- Lung injury

Rung \& systemic

inflammation

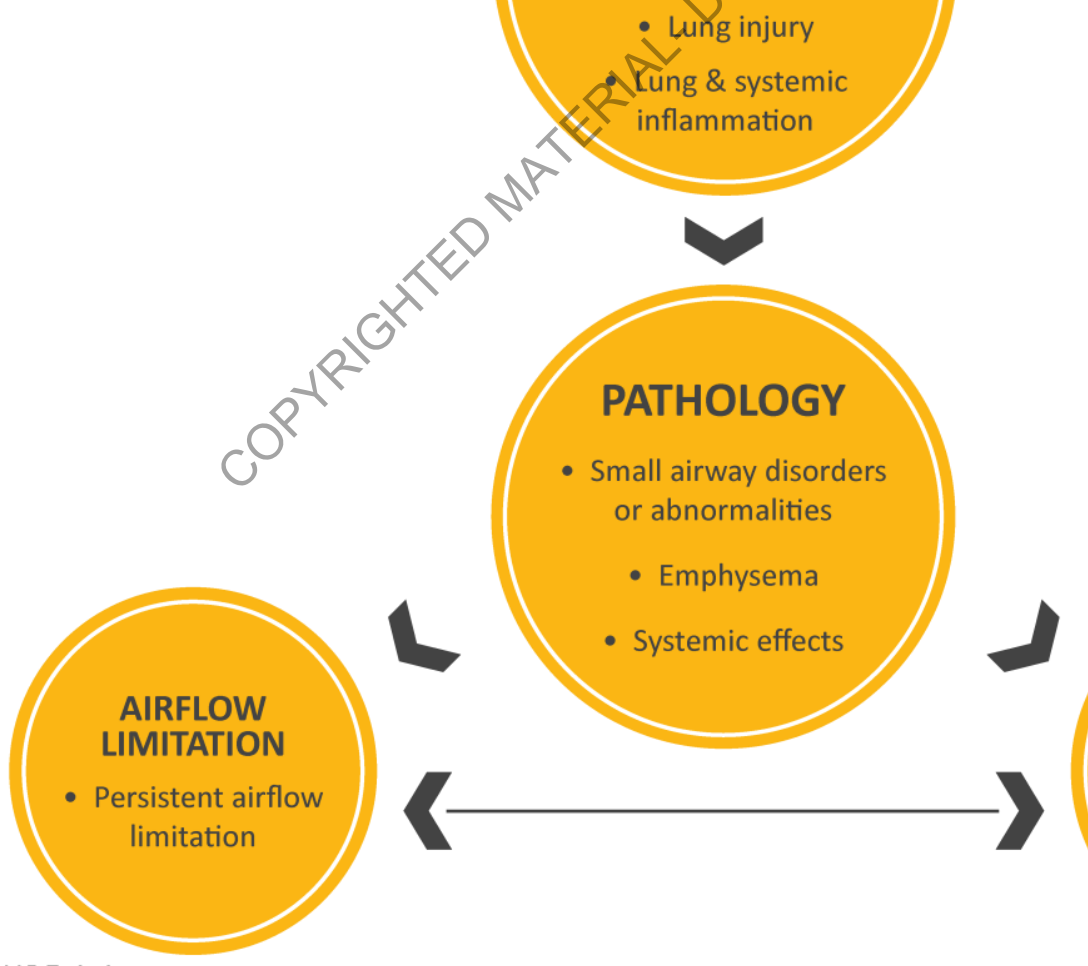

PATHO-

BIOLOGY

(n)

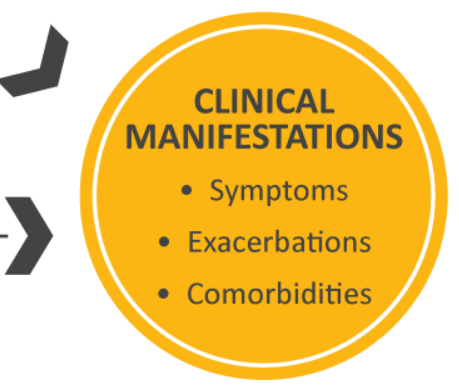

FIGURE 1.1 
The Burden of Obstructive Lung Diseases (BOLD) program has also used a standardized methodology comprising questionnaires and pre- and post-bronchodilator spirometry to assess the prevalence and risk factors for COPD in people aged 40 and over around the world. Surveys have been completed in 29 countries and studies are on-going in a further nine. $\frac{19}{}$ BOLD reported worse lung function than earlier studies, with a prevalence of COPD grade 2 or higher of $10.1 \%$ (SE 4.8) overall, $11.8 \%$ (SE 7.9) for men, and $8.5 \%$ (SE 5.8) for women $\underline{20}$ and a substantial prevalence of COPD of 3-11\% among neversmokers. .20 BOLD also examined the prevalence of COPD in north and sub-Saharan Africa and Saudi Arabia and found similar results. $\underline{21-24}$

Based on BOLD and other large scale epidemiological studies, it is estimated that the number of COPD cases was 384 million in 2010, with a global prevalence of $11.7 \%$ (95\% confidence interval (CI) $8.4 \%$ $15.0 \%) . \underline{25}$ Globally, there are around three million deaths annually. $\frac{26}{}$ With the increasing prevalence of smoking in developing countries, and aging populations in high-income countries, the prevalence of COPD is expected to rise over the next 30 years and by 2030 there may be over 4.5 million deaths annually from COPD and related conditions. $\underline{.2}, \underline{28}$

\section{Morbidity}

Morbidity measures traditionally include physician visits, emergency department visits, and hospitalizations. Although COPD databases for these outcome parameters are less readily available and usually less reliable than mortality databases, to date-studies on the available data indicate that morbidity due to COPD increases with age,,$\frac{15-17}{2}$ and in patients with COPD the development of comorbidities may be seen at an earlier age. ${ }^{29}$ Morbidity from COPD may be affected by other concomitant chronic conditions (e.g., cardiovascular disease,,$\underline{30}$ musculoskeletal impairment, diabetes mellitus) that are related to smoking, aging and COPD. These chronic conditions may significantly impair patient's health status, in addition fo interfering with COPD management and are major drivers of hospitalizations and costs for patients with COPD. $\underline{31}$

\section{Mortality}

The World Health Organization (WHO) publishes mortality statistics for selected causes of death annually for all WHO regions; additional information is available from the WHO Evidence for Health Policy Department. $\frac{32}{4}$ However, data must be interpreted with caution because of the inconsistent use of COPD terminology. In the $10^{\text {th }}$ revision of the International Statistical Classification of Diseases and Related Health Problems (ICD-10), deaths from COPD or chronic airways obstruction are included in the broad category of "COPD and allied conditions" (ICD-10 codes J42-46).

Under-recognition and under-diagnosis of COPD reduces the accuracy of mortality data. $\underline{33}, 34$ Furthermore, the accuracy of COPD diagnosis codes recorded in administrative health databases is also uncertain..,$\underline{35}$ In some jurisdictions, reliance on administrative health data, particularly those that only record hospitalizations, may underestimate the burden of COPD. $\frac{37}{2}$ The reliability of recording of COPD-related deaths in mortality data is also problematic. Although COPD is often a primary cause of death, it is more likely to be listed as a contributory cause of death or omitted from the death certificate entirely. $\frac{38}{}$ However, it is clear that COPD is one of the most important causes of death in most countries. For instance, in 2011, COPD was the third leading cause of death in the United States. $\underline{39}$ This increase in COPD-related mortality has mainly been driven by the expanding epidemic of smoking; 
reduced mortality from other common causes of death (e.g., ischemic heart disease, infectious diseases); the aging of the world's population, particularly in high-income countries; and scarcity of effective disease modifying therapies.

\section{Economic burden}

COPD is associated with significant economic burden. In the European Union, the total direct costs of respiratory disease are estimated to be about $6 \%$ of the total healthcare budget, with COPD accounting for $56 \%$ ( 38.6 billion Euros) of the cost of respiratory disease. $\frac{40}{-}$ In the United States the estimated direct costs of COPD are \$32 billion and the indirect costs $\$ 20.4$ billion. 11 COPD exacerbations account for the greatest proportion of the total COPD burden on the healthcare system. Not surprisingly, there is a striking direct relationship between the severity of COPD and the cost of care, and the cost distribution changes as the disease progresses. For example, hospitalization and ambulatory oxygen costs soar as COPD severity increases. Any estimate of direct medical expenditure for home-based care under-represents the true cost of home-based care to society, because it ignores the economic value of the care provided by family members to people with COPD.

In developing countries, direct medical costs may be less important than the impact of COPD on workplace and home productivity. Because the healthcare sector might not provide long-term supportive care services for severely disabled individuals, COPD may force at least two individuals to leave the workplace - the affected individual and a family member who must now stay home to care for their disabled relative. $\underline{42}$ Since human capital is often the most important national asset for developing countries, the indirect costs of COPD mayrepresent a serious threat to the economy.

\section{Social burden}

Since mortality offers only a limited perspective on the human burden of a disease, it is desirable to find other measures of disease burden that are consistent and measurable within and between nations. The authors of the GlobaiBurden of Disease (GBD) Study designed a method to estimate the fraction of mortality and disability attributable to major diseases and injuries using a composite measure of the burden of eâch health problem: the Disability-Adjusted Life Year (DALY). ${ }^{43}$ The DALYs for a specific condition are the sum of years lost because of premature mortality and years of life lived with disability, adjusted for the severity of disability. The GBD Study found that COPD is an increasing contributor to disability and mortality around the world. In 2005 COPD was the eighth leading cause of DALYs lost across the world but by 2013 COPD was ranked as the fifth leading cause of DALYs lost. $\underline{44}$ In the United States, COPD is the second leading cause of reduced DALYs, trailing only ischemic heart disease..$\underline{45}$ 


\section{FACTORS THAT INFLUENCE DISEASE DEVELOPMENT AND PROGRESSION}

Although cigarette smoking is the most well studied COPD risk factor, it is not the only risk factor and there is consistent evidence from epidemiologic studies that non-smokers may also develop chronic airflow limitation. $\underline{20}$ Much of the evidence concerning risk factors for COPD comes from cross-sectional epidemiological studies that identify associations rather than causal relationships. Nevertheless, compared to smokers with COPD, never smokers with chronic airflow limitation have fewer symptoms, milder disease and lower burden of systemic inflammation. ${ }^{46}$ Interestingly, never smokers with chronic airflow limitation do not appear to have an increased risk of lung cancer, or cardiovascular comorbidities, compared to those without chronic airflow limitation. However, there is evidence that they have an increased risk of pneumonia and mortality from respiratory failure. $\underline{46}$

Although several longitudinal studies of COPD have followed groups and populations for up to 20 years,, to date no studies have monitored the progression of the disease through its entire course, or included the pre and perinatal periods that may be important in shaping an individual's future COPD risk. Thus, the current understanding of risk factors for COPD is in many respects still incomplete.

COPD results from a complex interaction between genes and the environment. Cigarette smoking is the leading environmental risk factor for COPD, yet even for heavy smokers, fewer than $50 \%$ develop COPD during their lifetime. 47 Although genetics may folay a role in modifying the risk of COPD in smokers, there may also be other risk factors involved. For example, sex may influence whether a person takes up smoking or experiences certain occupational or environmental exposures; socioeconomic status may be linked to a child's birth weight (as it impacts on lung growth and development, and in turn on susceptibility to developing the disease); and longer life expectancy will allow greater lifetime exposure to risk factors. Understanding the relationships and interactions between risk factors requires further investigation.

\section{Genetic factors}

The genetic risk factor that is best documented is a severe hereditary deficiency of alpha-1 antitrypsin (AATD), $\underline{48}$ a major circulating inhibitor of serine proteases. Although AATD deficiency is relevant to only a small part of the world's population, it illustrates the interaction between genes and environmental exposures that predispose an individual to COPD.

A significant familial risk of airflow limitation has been observed in people who smoke and are siblings of patients with severe COPD, $\underline{49}$ suggesting that genetics together with environmental factors could influence this susceptibility. Single genes, such as the gene encoding matrix metalloproteinase 12 (MMP-12) and glutathione $S$-transferase have been related to a decline in lung function $\underline{50}$ or risk of COPD. $\frac{51}{~ S e v e r a l ~ g e n o m e-w i d e ~ a s s o c i a t i o n ~ s t u d i e s ~ h a v e ~ l i n k e d ~ g e n e t i c ~ l o c i ~ w i t h ~ C O P D ~(o r ~ F E V ~}$ or $_{1}$ $\mathrm{FEV}_{1} / \mathrm{FVC}$ as the phenotype) including markers near the alpha-nicotinic acetylcholine receptor, hedgehog interacting protein (HHIP), and several others. Nevertheless, it remains uncertain whether these genes are directly responsible for COPD or are merely markers of causal genes. $\frac{52-56}{2}$ 


\section{Age and sex}

Age is often listed as a risk factor for COPD. It is unclear if healthy aging as such leads to COPD or if age reflects the sum of cumulative exposures throughout life. $\stackrel{57}{ }$ Aging of the airways and parenchyma mimic some of the structural changes associated with COPD. $\frac{57}{2}$ In the past, most studies have reported that COPD prevalence and mortality are greater among men than women, but more recent data from developed countries has reported that the prevalence of COPD is now almost equal in men and

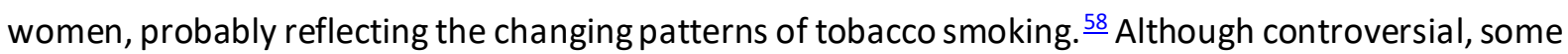
studies have even suggested that women are more susceptible to the effects of tobacco smoke than men,,$\frac{59-61}{}$ leading to more severe disease for the equivalent quantity of cigarettes consumed. This notion has been validated in animal studies and human pathology specimens, which have demonstrated a greater burden of small airway disease in females compared with males with COPD despite a similar history of tobacco smoke exposure. $\underline{62, \underline{63}}$

\section{FEV 1 PROGRESSION OVER TIME}

$\mathrm{Fev}_{1}$ in percent of predicted maximally

attained value

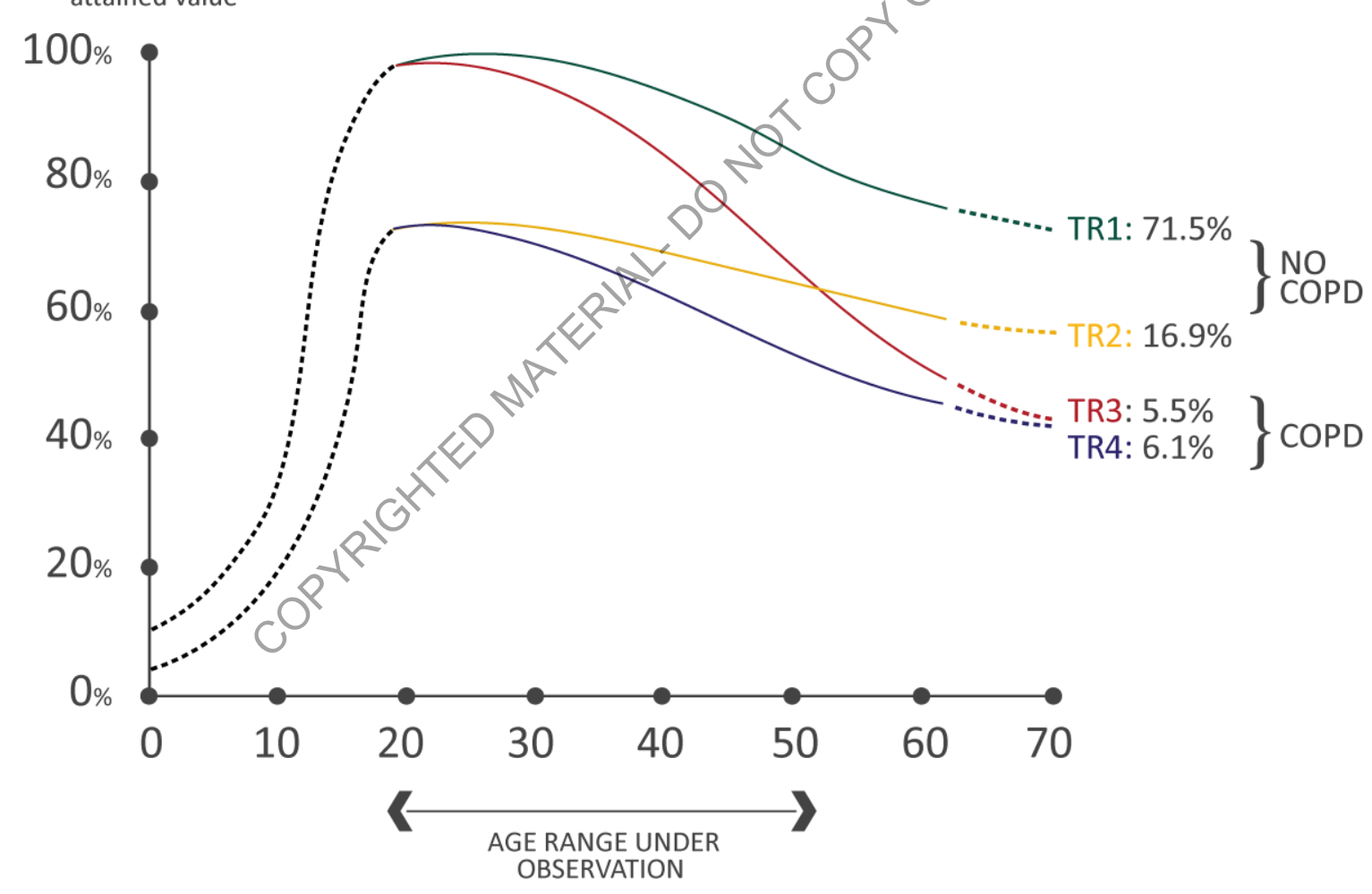

- TR1: Normal

- TR2: Small lungs but no COPD

- TR3: Normal initial FEV 1 with rapid decline leading to COPD

- TR4: Small lungs leading to COPD 
Note: This is a simplified diagram of $\mathrm{FEV}_{1}$ progression over time. In reality, there is tremendous heterogeneity in the rate of decline in $\mathrm{FEV}_{1}$ owing to the complex interactions of genes with environmental exposures and risk factors over an individual's lifetime [adapted from Lange et al NEJM 2015;373:111-22].

\section{Lung growth and development}

Processes occurring during gestation, birth, and exposures during childhood and adolescence affect lung growth. $\underline{64}, 65$ Reduced maximal attained lung function (as measured by spirometry) may identify individuals who are at increased risk for the development of COPD.,$\underline{4}$ Any factor that affects lung growth during gestation and childhood has the potential for increasing an individual's risk of developing COPD. For example, a large study and meta-analysis confirmed a positive association between birthweight and $\mathrm{FEV}_{1}$ in adulthood, $\frac{66}{6}$ and several studies have found an effect of early childhood lung infections. Factors in early life termed "childhood disadvantage factors" seem to be as important as heavy smoking in predicting lung function in adult life. $\frac{66}{6}$ One study evaluated three different longitudinal cohorts and found that approximately $50 \%$ of patients deyeloped COPD due to accelerated decline in $\mathrm{FEV}_{1}$ over time, while the other 50\% developed COPD due to abnormal lung growth and development (with normal decline in lung function over time. Figure 1.2). $\stackrel{?}{-}$ The Medical Research Council National Survey of Health and Development recently documented a synergistic interaction between smoking and infant respiratory infection as well as early life home overcrowding with lung function at age $43 . \frac{67}{}$

\section{Exposure to particles}

Across the world, cigarette smoking is the most commonly encountered risk factor for COPD. Cigarette smokers have a higher prevalence of respiratory symptoms and lung function abnormalities, a greater annual rate of decline in $\mathrm{FEV}_{1}$, and a greater $\mathrm{CO} P D$ mortality rate than non-smokers. ${ }^{68}$ Other types of tobacco (e.g., pipe, cigar, water pipe) $\frac{69-29}{2}$ and marijuana $\frac{72}{2}$ are also risk factors for COPD. Passive exposure to cigarette smoke, also known as environmental tobacco smoke (ETS), may also contribute to respiratory symptoms and COPD by increasing the lung's total burden of inhaled particles and gases. Smoking during pregnancy may pose a risk for the fetus, by affecting lung growth and development in utero, and possibly the priming of the immune system. $\underline{74}$

Occupational expostres, including organic and inorganic dusts, chemical agents and fumes, are an under-appreciated risk factor for COPD. ${ }^{10,75} \mathrm{~A}$ cross-sectional observational study demonstrated that self-reported exposure to workplace dust and fumes is not only associated with increased airflow limitation and respiratory symptoms, but also with more emphysema and gas trapping, assessed by computed tomography scan, in both men and women. ${ }^{76} \mathrm{An}$ analysis of the large U.S. population-based National Health and Nutrition Examination Survey III survey of almost 10,000 adults aged 30-75 years estimated the fraction of COPD attributable to workplace exposures was $19.2 \%$ overall, and $31.1 \%$ among never-smokers. $\underline{-7}$ These estimates are consistent with a statement published by the American Thoracic Society that concluded that occupational exposures account for $10-20 \%$ of either symptoms or functional impairment consistent with COPD. $\underline{78}$ The risk from occupational exposures in less regulated areas of the world is likely to be much higher than reported in studies from Europe and North America.

Wood, animal dung, crop residues, and coal, typically burned in open fires or poorly functioning 
stoves, may lead to very high levels of indoor air pollution. $\underline{79}$ There is growing evidence that indoor biomass exposure to modern and traditional fuels used during cooking may predispose women to develop COPD in many developing countries. $\frac{80-83}{}$ Almost three billion people worldwide use biomass and coal as their main source of energy for cooking, heating, and other household needs, so the population at risk worldwide is very large..$\underline{84,85}$

High levels of urban air pollution are harmful to individuals with existing heart or lung disease. The role of outdoor air pollution as a risk factor for COPD is unclear, but its role appears to be relatively small in adults compared to the role of cigarette smoking. 10 A recent cross-sectional analysis from China showed an association between ambient levels of particulate matter (PM2.5/10) and COPD prevalence. ${ }^{86}$ However, there is evidence that air pollution has a significant impact on lung maturation and development. For instance, the Children's Health Study found that children from communities with the highest levels of outdoor nitrogen dioxide $\left(\mathrm{NO}_{2}\right)$ and particulate matter $<2.5 \mu \mathrm{m}$ in aerodynamic diameter (PM2.5) were nearly 5 times more likely to have reduced lung function (defined as $\mathrm{FEV}_{1}<80 \%$ of predicted) compared to children from communities with the lowest levels of $\mathrm{NO}_{2}$ and $\mathrm{PM} 2.5$. 7 Importantly, reduction in ambient $\mathrm{NO}_{2}$ and $\mathrm{PM} 2.5$ levels significantly mitigated the risk of

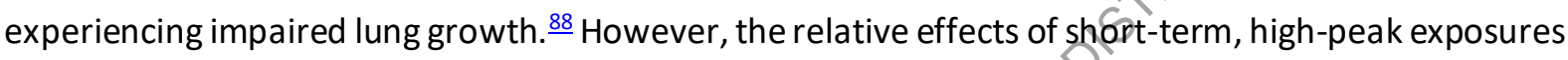
and long-term, low-level exposures are yet to be resolved.

\section{Socioeconomic status}

Poverty is consistently associated with airflow obstruction $\frac{89}{}$ and lower socioeconomic status is associated with an increased risk of developing COPD.90,91 It is not clear, however, whether this pattern reflects exposures to indoor and outdoor air pollutants, crowding, poor nutrition, infections, or other factors related to low socioeconomic status.

\section{Asthma and airway hyper-reactivity}

Asthma may be a risk factor for the development of chronic airflow limitation and COPD. In a report from a longitudinal cohort of the Tucson Epidemiological Study of Airway Obstructive Disease, adults with asthma were found to have a 12-fold higher risk of acquiring COPD over time compared to those without asthma, after adjusting for smoking. ${ }^{92}$ Another longitudinal study of people with asthma found that around $20 \%$ of subjects developed irreversible airflow limitation and reduced transfer coefficient. ${ }^{93} \mathrm{~A}$ third longitudinal study observed that self-reported asthma was associated with excess loss of $\mathrm{FEV}_{1}$ in the general population. ${ }^{94} \mathrm{~A}$ study examining the pattern of lung-growth decline in children with asthma found that $11 \%$ met lung function impairment consistent with the spirometric

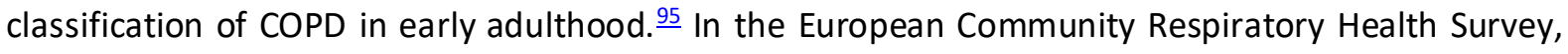
airway hyper-responsiveness was second only to cigarette smoking as the leading risk factor for COPD, responsible for $15 \%$ of the population attributable risk (smoking had a population attributable risk of $39 \%) . \underline{96}$ The pathology of chronic airflow limitation in asthmatic non-smokers and non-asthmatic smokers is markedly different, suggesting that the two disease entities may remain different even when presenting with similarly reduced lung function. $\underline{92,97,98}$ However, separating asthma from COPD in adults may be clinically difficult at times.

Airway hyper-responsiveness can exist without a clinical diagnosis of asthma and has been shown to be an independent predictor of COPD and respiratory mortality in population studies $\underline{99}, \underline{100}$ as well as 
an indicator of risk of excess decline in lung function in patients with mild COPD. $\frac{101}{1}$

\section{Chronic bronchitis}

In the seminal study by Fletcher and colleagues, chronic bronchitis was not associated with an accelerated decline in lung function. $\underline{91}, 102$ However, subsequent studies have observed an association between mucus hypersecretion and increased $\mathrm{FEV}_{1}$ decline, $\underline{\underline{103}}$ and in younger adults who smoke, the presence of chronic bronchitis has been associated with an increased likelihood of developing COPD. ${ }^{104}$ Chronic bronchitis has also been associated with an increased risk in the total number as well as severity of exacerbations. $\frac{105}{}$

\section{Infections}

A history of severe childhood respiratory infection has been associated with reduced lung function and increased respiratory symptoms in adulthood. $\underline{96}$ Susceptibility to infections plays a role in exacerbations of COPD but the effect on disease development is less clear. There is evidence that HIV patients are at increased risk of COPD compared to HIV negative controls $/ 11$ studies; pooled odds ratio for $1.14(95 \% \mathrm{Cl} 1.05,1.25) \underline{106}$; tuberculosis has also been identified as a risk factor for COPD. $\underline{107}$ In addition, tuberculosis is both a differential diagnosis for COPD and a potential comorbidity. $\underline{108,109}$

\section{PATHOLOGY, PATHOGENESIS AND PATHOPHYSIOLOGY}

Inhalation of cigarette smoke or other noxious particles, such as smoke from biomass fuels, causes lung inflammation. Lung inflammation is a normalresponse that appears to be modified in patients who develop COPD. This chronic inflammatory response may induce parenchymal tissue destruction (resulting in emphysema), and disruption of normal repair and defense mechanisms (resulting in small airway fibrosis). These pathological changes lead to gas trapping and progressive airflow limitation. A brief overview follows that describes and summarizes the pathologic changes in COPD, their cellular and molecular mechanisms, and how these underlie the physiological abnormalities and symptoms characteristic of this disease.

\section{Pathology}

Pathological changes characteristic of COPD are found in the airways, lung parenchyma, and pulmonary vasculature. $\frac{110}{1}$ The pathological changes observed in COPD include chronic inflammation, with increased numbers of specific inflammatory cell types in different parts of the lung, and structural changes resulting from repeated injury and repair. In general, the inflammatory and structural changes in the airways increase with disease severity and persist on smoking cessation. Most pathology data come from studies in smokers and the same balance of airway and parenchymal disease cannot necessarily be assumed when other factors are operative. Systemic inflammation may be present and could play a role in the multiple comorbid conditions found in patients with COPD. $\frac{111}{11}$

\section{Pathogenesis}

The inflammation observed in the respiratory tract of COPD patients appears to be a modification of the normal inflammatory response of the respiratory tract to chronic irritants such as cigarette smoke. The mechanisms for this amplified inflammation are not yet understood but may, at least in part, be 
genetically determined. Although some patients develop COPD without smoking, the nature of the inflammatory response in these patients is as yet unknown. Oxidative stress and an excess of proteinases in the lung are likely to further modify lung inflammation. Together, these mechanisms may lead to the characteristic pathological changes in COPD. Lung inflammation persists after smoking cessation through unknown mechanisms, although autoantigens and perturbations in the lung microbiome may play a role. $\underline{112, \underline{113}}$ Similar mechanisms may occur for concomitant chronic diseases.

Oxidative stress. Oxidative stress may be an important amplifying mechanism in COPD. 111,114 Biomarkers of oxidative stress (e.g., hydrogen peroxide, 8-isoprostane) are increased in the exhaled breath condensate, sputum, and systemic circulation of COPD patients. Oxidative stress is further increased during exacerbations. Oxidants are both generated by cigarette smoke and other inhaled particulates, and released from activated inflammatory cells such as macrophages and neutrophils. There may also be a reduction in endogenous antioxidants in COPD patients as a result of reduction in levels of the transcription factor Nrf2 that regulates many antioxidant genes. $\frac{108,115}{N}$

Protease-antiprotease imbalance. There is compelling evidence for ap imbalance in the lungs of COPD patients between proteases that break down connective tissue components and antiproteases that counterbalance this action. $\frac{116}{}$ Increased levels of several proteases, derived from inflammatory cells and epithelial cells, have been observed in COPD patients. There is increasing evidence that these proteases may interact with each other. Protease-mediated destruction of elastin, a major connective tissue component in lung parenchyma, is believed to be an important feature of emphysema but may be more difficult to establish in airway changes. 117

Inflammatory cells. COPD is characterized by increased numbers of macrophages in peripheral airways, lung parenchyma and pulmonary yessels, together with increased activated neutrophils and increased lymphocytes that include Tc1, Th1, Th17 and ILC3 cells. In some patients, there may also be increases in eosinophils, Th2 or ILC2 cells, especially where there is clinical overlap with asthma. All of these inflammatory cells, together with epithelial cells and other structural cells release multiple inflammatory mediators. 111 A recent study suggests that local IgA deficiency is associated with bacterial translocation, smâf airway inflammation and airway remodeling. $\underline{118}$

Inflammatory mediators. The wide variety of inflammatory mediators that have been shown to be increased in COPD patients attract inflammatory cells from the circulation (chemotactic factors), amplify the inflammatory process (proinflammatory cytokines), and induce structural changes (growth factors). $\underline{\underline{119}}$

Peribronchiolar and interstitial fibrosis. Peribronchiolar fibrosis and interstitial opacities have been reported in patients with COPD or those who are asymptomatic smokers. $112, \underline{120-122}$ An excessive production of growth factors may be found in smokers or those with preceding airway inflammation who have COPD. $\underline{123}$ Inflammation may precede the development of fibrosis or repeated injury of the airway wall itself may lead to excessive production of muscle and fibrous tissue. $\frac{124}{4}$ This may be a contributing factor to the development of small airways limitation and eventually the obliteration that may precede the development of emphysema. $\underline{125}$ 
Differences in inflammation between COPD and asthma. Although both COPD and asthma are associated with chronic inflammation of the respiratory tract, there are differences in the inflammatory cells and mediators involved in the two diseases. 126 Some patients with COPD have features consistent with asthma and may have a mixed inflammatory pattern with increased eosinophils. $\underline{127}$

\section{Pathophysiology}

There is now a good understanding of how the underlying disease process in COPD leads to the characteristic physiological abnormalities and symptoms. For example, inflammation and narrowing of peripheral airways leads to decreased $\mathrm{FEV}_{1} . \frac{128}{}$ Parenchymal destruction due to emphysema also contributes to airflow limitation and leads to decreased gas transfer. There is also emerging evidence to suggest that in addition to airway narrowing, there is a loss of small airways, which may contribute to airflow limitation. .29

Airflow limitation and gas trapping. The extent of inflammation, fibrosis, and luminal exudates in the small airways correlates with the reduction in the $\mathrm{FEV}_{1}$ and $\mathrm{FEV}_{1} / \mathrm{FV} \mathrm{C}$ ratio, and probably with the accelerated decline in $\mathrm{FEV}_{1}$ that is characteristic of COPD. 128 This peripheral airway limitation progressively traps gas during expiration, resulting in hyperinflation. Static hyperinflation reduces inspiratory capacity and is commonly associated with dynamichyperinflation during exercise leading to increased dyspnea and limitation of exercise capacity. These factors contribute to impairment of the intrinsic contractile properties of respiratory muscles. It is thought that hyperinflation develops early in the disease and is the main mechanism for exertional dyspnea. $.30, \underline{131}$ Bronchodilators acting on peripheral airways reduce gas trapping, thereby reducing lung volumes and improving symptoms and exercise capacity. $\underline{132}$

Gas exchange abnormalities. Gas exchange abnormalities result in hypoxemia and hypercapnia, and have several mechanisms in COPD. In general, gas transfer for oxygen and carbon dioxide worsens as the disease progresses. Reduced ventilation may also be due to reduced ventilatory drive or increased dead space ventilation. $\frac{131}{1}$ This may lead to carbon dioxide retention when it is combined with reduced ventilation, due to increased effort to breathe because of severe limitation and hyperinflation coupled with ventilatory muscle impairment. The abnormalities in alveolar ventilation and a reduced pulmonary vascular bed further worsen the $V_{A} / Q$ (ventilation perfusion ratio) abnormalities. 133

Mucus hypersecretion. Mucus hypersecretion, resulting in a chronic productive cough, is a feature of chronic bronchitis and is not necessarily associated with airflow limitation. Conversely, not all patients with COPD have symptomatic mucus hypersecretion. When present, mucus hypersecretion is due to an increased number of goblet cells and enlarged submucosal glands, both because of chronic airway irritation by cigarette smoke and other noxious agents. Several mediators and proteases stimulate mucus hypersecretion and many of them exert their effects through the activation of epidermal growth factor receptor $(E G F R) . \underline{134}$

Pulmonary hypertension. Pulmonary hypertension may develop late in the course of COPD and is due mainly to hypoxic vasoconstriction of the small pulmonary arteries, eventually resulting in 
structural changes that include intimal hyperplasia and later smooth muscle hypertrophy/hyperplasia. $\frac{135}{}$ Even in mild COPD, or in smokers susceptible to emphysema,,$\frac{136,137}{1}$ there are significant abnormalities in pulmonary microvascular blood flow, that worsen with disease progression. $\frac{138}{}$

An inflammatory response in vessels, similar to that seen in the airways, is also observed in COPD, along with evidence of endothelial cell dysfunction. The loss of the pulmonary capillary bed in emphysema may further contribute to increased pressure in the pulmonary circulation. Progressive pulmonary hypertension may lead to right ventricular hypertrophy and eventually to right-side cardiac failure. Interestingly, the diameter of pulmonary artery as measured on computed tomography (CT) scans has been shown to relate to the risk of exacerbation, independent of previous history of exacerbations. $\frac{139}{}$ This suggests that perturbations in pulmonary vasculature are major, but underrecognized, drivers of symptoms and exacerbations in COPD.

Exacerbations. Exacerbations of respiratory symptoms triggered by respiratory infections with bacteria or viruses (which may coexist), environmental pollutants, or unknown factors often occur in patients with COPD; a characteristic response with increased inflammation occurs during episodes of bacterial or viral infection. During exacerbations there is increased hyperinflation and gas trapping, with reduced expiratory flow, thus accounting for increased dyspnea. $\frac{140}{2}$ There is also worsening of $V_{A} / Q$ abnormalities that can result in hypoxemia. $\frac{141}{}$ During exacerbations there is evidence of increased airway inflammation. Other conditions (pneumonia, thromboembolism, and acute cardiac failure) may mimic or aggravate an exacerbation of COPD.

Systemic features. Most patients with COPD have concomitant chronic diseases linked to the same risk factors i.e., smoking, aging, and inactivity, which may have a major impact on health status and survival. .42 Airflow limitation and particularly hyperinflation affect cardiac function and gas exchange. $\frac{140}{}$ Inflammatory mediators in the circulation may contribute to skeletal muscle wasting and cachexia, and may initiate or worsen comorbidities such as ischemic heart disease, heart failure, osteoporosis, normocytic anemia, diabetes, and metabolic syndrome.

\section{REFERENCES}

1. American Lung Association Epidemiology and Statistics Unit. Trends in COPD (Chronic Bronchitis and Emphysema): Morbidity and Mortality. 2013.

https://www.lung.org/assets/documents/research/copd-trend-report.pdf (accessed 14 October 2018).

2. Kim V, Crapo J, Zhao H, et al. Comparison between an alternative and the classic definition of chronic bronchitis in COPDGene. Annals of the American Thoracic Society 2015; 12(3): 332-9.

3. Woodruff PG, Barr RG, Bleecker E, et al. Clinical Significance of Symptoms in Smokers with Preserved Pulmonary Function. N Engl J Med 2016; 374(19): 1811-21.

4. Regan EA, Lynch DA, Curran-Everett D, et al. Clinical and Radiologic Disease in Smokers With Normal Spirometry. JAMA Intern Med 2015; 175(9): 1539-49.

5. Lozano R, Naghavi M, Foreman K, et al. Global and regional mortality from 235 causes of death for 20 age groups in 1990 and 2010: a systematic analysis for the Global Burden of Disease Study 2010. Lancet 2012; 380(9859): 2095-128.

6. Vos T, Flaxman AD, Naghavi M, et al. Years lived with disability (YLDs) for 1160 sequelae of 289 diseases and injuries 1990-2010: a systematic analysis for the Global Burden of Disease Study 2010. Lancet 2012; 380(9859): 2163-96. 
7. Lange P, Celli B, Agusti A, et al. Lung-Function Trajectories Leading to Chronic Obstructive Pulmonary Disease. N Engl J Med 2015; 373(2): 111-22.

8. Stern DA, Morgan WJ, Wright AL, Guerra S, Martinez FD. Poor airway function in early infancy and lung function by age 22 years: a non-selective longitudinal cohort study. Lancet 2007; 370(9589): 75864.

9. Tashkin DP, Altose MD, Bleecker ER, et al. The lung health study: airway responsiveness to inhaled methacholine in smokers with mild to moderate airflow limitation. The Lung Health Study Research Group. Am Rev Respir Dis 1992; 145(2 Pt 1): 301-10.

10. Eisner MD, Anthonisen N, Coultas D, et al. An official American Thoracic Society public policy statement: Novel risk factors and the global burden of chronic obstructive pulmonary dis ease. Am J Respir Crit Care Med 2010; 182(5): 693-718.

11. Salvi SS, Barnes PJ. Chronic obstructive pulmonary disease in non-smokers. Lancet 2009; 374(9691): 733-43.

12. Mathers CD, Loncar D. Projections of global mortality and burden of disease from 2002 to 2030. PLoS Med 2006; 3(11): e442.

13. World Health Organization. World Health Organization (WHO) Website. 2016. http://www.who.int (accessed 14 October 2018).

14. World Health Organization. Global Burden of Disease Website. 2016. http://www.who.int/topics/global burden of disease (accessed 14 October 2018).

15. Halbert RJ, Natoli JL, Gano A, Badamgarav E, Buist AS, Mannino DM. Globat burden of COPD: systematic review and meta-analysis. Eur Respir J 2006; 28(3): 523-325

16. Quach A, Giovannelli J, Cherot-Kornobis N, et al. Prevalence and underdiagnosis of airway obstruction among middle-aged adults in northern France: The ELISABET study 2011-2013. Respir Med 2015; 109(12): 1553-61.

17. Menezes AM, Perez-Padilla R, Jardim JR, et al. Chronic obstructive pulmonary disease in five Latin American cities (the PLATINO study): a prevalence study. Lancet 2005; 366(9500): 1875-81.

18. Schirnhofer L, Lamprecht B, Vollmer WM, et al. COPD prevalence in Salzburg, Austria: results from the Burden of Obstructive Lung Disease (BOLD) Study. Chest 2007; 131(1): 29-36.

19. BOLD. Burden of Obstructive Lung Disease Initiative Webpage, published by Imperial College London. http://www.boldstudy.org/ (accessed 14 October 2018).

20. Lamprecht B, McBurnie MA, Vollmer WM, et al. COPD in never smokers: results from the populationbased burden of obstructive lung disease study. Chest 2011; 139(4): 752-63.

21. Al Ghobain M, Alhamad EH, Aloraíny HS, Al Kassimi F, Lababidi H, Al-Hajjaj MS. The prevalence of chronic obstructive pulmonary disease in Riyadh, Saudi Arabia: a BOLD study. Int J Tuberc Lung Dis 2015; 19(10): 1252-7.

22. Denguezli M, Daldoul H, Harrabi I, et al. COPD in Nonsmokers: Reports from the Tunisian PopulationBased Burden of Obstructive Lung Disease Study. PloS one 2016; 11(3): e0151981.

23. El Rhazi K, Nejjari C, BenJelloun MC, El Biaze M, Attassi M, Garcia-Larsen V. Prevalence of chronic obstructive pulmonary disease in Fez, Morocco: results from the BOLD study. Int J Tuberc Lung Dis 2016; 20(1):-136-41.

24. Obaseki DO, Erhabor GE, Gnatiuc L, Adewole OO, Buist SA, Burney PG. Chronic Airflow Obstruction in a Black African Population: Results of BOLD Study, lle-Ife, Nigeria. Copd 2016; 13(1): 42-9.

25. Adeloye D, Chua S, Lee $C$, et al. Global and regional estimates of COPD prevalence: Systematic review and meta-analysis. Journal of global health 2015; 5(2): 020415.

26. Global Burden of Disease Study Collaborators. Global, regional, and national age-sex specific all-cause and cause-specific mortality for 240 causes of death, 1990-2013: a systematic analysis for the Global Burden of Disease Study 2013. Lancet 2015; 385(9963): 117-71.

27. Lopez AD, Shibuya K, Rao $C$, et al. Chronic obstructive pulmonary disease: current burden and future projections. Eur Respir J 2006; 27(2): 397-412.

28. World Health Organization. Projections of mortality and causes of death, 2015 and 2030. http://www.who.int/healthinfo/global_burden_disease/projections/en/ (accessed 14 October 2018).

29. Divo MJ, Celli BR, Poblador-Plou B, et al. Chronic Obstructive Pulmonary Disease (COPD) as a disease of early aging: Evidence from the EpiChron Cohort. PloS one 2018; 13(2): e0193143.

30. Chen W, Thomas J, Sadatsafavi M, FitzGerald JM. Risk of cardiovascular comorbidity in patients with chronic obstructive pulmonary disease: a systematic review and meta-analysis. The Lancet Respiratory medicine 2015; 3(8): 631-9. 
31. Mannino DM, Higuchi K, Yu TC, et al. Economic Burden of COPD in the Presence of Comorbidities. Chest 2015; 148(1): 138-50.

32. World Health Organization. Evidence-informed policy-making. 2016. http://www.who.int/evidence (accessed 14 October 2018).

33. Buist AS, McBurnie MA, Vollmer WM, et al. International variation in the prevalence of COPD (the BOLD Study): a population-based prevalence study. Lancet 2007; 370(9589): 741-50.

34. Duong $\mathrm{M}$, Islam S, Rangarajan $\mathrm{S}$, et al. Global differences in lung function by region (PURE): an international, community-based prospective study. The Lancet Respiratory medicine 2013; 1(8): 599609.

35. Schneider A, Gantner L, Maag I, Borst MM, Wensing M, Szecsenyi J. Are ICD-10 codes appropriate for performance assessment in asthma and COPD in general practice? Results of a cross sectional observational study. BMC Health Serv Res 2005; 5(1): 11.

36. Cooke CR, Joo MJ, Anderson SM, et al. The validity of using ICD-9 codes and pharmacy records to identify patients with chronic obstructive pulmonary disease. BMC Health Serv Res 2011; 11: 37.

37. Stein BD, Bautista A, Schumock GT, et al. The validity of International Classification of Diseases, Ninth Revision, Clinical Modification diagnosis codes for identifying patients hospitalized for COPD exacerbations. Chest 2012; 141(1): 87-93.

38. Jensen HH, Godtfredsen NS, Lange P, Vestbo J. Potential misclassification of causes of death from COPD. Eur Respir J 2006; 28(4): 781-5.

39. Hoyert DL, Xu JQ. Deaths: preliminary data for 2011. Natl Vital Stat Rep 2011; 61(6): 1-65.

40. American Thoracic Society Foundation. The Global Burden of Lung Disease. 2014. http://foundation.thoracic.org/news/global-burden.php (accessed 14 October 2018).

41. Guarascio AJ, Ray SM, Finch CK, Self TH. The clinical and economic burden of chronic obstructive pulmonary disease in the USA. ClinicoEconomics and outcomes research : CEOR 2013; 5: 235-45.

42. Sin DD, Stafinski T, Ng YC, Bell NR, Jacobs P. The impact of Chronic obstructive pulmonary disease on work loss in the United States. Am J Respir Crit Care Med 2002; 165(5): 704-7.

43. Murray CJ, Lopez AD. Alternative projections of mortality and disability by cause 1990-2020: Global Burden of Disease Study. Lancet 1997; 349(9064): 1498-504.

44. GBD 2013 DALYs and HALE Collaborators, Murray CJ, Barber RM, et al. Global, regional, and national disability-adjusted life years (DALYs) for 306 diseases and injuries and healthy life expectancy (HALE) for 188 countries, 1990-2013: quantifying the epidemiological transition. Lancet 2015; 386(10009): 2145-91.

45. Murray CJ, Atkinson C, Bhalla K, et al. The state of US health, 1990-2010: burden of diseases, injuries, and risk factors. JAMA 2013; 310(6): 591-608.

46. Thomsen M, Nordestgaard BG, Vestbo J, Lange P. Characteristics and outcomes of chronic obstructive pulmonary disease in never smokers in Denmark: a prospective population study. The Lancet Respiratory medicine 2013; 1(7): 543-50.

47. Rennard SI, Vestboj. COPD: the dangerous underestimate of 15\%. Lancet 2006; 367(9518): 1216-9.

48. Stoller JK, Aboussouan LS. Alpha1-antitrypsin deficiency. Lancet 2005; 365(9478): 2225-36.

49. McCloskey SC, Patel BD, Hinchliffe SJ, Reid ED, Wareham NJ, Lomas DA. Siblings of patients with severe chronic obstructive pulmonary disease have a significant risk of airflow obstruction. Am J Respir Crit Care Med 2001; 164(8 Pt 1): 1419-24.

50. Hunninghake GM, Cho MH, Tesfaigzi Y, et al. MMP12, lung function, and COPD in high-risk populations. N Engl J Med 2009; 361: 2599-608.

51. Ding Z, Wang K, Li J, Tan Q, Tan W, Guo G. Association between glutathione S-transferase gene M1 and T1 polymorphisms and chronic obstructive pulmonary disease risk: A meta-analysis. Clinical genetics 2018.

52. Cho MH, Boutaoui N, Klanderman BJ, et al. Variants in FAM13A are associated with chronic obstructive pulmonary disease. Nat Genet 2010; 42(3): 200-2.

53. Pillai SG, Ge D, Zhu G, et al. A genome-wide association study in chronic obstructive pulmonary disease (COPD): identification of two major susceptibility loci. PLoS Genet 2009; 5(3): e1000421.

54. Soler Artigas M, Wain LV, Repapi E, et al. Effect of five genetic variants associated with lung function on the risk of chronic obstructive lung disease, and their joint effects on lung function. Am J Respir Crit Care Med 2011; 184(7): 786-95.

55. Repapi E, Sayers I, Wain LV, et al. Genome-wide association study identifies five loci associated with lung function. Nat Genet 2010; 42(1): 36-44. 
56. Cho MH, McDonald ML, Zhou X, et al. Risk loci for chronic obstructive pulmonary disease: a genomewide association study and meta-analysis. The Lancet Respiratory medicine 2014; 2(3): 214-25.

57. Mercado N, Ito K, Barnes PJ. Accelerated ageing of the lung in COPD: new concepts. Thorax 2015; 70(5): 482-9.

58. Landis SH, Muellerova H, Mannino DM, et al. Continuing to Confront COPD International Patient Survey: methods, COPD prevalence, and disease burden in 2012-2013. Int J Chron Obstruct Pulmon Dis 2014; 9: 597-611.

59. Foreman MG, Zhang L, Murphy J, et al. Early-onset chronic obstructive pulmonary disease is associated with female sex, maternal factors, and African American race in the COPDGene Study. Am J Respir Crit Care Med 2011; 184(4): 414-20.

60. Lopez Varela MV, Montes de Oca M, Halbert RJ, et al. Sex-related differences in COPD in five Latin American cities: the PLATINO study. Eur Respir J 2010; 36(5): 1034-41.

61. Silverman EK, Weiss ST, Drazen JM, et al. Gender-related differences in severe, early-onset chronic obstructive pulmonary disease. Am J Respir Crit Care Med 2000; 162(6): 2152-8.

62. Martinez FJ, Curtis JL, Sciurba F, et al. Sex differences in severe pulmonary emphysema. Am J Respir Crit Care Med 2007; 176(3): 243-52.

63. Tam A, Churg A, Wright JL, et al. Sex Differences in Airway Remodeling in a Mouse Model of Chronic Obstructive Pulmonary Disease. Am J Respir Crit Care Med 2016; 193(8): 825-34

64. Barker DJ, Godfrey KM, Fall C, Osmond C, Winter PD, Shaheen SO. Relation of birth weight and childhood respiratory infection to adult lung function and death from chronic obstructive airways disease. BMJ 1991; 303(6804): 671-5.

65. Todisco T, de Benedictis FM, Iannacci L, et al. Mild prematurity and respiratory functions. Eur J Pediatr 1993; 152(1): 55-8.

66. Lawlor DA, Ebrahim S, Davey Smith G. Association of birth weight with adult lung function: findings from the British Women's Heart and Health Study and a meta-analysis. Thorax 2005; 60(10): 851-8.

67. Allinson JP, Hardy R, Donaldson GC, Shaheen SO, Kuh D, Wedzicha JA. Combined Impact of Smoking and Early-Life Exposures on Adult Lung Function Trajectories. Am J Respir Crit Care Med 2017; 196(8): 1021-30.

68. Kohansal R, Martinez-Camblor P, Agusti A, Buist AS, Mannino DM, Soriano JB. The natural history of chronic airflow obstruction revisited: an analysis of the Framingham offspring cohort. Am J Respir Crit Care Med 2009; 180(1): 3-10.

69. Raad D, Gaddam S, Schunemann HJ, ef al. Effects of water-pipe smoking on lung function: a systematic review and meta-analysis. Chest 2011; 139(4): 764-74.

70. She J, Yang P, Wang Y, et al. Chinese water-pipe smoking and the risk of COPD. Chest 2014; 146(4): 924-31.

71. Gunen H, Tarraf H, Nemati A, Al Ghobain M, Al Mutairi S, Aoun Bacah Z. Waterpipe tobacco smoking. Tuberk Toraks 2016; 64(1): 94-6.

72. Tan WC, Lo C, JongA, et al. Marijuana and chronic obstructive lung disease: a population-based study. CMAJ 2009; 180(8): 814-20.

73. Yin P, Jiang CQ, Cheng KK, et al. Passive smoking exposure and risk of COPD among adults in Ch ina: the Guangzhou Biobank Cohort Study. Lancet 2007; 370(9589): 751-7.

74. Tager IB, Ngo L, Hanrahan JP. Maternal smoking during pregnancy. Effects on lung function during the first 18 months of life. Am J Respir Crit Care Med 1995; 152: 977-83.

75. Paulin LM, Diette GB, Blanc PD, et al. Occupational exposures are associated with worse morbidity in patients with chronic obstructive pulmonary disease. Am J Respir Crit Care Med 2015; 191(5): 557-65.

76. Marchetti N, Garshick E, Kinney GL, et al. Association between occupational exposure and lung function, respiratory symptoms, and high-resolution computed tomography imaging in COPDGene. Am J Respir Crit Care Med 2014; 190(7): 756-62.

77. Hnizdo E, Sullivan PA, Bang KM, Wagner G. Association between chronic obstructive pulmonary disease and employment by industry and occupation in the US population: a study of data from the Third National Health and Nutrition Examination Survey. Am J Epidemiol 2002; 156(8): 738-46.

78. Balmes J, Becklake M, Blanc P, et al. American Thoracic Society Statement: Occupational contribution to the burden of airway disease. Am J Respir Crit Care Med 2003; 167(5): 787-97.

79. Orozco-Levi M, Garcia-Aymerich J, Villar J, Ramirez-Sarmiento A, Anto JM, Gea J. Wood smoke exposure and risk of chronic obstructive pulmonary disease. Eur Respir J 2006; 27(3): 542-6. 
80. Gan WQ, FitzGerald JM, Carlsten C, Sadatsafavi M, Brauer M. Associations of ambient air pollution with chronic obstructive pulmonary disease hospitalization and mortality. Am J Respir Crit Care Med 2013; 187(7): 721-7.

81. Ezzati M. Indoor air pollution and health in developing countries. Lancet 2005; 366(9480): 104-6.

82. Zhou Y, Zou Y, Li X, et al. Lung function and incidence of chronic obstructive pulmonary disease after improved cooking fuels and kitchen ventilation: a 9-year prospective cohort study. PLoS Med 2014; 11(3): e1001621.

83. Sana A, Somda SMA, Meda N, Bouland C. Chronic obstructive pulmonary disease associated with biomass fuel use in women: a systematic review and meta-analysis. BMJ open respiratory research 2018; 5(1): e000246.

84. Assad NA, Balmes J, Mehta S, Cheema U, Sood A. Chronic obstructive pulmonary disease secondary to household air pollution. Semin Respir Crit Care Med 2015; 36(3): 408-21.

85. Sherrill DL, Lebowitz MD, Burrows B. Epidemiology of chronic obstructive pulmonary disease. Clin Chest Med 1990; 11(3): 375-87.

86. Liu S, Zhou Y, Liu S, et al. Association between exposure to ambient particulate matter and chronic obstructive pulmonary disease: results from a cross-sectional study in China. Thorax 2017; 72(9): 78895.

87. Gauderman WJ, Avol E, Gilliland F, et al. The effect of air pollution on lung development from 10 to 18 years of age. N Engl J Med 2004; 351(11): 1057-67.

88. Gauderman WJ, Urman R, Avol E, et al. Association of improved air quality with lung development in children. N Engl J Med 2015; 372(10): 905-13.

89. Townend J, Minelli C, Mortimer K, et al. The association between chronic airflow obstruction and poverty in 12 sites of the multinational BOLD study. Eur Respir L2017; 49(6).

90. Beran D, Zar HJ, Perrin C, Menezes AM, Burney P, Forum of International Respiratory Societies working group $\mathrm{c}$. Burden of asthma and chronic obstructivepulmonary disease and access to essential medicines in low-income and middle-income countries. The Lancet Respiratory medicine 2015; 3(2): 159-70.

91. Gershon AS, Warner L, Cascagnette P, Victor JC, Fo T. Lifetime risk of developing chronic obstructive pulmonary disease: a longitudinal populationstudy. Lancet 2011; 378(9795): 991-6.

92. Silva GE, Sherrill DL, Guerra S, Barbee RA. Asthma as a risk factor for COPD in a longitudinal study. Chest 2004; 126(1): 59-65.

93. Vonk JM, Jongepier H, Panhuysen CV, Schouten JP, Bleecker ER, Postma DS. Risk factors associated with the presence of irreversible airflow limitation and reduced transfer coefficient in patients with asthma after 26 years of follow up. Thorax 2003; 58(4): 322-7.

94. Lange P, Parner J, Vestbo J, Schnohr P, Jensen G. A 15-year follow-up study of ventilatory function in adults with asthma. N EngM Med 1998; 339(17): 1194-200.

95. McGeachie MJ, Yates KP, Zhou X, et al. Patterns of Growth and Decline in Lung Function in Persistent Childhood Asthma N Engl J Med 2016; 374(19): 1842-52.

96. de Marco R, Accordini S, Marcon A, et al. Risk factors for chronic obstructive pulmonary disease in a European cohort of young adults. Am J Respir Crit Care Med 2011; 183(7): 891-7.

97. Fabbri LM, Romagnoli M, Corbetta L, et al. Differences in airway inflammation in patients with fixed airflow obstruction due to asthma or chronic obstructive pulmonary disease. Am J Respir Crit Care Med 2003; 167(3): 418-24.

98. To T, Zhu J, Larsen K, et al. Progression from Asthma to Chronic Obstructive Pulmonary Disease (COPD): Is Air Pollution a Risk Factor? Am J Respir Crit Care Med 2016.

99. Rijcken B, Schouten JP, Weiss ST, Speizer FE, van der Lende R. The relationship of nonspecific bronchial responsiveness to respiratory symptoms in a random population sample. Am Rev Respir Dis 1987; 136(1): 62-8.

100. Hospers JJ, Postma DS, Rijcken B, Weiss ST, Schouten JP. Histamine airway hyper-responsiveness and mortality from chronic obstructive pulmonary disease: a cohort study. Lancet 2000; 356(9238): 13137.

101. Tashkin DP, Altose MD, Connett JE, Kanner RE, Lee WW, Wise RA. Methacholine reactivity predicts changes in lung function over time in smokers with early chronic obstructive pulmonary disease. The Lung Health Study Research Group. Am J Respir Crit Care Med 1996; 153(6 Pt 1): 1802-11.

102. Fletcher C, Peto R. The natural history of chronic airflow obstruction. BMJ 1977; 1(6077): 1645-8. 
103. Allinson JP, Hardy R, Donaldson GC, Shaheen SO, Kuh D, Wedzicha JA. The Presence of Chronic Mucus Hypersecretion across Adult Life in Relation to Chronic Obstructive Pulmonary Disease Development. Am J Respir Crit Care Med 2016; 193(6): 662-72.

104. Guerra S, Sherrill DL, Venker C, Ceccato CM, Halonen M, Martinez FD. Chronic bronchitis before age 50 years predicts incident airflow limitation and mortality risk. Thorax 2009; 64(10): 894-900.

105. Kim V, Han MK, Vance GB, et al. The chronic bronchitic phenotype of COPD: an analysis of the COPDGene Study. Chest 2011; 140(3): 626-33.

106. Bigna JJ, Kenne AM, Asangbeh SL, Sibetcheu AT. Prevalence of chronic obstructive pulmonary disease in the global population with HIV: a systematic review and meta-analysis. The Lancet Global health 2018; 6(2): e193-e202.

107. Byrne AL, Marais BJ, Mitnick CD, Lecca L, Marks GB. Tuberculosis and chronic respiratory disease: a systematic review. International journal of infectious diseases : IIID : official publication of the International Society for Infectious Diseases 2015; 32: 138-46.

108. Menezes AM, Hallal PC, Perez-Padilla R, et al. Tuberculosis and airflow obstruction: evidence from the PLATINO study in Latin America. Eur Respir J 2007; 30(6): 1180-5.

109. Jordan TS, Spencer EM, Davies P. Tuberculosis, bronchiectasis and chronic airflow obstruction. Respirology 2010; 15(4): 623-8.

110. Hogg JC, Timens W. The pathology of chronic obstructive pulmonary disease. Annual review of pathology 2009; 4: 435-59.

111. Barnes PJ. Inflammatory mechanisms in patients with chronic obstructivepulmonary disease. J Allergy Clin Immunol 2016; 138(1): 16-27.

112. Sze MA, Dimitriu PA, Suzuki M, et al. Host Response to the Lung Microbiome in Chronic Obstructive Pulmonary Disease. Am J Respir Crit Care Med 2015; 192(4): 438-45.

113. Lee SH, Goswami S, Grudo A, et al. Antielastin autoimmunity in tobacco smoking-induced emphysema. Nature medicine 2007; 13(5): 567-9.

114. Domej W, Oettl K, Renner W. Oxidative stress and free radicals in COPD--implications and relevance for treatment. Int J Chron Obstruct Pulmon Dis 2014;9: 1207-24.

115. Malhotra D, Thimmulappa R, Vij N, et al. Heightened endoplasmic reticulum stress in the lungs of patients with chronic obstructive pulmonary disease: the role of Nrf2-regulated proteasomal activity. Am J Respir Crit Care Med 2009; 180(12): 1196-207.

116. Stockley RA. Neutrophils and protease/antiprotease imbalance. Am J Respir Crit Care Med 1999; 160(5 Pt 2): S49-52.

117. Johnson SR. Untangling the protease web in COPD: metalloproteinases in the silent zone. Thorax 2016; 71(2): 105-6.

118. Polosukhin VV, Richmond BW, Du RH, et al. Secretory IgA Deficiency in Individual Small Airways Is Associated with Persistent Yhflammation and Remodeling. Am J Respir Crit Care Med 2017; 195(8): 1010-21.

119. Barnes PJ. Cellularand molecular mechanisms of chronic obstructive pulmonary disease. Clin Chest Med 2014; 35(1): 71-86.

120. Katzenstein AD, Mukhopadhyay S, Myers JL. Diagnosis of usual interstitial pneumonia and distinction from other fibrosing interstitial lung diseases. Human pathology 2008; 39(9): 1275-94.

121. Washko GR, Hunninghake GM, Fernandez IE, et al. Lung volumes and emphysema in smokers with interstitial lung abnormalities. N Engl J Med 2011; 364(10): 897-906.

122. Putman RK, Hatabu H, Araki T, et al. Association Between Interstitial Lung Abnormalities and All-Cause Mortality. Jama 2016; 315(7): 672-81.

123. Churg A, Tai H, Coulthard T, Wang R, Wright JL. Cigarette smoke drives small airway remodeling by induction of growth factors in the airway wall. Am J Respir Crit Care Med 2006; 174(12): 1327-34.

124. Rennard SI, Wachenfeldt K. Rationale and emerging approaches for targeting lung repair and regeneration in the treatment of chronic obstructive pulmonary disease. Proc Am Thorac Soc 2011; 8(4): 368-75.

125. Hogg JC, McDonough JE, Gosselink JV, Hayashi S. What drives the peripheral lung-remodeling process in chronic obstructive pulmonary disease? Proc Am Thorac Soc 2009; 6(8): 668-72.

126. Barnes PJ. Immunology of asthma and chronic obstructive pulmonary disease. Nature reviews Immunology 2008; 8(3): 183-92.

127. Global Initiative for Asthma. 2015 Asthma, COPD and Asthma-COPD Overlap Syndrome (ACOS). 2015 (accessed 14 October 2018). 
128. Hogg JC, Chu F, Utokaparch S, et al. The nature of small-airway obstruction in chronic obstructive pulmonary disease. N Engl J Med 2004; 350(26): 2645-53.

129. McDonough JE, Yuan R, Suzuki M, et al. Small-airway obstruction and emphysema in chronic obstructive pulmonary disease. N Engl J Med 2011; 365(17): 1567-75.

130. Ofir D, Laveneziana P, Webb KA, Lam YM, O'Donnell DE. Mechanisms of dyspnea during cycle exercise in symptomatic patients with GOLD stage I chronic obstructive pulmonary disease. Am J Respir Crit Care Med 2008; 177(6): 622-9.

131. Elbehairy AF, Ciavaglia CE, Webb KA, et al. Pulmonary Gas Exchange Abnormalities in Mild Chronic Obstructive Pulmonary Disease. Implications for Dyspnea and Exercise Intolerance. Am J Respir Crit Care Med 2015; 191(12): 1384-94.

132. Casaburi R, Maltais F, Porszasz J, et al. Effects of tiotropium on hyperinflation and treadmill exercise tolerance in mild to moderate chronic obstructive pulmonary disease. Annals of the American Thoracic Society 2014; 11(9): 1351-61.

133. Rodriguez-Roisin R, Drakulovic M, Rodriguez DA, Roca J, Barbera JA, Wagner PD. Ventilation-perfusion imbalance and chronic obstructive pulmonary disease staging severity. J Appl Physiol 2009; 106(6): 1902-8.

134. Burgel PR, Nadel JA. Epidermal growth factor receptor-mediated innate immune,responses and their roles in airway diseases. Eur Respir J 2008; 32(4): 1068-81.

135. Sakao S, Voelkel NF, Tatsumi K. The vascular bed in COPD: pulmonary hypertension and pulmonary vascular alterations. Eur Respir Rev 2014; 23(133): 350-5.

136. Iyer KS, Newell JD, Jr., Jin D, et al. Quantitative Dual-Energy Computed Jomography Supports a Vascular Etiology of Smoking-induced Inflammatory Lung Disease. Am J Respir Crit Care Med 2016; 193(6): 652-61.

137. Alford SK, van Beek EJ, McLennan G, Hoffman EA. Heterogeneity of pulmonary perfusion as a mechanistic image-based phenotype in emphysema susceptible smokers. Proc Natl Acad Sci U S A 2010; 107(16): 7485-90.

138. Peinado VI, Pizarro S, Barbera JA. Pulmonary vascular involvement in COPD. Chest 2008; 134(4): 80814.

139. Wells JM, Washko GR, Han MK, et al. Pulmonary arterial enlargement and acute exacerbations of COPD. N Engl J Med 2012; 367(10): 913-21.

140. Parker CM, Voduc N, Aaron SD, Webb KA, O'Donnell DE. Physiological changes during symptom recovery from moderate exacerbations of COPD. Eur Respir J 2005; 26(3): 420-8.

141. Barbera JA, Roca J, Ferrer A, et al. Mechanisms of worsening gas exchange during acute exacerbations of chronic obstructive pulmonary disease. Eur Respir J 1997; 10(6): 1285-91.

142. Miller J, Edwards LD, Agusti A, et al. Comorbidity, systemic inflammation and outcomes in the ECLIPSE cohort. Respir Med 2013, 107(9): 1376-84. 


\section{CHAPTER 2: DIAGNOSIS AND INITIAL ASSESSMENT}

\section{OVERALL KEY POINTS:}

- COPD should be considered in any patient who has dyspnea, chronic cough or sputum production, a history of recurrent lower respiratory tract infections and/or a history of exposure to risk factors for the disease.

- Spirometry is required to make the diagnosis; the presence of a post-bronchodilator $F E V_{1} / F V C<0.70$ confirms the presence of persistent airflow limitation.

- The goals of COPD assessment are to determine the level of airflow limitation, the impact of disease on the patient's health status, and the risk of future events (such as exacerbations, hospital admissions, or death), in order to guide therapy.

- Concomitant chronic diseases occur frequently in COPD patients, including cardiovascular disease, skeletal muscle dysfunction, metabolic syndrome, osteoporosis, depression, anxiety, and lung cancer. These comorbidities should be actively sought and treated appropriately when present as they can infuence mortality and hospitalizations independently.

\section{PATHWAYS TO THE DIAENOSIS OF COPD}
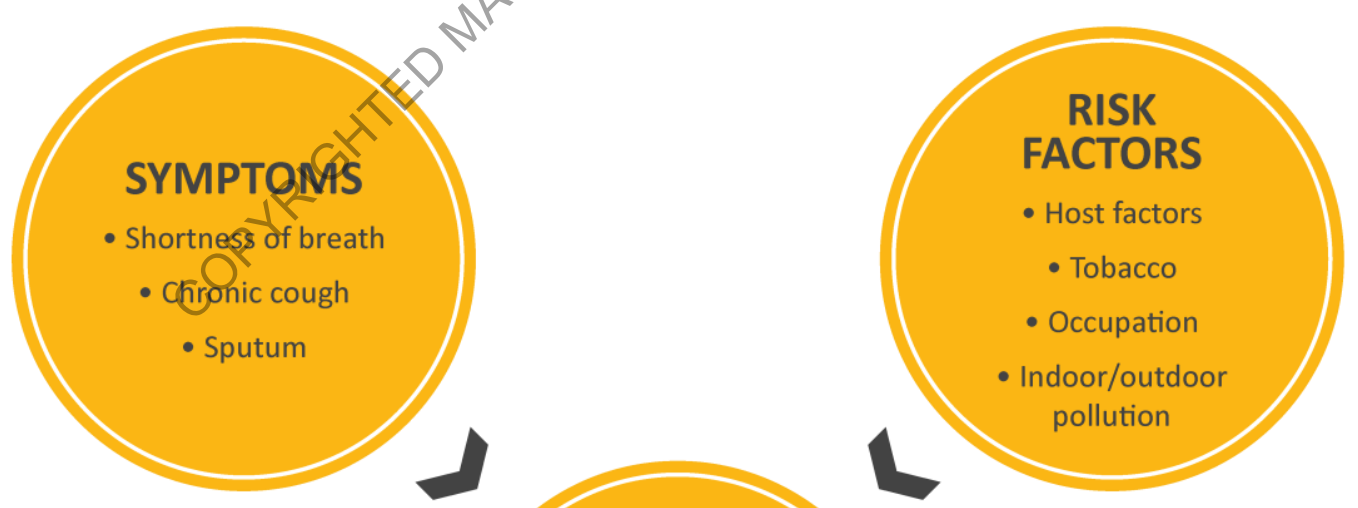

\section{SPIROMETRY:}

Required to establish diagnosis 


\section{DIAGNOSIS}

COPD should be considered in any patient who has dyspnea, chronic cough or sputum production, and/or a history of exposure to risk factors for the disease (Figure 2.1 and Table 2.1). Spirometry is required to make the diagnosis in this clinical context 1 ; the presence of a post-bronchodilator $\mathrm{FEV}_{1} / \mathrm{FVC}<0.70$ confirms the presence of persistent airflow limitation and thus of COPD in patients with appropriate symptoms and significant exposures to noxious stimuli.

\section{KEY INDICATORS FOR CONSIDERING A DIAGNOSIS OF COPD}

Consider COPD, and perform spirometry, if any of these indicators are present in an individual over age 40.

These indicators are not diagnostic themselves, but the presence of multiple key indicators increases the probability of a diagnosis of COPD. Spirometry is required to establish a diagnosis of COPD.

Dyspnea that is:

Progressive over time.

Characteristically worse with exercise.

Persistent.

Chronic Cough:

May be intermittent and may be unproductive

Recurrent wheeze.

Chronic Sputum Production: Any pattern of chronic sputum production may indicate COPD.

Recurrent Lower Respiratory Tract Infections

\begin{tabular}{ll}
\hline History of Risk Factors: & $\begin{array}{l}\text { Host factors (such as genetic factors, congenital/developmental abnormalities etc.). } \\
\text { Tobacco smoke (including popular local preparations). } \\
\text { Smoke from home (colking and heating fuels. } \\
\text { Occupational dusts, vapors, fumes, gases and other chemicals. }\end{array}$ \\
\hline Family History of COPD & For example low birthweight, childhood respiratory infections etc.
\end{tabular}

and/or Childhood Factors:

TABLE 2.1

\section{SYMPTOMS}

Chronic and progressive dyspnea is the most characteristic symptom of COPD. Cough with sputum production is present in up to $30 \%$ of patients. These symptoms may vary from day-to-day ${ }^{2}$ and may precede the development of airflow limitation by many years. Individuals, particularly those with COPD risk factors, presenting with these symptoms should be examined to search for the underlying cause(s). These patient symptoms should be used to help develop appropriate interventions. Significant airflow limitation may also be present without chronic dyspnea and/or cough and sputum production and vice versa. . $^{3}$ Although COPD is defined on the basis of airflow limitation, in practice the decision to seek medical help is usually determined by the impact of symptoms on a patient's functional status. A person may seek medical attention either because of chronic respiratory symptoms or because of an acute, transient episode of exacerbated respiratory symptoms. 
Dyspnea. Dyspnea, a cardinal symptom of COPD, is a major cause of the disability and anxiety that is associated with the disease. ${ }^{4}$ Typical COPD patients describe their dyspnea as a sense of increased effort to breathe, chest heaviness, air hunger, or gasping.. However, the terms used to describe dyspnea may vary both individually and culturally. $\frac{5}{5}$

Cough. Chronic cough is often the first symptom of COPD and is frequently discounted by the patient as an expected consequence of smoking and/or environmental exposures. Initially, the cough may be intermittent, but subsequently may be present every day, often throughout the day. Chronic cough in COPD may be productive or unproductive. $\underline{6}$ In some cases, significant airflow limitation may develop without the presence of a cough. Other causes of chronic cough are listed in Table 2.2.

Sputum production. COPD patients commonly raise small quantities of tenacious sputum with coughing. Regular production of sputum for three or more months in two consecutive years (in the absence of any other conditions that may explain it) is the classical definition of (chronic bronchitis, $\underline{\underline{ }}$ but this is a somewhat arbitrary definition that does not reflect the entire range of sputum production that occurs in COPD. Sputum production is often difficult to evaluate because patients may swallow sputum rather than expectorate it, a habit that is subject to significant cultural and sex variation. Furthermore, sputum production can be intermittent with periods of flare-up interspersed with periods of remission. - Patients producing large volumes of sputum may have underlying bronchiectasis. The presence of purulent sputum reflects an increase in inflammatory mediators, $, \underline{9}, 10$ and its development may identify the onset of a bacterial exacerbation, though the association is relatively weak. $\stackrel{10,11}{1}$

\section{OTHER CAUSES OF CHRONIC COUGH}

\section{INTRATHORACIC}

- Asthma

- Lung Cancer

- Tuberculosis

- Bronchiectasis

- Left Heart Failure

- Interstitial Lung Disease

- Cystic Fibrosis

- Idiopathic Cough

\section{EXTRATHORACIC}

- Chronic Allergic Rhinitis

- Post Nasal Drip Syndrome (PNDS)

- Upper Airway Cough Syndrome (UACS)

- Gastroesophageal Reflux

- Medication (e.g. ACE Inhibitors)

TABLE 2.2 
Wheezing and chest tightness. Wheezing and chest tightness are symptoms that may vary between days, and over the course of a single day. Audible wheeze may arise at the laryngeal level and need not be accompanied by abnormalities heard on auscultation. Alternatively, widespread inspiratory or expiratory wheezes can be present on auscultation. Chest tightness often follows exertion, is poorly localized, is muscular in character, and may arise from isometric contraction of the intercostal muscles. An absence of wheezing or chest tightness does not exclude a diagnosis of COPD, nor does the presence of these symptoms confirm a diagnosis of asthma.

Additional features in severe disease. Fatigue, weight loss and anorexia are common problems in patients with severe and very severe COPD. $\underline{12,} \underline{\underline{13}}$ They have prognostic importance $\frac{14,15}{15}$ and can also be a sign of other diseases, such as tuberculosis or lung cancer, and therefore should always be investigated. Syncope during cough occurs due to rapid increases in intrathoracic pressure during prolonged attacks of coughing. Coughing spells may also cause rib fractures, which are sometimes asymptomatic. Ankle swelling may be the only indicator of the presence of cor pulmonale. Symptoms of depression and/or anxiety merit specific enquiry when obtaining the medical history because they are common in COPD $\underline{16}$ and are associated with an increased risk of exacerbations and poorer health status.

\section{MEDICAL HISTORY}

A detailed medical history of a new patient who is known, or suspected, to have COPD should include:

- Patient's exposure to risk factors, such as smoking and occupational or environmental exposures.

- Past medical history, including asthma, allergy, sinusitis, or nasal polyps; respiratory infections in childhood; other chrónic respiratory and non-respiratory diseases.

- Family history of COPD orother chronic respiratory disease.

- Pattern of symptom development: COPD typically develops in adult life and most patients are conscious of increased breathlessness, more frequent or prolonged "winter colds," and some social restriction for a number of years before seeking medical help.

- History of exacerbations or previous hospitalizations for respiratory disorder. Patients may be aware of periodic worsening of symptoms even if these episodes have not been identified as exacerbations of COPD.

- Presence of comorbidities, such as heart disease, osteoporosis, musculoskeletal disorders, and malignancies that may also contribute to restriction of activity.

- Impact of disease on patient's life, including limitation of activity, missed work and economic impact, effect on family routines, feelings of depression or anxiety, well-being and sexual activity.

- Social and family support available to the patient.

- Possibilities for reducing risk factors, especially smoking cessation. 
- Spirometers need calibration on a regular basis.

- Spirometers should produce hard copy or have a digital display of the expiratory curve to permit detection of technical errors or have an automatic prompt to identify an unsatisfactory test and the reason for it.

- The supervisor of the test needs training in optimal technique and quality performance.

- Maximal patient effort in performing the test is required to avoid underestimation of values and hence errors in diagnosis and management.

BRONCHODILATION

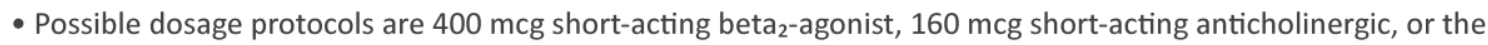
two combined. ${ }^{a}$ FEV $_{1}$ should be measured 10-15 minutes after a short-acting beta ${ }_{2}$-agonist is given, or 30-45 minutes after a short-acting anticholinergic or a combination of both classes of drugs.

\section{PERFORMANCE}

- Spirometry should be performed using techniques that meet published standards. ${ }^{b}$

- The expiratory volume/time traces should be smooth and free from irregularities, The pause between inspiration and expiration should be $<1$ second.

- The recording should go on long enough for a volume plateau to be reached, which may take more than 15 seconds in severe disease.

- Both FVC and $\mathrm{FEV}_{1}$ should be the largest value obtained from any of three technically satisfactory curves and the FVC and $\mathrm{FEV}_{1}$ values in these three curves should vary by no more than $5 \%$ or $150 \mathrm{ml}$, whichever is greater.

- The FEV $\mathrm{FVVC}_{1} / \mathrm{Fatio}$ should be taken from the technically acceptable curve with the largest sum of FVC and FEV

\section{EVALUATION}

- Spirometry measurements are evaluated by comparison of the results with appropriate reference values based on age, height, sex, and race.

- The presence of a postbronchodilator $\mathrm{FEV}_{1} / \mathrm{FV} C 0.70$ confirms the presence of airflow limitation.

a Pellegrino et al. Eur Respir J 2005; 26(5)! 948-68;

b Miller et al. Eur Respir J 2005; 26(2):319-38.

TABLE 2.3

\section{Physical examingtion}

Although an important part of patient care, a physical examination is rarely diagnostic in COPD. Physical signs of airflow limitation are usually not present until significant impairment of lung function has occurred, $, \underline{17}, \underline{18}$ and detection based on physical examination has relatively low sensitivity and specificity. A number of physical signs may be present in COPD, but absence does not exclude the diagnosis.

\section{Spirometry}

Spirometry is the most reproducible and objective measurement of airflow limitation. It is a noninvasive and readily available test. Despite its good sensitivity, peak expiratory flow measurement alone cannot be reliably used as the only diagnostic test because of its weak specificity. $\stackrel{19}{ }$ Good quality spirometric measurement is possible in any healthcare setting and all healthcare workers who care for COPD patients should have access to spirometry. Some of the factors needed to achieve accurate test results are summarized in Table 2.3. 20,21 
Spirometry should measure the volume of air forcibly exhaled from the point of maximal inspiration (forced vital capacity, FVC) and the volume of air exhaled during the first second of this maneuver (forced expiratory volume in one second, $\mathrm{FEV}_{1}$ ), and the ratio of these two measurements (FEV $1 / F V C$ ) should be calculated. The ratio between $\mathrm{FEV}_{1}$ and slow vital capacity (VC), FEV $1 / \mathrm{VC}$, is sometimes measured instead of the $\mathrm{FEV}_{1} / \mathrm{FVC}$ ratio. This will often lead to lower values of the ratio, especially in pronounced airflow limitation. Spirometry measurements are evaluated by comparison with reference values $\underline{21}$ based on age, height, sex, and race.

A normal spirometry tracing is shown in Figure 2.2A. A spirometry tracing typical of a patient with obstructive disease is shown in Figure 2.2B. Patients with COPD typically show a decrease in both FEV 1 and FVC.
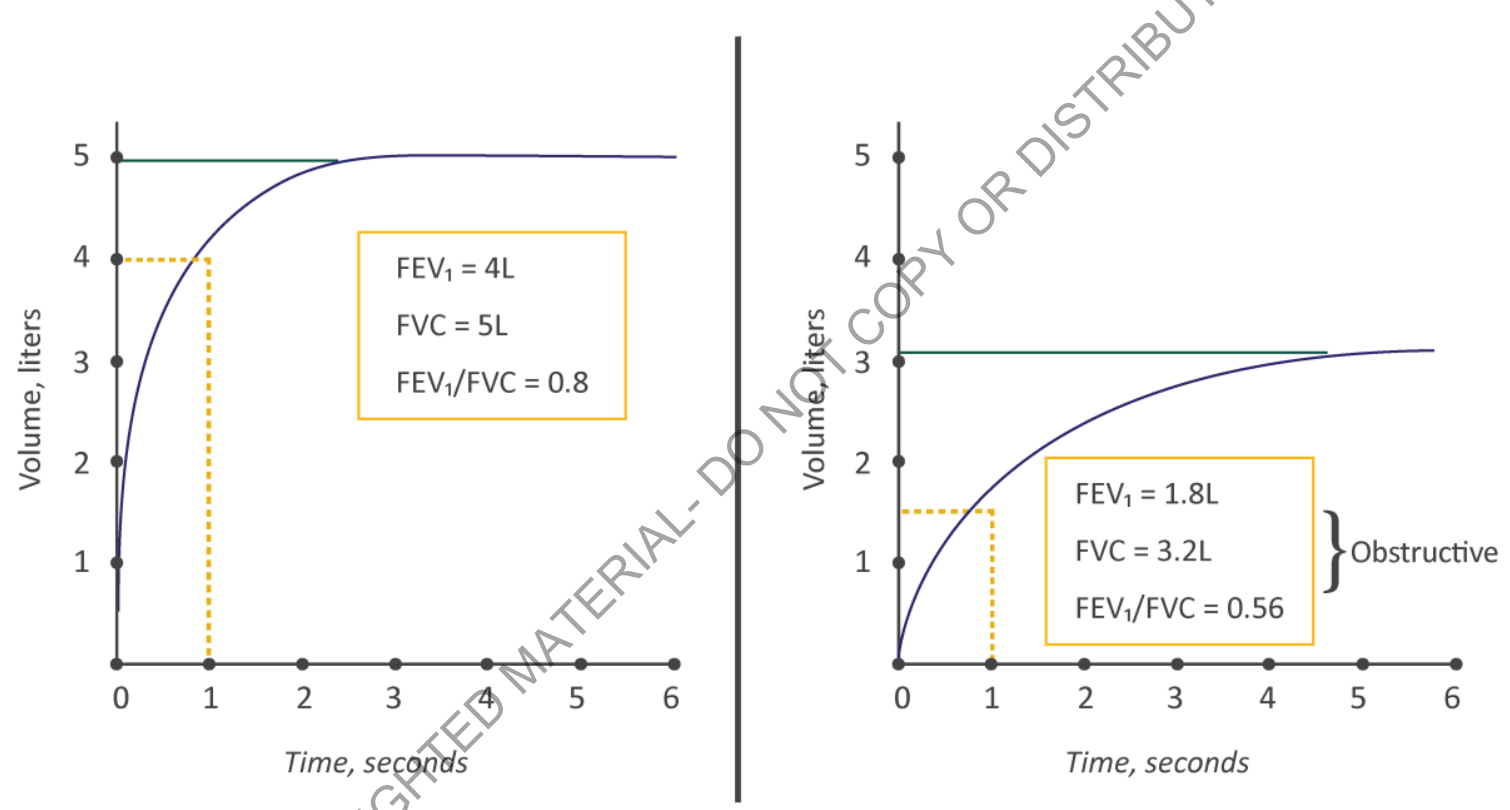

$\mathrm{FVC}=$

$\mathrm{FEV}_{1}=$

The spirometric criterion for airflow limitation remains a post-bronchodilator fixed ratio of $\mathrm{FEV}_{1} / \mathrm{FVC}$ $<0.70$. This criterion is simple and independent of reference values, and has been used in numerous clinical trials that form the evidence base from which most of our treatment recommendations are drawn. It should be noted that the use of the fixed $\mathrm{FEV}_{1} / \mathrm{FVC}$ ratio to define airflow limitation may result in more frequent diagnosis of COPD in the elderly,, $2 \underline{23}$ and less frequent diagnosis in adults $<45$ years, $\underline{\underline{23}}$ especially in mild disease, compared to using a cut-off based on the lower limit of normal (LLN) values for $\mathrm{FEV}_{1} / \mathrm{FVC}$.

The LLN values are based on the normal distribution and classify the bottom $5 \%$ of the healthy population as abnormal. From a scientific or clinical perspective, it is difficult to determine which of 
these criteria will result in optimal COPD diagnostic accuracy. However, LLN values are highly dependent on the choice of valid reference equations using post-bronchodilator $F E V_{1}$, and there are no longitudinal studies available validating the use of the LLN, or studies using reference equations in populations where smoking is not the major cause of COPD.

Normal spirometry may be defined by a new approach from the Global Lung Initiative (GLI). $\stackrel{24,25}{2}$ Using GLI equations, $z$ scores were calculated for $\mathrm{FEV}_{1}, \mathrm{FVC}$, and $\mathrm{FEV}_{1} / \mathrm{FVC}$. The diagnostic algorithm was initially based on a single threshold, namely a $z$ score of -1.64 (defining the LLN at the fifth percentile of the normal distribution). The results were compared to fixed ratio data. The findings suggest that among adults with GLI-defined normal spirometry, the use of a fixed ratio may misclassify individuals as having respiratory impairment. It is important that these findings are reproduced in other cohorts.

The risk of misdiagnosis and over-treatment of individual patients using the fixed ratio as a diagnostic criterion is limited, as spirometry is only one parameter for establishing the clinicaldiagnosis of COPD; the additional parameters being symptoms and other risk factors. Diagnostic simplicity and consistency are crucial for the busy clinician. Thus, GOLD favors the use of the fixed ratio over LLN.

Assessment of the presence or absence of airflow obstruction based on a single measurement of the post-bronchodilator $\mathrm{FEV}_{1} / \mathrm{FVC}$ ratio should be confirmed by repeat spirometry on a separate occasion if the value is between 0.6 and 0.8 , as in some cases the ratio may change as a result of biological variation when measured at a later interval. $\underline{26}, \underline{27}$ If the initial post-bronchodilator $\mathrm{FEV}_{1} / \mathrm{FVC}$ ratio is less than 0.6 it is very unlikely to rise above 0.7 spontaneously. $\underline{26}$

While post-bronchodilator spirometry is required for the diagnosis and assessment of COPD, assessing the degree of reversibility of airflow limitation (e.g., measuring FEV ${ }_{1}$ before and after bronchodilator or corticosteroids) to inform therapeutic decisions is no longer recommended. $\frac{28}{2}$ The degree of reversibility has not been shown to augment the diagnosis of COPD, differentiate the diagnosis from asthma, or to predict the response to long-term treatment with bronchodilators or corticosteroids. $\underline{\underline{29}}$

The role of screening spirometry in the general population is controversial. ${ }^{30,31}$ In asymptomatic individuals without any significant exposures to tobacco or other noxiou s stimuli, screening spirometry is probably not indicated; whereas in those with symptoms or risk factors (e.g., > 20 pack-years of smoking or recurrent chest infections), the diagnostic yield for COPD is relatively high and spirometry should be considered as a method for early case finding. $.32,33$ Both FEV ${ }_{1}$ and FVC predict all-cause mortality independent of tobacco smoking, and abnormal lung function identifies a subgroup of smokers at increased risk for lung cancer. This has been the basis of an argument that screening spirometry should be employed as a global health assessment tool. $\stackrel{34}{\underline{35}} \mathrm{~A}$ risk score based on routine data from electronic health records in primary care may facilitate case-finding. $\frac{36}{}$ However, there are no data to indicate that screening spirometry is effective in directing management decisions or in improving COPD outcomes in patients who are identified before the development of significant symptoms. $\frac{37}{}$ This may reflect the design and application of current case finding instruments that have not been utilized to identify patients with undiagnosed COPD who are most likely to benefit from existing therapies. $\underline{38, \underline{39}}$ Thus, GOLD advocates active case finding $\underline{32}, \underline{40}, \underline{41}$ i.e., performing spirometry in patients with symptoms and/or risk factors, but not screening spirometry. Systematic active casefinding in a primary care setting via mail-out of a screening questionnaire was also found to be an 
effective way to identify undiagnosed COPD patients. $\underline{.2}$

Interpretation of the severity of lung function impairment is dependent on having appropriate reference values. The Prospective Urban and Rural Epidemiological (PURE) study analyzed prebronchodilator spirometry data from 153,996 healthy people with less than 5 pack-year smoking histories in 17 countries and observed wide variation in lung function. ${ }^{43}$ For instance, compared with individuals living in North America or Europe, people living in Southeast Asia had FEV 1 values that were on average $31 \%$ lower, adjusted for age, height and sex. Similarly, those living in sub-Saharan Africa, East Asia, Middle East and South America had FEV ${ }_{1}$ values that were on average $21 \%, 13 \%, 11 \%$, and $6 \%$ lower than individuals living in North America or Europe, respectively, independent of age, height, sex, and smoking status. $\underline{-43}$ Unless relevant predicted values are used the severity of airflow limitation will be overestimated.

\section{ASSESSMENT}

The goals of COPD assessment are to determine the level of airflow limitation, its impact on the patient's health status and the risk of future events (such as exacerbations, hospital admissions or death), in order to, eventually, guide therapy.

To achieve these goals, COPD assessment must consider the following aspects of the disease separately:

- The presence and severity of the spirometric abnormality

- Current nature and magnitude of the patient's symptoms

- History of moderate and severe exacérbations and future risk

- Presence of comorbidities

\section{Classification of severity of dirflow limitation}

The classification of airflow limitation severity in COPD is shown in Table 2.4. Specific spirometric cutpoints are used for purposes of simplicity. Spirometry should be performed after the administration of an adequate dose of at least one short-acting inhaled bronchodilator in order to minimize variability.

It should be noted that there is only a weak correlation between $\mathrm{FEV}_{1}$, symptoms and impairment of a patient's health status. $\stackrel{44,45}{4}$ For this reason, formal symptomatic assessment is required. 


\section{In patients with FEV1/FVC $<0.70$ :}

\begin{tabular}{lll} 
GOLD 1: & Mild & $\mathrm{FEV}_{1} \geq 80 \%$ predicted \\
\hline GOLD 2: & Moderate & $50 \% \leq \mathrm{FEV}_{1}<80 \%$ predicted \\
\hline GOLD 3: & Severe & $30 \% \leq \mathrm{FEV}_{1}<50 \%$ predicted \\
\hline GOLD 4: & Very Severe & $\mathrm{FEV}_{1}<30 \%$ predicted
\end{tabular}

TABLE 2.4

\section{Assessment of symptoms}

Here we present the two measures of symptoms that are most widely used.

In the past, COPD was viewed as a disease largely characterized by breathlessness. A simple measure of breathlessness such as the Modified British Medical Research Council (mMRC) Questionnaire ${ }^{46}$ (Table 2.5) was considered adequate for assessment of sypptoms, as the mMRC relates well to other measures of health status $\underline{47}$ and predicts future mortality risk. $\frac{48,49}{\underline{4}}$

\section{MODIFIED MRC DYSPAEÁ SCALE ${ }^{a}$}

\section{PLEASE TICK IN THE BOX THAT APPLIES TO YOU | ONE BOX ONLY | Grades 0 - 4}

mMRC Grade 0.
mMRC Grade 2.
mMRC Grade 3.
I walk slower than people of the same age on the level because
my own pace on the level.
mMRC Grade 4.
minutes on the level.

${ }^{\text {a }}$ Fletcher CM. BMJ 1960; 2: 1662.

TABLE 2.5 
However, it is now recognized that COPD impacts patients beyond just dyspnea. $\underline{50}$ For this reason, a comprehensive assessment of symptoms is recommended rather than just a measure of breathlessness. The most comprehensive disease-specific health status questionnaires such as the Chronic Respiratory Questionnaire (CRQ) $\frac{51}{1}$ and St. George's Respiratory Questionnaire (SGRQ) $\frac{52}{\text { are }}$ too complex to use in routine practice, but shorter comprehensive measures e.g., COPD Assessment Test $\left(\mathrm{CAT}^{\mathrm{TM}}\right)$ and The COPD Control Questionnaire $\left(\mathrm{The} \mathrm{CCQ}^{\odot}\right)$ have been developed and are suitable.

COPD Assessment Test (CAT $\left.{ }^{\mathrm{TM}}\right){ }^{4}{ }^{4}$ The COPD Assessment Test ${ }^{\mathrm{TM}}$ is an 8-item uni-dimensional measure of health status impairment in COPD (Figure 2.3). $\underline{53}$ It was developed to be applicable worldwide and validated translations are available in a wide range of languages. The score ranges from $0-40$, correlates very closely with the SGRQ, and has been extensively documented in numerous publications. $\frac{54}{4}$

\section{Choice of thresholds}

The $\mathrm{CAT}^{\mathrm{TM}}$ and the $\mathrm{CCQ}^{\odot}$ provide measures of the symptomatic impact of COPD but do not categorize patients into symptom severity groups for the purpose of treatment. The SGRQ is the most widely documented comprehensive measure; scores $<25$ are uncommon in diagnosed COPD patients $\underline{55}$ and scores $\geq 25$ are very uncommon in healthy persons. $\underline{56,57}$ Therefore, it is recommended that a symptom score equivalent to SGRQ score $\geq 25$ should be used as the threshold for considering regular treatment for symptoms including breathlessness, particularly since-this corresponds to the range of severity seen in patients recruited to the trials that have frovided the evidence base for treatment recommendations. The equivalent cut-point for the CAT ${ }^{\mathrm{TM}}$ is $10 . \underline{58}$

An equivalent $\mathrm{mMRC}$ score cannot be calculatéd because a simple breathlessness cut-point cannot equate to a comprehensive symptom score cut-point. The great majority of patients with an SGRQ of $\geq 25$ will have an $m M R C$ of $\geq 1$; however patients with $m M R C<1$ may also have a number of other COPD symptoms. $\underline{59}$ For this reason, the use of a comprehensive symptom assessment is recommended. However, becaúse use of the $\mathrm{mMRC}$ is widespread, an $\mathrm{mMRC}$ of $\geq 2$ is still included as a threshold for separating "Jess breathlessness" from "more breathlessness." Nevertheless, users are cautioned that assessment of other symptoms is required. $\underline{59}$

There are other scales available such as the COPD Control Questionnaire (CCQ) and the Chronic Respiratory Disease Questionnaire (CRQ) that will not be discussed in detail.

\section{Assessment of exacerbation risk}

COPD exacerbations are defined as an acute worsening of respiratory symptoms that result in additional therapy. $\frac{60-63}{}$ These events are classified as mild (treated with short acting bronchodilators (SABDs) only), moderate (treated with SABDs plus antibiotics and/or oral corticosteroids) or severe (patient requires hospitalization or visits the emergency room). Severe exacerbations may also be associated with acute respiratory failure. A number of large studies that classified patients using the GOLD spirometric grading systems have been conducted. $\frac{64-66}{}$ These studies demonstrate that

\footnotetext{
4 The COPD Assessment Test was developed by a multi-disciplinary group of international experts in COPD supported by GSK. COPD Assessment Test and the CAT TM logo is a trademark of the GlaxoSmithKline group of companies. (๑) 2009 GlaxoSmithKline. All rights reserved. GSK activities wi th respect to the COPD Assessment Test $^{\mathrm{TM}}$ are overseen by a governance board that includes independent external experts, one of whom chairs the board.
} 
exacerbation rates vary greatly between patients $\frac{66}{6}$ and during follow-up. $\frac{67}{6}$ The best predictor of having frequent exacerbations (defined as two or more exacerbations per year) is a history of earlier treated events. $\underline{.6}$

\section{CAT $^{\mathrm{TM}}$ ASSESSMENT}

For each item below, place a mark ( $\mathrm{x}$ ) in the box that best describes you currently.

Be sure to only select one response for each question.

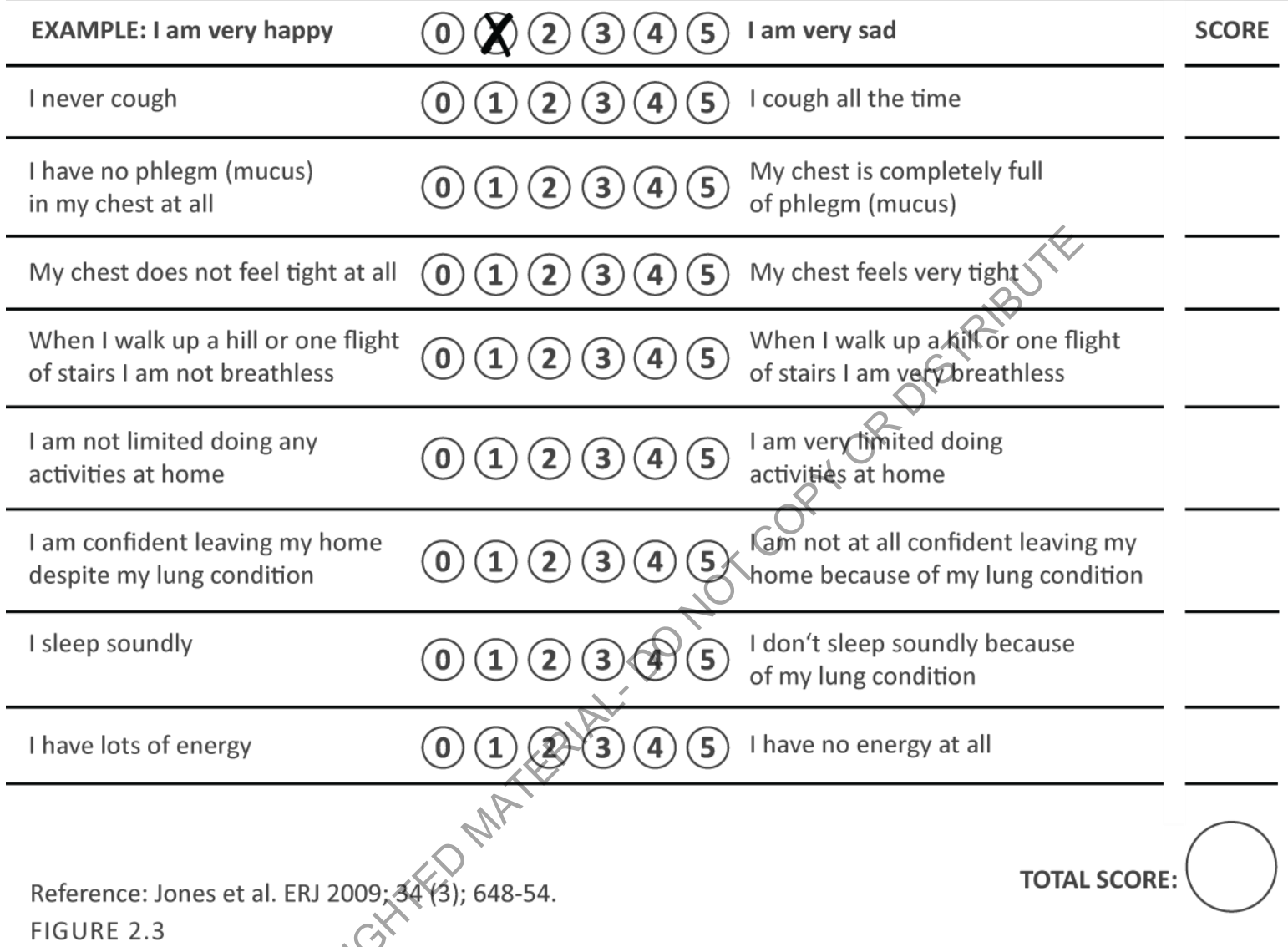

In addition, deteriorating airflow limitation is associated with an increasing prevalence of exacerbations, hospitalization $\underline{68}$ and risk of death. $\frac{55,69}{6}$ Hospitalization for a COPD exacerbation is associated with poor prognosis and increased risk of death. $\underline{70}$ There is also a significant relationship between spirometric severity and the risk of exacerbation and death. At the population level, approximately $20 \%$ of GOLD 2 (moderate airflow limitation) patients may experience frequent exacerbations requiring treatment with antibiotics and/or systemic corticosteroids. $\frac{66}{6}$ The risk of exacerbations is significantly higher for patients with GOLD 3 (severe) and GOLD 4 (very severe). However, $\mathrm{FEV}_{1}$ by itself lacks sufficient precision (i.e., wide variation) to be used clinically as a predictor of exacerbation or mortality in patients with COPD. $\underline{69}$

The association between blood eosinophil count and risk of exacerbations is outlined in Chapter 3. 


\section{Assessment of concomitant chronic diseases (comorbidities)}

Patients with COPD often have important concomitant chronic illnesses at the time of diagnosis and COPD represents an important component of multimorbidity development particularly in the elderly in response to common risk factors (e.g., aging, smoking, alcohol, diet and inactivity). $\frac{70-73}{}$ COPD itself also has significant extrapulmonary (systemic) effects including weight loss, nutritional abnormalities and skeletal muscle dysfunction. Skeletal muscle dysfunction is characterized by both sarcopenia (loss of muscle cells) and abnormal function of the remaining cells. ${ }^{74}$ Its causes are likely multifactorial (e.g., inactivity, poor diet, inflammation and hypoxia) and it can contribute to exercise intolerance and poor health status in patients with COPD. Importantly, skeletal muscle dysfunction is a rectifiable source of exercise intolerance. $\underline{75}$

Common comorbidities include cardiovascular disease, $\underline{76}$ skeletal muscle dysfunction, metabolic syndrome, osteoporosis, depression, anxiety and lung cancer. The existence of COPD may actually increase the risk for other diseases; this is particularly striking for COPD and lung cancer. 77,78 Whether this association is due to common risk factors (e.g., smoking), involvement of susceptibility genes, or impaired clearance of carcinogens is not clear.

Comorbidities can occur in patients with mild, moderate or severe airflow limitation, $\underline{55}$ influence mortality and hospitalizations independently, $\underline{79}$ and deserve specific treatment. Therefore, comorbidities should be looked for routinely, and treatedappropriately, in any patient with COPD. Recommendations for the diagnosis, assessment of severity, and management of individual comorbidities in patients with COPD are the same as for all other patients. A more detailed description of the management of COPD and comorbidities isprovided in Chapter 6.

\section{Combined COPD assessment}

An understanding of the impact of COPD on an individual patient combines the symptomatic assessment with the patient's, spirometric classification and/or risk of exacerbations. The " $A B C D$ " assessment tool of the 2011 GOLD update was a major step forward from the simple spirometric grading system of the earlier versions of GOLD because it incorporated patient-reported outcomes and highlighted the importance of exacerbation prevention in the management of COPD. However, there were some important limitations. Firstly, the $A B C D$ assessment tool performed no better than the spirometric grades for mortality prediction or other important health outcomes in COPD. $\underline{69,80,81}$ Moreover, group " $D$ " outcomes were modified by two parameters: lung function and/or exacerbation history, which caused confusion. $\underline{45}$ To address these and other concerns (while at the same time maintaining consistency and simplicity for the practicing clinician), a refinement of the $A B C D$ assessment tool is proposed that separates spirometric grades from the "ABCD" groups. For some therapeutic recommendations, $A B C D$ groups will be derived exclusively from patient symptoms and their history of exacerbation. Spirometry, in conjunction with patient symptoms and history of moderate and severe exacerbations, remains vital for the diagnosis, prognostication and consideration of other important therapeutic approaches. This new approach to assessment is illustrated in Figure 2.4.

In the revised assessment scheme, patients should undergo spirometry to determine the severity of airflow limitation (i.e., spirometric grade). They should also undergo assessment of either dyspnea 
using mMRC or symptoms using CAT ${ }^{\mathrm{TM}}$. Finally, their history of moderate and severe exacerbations (including prior hospitalizations) should be recorded.

The number provides information regarding severity of airflow limitation (spirometric grade 1 to 4 ) while the letter (groups $A$ to $D$ ) provides information regarding symptom burden and risk of exacerbation which can be used to guide therapy. $\mathrm{FEV}_{1}$ is a very important parameter at the population-level in the prediction of important clinical outcomes such as mortality and hospitalizations or prompting consideration for non-pharmacological therapies such as lung volume reduction or lung transplantation. However, it is important to note that at the individual patient level, $\mathrm{FEV}_{1}$ loses precision and thus cannot be used alone to determine all therapeutic options. Furthermore, in some circumstances, such as during hospitalization or urgent presentation to the clinic or emergency room, the ability to assess patients based on symptoms and exacerbation history, independent of the spirometric value, allows clinicians to initiate a treatment plan based on the revised $A B C D$ scheme alone. This assessment approach acknowledges the limitations of $\mathrm{FEV}_{1}$ in making treatment decisions for individualized patient care and highlights the importance of patient symptoms and exacerbation risks in guiding therapies in COPD. The separation of airflow limitation from clinical parameters makes it clearer what is being evaluated and ranked. This will facilitate more precise treatment recommendations based on parameters that are driving the patient's symptoms at any given time.

\section{THE REFINED ABCD ASSESSMÉNT TOOL}

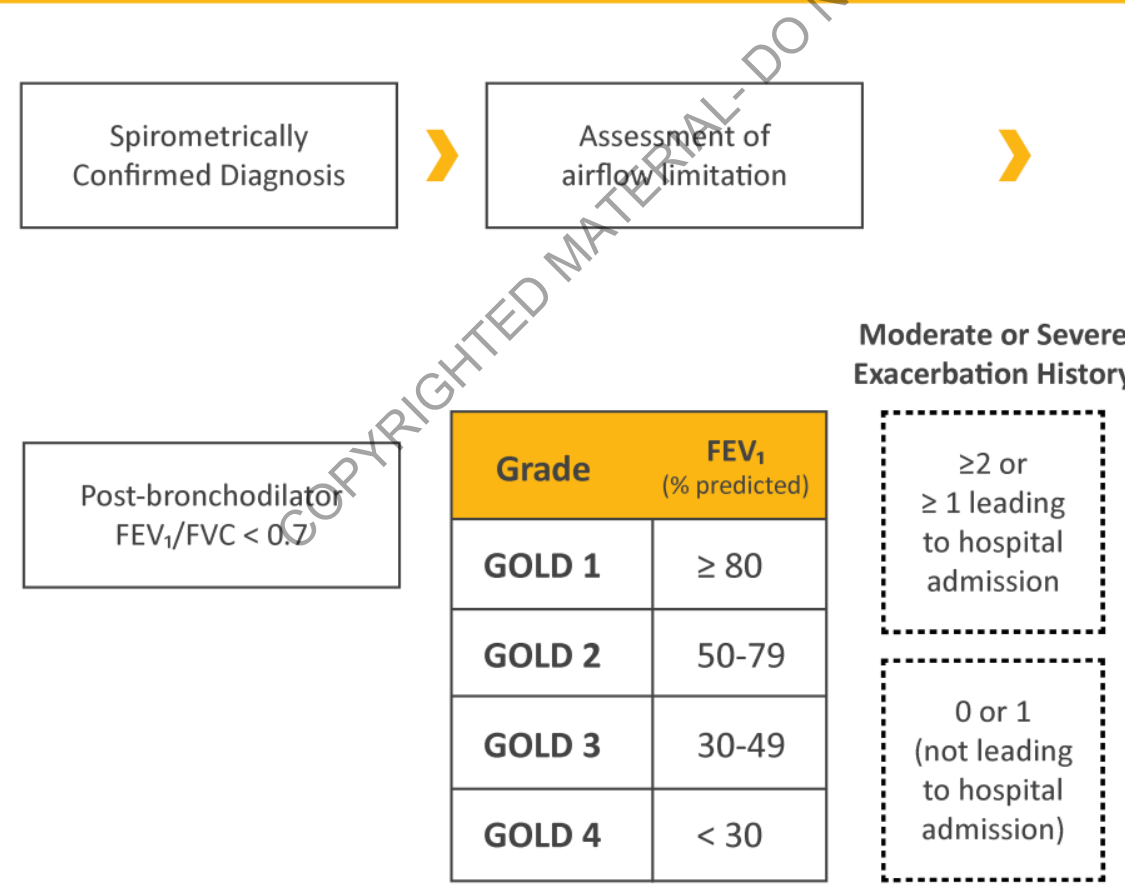

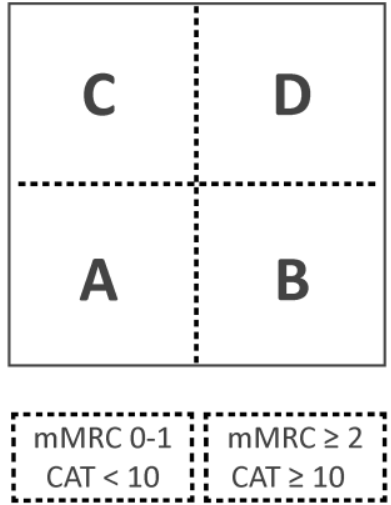

Symptoms

FIGURE 2.4

Example: Consider two patients - both patients with $\mathrm{FEV}_{1}<30 \%$ of predicted, CAT ${ }^{\mathrm{TM}}$ scores of 18 and one with no exacerbations in the past year and the other with three moderate exacerbations in the 
past year. Both would have been labelled GOLD D in the prior classification scheme. However, with the new proposed scheme, the subject with three moderate exacerbations in the past year would be labelled GOLD grade 4, group D.

Individual decisions on pharmacotherapeutic approaches would use the recommendations in Chapter 4 based on the $A B C D$ assessment to treat the patient's major problem at this time i.e., persistent exacerbations. The other patient, who has had no exacerbations, would be classified as GOLD grade 4, group B. In such patients - besides pharmacotherapy and rehabilitation - lung volume reduction, lung transplant or bullectomy may be important considerations for therapy given their symptom burden and level of spirometric limitation.

Note: In cases where there is a marked discordance between the level of airflow limitation and the perceived symptoms, a more detailed evaluation should be carried out to better understand lung mechanics (e.g., full lung function tests), lung structure (e.g., computed tomography) and/or comorbidities (e.g., ischemic heart disease) that might impact patient symptoms. In some cases, patients may endorse minimal symptoms despite demonstrating severe aifflow limitation. Adapting to the limitations induced by COPD, these patients may reduce their level of physical activity in a way that may result in an underestimation of the symptom load. In these cases, exercise tests like the 6minute walking distance may reveal that the patients are severely constrained and do need more intense treatment than the initial evaluation would have suggested.

The role of spirometry for the diagnosis, assessment and follow-up of COPD is summarized in Table 2.6.

\section{ROLE OF SPIROMETRX}

- Diagnosis

- Assessment of severity of airflow bbstruction (for prognosis)

- Follow-up assessment

» Therapeutic decisions.

- Pharmacological in selected circumstances

(e.g., discrepancy between spirometry and level of symptoms).

- Consider alternative diagnoses when symptoms are disproportionate to degree of airflow obstruction.

- Non-pharmacological (e.g., interventional procedures).

» Identification of rapid decline. 


\section{Alpha-1 antitrypsin deficiency (AATD)}

Alpha-1 antitrypsin deficiency (AATD) screening. The World Health Organization recommends that all patients with a diagnosis of COPD should be screened once especially in areas with high AATD prevalence. $.22,83$ Although the classical patient is young ( $<45$ years) with panlobular basal emphysema, it has become recognized that delay in diagnosis has led to identification of some AATD patients when they are older and have a more typical distribution of emphysema (centrilobular apical). $\frac{84}{} \mathrm{~A}$ low concentration ( $<20 \%$ normal) is highly suggestive of homozygous deficiency. Family members should be screened and, together with the patient, referred to specialist centers for advice and management (see Chapter 3).

\section{Additional investigations}

The following additional investigations may be considered as part of the diagnosis and assessment of COPD.

Imaging. A chest X-ray is not useful to establish a diagnosis in COPD, butit is valuable in excluding alternative diagnoses and establishing the presence of significant comarbidities such as concomitant respiratory (pulmonary fibrosis, bronchiectasis, pleural diseases), skeletal (e.g., kyphoscoliosis), and cardiac diseases (e.g., cardiomegaly). Radiological changes associated with COPD include signs of lung hyperinflation (flattened diaphragm and an increase in the volume of the retrosternal air space), hyperlucency of the lungs, and rapid tapering of the vascular markings. Computed tomography (CT) of the chest is not routinely recommended except for detection of bronchiectasis and COPD patients that meet the criteria for lung cancer risk assessment. The presence of emphysema in particular may increase the risk for development of lung cancer. However, CT scanning may be helpful in the differential diagnosis where concomitant diseases are present. In addition, if a surgical procedure such as lung volume reduction, $\underline{\underline{85}}$ or increasingly non-surgical based lung volume reduction $\underline{86}$ is contemplated, a chest CT scan is necessary since the distribution of emphysema is one of the most important determinants of surgical suitability. A CT scan is also required for patients being evaluated for lung transplantation.

Lung volumes and diffusing capacity. COPD patients exhibit gas trapping (a rise in residual volume) from the early stages of the disease, and as airflow limitation worsens, static hyperinflation (an increase in total lung capacity) occurs. These changes can be documented by body plethysmography, or less accurately by helium dilution lung volume measurement. These measurements help characterize the severity of COPD but are not essential to patient management. Measurement of diffusing capacity (DLCO) provides information on the functional impact of emphysema in COPD and is often helpful in patients with breathlessness that may seem out of proportion to the degree of airflow limitation.

Oximetry and arterial blood gas measurement. Pulse oximetry can be used to evaluate a patient's arterial oxygen saturation and need for supplemental oxygen therapy. Pulse oximetry should be used to assess all patients with clinical signs suggestive of respiratory failure or right heart failure. If peripheral arterial oxygen saturation is $<92 \%$ arterial or capillary blood gases should be assessed. $\underline{87,88}$ 
Exercise testing and assessment of physical activity. Objectively measured exercise impairment, assessed by a reduction in self-paced walking distance $\stackrel{89,90}{0}$ or during incremental exercise testing in a laboratory, $\underline{\underline{91}}$ is a powerful indicator of health status impairment and predictor of prognosis; exercise capacity may fall in the year before death. .22 Walking tests can be useful for assessing disability and risk of mortality $\underline{93}$ and are used to assess the effectiveness of pulmonary rehabilitation. Both the paced shuttle walk test ${ }^{94}$ and the unpaced 6 -minute walk test can be used. $\underline{95, \underline{96}}$ As the course length has a substantial impact on the distance walked, existing reference equations established for a 30 meter course cannot be applied to predict the distance achieved on shorter courses. .97 Laboratory testing using cycle or treadmill ergometry can assist in identifying co-existing or alternative conditions e.g., cardiac diagnoses.

Monitoring of physical activity may be more relevant regarding prognosis than evaluating exercise capacity..$\underline{98}$ This can be conducted using accelerometers or multi-sensor instruments.

Composite scores. Several variables identify patients at increased risk for mortality including $\mathrm{FEV}_{1}$, exercise tolerance assessed by walking distance or peak oxygen consumption, weight loss, and reduction in arterial oxygen tension. A relatively simple approach to identifying disease severity using a combination of most of the above variables has been proposed. The BODE (Body mass index, Obstruction, Dyspnea, and Exercise) method gives a composite score that is a better predictor of subsequent survival than any single component. $\underline{99}, 100$ Simpler alternatives that do not include an exercise test have been suggested but all these approaches need validation across a wide range of disease severities and clinical settings to confirm that they are suitable for routine clinical use. 101,102

Differential diagnoses. In some patients with chronic asthma, a clear distinction from COPD is not possible using current imaging and physiological testing techniques, and for such patients it is assumed that asthma and COPD coexist. The diágnosis Asthma-COPD Overlap Syndrome (ACOS) or AsthmaCOPD Overlap (ACO) has been coined to acknowledge that this represents overlap of common disorders causing chronic airflow limitation rather than a distinct syndrome. For details please refer to the Appendix. Most other potential differential diagnoses are easier to distinguish from COPD (Table 2.7).

Other considerations. It is clear that some patients without evidence of airflow limitation have evidence of structural lung disease on chest imaging (emphysema, gas trapping, airway wall thickening) that is consistent with what is found in patients with COPD. Such patients may report exacerbations of respiratory symptoms or even require treatment with respiratory medications on a chronic basis. Whether these patients have acute or chronic bronchitis, a persistent form of asthma or an earlier presentation of what will become COPD as it is currently defined, is unclear at present and will require further study. 


\section{DIFFERENTIAL DIAGNOSIS OF COPD}

\section{DIAGNOSIS SUGGESTIVE FEATURES}

COPD Onset in mid-life.

Symptoms slowly progressive.

History of tobacco smoking or exposure to other types of smoke.

\begin{tabular}{ll}
\hline Asthma & Onset early in life (often childhood). \\
& Symptoms vary widely from day to day. \\
& Symptoms worse at night/early morning. \\
Allergy, rhinitis, and/or eczema also present. & Family history of asthma. \\
Obesity coexistence.
\end{tabular}

Congestive Heart Failure Chest X-ray shows dilated heart, pulmonary edema.

Pulmonary function tests indicate volume restriction, not airflow limitation.

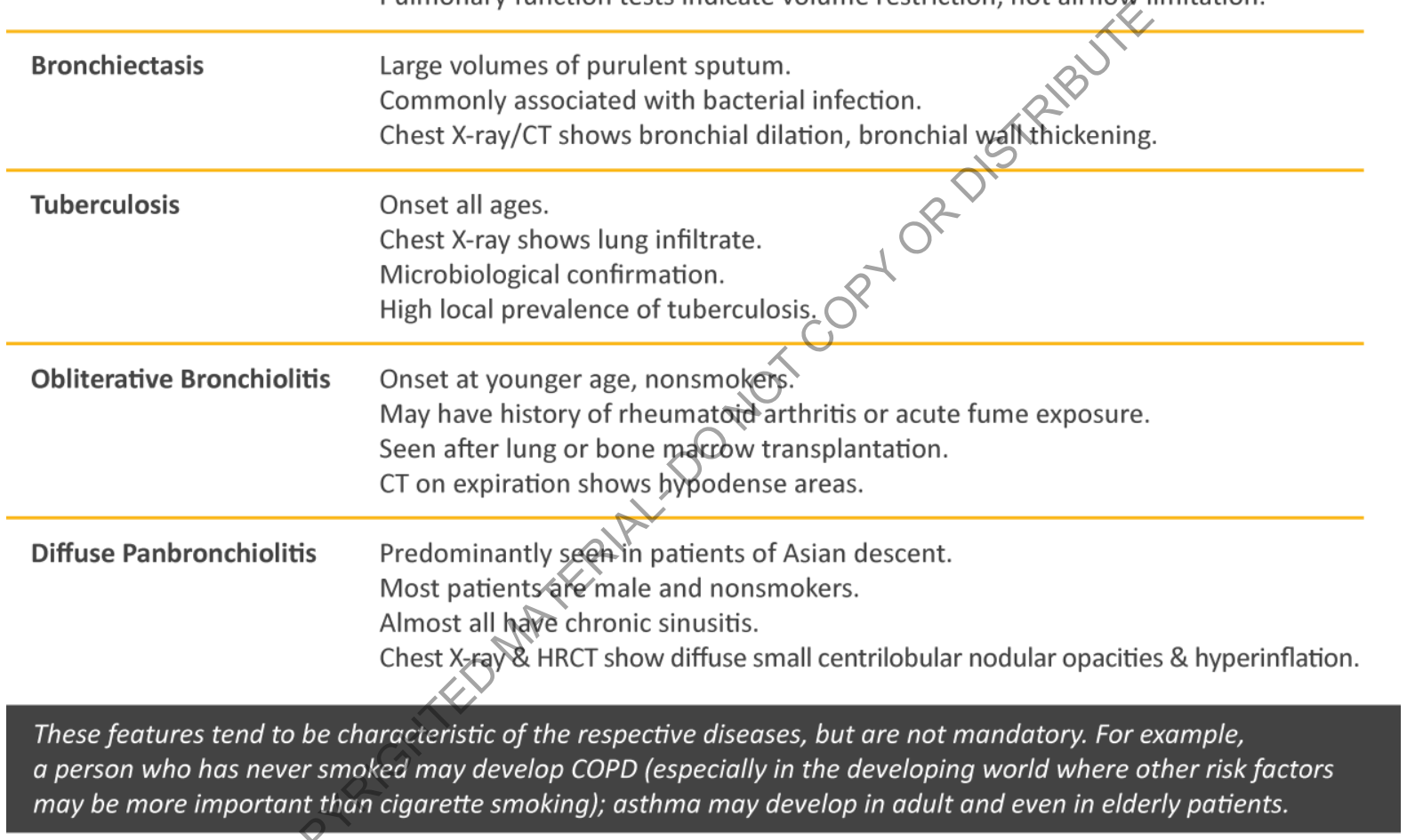

TABLE 2.7

\section{REFERENCES}

1. Buist AS, McBurnie MA, Vollmer WM, et al. International variation in the prevalence of COPD (the BOLD Study): a population-based prevalence study. Lancet 2007; 370(9589): 741-50.

2. Kessler R, Partridge MR, Miravitlles M, et al. Symptom variability in pati ents with severe COPD: a panEuropean cross-sectional study. Eur Respir J 2011; 37(2): 264-72.

3. Montes de Oca M, Perez-Padilla R, Talamo C, et al. Acute bronchodilator responsiveness in subjects with and without airflow obstruction in five Latin American cities: the PLATINO study. Pulm Pharmacol Ther 2010; 23(1): 29-35.

4. Miravitlles M, Worth H, Soler Cataluna JJ, et al. Observational study to characterise 24-hour COPD symptoms and their relationship with patient-reported outcomes: results from the ASSESS study. Respir Res 2014; 15: 122. 
5. Elliott MW, Adams L, Cockcroft A, MacRae KD, Murphy K, Guz A. The language of breathlessness. Use of verbal descriptors by patients with cardiopulmonary disease. Am Rev Respir Dis 1991; 144(4): 82632.

6. Cho SH, Lin HC, Ghoshal AG, et al. Respiratory disease in the Asia-Pacific region: Cough as a key symptom. Allergy Asthma Proc 2016; 37(2): 131-40.

7. Medical Research Council Committee on the Aetiology of Chronic Bronchitis. Definition and classification of chronic bronchitis for clinical and epidemiological purposes. A report to the Medical Research Council by their Committee on the Aetiology of Chronic Bronchitis. Lancet 1965; 1(7389): 775-9.

8. Allinson JP, Hardy R, Donaldson GC, Shaheen SO, Kuh D, Wedzicha JA. The Presence of Chronic Mucus Hypersecretion across Adult Life in Relation to Chronic Obstructive Pulmonary Disease Development. Am J Respir Crit Care Med 2016; 193(6): 662-72.

9. Soler N, Esperatti M, Ewig S, Huerta A, Agusti C, Torres A. Sputum purulence-guided antibiotic use in hospitalised patients with exacerbations of COPD. Eur Respir J 2012; 40(6): 1344-53.

10. Brusse-Keizer MG, Grotenhuis AJ, Kerstjens HA, et al. Relation of sputum colour to bacterial load in acute exacerbations of COPD. Respir Med 2009; 103(4): 601-6.

11. Stockley RA, O'Brien C, Pye A, Hill SL. Relationship of sputum color to nature and outpatient management of acute exacerbations of COPD. Chest 2000; 117(6): 1638-45.

12. von Haehling S, Anker SD. Cachexia as a major underestimated and unmet medical need: facts and numbers. Journal of cachexia, sarcopenia and muscle 2010; 1(1): 1-5.

13. Schols AM, Soeters PB, Dingemans AM, Mostert R, Frantzen PJ, Wouters EF. Prevalence and characteristics of nutritional depletion in patients with stable COPDeligible for pulmonary rehabilitation. Am Rev Respir Dis 1993; 147(5): 1151-6.

14. Rutten EP, Calverley PM, Casaburi R, et al. Changes in body composition in patients with chronic obstructive pulmonary disease: do they influence patient-related outcomes? Annals of nutrition \& metabolism 2013; 63(3): 239-47.

15. Schols AM, Broekhuizen R, Weling-Scheepers CA, Wouters EF. Body composition and mortality in chronic obstructive pulmonary disease. Am J Clin Nutr 2005; 82(1): 53-9.

16. Hanania NA, Mullerova H, Locantore NW, et aDeterminants of depression in the ECLIPSE chronic obstructive pulmonary disease cohort. Am J Respir Crit Care Med 2011; 183(5): 604-11.

17. Holleman DR, Jr., Simel DL. Does the clinical examination predict airflow limitation? Jama 1995; 273(4): 313-9.

18. Kesten S, Chapman KR. Physician perceptions and management of COPD. Chest 1993; 104(1): $254-8$.

19. Jackson $\mathrm{H}$, Hubbard R. Detecting chronic obstructive pulmonary disease using peak flow rate: cross sectional survey. BMJ 2003, 327(7416): 653-4.

20. Miller MR, Hankinson J, Brúsasco V, et al. Standardisation of spirometry. Eur Respir J 2005; 26(2): 31938.

21. Pellegrino R, ViegiG, Brusasco V, et al. Interpretative strategies for lung function tests. Eur Respir J 2005; 26(5): 948-68.

22. van Dijk W, Tan W, Li P, et al. Clinical relevance of fixed ratio vs lower limit of normal of FEV1/FVC in COPD: patient-reported outcomes from the CanCOLD cohort. Annals of family medicine $2015 ; 13(1)$ : 41-8.

23. Guder G, Brenner S, Angermann CE, et al. "GOLD or lower limit of normal definition? A comparison with expert-based diagnosis of chronic obstructive pulmonary disease in a prospective cohort-study". Respir Res 2012; 13(1): 13.

24. Vaz Fragoso CA, McAvay G, Van Ness PH, et al. Phenotype of normal spirometry in an aging population. Am J Respir Crit Care Med 2015; 192(7): 817-25.

25. Vaz Fragoso CA, McAvay G, Van Ness PH, et al. Phenotype of Spirometric Impairment in an Aging Population. Am J Respir Crit Care Med 2016; 193(7): 727-35.

26. Aaron SD, Tan WC, Bourbeau J, et al. Diagnostic Instability and Reversals of Chronic Obstructive Pulmonary Disease Diagnosis in Individuals with Mild to Moderate Airflow Obstruction. Am J Respir Crit Care Med 2017; 196(3): 306-14.

27. Schermer TR, Robberts B, Crockett AJ, et al. Should the diagnosis of COPD be based on a single spirometry test? NPJ Prim Care Respir Med 2016; 26: 16059.

28. Albert $P$, Agusti $A$, Edwards $L$, et al. Bronchodilator responsiveness as a phenotypic characteristic of established chronic obstructive pulmonary disease. Thorax 2012; 67(8): 701-8. 
29. Hansen JE, Porszasz J. Counterpoint: Is an increase in FEV(1) and/or FVC $>/=12 \%$ of control and $>/=$ $200 \mathrm{~mL}$ the best way to assess positive bronchodilator response? No. Chest 2014; 146(3): 538-41.

30. Siu AL, Bibbins-Domingo K, Grossman DC, et al. Screening for Chronic Obstructive Pulmonary Disease: US Preventive Services Task Force Recommendation Statement. Jama 2016; 315(13): 1372-7.

31. Qaseem A, Snow V, Shekelle $P$, et al. Diagnosis and management of stable chronic obstructive pulmonary disease: a clinical practice guideline from the American College of Physicians. Ann Intern Med 2007; 147(9): 633-8.

32. Hill K, Goldstein RS, Guyatt GH, et al. Prevalence and underdiagnosis of chronic obstructive pulmonary disease among patients at risk in primary care. CMAJ 2010; 182(7): 673-8.

33. Lopez Varela MV, Montes de Oca M, Rey A, et al. Development of a simple screening tool for opportunistic COPD case finding in primary care in Latin America: The PUMA study. Respirology 2016; 21(7): 1227-34.

34. Tammemagi MC, Lam SC, McWilliams AM, Sin DD. Incremental value of pulmonary function and sputum DNA image cytometry in lung cancer risk prediction. Cancer prevention research (Philadelphia, Pa) 2011; 4(4): 552-61.

35. de-Torres JP, Wilson DO, Sanchez-Salcedo P, et al. Lung cancer in patients with chronic obstructive pulmonary disease. Development and validation of the COPD Lung Cancer Screening Score. Am J Respir Crit Care Med 2015; 191(3): 285-91.

36. Haroon S, Adab P, Riley RD, Fitzmaurice D, Jordan RE. Predicting risk of undiagnosed COPD: development and validation of the TargetCOPD score. Eur Respir J 2017; 49(6).

37. U.S. Preventive Services Task Force, Siu AL, Bibbins-Domingo K, et al. Screening for Chronic Obstructive Pulmonary Disease: US Preventive Services Task Force Recommendation Statement. JAMA 2016; 315(13): 1372-7.

38. Tan WC, Sin DD, Bourbeau J, et al. Characteristics of COPD in never-smokers and ever-smokers in the general population: results from the CanCOLD study. Thorax 2015; 70(9): 822-9.

39. Han MK, Steenrod AW, Bacci ED, et al. Identifying Patients with Undiagnosed COPD in Primary Care Settings: Insight from Screening Tools and Epidemiologic Studies. Chronic Obstr Pulm Dis (Miami) 2015; 2(2): 103-21.

40. Dirven JA, Tange HJ, Muris JW, van Haaren KM, Vink G, van Schayck OC. Early detection of COPD in general practice: implementation, workload and socioeconomic status. A mixed methods observational study. Prim Care Respir J 2013; 22(3): 338-43.

41. Le Rouzic O, Roche N, Cortot AB, et aR Defining the $<$ frequent exacerbator $\gg$ phenotype in COPD: a hypothesis-free approach. Chest 2017.

42. Jordan RE, Adab P, Sitch A, et a Fargeted case finding for chronic obstructive pulmonary disease versus routine practice in primary care (TargetCOPD): a cluster-randomised controlled trial. The Lancet Respiratory medicine 2016; 4(9): 720-30.

43. Duong $M$, Islam $S$, Rangarajan $S$, et al. Global differences in lung function by region (PURE): an international, community-based prospective study. The Lancet Respiratory medicine 2013; 1(8): 599609.

44. Jones PW. Health status and the spiral of decline. COPD 2009; 6(1): 59-63.

45. Han MK, Muellerova H, Curran-Everett D, et al. GOLD 2011 disease severity classification in COPDGene: a prospective cohort study. The Lancet Respiratory medicine 2013; 1(1): 43-50.

46. Fletcher CM. Standardised questionnaire on respiratory symptoms: a statement prepared and approved by the MRC Committee on the Aetiology of Chronic Bronchitis (MRC breathlessness score). BMJ 1960; 2: 1662.

47. Bestall JC, Paul EA, Garrod R, Garnham R, Jones PW, Wedzicha JA. Usefulness of the Medical Research Council (MRC) dyspnea scale as a measure of disability in patients with chronic obstructive pulmonary disease. Thorax 1999; 54(7): 581-6.

48. Sundh J, Janson C, Lisspers K, Stallberg B, Montgomery S. The Dyspnea, Obstruction, Smoking, Exacerbation (DOSE) index is predictive of mortality in COPD. Prim Care Respir J 2012; 21(3): 295-301.

49. Nishimura K, Izumi T, Tsukino M, Oga T. Dyspnea is a better predictor of 5-year survival than airway obstruction in patients with COPD. Chest 2002; 121(5): 1434-40.

50. Jones PW. Health status measurement in chronic obstructive pulmonary disease. Thorax 2001; 56(11): 880-7.

51. Guyatt GH, Berman LB, Townsend M, Pugsley SO, Chambers LW. A measure of quality of life for clinical trials in chronic lung disease. Thorax 1987; 42(10): 773-8. 
52. Jones PW, Quirk FH, Baveystock CM, Littlejohns P. A self-complete measure of health status for chronic airflow limitation. The St. George's Respiratory Questionnaire. Am Rev Respir Dis 1992; 145(6): 1321-7.

53. Jones PW, Harding G, Berry P, Wiklund I, Chen WH, Kline Leidy N. Development and first validation of the COPD Assessment Test. Eur Respir J 2009; 34(3): 648-54.

54. Karloh M, Fleig Mayer A, Maurici R, Pizzichini MM, Jones PW, Pizzichini E. The COPD Assessment Test: What Do We Know So Far?: A Systematic Review and Meta-Analysis About Clinical Outcomes Prediction and Classification of Patients Into GOLD Stages. Chest 2016; 149(2): 413-25.

55. Agusti A, Calverley PM, Celli B, et al. Characterisation of COPD heterogeneity in the ECLIPSE cohort. Respir Res 2010; 11: 122.

56. Nishimura K, Mitsuma S, Kobayashi A, et al. COPD and disease-specific health status in a working population. Respir Res 2013; 14: 61.

57. Miravitlles M, Soriano J, Garcia-Rio F, et al. Prevalence of COPD in Spain: impact of undiagnosed COPD on quality of life and daily life activities. Thorax 2009; 64: 863-8.

58. Jones PW, Tabberer M, Chen WH. Creating scenarios of the impact of COPD and their relationship to COPD Assessment Test (CAT) scores. BMC Pulm Med 2011; 11: 42.

59. Jones PW, Adamek L, Nadeau G, Banik N. Comparisons of health status scores with MRC grades in COPD: implications for the GOLD 2011 classification. Eur Respir J 2013; 42(3): 647-54.

60. Hurst JR, Wedzicha JA. What is (and what is not) a COPD exacerbation: thoughts from the new GOLD guidelines. Thorax 2007; 62(3): 198-9.

61. Wedzicha JA, Seemungal TA. COPD exacerbations: defining their cause and prevention. Lancet 2007; 370(9589): 786-96.

62. Seemungal TA, Donaldson GC, Paul EA, Bestall JC, Jeffries DJ, Wedzicha JA. Effect of exacerbation on quality of life in patients with chronic obstructive pulmonary disease. Am J Respir Crit Care Med 1998; 157(5 Pt 1): 1418-22.

63. Burge S, Wedzicha JA. COPD exacerbations: definitions and classifications. Eur Respir J Suppl 2003; 41: 46s-53s.

64. Decramer M, Celli B, Kesten S, et al. Effect of tiotropium on outcomes in patients with moderate chronic obstructive pulmonary disease (UPLIFT): a prespecified subgroup analysis of a randomised controlled trial. Lancet 2009; 374(9696): 1171-8.

65. Jenkins CR, Jones PW, Calverley PM, et al. Efficacy of salmeterol/fluticasone propionate by GOLD stage of chronic obstructive pulmonary disease: analysis from the randomised, placebo-controlled TORCH study. Respir Res 2009; 10: 59.

66. Hurst JR, Vestbo J, Anzueto A, et al. Susceptibility to exacerbation in chronic obstructive pulmonary disease. N Engl J Med 2010,363(12): 1128-38.

67. Han MK, Quibrera PM, Carretta EE, et al. Frequency of exacerbations in patients with chronic obstructive pulmonary disease: an analysis of the SPIROMICS cohort. The Lancet Respiratory medicine 2017; 5(8): 619-26.

68. Mullerova H, Maselli DJ, Locantore N, et al. Hospitalized exacerbations of COPD: risk factors and outcomes in the ECLIPSE cohort. Chest 2015; 147(4): 999-1007.

69. Soriano JB, Lamprecht B, Ramirez AS, et al. Mortality prediction in chronic obstructive pulmonary disease comparing the GOLD 2007 and 2011 staging systems: a pooled analysis of individual patient data. The Lancet Respiratory medicine 2015; 3(6): 443-50.

70. Soler-Cataluna JJ, Martinez-Garcia MA, Roman Sanchez P, Salcedo E, Navarro M, Ochando R. Severe acute exacerbations and mortality in patients with chronic obstructive pulmonary disease. Thorax 2005; 60(11): 925-31.

71. Soriano JB, Visick GT, Muellerova H, Payvandi N, Hansell AL. Patterns of comorbidities in newly diagnosed COPD and asthma in primary care. Chest 2005; 128(4): 2099-107.

72. National Institute for Health and Care Excellence. Multimorbidity: clinical assessment and management, in press. 2016. https://www.nice.org.uk/guidance/indevelopment/gidcgwave0704/documents (accessed 14 October 2018).

73. Vanfleteren LE, Spruit MA, Groenen M, et al. Clusters of comorbidities based on validated objective measurements and systemic inflammation in patients with chronic obstructive pulmonary disease. Am J Respir Crit Care Med 2013; 187(7): 728-35.

74. Wagner PD. Possible mechanisms underlying the development of cachexia in COPD. Eur Respir J 2008; 31(3): 492-501. 
75. Maltais F, Decramer M, Casaburi R, et al. An official American Thoracic Society/European Respiratory Society statement: update on limb muscle dysfunction in chronic obstructive pulmonary disease. Am J Respir Crit Care Med 2014; 189(9): e15-62.

76. Chen W, Thomas J, Sadatsafavi M, FitzGerald JM. Risk of cardiovascular comorbidity in patients with chronic obstructive pulmonary disease: a systematic review and meta-analysis. The Lancet Respiratory medicine 2015; 3(8): 631-9.

77. Brenner DR, Boffetta P, Duell EJ, et al. Previous lung diseases and lung cancer risk: a pooled analysis from the International Lung Cancer Consortium. Am J Epidemiol 2012; 176(7): 573-85.

78. Fry JS, Hamling JS, Lee PN. Systematic review with meta-analysis of the epidemiological evidence relating FEV1 decline to lung cancer risk. BMC cancer 2012; 12: 498.

79. Mannino DM, Thorn D, Swensen A, Holguin F. Prevalence and outco mes of diabetes, hypertension and cardiovascular disease in COPD. Eur Respir J 2008; 32(4): 962-9.

80. Goossens LM, Leimer I, Metzdorf N, Becker K, Rutten-van Molken MP. Does the 2013 GOLD classification improve the ability to predict lung function decline, exacerbations and mortality: a posthoc analysis of the 4-year UPLIFT trial. BMC Pulm Med 2014; 14: 163.

81. Kim J, Yoon HI, Oh YM, et al. Lung function decline rates according to GOLD group in patients with chronic obstructive pulmonary disease. Int J Chron Obstruct Pulmon Dis 2015; 10: 1819-27.

82. WHO meeting participants. Alpha 1-antitrypsin deficiency: memorandum fromą WHO meeting. Bull World Health Organ 1997; 75(5): 397-415.

83. Miravitlles M, Dirksen A, Ferrarotti I, et al. European Respiratory Society Statement: diagnosis and treatment of pulmonary disease in alpha1-antitrypsin deficiency. Eur Bespir J 2017; 50(5).

84. Parr DG, Stoel BC, Stolk J, Stockley RA. Pattern of emphysema distribution in alpha1-antitrypsin deficiency influences lung function impairment. Am J Respir Crit Care Med 2004; 170(11): 1172-8.

85. Fishman A, Martinez F, Naunheim K, et al. A randomized trial comparing lung-volume-reduction surgery with medical therapy for severe emphysema. N Engl J Med 2003; 348(21): 2059-73.

86. Klooster K, ten Hacken NH, Hartman JE, Kerstjens HA, Van Rikxoort EM, Slebos DJ. Endobronchial Valves for Emphysema without Interlobar Collaterat Ventilation. N Engl J Med 2015; 373(24): 2325-35.

87. Amalakanti S, Pentakota MR. Pulse Oximetry Overestimates Oxygen Saturation in COPD. Respir Care 2016; 61(4): 423-7.

88. Kelly AM, McAlpine R, Kyle E. How accurate are pulse oximeters in patients with acute exacerbations of chronic obstructive airways disease? Respir Med 2001; 95(5): 336-40.

89. Durheim MT, Smith PJ, Babyak MA, et al. Six-minute-walk distance and accelerometry predict outcomes in chronic obstructive pulmonary disease independent of Global Initiative for Chronic Obstructive Lung Disease 2011 Group. Annals of the American Thoracic Society 2015; 12(3): 349-56.

90. Pinto-Plata VM, Cote C, Cabral H, Taylor J, Celli BR. The 6-min walk distance: change over time and value as a predictor of survival in severe COPD. Eur Respir J 2004; 23(1): 28-33.

91. Oga T, Nishimura K, Tsukino M, Sato S, Hajiro T. Analysis of the factors related to mortality in chronic obstructive pulmonary disease: role of exercise capacity and health status. Am J Respir Crit Care Med 2003; 167(4): 544-9.

92. Polkey MI, Spruit MA, Edwards LD, et al. Six-minute-walk test in chronic obstructive pulmonary disease: minimal clinically important difference for death or hospitalization. Am J Respir Crit Care Med 2013; 187(4): 382-6.

93. Celli B, Tetzlaff K, Criner G, et al. The 6-Minute-Walk Distance Test as a Chronic Obstructive Pulmonary Disease Stratification Tool. Insights from the COPD Biomarker Qualification Consortium. Am J Respir Crit Care Med 2016; 194(12): 1483-93.

94. Revill SM, Morgan MD, Singh SJ, Williams J, Hardman AE. The endurance shuttle walk: a new field test for the assessment of endurance capacity in chronic obstructive pulmonary disease. Thorax 1999; 54(3): 213-22.

95. Casanova C, Cote CG, Marin JM, et al. The 6-min walking distance: long-term follow up in patients with COPD. Eur Respir J 2007; 29(3): 535-40.

96. Puente-Maestu L, Palange P, Casaburi R, et al. Use of exercise testing in the evaluation of interventional efficacy: an official ERS statement. Eur Respir J 2016; 47(2): 429-60.

97. Beekman E, Mesters I, Hendriks EJ, et al. Course length of 30 metres versus 10 metres has a significant influence on six-minute walk distance in patients with COPD: an experimental crossover study. Journal of physiotherapy 2013; 59(3): 169-76.

98. Waschki B, Kirsten A, Holz O, et al. Physical activity is the strongest predictor of all-cause mortality in patients with COPD: a prospective cohort study. Chest 2011; 140(2): 331-42. 
99. Guerra B, Haile SR, Lamprecht B, et al. Large-scale external validation and comparison of prognostic models: an application to chronic obstructive pulmonary disease. BMC Med 2018; 16(1): 33.

100. Celli BR, Cote CG, Marin JM, et al. The body-mass index, airflow obstruction, dyspnea, and exercise capacity index in chronic obstructive pulmonary disease. N Engl J Med 2004; 350(10): 1005-12.

101. Jones RC, Donaldson GC, Chavannes NH, et al. Derivation and validation of a composite index of severity in chronic obstructive pulmonary disease: the DOSE Index. Am J Respir Crit Care Med 2009; 180(12): 1189-95.

102. Puhan MA, Garcia-Aymerich J, Frey M, et al. Expansion of the prognostic assessment of patients with chronic obstructive pulmonary disease: the updated BODE index and the ADO index. Lancet 2009; 374(9691): 704-11. 


\section{CHAPTER 3: EVIDENCE SUPPORTING PREVENTION AND MAINTENANCE THERAPY}

\section{OVERALL KEY POINTS:}

- Smoking cessation is key. Pharmacotherapy and nicotine replacement reliably increase long-term smoking abstinence rates. Legislative smoking bans and counselling, delivered by healthcare professionals improve quit rates.

- The effectiveness and safety of e-cigarettes as a smoking cessation aid is uncertain at present.

- Pharmacological therapy can reduce COPD symptoms, reduce the frequency and severity of exacerbations, and improve health status and exercise tolerance.

- Each pharmacological treatment regimen should be individualized and guided by the severity of symptoms, risk of exacerbations, side-effects, comorbidities, drug availability and cost, and the patient's response, preference and ability to use various drug delivery devices.

- Inhaler technique needs to be assessed regularly.

- Influenza vaccination decreases the incidence of lower respiratory tract infections.

- Pneumococcal vaccination decreases lower respiratory tract infections.

- Pulmonary rehabilitation improves symptoms, quality of life, and physical and emotional participation in everyday activities.

- In patients with severe resting chronic hypoxemia, long-term oxygen therapy improves survival.

- In patients with stable COPD and resting or exercise-induced moderate desaturation, long-term oxygen treatment should not be prescribed routinely. However, individual patient factors must be considered when evaluating the patient's need for supplemental oxygen.

- In patients with severe chronic hypercapnia and a history of hospitalization for acute respiratory failure, long-term non-invasive ventilation may decrease mortality and prevent re-hospitalization.

- In select patients with advanced emphysema refractory to optimized medical care, surgical or bronchoscopic interventional treatments may be beneficial.

- Palliative approaches are effective in controlling symptoms in advanced COPD. 
This chapter summarizes the evidence about the effectiveness and safety of maintenance and prevention strategies in COPD. The way in which the evidence is translated into clinical practice is provided in Chapter 4.

\section{SMOKING CESSATION}

Smoking cessation has the greatest capacity to influence the natural history of COPD. If effective resources and time are dedicated to smoking cessation, long-term quit success rates of up to $25 \%$ can be achieved. $\underline{1}$ Besides individual approaches to smoking cessation, legislative smoking bans are effective in increasing quit rates and reducing harm from second-hand smoke exposure. ?

\section{Pharmacotherapies for smoking cessation}

Nicotine replacement products. Nicotine replacement therapy (nicotine gum, inhaler, nasal spray, transdermal patch, sublingual tablet, or lozenge) reliably increases long-term smoking abstinence rates $\frac{3-5}{5}$ and is significantly more effective than placebo. Medical contraindications to nicotine replacement therapy include recent myocardial infarction or stroke. $6, \underline{7}$ The contraindication to nicotine replacement therapy after acute coronary syndrome remains unclear and the evidence suggests that this treatment should be started $>2$ weeks after acardiovascular event. - Continuous chewing of nicotine gum produces secretions that are swallowed rather than absorbed through the buccal mucosa resulting in little absorption and potentially causing nausea. Acidic beverages, particularly coffee, juices, and soft drinks, interfere with the absorption of nicotine.

E-cigarettes are increasingly used as a form of nicotine replacement therapy, although their efficacy in this setting remains controversial. $.9-13$ Theiroverall safety profile has not been well defined and some organizations have suggested caution and additional data collection before widespread advocacy. $\underline{14}$ Recent data suggest that e-cigarette inhalation alters the lung host response in smokers. $\underline{\underline{15}}$

Pharmacological products. Varenicline,,$\underline{16}$ bupropion, $\underline{\underline{17}}$ and nortriptyline $\frac{18}{}$ have been shown to increase long-term quit rates, $\underline{18}$ but should always be used as a component of a supportive intervention program rather than a sole intervention for smoking cessation. The effectiveness of the

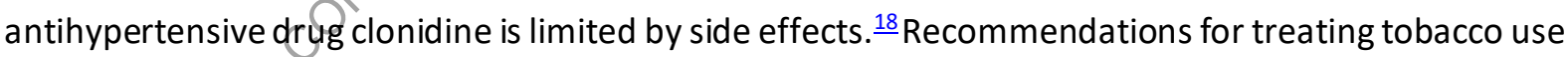
and dependence are summarized in Chapter 4.

A five-step program for intervention (Table 3.1) $3,5,19$ provides a helpful strategic framework to guide healthcare providers interested in helping their patients stop smoking. $-, \underline{2,}, \underline{20}$ Because tobacco dependence is a chronic disease,,$\frac{3,5}{-5}$ clinicians should recognize that relapse is common and reflects the chronic nature of dependence and addiction, and does not represent failure on the part of the patient or the clinician. 


\section{BRIEF STRATEGIES TO HELP THE PATIENT WILLING TO QUIT}

- ASK:

Systematically identify all tobacco users at every visit.

Implement an office-wide system that ensures that, for EVERY patient at EVERY

clinic visit, tobacco-use status is queried and documented.

- ADVISE: $\quad$ Strongly urge all tobacco users to quit.

In a clear, strong, and personalized manner, urge every tobacco user to quit.

- ASSESS: $\quad$ Determine willingness and rationale of patient's desire to make a quit attempt. Ask every tobacco user if he or she is willing to make a quit attempt at this time (e.g., within the next 30 days).

- ASSIST: $\quad$ Aid the patient in quitting. Help the patient with a quit plan; provide practical counseling; provide intra-treatment social support; help the patient obtain extra-treatment social support; recommend use of approved pharmacotherapy except in special circumstances; provide supplementary materials.

- ARRANGE:

Schedule follow-up contact.

Schedule follow-up contact, either in person or via tetephone.

TABLE 3.1

Counseling delivered by physicians and other health professionals significantly increases quit rates

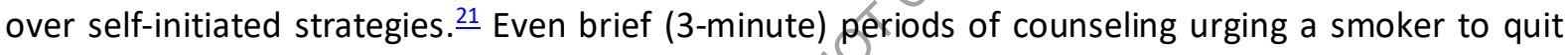
improve smoking cessation rates. $\frac{21}{-}$ There is a relationship between counseling intensity and cessation success. 2 Ways to intensify treatment include increasing the length of the treatment session, the number of treatment sessions, and the number of weeks over which the treatment is delivered. Sustained quit rates of $10.9 \%$ at 6 months have been achieved when clinician tutorials and feedback are linked to counseling sessions. $\underline{23}$ Financial incentive models for smoking cessation have also been reported to be effective in facilitating smoking cessation. In general, incentive programs were more effective than usual care in increasing smoking cessation rates at 6 months. $\underline{24}$ The combination of pharmacotherapy and behavioral support increases smoking cessation rates. $\underline{25}$

\section{VACCINATIONS}

\section{Influenza vaccine}

Influenza vaccination can reduce serious illness (such as lower respiratory tract infections requiring hospitalization $)^{26}$ and death in COPD patients..$^{27-30}$ Only a few studies have evaluated exacerbations and they have shown significant reduction in the total number of exacerbations per vaccinated subject compared with those who received placebo. $\underline{27}$ Vaccines containing either killed or live inactivated viruses are recommended $\underline{31}$ as they are more effective in elderly patients with COPD. $\underline{32}$ Findings from a population-based study suggested that COPD patients, particularly the elderly, had decreased risk of ischemic heart disease when they were vaccinated with influenza vaccine over many years. $\underline{33}$ Occurrence of adverse reactions is generally mild and transient. 
- Influenza vaccination reduces serious illness and death in COPD patients (EvidenceB).

- The 23-valent pneumococcal polysaccharide vaccine (PPSV23) has been shown to reduce the incidence of community - acquired pneumonia in COPD patients aged $<65$ years with an $\mathrm{FEV}_{1}<40 \%$ predicted and in those with comorbidities (Evidence B).

- In the general population of adults $\geq 65$ years the 13 -valent conjugated pneumococcal vaccine (PCV13) has demonstrated significant efficacy in reducing bacteremia \& serious invasive pneumococcal disease (Evidence B).

TABLE 3.2

\section{Pneumococcal vaccine}

Pneumococcal vaccinations, PCV13 and PPSV23, are recommended for all patients $\geq 65$ years of age (Table 3.2). The PPSV23 is also recommended for younger COPD patients with significant comorbid conditions including chronic heart or lung disease. ${ }^{34}$ Specific data on the effects of PPSV and PCV in COPD patients are limited and contradictory. $\frac{35}{\mathrm{~A}}$ systematic review of injectable vaccines in COPD patients identified twelve randomized studies for inclusion and observed injectable polyvalent pneumococcal vaccination provides significant protection again $5 t$ community-acquired pneumonia, although no evidence indicates that vaccination reduced the risk of confirmed pneumococcal pneumonia, which was a relatively rare event. Vaccination reduced the likelihood of a COPD exacerbation, and moderate-quality evidence suggests the benefits of pneumococcal vaccination in COPD patients. Evidence was insufficient for comparison of different pneumococcal vaccine types. $\frac{36}{\text { Th }}$ PPSV23 has been shown to reduce the incidence of community-acquired pneumonia in COPD patients $<65$ years, with an $\mathrm{FEV}_{1}<40 \%$ predicted, ar comorbidities (especially cardiac comorbidities). ${ }^{37}$ The PCV13 has been shown to exhibit at least the same or greater immunogenicity than the PPSV23 up to two years after vaccination in COPD patients. $\frac{38}{-}$ In a large RCT PCV13 demonstrated significant efficacy for the prevention of vaccine-typerommunity-acquired pneumonia (45.6\%) and vaccine-type invasive pneumococcal disease (75\%) amóng adults $\geq 65$ years and the efficacy persisted for at least 4 years. .99

\section{PHARMACOBOGICAL THERAPY FOR STABLE COPD}

\section{Overview of the medications}

Pharmacological therapy for COPD is used to reduce symptoms, reduce the frequency and severity of exacerbations, and improve exercise tolerance and health status. To date, there is no conclusive clinical trial evidence that any existing medications for COPD modify the long-term decline in lung function. ${ }^{40-44}$ Post-hoc evidence of such an effect with long-acting bronchodilators and/or inhaled corticosteroids $\underline{45}, 46$ requires confirmation in specifically designed trials.

The classes of medications commonly used to treat COPD are shown in Table 3.3. The choice within each class depends on the availability and cost of medication and favorable clinical response balanced against side effects. Each treatment regimen needs to be individualized as the relationship between severity of symptoms, airflow limitation, and severity of exacerbations can differ between patients. 


\section{Bronchodilators}

Bronchodilators are medications that increase $\mathrm{FEV}_{1}$ and/or change other spirometric variables. They act by altering airway smooth muscle tone and the improvements in expiratory flow reflect widening of the airways rather than changes in lung elastic recoil. Bronchodilators tend to reduce dynamic hyperinflation at rest and during exercise, $\underline{47}, \underline{\underline{8}}$ and improve exercise performance. The extent of these changes, especially in patients with severe and very severe COPD, is not easy to predict from the improvement in $\mathrm{FEV}_{1}$ measured at rest. 49,50

Bronchodilator dose-response ( $\mathrm{FEV}_{1}$ change) curves are relatively flat with all classes of bronchodilators. $\frac{51-57}{\text { Increasing the dose of either a beta }}{ }_{2}$-agonist or an anticholinergic by an order of magnitude, especially when given by a nebulizer, appears to provide subjective benefit in acute episodes $\frac{58}{6}$ but is not necessarily helpful in stable disease. $\frac{59}{}$ Bronchodilator medications in COPD are most often given on a regular basis to prevent or reduce symptoms. Toxicity is also dose-related (Table 3.3). Use of short acting bronchodilators on a regular basis is not generally recommended. 


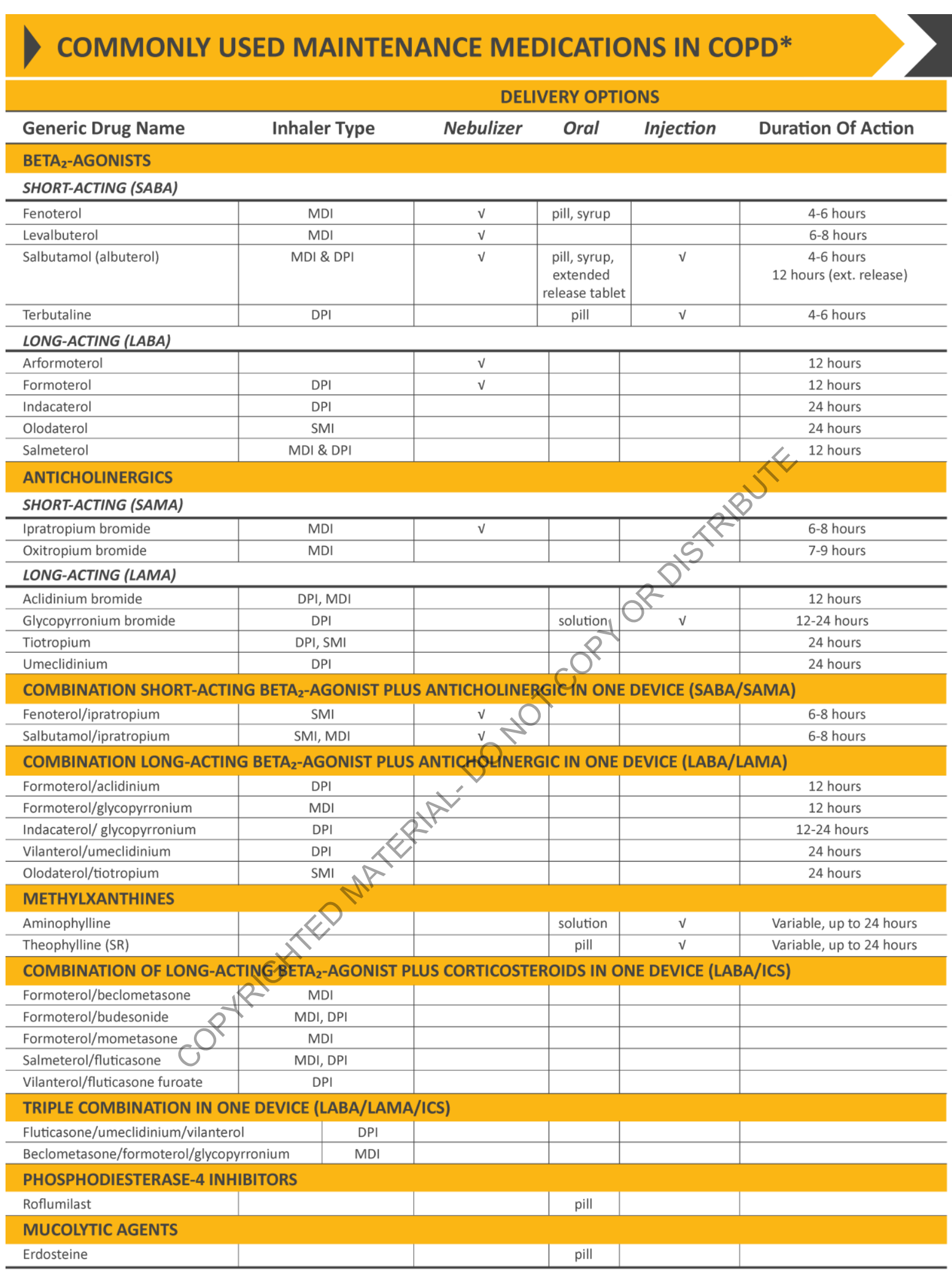

*Not all formulations are available in all countries. In some countries other formulations and dosages may be available. $M D I=$ metered dose inhaler; $D P I=$ dry powder inhaler; $S M I=$ soft mist inhaler

TABLE 3.3 
Beta $_{2}$-agonists. The principal action of beta ${ }_{2}$-agonists is to relax airway smooth muscle by stimulating beta 2 -adrenergic receptors, which increases cyclic AMP and produces functional antagonism to bronchoconstriction. There are short-acting (SABA) and long-acting (LABA) beta $2^{-}$ agonists. The effect of SABAs usually wears off within 4 to 6 hours. $\underline{53,54}$ Regular and as-needed use of SABAs improve FEV ${ }_{1}$ and symptoms. .60 For single-dose, as-needed use in COPD, there appears to be no advantage in routinely using levalbuterol over conventional bronchodilators. ${ }^{61}$ LABAs show duration of action of 12 or more hours and do not preclude additional benefit from as-needed SABA therapy. $\underline{62}$

Formoterol and salmeterol are twice-daily LABAs that significantly improve $\mathrm{FEV}_{1}$ and lung volumes, dyspnea, health status, exacerbation rate and number of hospitalizations, $\underline{63}$ but have no effect on mortality or rate of decline of lung function. Indacaterol is a once daily LABA that improves breathlessness, $, \underline{64}, 65$ health status $\underline{65}$ and exacerbation rate. $\frac{65}{6}$ Some patients experience cough following the inhalation of indacaterol. Oladaterol and vilanterol are additional once daily LABAs that improve lung function and symptoms. $\underline{66, \underline{67}}$

Adverse effects. Stimulation of beta ${ }_{2}$-adrenergic receptors can produce resting sinus tachycardia and has the potential to precipitate cardiac rhythm disturbances in susceptible patients. Exaggerated somatic tremor is troublesome in some older patients treated with higher doses of beta 2 -agonists, regardless of route of administration. Although hypokalemia can occur, especially when treatment is combined with thiazide diuretics, $\underline{\underline{6}}$ and oxygen consumption can be increased under resting conditions in patients with chronic heart failure, $\underline{69}$ these metabolic effects decrease over time (i.e., show tachyphylaxis). Mild falls in partial pressure of oxygen $\left(\mathrm{PaO}_{2}\right)$ can occur after administration of both SABAs and $\angle A B A s=0$ but the clinical significance of these changes is uncertain. Despite prior concerns related to the use of beta $_{2}$-agonists in the management of asthma, no association between beta $_{2}$-agonist use and loss of lung function of increased mortality has been reported in COPD. $\underline{6}, \underline{71}, \underline{72}$

\section{Antimuscarinic drugs}

Antimuscarinic drugs block the bronchoconstrictor effects of acetylcholine on M3 muscarinic receptors expressed in airway smooth muscle. $\frac{73}{3}$ Short-acting antimuscarinics (SAMAs), namely ipratropium and oxitropium, also block the inhibitory neuronal receptor $M 2$, which potentially can cause vagally induced Bronchoconstriction..$\underline{74}$ Long-acting antimuscarinic antagonists (LAMAs), such as tiotropium, aclidinium, glycopyrronium bromide and umeclidinium have prolonged binding to $\mathrm{M} 3$ muscarinic receptors, with faster dissociation from M2 muscarinic receptors, thus prolonging the duration of bronchodilator effect. $\underline{73}$

A systematic review of randomized controlled trials concluded that ipratropium, a short acting muscarinic antagonist, alone provided small benefits over short-acting beta ${ }_{2}$-agonist in terms of lung function, health status and requirement for oral steroids. $\underline{75}$ Among LAMAs, some are administered once a day (tiotropium and umeclidinium), others twice a day (aclidinium), and some are approved for once daily dosing in some countries and twice daily dosing in others (glycopyrronium). $\underline{73}, 76$ LAMA treatments (tiotropium) improve symptoms and health status. $\underline{73, \underline{77}}$ They also improve the effectiveness of pulmonary rehabilitation $\underline{78, \underline{79}}$ and reduce exacerbations and related hospitalizations. ${ }^{7 \underline{ }}$ Clinical trials have shown a greater effect on exacerbation rates for LAMA treatment (tiotropium) versus LABA treatment. $\underline{80,81}$ In a long-term clinical trial of 5,993 patients with COPD, tiotropium added to other 


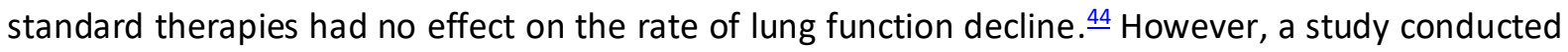
in patients with early stage COPD defined by low symptom burden and mild to moderate airflow obstruction treated with tiotropium showed an increase in $\mathrm{FEV}_{1}$, reduction in moderate but not severe exacerbations, and attenuation of the post-bronchodilator, but not pre-bronchodilator decline in $\mathrm{FEV}_{1} \cdot \underline{.2}$

Adverse effects. Inhaled anticholinergic drugs are poorly absorbed which limits the troublesome systemic effects observed with atropine. $\underline{73}, \underline{\underline{3}}$ Extensive use of this class of agents in a wide range of doses and clinical settings has shown them to be very safe. The main side effect is dryness of mouth. $\underline{74,84}$ Although occasional urinary symptoms have been reported, there are no data to prove a true causal relationship. $\frac{.5}{5}$ Some patients using ipratropium report a bitter, metallic taste. An unexpected small increase in cardiovascular events in COPD patients regularly treated with ipratropium bromide has been reported. $\frac{86,87}{2}$ In a large, long-term clinical trial in COPD patients, tiotropium added to other standard therapies had no effect on cardiovascular risk. ${ }^{44}$ Although there were some initial concerns regarding the safety of tiotropium delivery via the Respimat ${ }^{\circledR 8}$ inhaler, the findings of a large trial observed no difference in mortality or exacerbation rates when comparing tiotropium in a dry-powder inhaler and the Respimat ${ }^{\circledR}$ inhaler. .99 There are less safety data available for the other LAMAs, but the rate of anti-cholinergic side effects for drugs in this class appears to be low and generally similar. Use of solutions with a facemask can precipitate acute glaucoma, probably as a direct result of the contact between the solution and the eye. $\frac{90-92}{}$

\section{Methylxanthines}

Controversy remains about the exact effects of xanthine derivatives. They may act as non-selective phosphodiesterase inhibitors, but have also been reported to have a range of non-bronchodilator actions, the significance of which is dispured. $\frac{93-95}{}$ Data on duration of action for conventional, or even slow-release, xanthine preparations are lacking in COPD.

Theophylline, the most commonly used methylxanthine, is metabolized by cytochrome P450 mixed function oxidases. Clearance of the drug declines with age. Many other physiological variables and drugs modify theophylline metabolism. Enhanced inspiratory muscle function has been reported in patients treated with methylxanthines, $\underline{93}$ but whether this reflects a reduction in gas trapping or a primary effect on the respiratory skeletal muscles is not clear. All studies that have shown efficacy of theophylline in COPD were performed with sustained-release preparations.

There is evidence for a modest bronchodilator effect compared with placebo in stable COPD. $\underline{96}$ Addition of theophylline to salmeterol produces a greater improvement in $\mathrm{FEV}_{1}$ and breathlessness than salmeterol alone. $\underline{.9}, \underline{98}$ There is limited and contradictory evidence regarding the effect of lowdose theophylline on exacerbation rates. $\underline{99}, \underline{100}$

Adverse effects. Toxicity is dose-related, which is a particular problem with xanthine derivatives because their therapeutic ratio is small and most of the benefit occurs only when near-toxic doses are given. ${ }^{94,96}$ Methylxanthines are non-specific inhibitors of all phosphodiesterase enzyme subsets, which explains their wide range of toxic effects. Problems include the development of palpitations caused by atrial and ventricular arrhythmias (which can prove fatal) and grand mal convulsions (which can occur irrespective of prior epileptic history). Other side effects include headaches, insomnia, nausea, 
and heartburn, and these may occur within the therapeutic range of serum levels of theophylline. These medications also have significant interactions with commonly used medications such as digitalis and coumadin, among others. Unlike the other bronchodilator classes, xanthine derivatives may predispose patients to an increased risk of overdose (either intentional or accidental).

\section{BRONCHODILATORS IN STABLE COPD}

- Inhaled bronchodilators in COPD are central to symptom management and commonly given on a regular basis to prevent or reduce symptoms (Evidence A).

- Regular and as-needed use of SABA or SAMA improves FEV $_{1}$ and symptoms (Evidence A).

- Combinations of SABA and SAMA are superior compared to either medication alone in improving $\mathrm{FEV}_{1}$ and symptoms (Evidence A).

- LABAs and LAMAs significantly improve lung function, dyspnea, health status, and redage exacerbation rates (Evidence A).

- LAMAs have a greater effect on exacerbation reduction compared with LABAs (Evidence A) and decrease hospitalizations (Evidence B).

- Combination treatment with a LABA and LAMA increases FEV ${ }_{1}$ andreduces symptoms compared to monotherapy (Evidence A).

- Combination treatment with a LABA/LAMA reduces exacerbations compared to monotherapy (Evidence B).

- Tiotropium improves the effectiveness of pulmoprary rehabilitation in increasing exercise performance (Evidence B).

- Theophylline exerts a small bronchodilator effect in stable COPD (Evidence A) and that is associated with modest symptomatic benefits (Evidence B).

TABLE 3.4

\section{Combination bronchodilator therapy}

Combining bronchodilators with different mechanisms and durations of action may increase the degree of bronchodilation with a lower risk of side-effects compared to increasing the dose of a single bronchodilator. $\frac{101}{1}$ Combinations of SABAs and SAMAs are superior compared to either medication

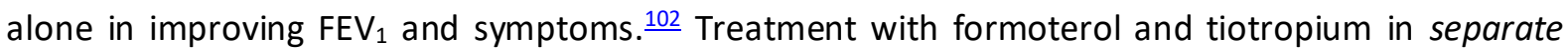
inhalers has a bigger impact on $\mathrm{FEV}_{1}$ than either component alone. $\underline{103}$ There are numerous combinations of a LABA and LAMA in a single inhaler available (Table 3.3). These combinations improve lung function compared to placebo $\frac{101}{}$; this improvement is consistently greater than long acting bronchodilator monotherapy effects although the magnitude of improvement is less than the fully additive effect predicted by the individual component responses. $\underline{104}$ In studies where patient reported outcomes (PROs) are the primary endpoint or in pooled analyses, combination bronchodilators have a greater impact on PROs compared to monotherapies. $\frac{105-108}{1 n}$ one clinical trial, combination LABA/LAMA treatment had the greatest improvement in quality of life compare to 
placebo or its individual bronchodilator components in patients with a greater baseline symptom burden. $\frac{109}{2}$ These clinical trials deal with group mean data, but symptom responses to LABA/LAMA combinations are best evaluated on an individual patient basis. A lower dose, twice daily regimen for a LABA/LAMA has also been shown to improve symptoms and health status in COPD patients $\frac{110}{10}$ (Table 3.4). These findings have been shown in people across different ethnic groups (Asian as well as European). .111

Most studies with LABA/LAMA combinations have been performed in patients with a low rate of exacerbations. One study in patients with a history of exacerbations indicated that a combination of long-acting bronchodilators is more effective than long-acting bronchodilator monotherapy for preventing exacerbations. $\frac{112}{12}$ Another large study found that combining a LABA with a LAMA did not reduce exacerbation rate as much as expected compared with a LAMA alone. $\frac{113}{}$ Another study in patients with a history of exacerbations confirmed that a combination LABA/LAMA decreased exacerbations to a greater extent than an ICS/LABA combination. 114 However, (another study in a population with high exacerbation risk ( $\geq 2$ exacerbations and/or 1 hospitalization in the previous year) reported that ICS/LABA decreased exacerbations to a greater extent than an LABA/LAMA combination at higher blood eosinophil concentrations (see Chapter 2).9.55

\section{Anti-inflammatory agents}

To date, exacerbations (e.g., exacerbation rate, patients with at least one exacerbation, time-to-first exacerbation) represent the main clinically relevant end-point used for efficacy assessment of drugs with anti-inflammatory effects (Table 3.5).

\section{Inhaled corticosteroids (ICS)}

Preliminary general considerations. In vitro evidence suggests that COPD-associated inflammation has limited responsiveness to corticosteroids. Moreover, some drugs including beta $2^{-}$ agonists, theophylline or macrolides may partially facilitate corticosteroid sensitivity in COPD. $\underline{116,117}$ The clinical relevance of this effect has not yet been fully established.

In vivo data suggest that the dose-response relationships and long-term ( $>3$ years) safety of inhaled corticosteroids (ICS) in patients with COPD are unclear and require further investigation. $\frac{109}{\text { Because }}$ the effects of ICS in COPD can be modulated by the concomitant use of long-acting bronchodilators, these two therapeutic options are discussed separately.

Efficacy of ICS (alone). Most studies have found that regular treatment with ICS alone does not modify the long-term decline of FEV ${ }_{1}$ nor mortality in patients with COPD. $\underline{118}$ Studies and metaanalyses assessing the effect of regular treatment with ICS alone on mortality in patients with COPD have not provided conclusive evidence of benefit. $\frac{118}{1}$ In the TORCH trial, a trend toward higher mortality was observed for patients treated with fluticasone propionate alone compared to those receiving placebo or salmeterol plus fluticasone propionate combination. $\underline{119}$ However, an increase in mortality was not observed in COPD patients treated with fluticasone furoate in the Survival in Chronic Obstructive Pulmonary Disease with Heightened Cardiovascular Risk (SUMMIT) trial. $\frac{120}{}$ However, in moderate COPD, fluticasone furoate alone or in combination with vilanterol was associated with slower decline in $\mathrm{FEV}_{1}$ compared with placebo or vilanterol alone by on average $9 \mathrm{ml} /$ year. $\underline{121}$ 


\section{ANTI-INFLAMMATORY THERAPY IN STABLE COPD}

\section{INHALED CORTICOSTEROIDS}

- An ICS combined with a LABA is more effective than the individual components in improving lung function and health status and reducing exacerbations in patients with exacerbations and moderate to very severe COPD (Evidence A).

- Regular treatment with ICS increases the risk of pneumonia especially in those with severe disease (Evidence A).

- Triple inhaled therapy of ICS/LAMA/LABA improves lung function, symptoms and health status and reduces exacerbations compared to ICS/LABA, LABA/LAMA or LAMA monotherapy (Evidence A).

\section{ORAL GLUCOCORTICOIDS}

- Long-term use of oral glucocorticoids has numerous side effects (Evidence A) with no evidence of benefits (Evidence C).

PDE4 INHIBITORS

- In patients with chronic bronchitis, severe to very severe COPD and a history of exacerbations: " A PDE4 inhibitor improves lung function and reduces moderate and severe exacerbations (Evidence A). " A PDE4 inhibitor improves lung function and decreases exacerbations in patients who are on fixed-dose LABA/ICS combinations (Evidence A).

\section{ANTIBIOTICS}

- Long-term azithromycin and erythromycin therapy reduces exacerbations over one year (Evidence A).

- Treatment with azithromycin is associated with an increased incidence of bacterial resistance (Evidence A) and hearing test impairments (Evidence B).

\section{MUCOREGULATORS AND ANTIOXIDANT AGENTS}

- Regular treatment with mucolytics such $\mathrm{a}_{\mathrm{S}}$ erdosteine, carbocysteine and NAC reduces the risk of exacerbations in select populations (Evidence B).

\section{OTHER ANTI-INFLAMMATORY AGENTS}

- Simvastatin does not prevent exacerbations in COPD patients at increased risk of exacerbations and without indications for statin therapy (Evidence A). However, observational studies suggest that statins may have positive effects on some outcomes in patients with COPD who receive them for cardiovascular and metabolic indications (Evidence C).

- Leukotriene modifiers have not been tested adequately in COPD patients.

TABLE 3.5

ICS in combination with long-acting bronchodilator therapy. In patients with moderate to very severe COPD and exacerbations, an ICS combined with a LABA is more effective than either component alone in improving lung function, health status and reducing exacerbations. $\underline{122,123}$ Clinical trials powered on all-cause mortality as the primary outcome failed to demonstrate a statistically significant effect of combination therapy on survival. $. \underline{19}, \underline{120}$

Most studies that found a beneficial effect of LABA/ICS fixed dose combination (FDC) over LABA alone on exacerbation rate, recruited patients with a history of at least one exacerbation in the previous 
year. $\frac{122}{}$ A pragmatic RCT conducted in a primary healthcare setting in the United Kingdom compared a LABA/ICS combination with usual care. Findings showed an $8.4 \%$ reduction in moderate-to-severe exacerbations (primary outcome) and a significant improvement in CAT ${ }^{\mathrm{TM}}$ score, with no difference in the rate of healthcare contacts or pneumonias. However, basing recommendations on these results is difficult because of the heterogeneity of treatments reported in the usual care group, the higher rate of treatment changes in the group receiving the LABA/ICS combination of interest, and the medical practice patterns unique to the UK region where the study was conducted. .24

Blood eosinophil count. A number of recent studies have shown that blood eosinophil counts predict the magnitude of the effect of ICS (added on top of regular maintenance bronchodilator treatment) in preventing future exacerbations. $\frac{115,125-129}{12}$ There is a continuous relationship between blood eosinophil counts and ICS effects; no and/or small effects are observed at lower eosinophil counts, with incrementally increasing effects observed at higher eosinophil counts. Data modelling indicates that ICS containing regimens have little or no effect at a blood eosinophil count $<100$ cells $/ \mu \mathrm{L}, \underline{125}$ therefore this threshold can be used to identify patients with a lowlikelihood of treatment benefit with ICS. The threshold of a blood eosinophil count $>300$ cells/ $\mu$ Lidentifies the top of the continuous relationship between eosinophils and ICS, and can be usedto identify patients with the greatest likelihood of treatment benefit with ICS. All in all, therefore, blood eosinophil counts can help clinicians estimate the likelihood of a beneficial preventive response to the addition of ICS to regular bronchodilator treatment, and thus can be used as a biomarkef in conjunction with clinical assessment when making decisions regarding ICS use.

Sources of evidence include: 1) Post-hoc analysescomparing ICS/LABA versus LABA $\frac{125,126,128}{\text {; }}$ 2) Prespecified analyses comparing triple therapy versus LAMA/LABA or LAMA $\underline{115,127,129}$; and, 3) other analyses comparing ICS/LABA versus LABA/LAMA $\frac{130}{30}$ or studying ICS withdrawal. $\underline{131-133}$

The treatment effect of ICS containing regimens (ICS/LAMA/LABA and ICS/LABA vs LABA/LAMA) is higher in patients with high exacerbation risk ( $\geq 2$ exacerbations and / or 1 hospitalization in the previous year). $\underline{114}, \underline{115}, \underline{127}$ Thus, the use of blood eosinophil counts to predict ICS effects should always be combined with clinical assessment of exacerbation risk (as indicated by the previous history of exacerbations). Othen factors (smoking status, ethnicity, geographical location) could influence the relationship between ICS effect and blood eosinophil count, but remains to be further explored. The mechanism for an increased ICS effect in COPD patients with higher blood eosinophil counts remains unclear.

The repeatability of blood eosinophil counts in a large primary care population appears reasonable, $\underline{\underline{134}}$

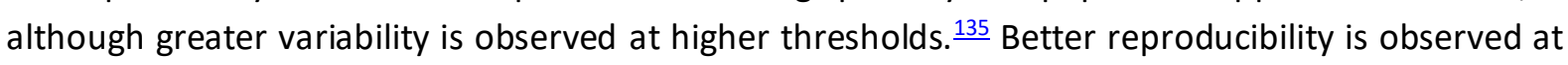
the lower thresholds (e.g., 100 cells $/ \mu \mathrm{L}$ ). 136

Cohort studies have produced differing results with regard to the ability of blood eosinophils to predict future exacerbation outcomes, with either no relationship $\frac{137}{}$ or a positive relationship reported. $.38,139$ Differences between studies are likely to be related to different previous exacerbation histories and ICS use. There is insufficient evidence to recommend that blood eosinophils should be used to predict future exacerbation risk on an individual basis in COPD patients. 
Adverse effects. There is high quality evidence from randomized controlled trials (RCTs) that ICS use is associated with higher prevalence of oral candidiasis, hoarse voice, skin bruising and pneumonia. $\frac{118}{1}$ This excess risk has been confirmed in ICS studies using fluticasone furoate, even at low doses. .40 Patients at higher risk of pneumonia include those who currently smoke, are aged $\geq 55$ years, have a history of prior exacerbations or pneumonia, a body mass index $(\mathrm{BMI})<25 \mathrm{~kg} / \mathrm{m}^{2}$, a poor MRC dyspnea grade and/or severe airflow limitation. $\frac{141,142}{1}$ Independent of ICS use, there is evidence that a blood eosinophil count $<2 \%$ increases the risk of developing pneumonia. ${ }^{143}$ In studies of patients with moderate COPD, ICS by itself or in combination with a LABA did not increase the risk of pneumonia. $. \underline{120}, \underline{142}$

Results from RCTs have yielded varied results regarding the risk of decreased bone density and fractures with ICS treatment, which may be due to differences in study designs and/or differences between ICS compounds. ${ }^{42,140,144-146}$ Results of observational studies suggest that ICS treatment could also be associated with increased risk of diabetes/poor control of diabetes, 147 cataracts, 148 and mycobacterial infection $\frac{149}{}$ including tuberculosis. $\frac{150,151}{1}$ In the absence of RCT data on these issues, it is not possible to draw firm conclusions. ${ }^{152} \mathrm{An}$ increased risk of tuberculosis has been found in both observational studies and a meta-analysis of RCTs. $\underline{124}, \underline{125}$

Withdrawal of ICS. Results from withdrawal studies provide equivocal results regarding consequences of withdrawal on lung function, symptoms and exacerbations. $\stackrel{153-157}{ }$ Some studies, but not all, have shown an increase in exacerbations and/or symptoms following ICS withdrawal, while others have not. There has been evidence for a modest decrease in FEV $\mathrm{V}_{1}$ (approximately $40 \mathrm{~mL}$ ) with ICS withdrawal, $\frac{157}{\underline{1}}$ which could be associated with increased baseline circulating eosinophil level. $\frac{131}{1} \mathrm{~A}$ recent study examining ICS withdrawal on a background of dual bronchodilator therapy demonstrated that both $\mathrm{FEV}_{1}$ loss and an increase in exacerbation frequency associated with ICS withdrawal was greatest among patients with a blood eosinophil count $\geq 300$ cells $/ \mu$ l at baseline. $\frac{133}{\text { Differences }}$ between studies may relate to differences in methodology, including the use of background longacting bronchodilator medication(s) which may minimize any effect of ICS withdrawal.

\section{Triple inhaled theragy}

The step up in inhated treatment to LABA plus LAMA plus ICS (triple therapy) can occur by various approaches. $\frac{158}{}$ This may improve lung function, patient reported outcomes and prevent exacerbations. $\frac{159-162}{}$ Adding a LAMA to existing LABA/ICS improves lung function and patient reported outcomes, in particular exacerbation risk. $\frac{160,163-166}{1} \mathrm{~A}$ double-blind, parallel group, RCT reported that treatment with single inhaler triple therapy had greater clinical benefits compared to tiotropium in patients with symptomatic COPD, $\mathrm{FEV}_{1}<50 \%$, and a history of exacerbations $\frac{129}{2}$ but double-blind RCTs have reported benefits of single-inhaler triple therapy compared with LABA/LAMA combination therapy. $\underline{115,127}$ 


\section{Oral glucocorticoids}

Oral glucocorticoids have numerous side effects, including steroid myopathy $\frac{167}{}$ which can contribute to muscle weakness, decreased functionality, and respiratory failure in subjects with very severe COPD. Systemic glucocorticoids for treating acute exacerbations in hospitalized patients, or during emergency department visits, have been shown to reduce the rate of treatment failure, the rate of relapse and improve lung function and breathlessness. $\frac{168}{}$ Conversely, prospective studies on the longterm effects of oral glucocorticoids in stable COPD are limited. $\underline{169}, \underline{170}$ Therefore, while oral glucocorticoids play a role in the acute management of exacerbations, they have no role in the chronic daily treatment in COPD because of a lack of benefit balanced against a high rate of systemic complications.

\section{Phosphodiesterase-4 (PDE4) inhibitors}

Efficacy. The principal action of PDE4 inhibitors is to reduce inflammation by inhibiting the breakdown of intracellular cyclic AMP. $\stackrel{171}{ }$ Roflumilast is a once daily oral medication with no direct bronchodilator activity. Roflumilast reduces moderate and severe exacerbations treated with systemic corticosteroids in patients with chronic bronchitis, severe to very severe COPD, and a history of exacerbations. $\frac{172}{}$ The effects on lung function are also seen when foflumilast is added to long-acting bronchodilators, $\underline{173}$ and in patients who are not controlled on fixed-dose LABA/ICS combinations. $\frac{174}{}$ The beneficial effects of roflumilast have been reported to be greater in patients with a prior history of hospitalization for an acute exacerbation. $\frac{175,176}{1}$ There has been no study directly comparing roflumilast with an inhaled corticosteroid.

Adverse effects. PDE4 inhibitors have more adverse effects than inhaled medications for COPD. $\frac{177}{}$ The most frequent are diarrhea, nausea, reduced appetite, weight loss, abdominal pain, sleep disturbance, and headache. Adverse effects have led to increased withdrawal rates from clinical trials. Adverse effects seem to occur earlyduring treatment, are reversible, and diminish over time with continued treatment. In controlled studies an average unexplained weight loss of $2 \mathrm{~kg}$ has been seen and weight monitoring during treatment is advised, in addition to avoiding roflumilast treatment in underweight patients. Roflumilast should also be used with caution in patients with depression.

\section{Antibiotics}

In older studies prophylactic, continuous use of antibiotics had no effect on the frequency of exacerbations in COPD $\underline{178,179}$ and a study that examined the efficacy of chemoprophylaxis undertaken in winter months over a period of 5 years concluded that there was no benefit. ${ }^{180}$ More recent studies have shown that regular use of some antibiotics may reduce exacerbation rate. $\underline{181,182}$

Azithromycin ( $250 \mathrm{mg} /$ day or $500 \mathrm{mg}$ three times per week) or erythromycin (500 mg two times per day) for one year in patients prone to exacerbations reduced the risk of exacerbations compared to usual care. $\frac{183-185}{}$ Azithromycin use was associated with an increased incidence of bacterial resistance, prolongation of QTc interval, and impaired hearing tests. $\frac{185}{\mathrm{~A}}$ post-hoc analysis suggests lesser benefit in active smokers. $\frac{176}{}$ There are no data showing the efficacy or safety of chronic azithromycin treatment to prevent COPD exacerbations beyond one-year of treatment. 
Pulse therapy with moxifloxacin ( $400 \mathrm{mg} /$ day for 5 days every 8 weeks) in patients with chronic bronchitis and frequent exacerbations had no beneficial effect on exacerbation rate overall. .186

\section{Mucolytic (mucokinetics, mucoregulators) and antioxidant agents (NAC, carbocysteine)}

In COPD patients not receiving inhaled corticosteroids, regular treatment with mucolytics such as erdosteine, carbocysteine and $\mathrm{N}$-acetylcysteine may reduce exacerbations and modestly improve health status. $\frac{187-189}{}$ Due to the heterogeneity of studied populations, treatment dosing and concomitant treatments, currently available data do not allow one to identify precisely the potential target population for antioxidant agents in COPD. $\frac{188}{}$

\section{Other drugs with anti-inflammatory potential}

Two RCTs in COPD patients performed before 2005 that investigated the use of an immunoregulator reported a decrease in the severity and frequency of exacerbations. 190,191 Additional studies are needed to examine the long-term effects of this therapy in patients receiving currently recommended COPD maintenance therapy.

Nedocromil and leukotriene modifiers have not been tested adequately in COPD patients and the available evidence does not support their use. $\underline{192,193}$

There was no evidence of benefit, and some evidence of harm, including malignancy and pneumonia, following treatment with an anti-TNF-alpha antibody (infliximab) in moderate to severe COPD. $\underline{194}$

Simvastatin did not prevent exacerbations in patients with COPD who had no metabolic or cardiovascular indication for statin treatment. $\frac{195}{1}$ An association between statin use and improved outcomes (including decreased exacerbations and mortality) has been reported in observational studies of patients with COPD who received them for cardiovascular and metabolic indications. $\frac{196}{}$

There is no evidence that supplementation with vitamin $D$ has a positive impact on exacerbations in unselected patients. $\frac{197}{7}$

\section{Issues related to inhaled delivery}

When a treatment is given by the inhaled route the importance of education and training in inhaler device technique cannot be over-emphasized. Inhalation devices include nebulizers, metered-dose inhalers (MDIs) used without spacers, soft-mist inhalers and breath-actuated devices i.e., breathactuated MDIs (BAIs) and single-dose and multi-dose dry powder inhalers (DPIs). $\stackrel{198}{ }$ In multi-dose DPIs, the powder is contained in a reservoir or in individual blisters. $\frac{198}{}$ All classes of inhaled drugs are not available in all types of device. Particles $>5$ microns $(\mu \mathrm{m})$ are most likely to be deposited in the oropharynx. For drug delivery to the lower respiratory tract and lungs, particle size (mass-median aerodynamic diameter) can be fine $(2-5 \mu \mathrm{m})$ or extra-fine $(<2 \mu \mathrm{m})$, which influences the total respirable fraction (particles $<5 \mu \mathrm{m}$ ) and the amount and site of drug deposition (more peripheral deposition with extra-fine particles). $\underline{198}$ Randomized controlled trials have not identified superiority of one device/formulation. .198 However, patients included in these trials are usually those who master 
inhalation technique and receive proper education and follow-up regarding this issue, and therefore may not be reflective of normal clinical practice. On average more than two thirds of patients make at least one error in using an inhalational device. $\frac{199-201}{A}$ A rigorous, prospective observational study of COPD patients discharged from the hospital confirmed appropriate adherence to the use of a DPI in only $23 \%$ of patients. .202

Observational studies have identified a significant relationship between poor inhaler use and symptom control in patients with COPD. $\underline{200}$ Determinants of poor inhaler technique in asthma and COPD patients include: older age, use of multiple devices, and lack of previous education on inhaler technique. $\underline{203}$ In such populations, education improves inhalation technique in some but not all patients, $\underline{203}$ especially when the "teach-back" approach (patients being asked to show how the device has to be used) is implemented. $\frac{204}{}$ It is important to check that patients continue to use their device correctly. Lack of placebo devices within clinical areas is often a limitation and barrier to providing quality inhaler technique instruction to patients. Encouraging a patient to bring their own devices to clinic is a useful alternative. Those who do not reach mastery may require a change in inhalational delivery device.

\section{THE INHALED ROUTE}

- When a treatment is given by the inhaled route, the importance of ducation and training in inhaler device technique cannot be over-emphasized.

- The choice of inhaler device has to be individually tailoredand will depend on access, cost, prescriber, and most importantly, patient's ability and preference.

- It is essential to provide instructions and to demonstrate the proper inhalation technique when prescribing a device, to ensure that inhaler technique is adequate and re-check at each visit that patients continue to use their inhaler correctly.

- Inhaler technique (and adherence totherapy) should be assessed before concluding that the current therapy is insufficient.

TABLE 3.6

The main errors indelivery device use relate to problems with inspiratory flow, inhalation duration, coordination, dose preparation, exhalation maneuver prior to inhalation and breath-holding following dose inhalation (Table 3.6). .02 Specific instructions are available for each type of device. $\frac{198}{}$ Observational studies in patients with COPD show that, although the type and frequency of inhalation errors vary between devices depending on their characteristics, there is no device obviating the need to explain, demonstrate and regularly check inhalation technique. ${ }^{205-211}$ Strategies for inhaler choice based on patients' characteristics have been proposed by experts and consensus-based taskforces (Table 3.6), but none have yet been prospectively tested. $\underline{198,211}, \underline{212}$ There is no evidence for superiority of nebulized therapy over hand-held devices in patients who are able to use these devices properly. 


\section{OTHER PHARMACOLOGICAL TREATMENTS}

\section{ALPHA-1 ANTITRYPSIN AUGMENTATION THERAPY}

- Intravenous augmentation therapy may slow down the progression of emphysema (Evidence B).

\section{ANTITUSSIVES}

- There is no conclusive evidence of a beneficial role of antitussives in patients with COPD (Evidence C).

\section{VASODILATORS}

- Vasodilators do not improve outcomes and may worsen oxygenation (Evidence B).

TABLE 3.7

Alpha-1 antitrypsin augmentation therapy. The logical approacb to minimize the development and progression of lung disease in AATD patients is alpha-1-antitrypsin augmentation. Such therapy has been available in many, though not all, countries since the 1980s. Because AATD is rare, formal clinical trials to assess efficacy with conventional spirometric outcome have never been undertaken. However, a wealth of observational studies suggest a reduction in spirometric progression in treated versus non-treated patients ${ }^{213}$ and that this reduction is most effective for patients with $\mathrm{FEV}_{1} 35-49 \%$ predicted. .14 Never or ex-smokers with an $\mathrm{FEV}_{1}$ of $35-60 \%$ predicted have been suggested as those most suitable for AATD augmentation therapy (Evidence B).

More recently studies using sensitive parameters of emphysema progression determined by CT scans have provided evidence for an effect on preserving lung tissue compared to placebo. $\frac{215-217}{\text { Based on }}$ the most recent trial the indications for therapy have been extended to include "those patients with evidence of progressive lung disease despite other optimal therapy." However, not all patients with AATD develop or persist with rapid spirometric progression especially following smoking cessation. 1218 Since the purpose of augmentation therapy is to preserve lung function and structure it seems logical to reserve such expensive therapy for those with evidence of continued and rapid progression following smoking cessation. $\underline{218}$

The indication for AAT augmentation is emphysema although there are no fixed criteria for diagnosis or confirmation. The evidence for augmentation therapy efficacy varies according to the outcome studied. 129 Intravenous augmentation therapy has been recommended for individuals with alpha-1 antitrypsin deficiency (AATD) and an $\mathrm{FEV}_{1} \leq 65 \%$ predicted based on previous observational studies. However, the recent study powered on CT scan as an outcome has recommended that all patients with evidence of progressive lung disease should be considered for those with lung disease related to $\mathrm{AATD}$, and an $\mathrm{FEV}_{1}>65 \%$. Individual discussion is recommended with consideration of the cost of therapy and lack of evidence for much benefit. ${ }^{220}$ The main limitation for this therapy is very high cost and lack of availability in many countries. 
Antitussives. The role of antitussives in patients with COPD is inconclusive. $\underline{221}$

Vasodilators. Vasodilators have not been properly assessed in COPD patients with severe/disproportionate pulmonary hypertension. Inhaled nitric oxide can worsen gas exchange because of altered hypoxic regulation of ventilation-perfusion balance and is contraindicated in stable COPD. ${ }^{222}$ Studies have shown that sildenafil does not improve the results of rehabilitation in patients with COPD and moderately increases pulmonary artery pressure. ${ }^{223}$ Tadalafil does not appear improve exercise capacity or health status in COPD patients with mild pulmonary hypertension. $\underline{224}$

\section{REHABILITATION, EDUCATION \& SELF-MANAGEMENT}

\section{Pulmonary rehabilitation}

Pulmonary rehabilitation is defined as "a comprehensive intervention based on thorough patient assessment followed by patient-tailored therapies that include, but are not limited to, exercise training, education, self-management intervention aiming at behavior change, designed to improve the physical and psychological condition of people with chronic respinatory disease and to promote the long-term adherence to health-enhancing behaviors." 225

Pulmonary rehabilitation should be considered part of integrated patient management, and usually includes a range of healthcare professionals to ensure optimum coverage of the many aspects involved. $\underline{226}$ Patients should undergo careful assessment prior to enrollment, including identification of the patient's goals, specific healthcare needs, smoking status, nutritional health, self-management capacity, health literacy, psychological health status and social circumstances, comorbid conditions as well as exercise capabilities and limitations. 227,228 Optimum benefits are achieved from programs lasting 6 to 8 weeks. Available evidence indicates that there are no additional benefits from extending

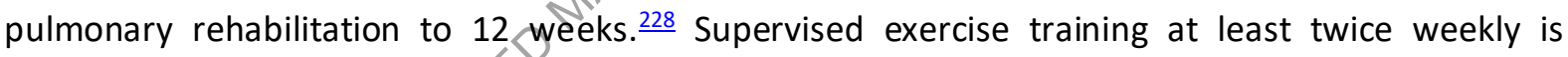
recommended, and this cap include any regimen from endurance training, interval training, resistance/strength training, upper and lower limbs ideally should be included as well as walking exercise; flexibility, inspiratory muscle training and neuromuscular electrical stimulation can also be incorporated. In all cases the rehabilitation intervention (content, scope, frequency, and intensity) should be individualized to maximize personal functional gains. 228 The importance of long-term behavior change to improve physical functionality, and reduce the psychological impact of COPD, should be emphasized to the patient.

The benefits to COPD patients from pulmonary rehabilitation are considerable (Table 3.8), and rehabilitation has been shown to be the most effective therapeutic strategy to improve shortness of breath, health status and exercise tolerance. .229 Pulmonary rehabilitation is appropriate for most patients with COPD; improved functional exercise capacity and health related quality of life have been demonstrated across all grades of COPD severity, although the evidence is especially strong in patients with moderate to severe disease. Even patients with chronic hypercapnic failure show benefit. $\underline{230}$ Limited data exist regarding the effectiveness of pulmonary rehabilitation after an acute exacerbation of COPD, but systematic reviews have shown that among those patients who have had a recent exacerbation ( $\leq 2$ weeks from prior hospitalization), pulmonary rehabilitation can reduce readmissions 
and mortality. $\underline{231}$ However, initiating pulmonary rehabilitation before the patient's discharge may

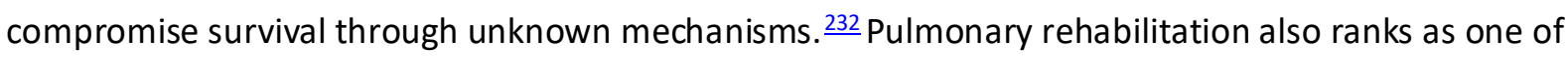
the most cost-effective treatment strategies, with an estimated cost per quality-adjusted life year (QALY) of $£ 2,000-£ 8,000 . \underline{226}$

\section{PULMONARY REHABILITATION, SELF-MANAGEMENT}

AND INTEGRATIVE CARE IN COPD

PULMONARY REHABILITATION

- Pulmonary rehabilitation improves dyspnea, health status and exercise tolerance in stable patients (Evidence A).

- Pulmonary rehabilitation reduces hospitalization among patients who have had a recent exacerbation ( $\leq 4$ weeks from prior hospitalization) (Evidence B).

\section{EDUCATION AND SELF-MANAGEMENT}

- Education alone has not been shown to be effective (Evidence C).

- Self-management intervention with communication with a health care professionakmproves health status and decreases hospitalizations and emergency department visits (Evidence B).

\section{INTEGRATED CARE PROGRAMS}

- Integrated care and telehealth have no demonstrated benefit at this fime (Evidence B).

TABLE 3.8

There are many challenges with pulmonary rehabilitation. Referral of patients who might benefit, uptake and completion of pulmonary rehabilitation is frequently limited, partly through provider ignorance as well as patients' lack of awarehess of availability or benefits. Another challenge is encouraging sustained long-term physical activity. Although the approach may need to be personalized, behavioral lifestyle physical activity intervention has shown promising results i.e., the potential to decrease sedentarityand increase physical activity in patients with moderate to severe COPD. $\frac{233}{}$ A major barrier to full participation is access, which is particularly limited by geography, culture, finances, transport and other logistics. $\underline{225,234,235}$ Pulmonary rehabilitation can be conducted at a range of sites. $\underline{225}$ Community-based and home-based programs including online supported pulmonary rehabilitation can be as effective as hospital-based programs, $\underline{236}, \underline{237}$ as long as the frequency and intensity are equivalent. $\frac{238}{2}$ There is also evidence that standardized home-based pulmonary rehabilitation programmes improve dyspnea in COPD patients. $\frac{239}{2}$ Home rehabilitation may especially be a solution for many patients who live outside the reach of facility-based programs. Another challenge is that the benefits of rehabilitation tend to wane over time. There is insufficient evidence, with conflicting research findings in the 11 available RCTs, to recommend continuation of lower intensity or lower frequency exercise programmes with the aim of maintaining benefit long-term. However, if such programs are available they should target health behavior taking into account the patient's own preferences, needs and personal goals. $\underline{228,240}$ 


\section{Education, self-management and integrative care}

Education. Patient "education" often takes the form of providers giving information and advice, and assumes that knowledge will lead to behavior change. Although enhancing patient knowledge is an important step towards behavior change, didactic group sessions are insufficient for promoting selfmanagement skills. Topics such as smoking cessation, correct use of inhaler devices, early recognition of exacerbation, decision-making and taking action, and when to seek help, surgical interventions, considering advance directives, and others will be better dealt with using self-management interventions. Personalized education and training that takes into account specific issues relating to the individual patients, and that aims to enhance long-term functionality and appropriate health behaviors are likely to benefit patients more. These are addressed under self-management.

Self-management. A recent Delphi process has resulted in a conceptual definition for COPD selfmanagement interventions: "A COPD self-management intervention is structured but personalized and often multi-component, with goals of motivating, engaging and supporting the patients to positively adapt their health behavior(s) and develop skills to better manage their disease."ㄴ1 The process requires iterative interactions between patients and healthcare professionals who are competent in delivering self-management interventions. Behavior change techniques are used to elicit patient motivation, confidence and competence. Literacy sensitive approaches are used to enhance comprehensibility. $\underline{241}$

Systematic reviews have provided evidence that self-management interventions improve outcomes in COPD. Cochrane reviews on COPD self-management have reported that self-management interventions that include written negotiated action plans for worsening symptoms lead to a lower probability of both respiratory-related hospitalization and all cause hospitalizations. A recent Cochrane review on COPD self-management interventions that includes action plans for exacerbations demonstrated lower probability of respiratory-related hospital admissions and improvements in

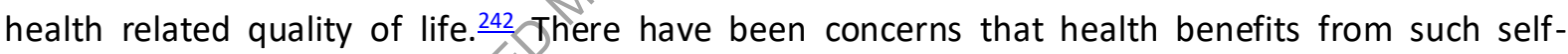
management programs in COPQ Could be counterbalanced by increased mortality..$\underline{243,244}$ The Cochrane review and another meta-analysis, however, reported no impact of self-management interventions on overall mortality. $\frac{242,245}{2}$ The Cochrane review did find a small, but statistically significant, higher respiratory related mortality rate in the self-management intervention group as compared to usual care. However, the authors also indicate the results should be interpreted with caution as misclassification in cause of death is common, the overall effect was dominated by two studies, and no effect on all-cause mortality was seen in the overall analysis. Furthermore, two recent independent, well designed studies, the COMET $\underline{246}$ and the PIC-COPD,, 47 have shown the potential for reduction in mortality from integrated case management with self-management interventions. The program in these two studies may have promoted earlier appropriate treatment for exacerbations, which could have prevented some fatal complications.

There remain problems with heterogeneity among interventions, consistency of their application, specifics of the intervention, patient populations, follow-up times and outcome measures that make generalization difficult in real life. It is also challenging to formulate clear recommendations regarding the most effective form and content of a self-management intervention in COPD given the range of heterogeneity across studies, and lack of precise definitions of self-management components (e.g., 
skills taught) and fidelity measures. The recent conceptual definition should help redress these deficiencies.

Integrated care programs. COPD is a complex disease that requires the input of multiple care providers who need to work together closely. In principle, use of a formal structured program that determines how each component is delivered should make care more efficient and effective, but the evidence for this is divided. A meta-analysis of small trials concluded that an integrated care program improved a number of clinical outcomes, although not mortality. $\underline{248}$ In contrast, a large multicenter study in primary care within an existing well-organized system of care did not confirm this. $\frac{249}{}$ Besides, delivering integrated interventions by telemedicine did not show a significant effect. $\frac{250,251}{2}$ The pragmatic conclusion is that well organized care is important, but there may be no advantage in structuring it tightly into a formalized program. Furthermore, integrated care needs to be individualized to the stage of the person's illness and health literacy.

\section{SUPPORTIVE, PALLIATIVE, END-OF-LIFE \&HOSPICE CARE}

\section{Symptom control and palliative care}

Palliative care is a broad term that encompasses approaches to symptom control as well as management of terminal patients close to death. The goal of palliative care is to prevent and relieve suffering, and to support the best possible qualityof life for patients and their families, regardless of the stage of disease or the need for other therapies. $\frac{252}{2}$ COPD is a highly symptomatic disease and has many elements such as fatigue, dyspnea, depression, anxiety, insomnia that require symptom-based palliative treatments. There is evidence that patients with COPD are less likely to receive such services compared to patients with lung cancern 253,254 Palliative care expands traditional disease-model medical treatment to increase the focus on the goals of enhancing quality of life, optimizing function, helping with decision-making about end-of-life care, and providing emotional and spiritual support to patients and their families. ${ }^{252}$ Palliative approaches are essential in the context of end-of-life care as well as hospice care (a modelfor delivery of end-of-life care for patients who are terminally ill and predicted to have less than 6 months to live). Increasingly, palliative care teams are available for consultation for hospitalized patients. $\frac{255}{}$ Availability for outpatient palliative care consultation is less common, and has been shown to improve quality of life, reduce symptoms and even prolong survival for patients with advanced lung cancer. $\underline{254}$

\section{Therapy relevant to all patients with COPD}

Even when receiving optimal medical therapy many patients with COPD continue to experience distressing breathlessness, impaired exercise capacity, fatigue, and suffer panic, anxiety and depression. .235 Some of these symptoms can be improved by wider use of palliative therapies that in the past have often been restricted to end-of-life situations.

Palliative treatment of dyspnea. Opiates, ${ }^{256-258}$ neuromuscular electrical stimulation (NMES), $, 258,259$ chest wall vibration (CWV) $)^{258}$ and fans blowing air onto the face $\underline{258,260,261}$ can relieve breathlessness. 
Immediate-release morphine extended exercise endurance time in over half of patients with advanced COPD, although further research is required to determine what patient characteristics predict response. $\frac{262}{}$ Oxygen may offer some benefit even if the patient is not hypoxemic $\left(\mathrm{SpO}_{2}>92 \%\right)$. $\frac{263}{}$ Pulmonary rehabilitation is effective and in severe cases non-invasive ventilation can also reduce daytime breathlessness. Refractory dyspnea may be more effectively managed with a multidisciplinary integrated palliative and respiratory care service. .64

There is no evidence for a beneficial effect of benzodiazepines 265 and there is not enough data to recommend distractive auditory stimuli (music), relaxation, counseling and support, with or without breathing relaxation training, or psychotherapy. $\underline{266}$

Nutritional support. Low BMI and particularly low fat free mass is associated with worse outcomes in people with COPD. $\frac{267}{2}$ In malnourished patients with COPD, nutritional supplementation promotes significant weight gain and leads to significant improvements in respiratory muscle strength and overall health-related quality of life. $\frac{268}{}$

Panic, anxiety \& depression. The causes of depression and anxiety symptoms in people with COPD are multifactorial and include behavioral, social and biological factors. $\frac{269}{}$ Pulmonary rehabilitation may help reduce anxiety symptoms. The efficacy of antidepressants in patients with COPD has been inconclusive, possibly as a result of methodological issues in the published trials. Cognitive behavioral therapy and mind-body interventions (e.g., mindfulness-based therapy, yoga, and relaxation) can reduce anxiety and depression andmind-body interventions also improve physical outcomes such as lung function, dyspnea, exercise capacity and fatigue in people with COPD and psychological problems. .270

Fatigue. Fatigue in people with COPD Can be improved by self-management education, pulmonary rehabilitation, nutritional support and mind-body interventions. $\frac{271}{\underline{3}}$

\section{End-of-life and hospicercare}

In many patients, the disease trajectory in COPD is marked by a gradual decline in health status and increasing symptoms, punctuated by acute exacerbations that are associated with an increased risk of dying. $\frac{272}{}$ Although mortality rates following hospitalization for an acute exacerbation of COPD are declining, $\underline{273}$ reported rates still vary from $23 \% \underline{274}$ to $80 \% . \underline{275}$ Progressive respiratory failure, cardiovascular diseases, malignancies and other diseases are the primary cause of death in patients with COPD hospitalized for an exacerbation. $\underline{275}$ In qualitative studies, as well as describing the high symptom burden, patients with COPD and their families describe a need for a better understanding of their condition and the psychological impact of living and dying with COPD. $\underline{276}$ Palliative care is a broad term that includes approaches to symptom control as well as management of terminal patients close to death. Palliative care, end-of-life care, and hospice care are important components of the care of patients with advanced COPD.

End-of-life care should also include discussions with patients and their families about their views on resuscitation, advance directives and place of death preferences. .277 At an individual level, prediction of 6-month survival in patients with COPD is unreliable and therefore early discussion of these issues 
is important together with phased introduction of supportive care. $\stackrel{278}{ }$ Hospitalization may be a trigger to initiate discussion of advance care planning. Patients and their families live with uncertainty about the timing of death and fear death will result from worsening dyspnea and suffocation. $\frac{279}{\text { Good }}$ advance care planning can reduce anxiety for patients and their families by talking about death and dying and offering emotional support. It can also ensure that care is consistent with their wishes and avoids unnecessary, unwanted and costly invasive approaches. $\underline{280,281}$

\section{PALLIATIVE CARE, END OF LIFE AND HOSPICE CARE IN COPD}

\footnotetext{
- Opiates, neuromuscular electrical stimulation (NMES), oxygen and fans blowing air on to the face can relieve breathlessness (Evidence C).

- In malnourished patients, nutritional supplementation may improve respiratory muscle strength and overall health status (Evidence B).

- Fatigue can be improved by self-management education, pulmonary rehabilitation, nutritional support and mind-body interventions (Evidence B).
}

\section{TABLE 3.9}

For patients with very advanced or terminal illness, hospice services may provide additional benefit. Hospice services often focus on patients with severe disability or symptom burden and may provide these services within the patient's home or in hospice beds in dedicated hospice units or other institutions such as hospitals or nursing homes. Organizations such as the National Hospice and Palliative Care Organization $\stackrel{282}{ }$ provide guidance for selecting patients with non-cancer diseases like COPD for access to hospice services (for example, disabling dyspnea at rest that is poorly responsive to bronchodilators and progression of advanced disease demonstrated by increasing hospitalizations or emergency department visits). 253,254 These guidelines discuss the difficulties in accurately predicting the prognosis of patients with advanced COPD, but recognize the appropriateness of providing hospice services for some of these patients. ${ }^{252}$ Key points for palliative, end-of-life and hospice care in COPD are summarized in Table 3.9.

\section{OTHER TREATMENTS}

\section{Oxygen therapy and ventilatory support}

Oxygen therapy. The long-term administration of oxygen ( $>15$ hours per day) to patients with chronic respiratory failure has been shown to increase survival in patients with severe resting

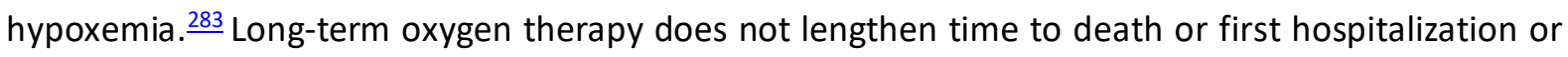
provide sustained benefit for any of the measured outcomes in patients with stable COPD and resting or exercise-induced moderate arterial oxygen desaturation. $\frac{284}{}$ Breathlessness may be relieved in COPD patients who are either mildly hypoxemic, or non-hypoxemic but do not otherwise qualify for home oxygen therapy, when oxygen is given during exercise training; however, studies have shown no improvement of breathlessness in daily life and no benefit on health related quality of life (Table 3.10)..$\underline{284,285}$ 
Although air travel is safe for most patients with chronic respiratory failure who are on long-term oxygen therapy,, 286 patients should ideally maintain an in-flight $\mathrm{PaO}_{2}$ of at least $6.7 \mathrm{kPa}(50 \mathrm{mmHg})$. Studies indicate that this can be achieved in those with moderate to severe hypoxemia at sea level by supplementary oxygen at 3 liters/min by nasal cannula or $31 \%$ by Venturi facemask. .287 Those with a resting oxygen saturation $>95 \%$ and 6 -minute walk oxygen saturation $>84 \%$ may travel without further assessment, $\underline{288}$ although it is important to emphasize that resting oxygenation at sea level does not exclude the development of severe hypoxemia when travelling by air. 286 Careful consideration should be given to any comorbidity that may impair oxygen delivery to tissues (e.g., cardiac impairment, anemia). Also, walking along the aisle may profoundly aggravate hypoxemia. $\frac{289}{2}$

\section{Ventilatory Support}

During exacerbations of COPD. Noninvasive ventilation (NIV) in the form of noninvasive positive pressure ventilation (NPPV) is the standard of care for decreasing morbidity and mortality in patients hospitalized with an exacerbation of COPD and acute respiratory failure $290-292$ (see also Chapter 5).

Stable patient. In patients with both COPD and obstructive sleep apnea there are clear benefits associated with the use of continuous positive airway pressure (CPAP) to improve both survival and the risk of hospital admissions. 293

Whether to use NPPV chronically at home to treat patients with acute on chronic respiratory failure following hospitalization remains undetermined ang outcome may be affected by persistent hypercapnia. $\frac{294}{A}$ recent multicenter (13 sites) prospective RCT of COPD patients ( $n=116$ ) with persistent hypercapnia $\left(\mathrm{PaCO}_{2}>53 \mathrm{mmHg}\right.$ ) after 2-4 weeks of hospital discharge because an acute episode of exacerbation, compared the effect's of home noninvasive ventilation (NIV) plus oxygen compared to home oxygen alone on time to readmission or death. ${ }^{294}$ Patients with $\mathrm{BMI}>35 \mathrm{~kg} / \mathrm{m}^{2}$, obstructive sleep apnea syndrome, or other causes of respiratory failure were excluded. Of 2,021 patients screened, only 124 ( $6 \%$ ) were eligible. Results showed that adding home NIV to oxygen therapy significantly prolonged the time to readmission or death within 12 months. .94

Two previous retrospective studies $\underline{295,296}$ and two of three RCTs $\underline{294,297-300}$ reported reductions in rehospitalization and improved survival with using NPPV post-hospitalization. Two studies reported decreases in mortality and hospitalization rates while another showed no benefit of NPPV for survival. Several factors may account for discrepancies: differences in patient selection, underpowered studies, NPPV settings incapable of achieving adequate ventilation, and poor adherence with NPPV therapy. $\frac{301}{}$ NPPV when indicated should be instituted and monitored under the direction of personnel familiar with the process and the devices utilized. $\frac{302,303}{2}$ In patients with both COPD and obstructive sleep apnea there are clear benefits associated with the use of continuous positive airway pressure (CPAP) to improve both survival and the risk of hospital admissions. $\frac{293}{}$ 


\section{OXYGEN THERAPY}

- The long-term administration of oxygen increases survival in patients with severe chronic resting arterial hypoxemia (Evidence A).

- In patients with stable COPD and moderate resting or exercise-induced arterial desaturation, prescription of long-term oxygen does not lengthen time to death or first hospitalization or provide sustained benefit in health status, lung function and 6-minute walk distance (Evidence A).

- Resting oxygenation at sea level does not exclude the development of severe hypoxemia when traveling by air (Evidence C).

- NPPV may improve hospitalization-free survival in selected patients after recent hospitalization, particularly in those with pronounced daytime persistent hypercapnia ( $\mathrm{PaCO} 2 \geq 52 \mathrm{mmHg}$ ) (Evidence B).

TABLE 3.10

\section{INTERVENTIONAL THERAPY}

\section{Surgical Interventions}

Lung volume reduction surgery (LVRS). LVRS is a surgical procedure in which parts of the lungs are resected to reduce hyperinflation, $\underline{304}$ making respiratory muscles more effective pressure generators by improving their mechanical efficiency. 305,306 LVRS increases the elastic recoil pressure of the lung and thus improves expiratory flow rátes and reduces exacerbations. 307,308 In an RCT that included severe emphysema patients, with an upper-lobe emphysema and low post-rehabilitation exercise capacity, LVRS resulted in improved survival when compared to medical treatment. 309 In similar patients with high post-pulmonary rehabilitation exercise capacity, no difference in survival was noted after LVRS, although health status and exercise capacity improved. LVRS has been demonstrated to result in higher mortality than medical management in severe emphysema patients with an $\mathrm{FEV}_{1} \leq 20 \%$ predicted and either homogeneous emphysema high resolution computed tomography or a DLCQ of $\leq 20 \%$ of predicted. $\frac{310}{}$ A prospective economic analysis indicated that LVRS is costly relative to healthcare programs that do not include surgery.

Bullectomy. Bullectomy is an older surgical procedure for bullous emphysema. Removal of a large bulla that does not contribute to gas exchange and is, or has been, responsible for complications decompresses the adjacent lung parenchyma. In selected patients with relatively preserved underlying lung, bullectomy is associated with decreased dyspnea, improved lung function and exercise tolerance. $\frac{312}{}$ Pulmonary hypertension, hypercapnia and severe emphysema are not absolute contraindications for bullectomy.

Lung transplantation. In appropriately selected patients with very severe COPD, lung transplantation has been shown to improve health status and functional capacity but not prolong survival. $\frac{312-314}{12}$ Over $70 \%$ of lung transplants conducted in COPD patients are double lung transplants; the remainder are single lung transplants. $\frac{315}{3}$ Bilateral lung transplantation has been reported to provide longer survival than single lung transplantation in COPD patients, especially those $<60$ years 
of age. $\frac{316}{}$ The median survival for lung transplantation in all COPD patients has increased to 5.5 years; it is 7 years in those receiving a bilateral lung transplant and 5 years in those receiving a single lung transplant. $\underline{315}$

Lung transplantation is limited by the shortage of donor organs and cost. The complications most commonly seen in COPD patients after lung transplantation are acute rejection, bronchiolitis obliterans, opportunistic infections and lymphoproliferative disease. $\underline{317}$

\section{Bronchoscopic interventions to reduce hyperinflation in severe emphysema}

Due to the morbidity and mortality associated with LVRS, less invasive bronchoscopic approaches to lung reduction have been examined. $\frac{318}{2}$ These include a variety of different bronchoscopic procedures. $\frac{318}{}$ Although these techniques differ markedly from one another they are similar in their objective to decrease thoracic volume to improve lung, chest wall and respiratory muscle mechanics.

Prospective studies have shown that the use of bronchial stents is not effective. $\frac{319}{A}$ multicenter study examining the effects of a lung sealant to create lung reduction was discontinued prematurely; while the study reported significant benefits in some physiologic parameters, the intervention was associated with significant morbidity and mortality.

A large prospective multicenter RCT of endobronchial valve placement showed statistically significant improvements in $\mathrm{FEV}_{1}$ and 6-minute walk distance compared to control therapy at 6 months post intervention. ${ }^{321}$ However, the magnitude of the observed improvements was not clinically meaningful. Subsequently, efficacy of the same endobronchial valve has been studied in patients with heterogeneous, $\frac{322}{2}$ or heterogeneous and homogenous emphysema ${ }^{323}$ with mixed outcomes. Nonsignificant increases in median $\mathrm{FEV}_{1}$ at three months post valve implantation in one study was attributed to valve placement in somerpatients with interlobar collateral ventilation. 322 Another study showed significant increases in $\mathrm{FEV}_{1}$ and 6-minute walk distance in subjects selected for the absence of interlobar collateral ventilation compared to the control group at 6 months. 223 Adverse effects in the endobronchial valve treatment group in both studies included pneumothorax, valve removal or valve replacement. $\frac{323}{G}$ Greater benefit was shown in patents with heterogeneous compared to those with homogenous emphysema. .233 An RCT of endobronchial valve placement compared with usual care conducted only in homogenous emphysematous patients without interlobar collateral ventilation reported improvements in $\mathrm{FEV}_{1}, 6$-minute walk distance and health status at 6 months with targeted lobe reduction in $97 \%$ of subjects as measured by volumetric $\mathrm{CT}$ (mean reduction $1,195 \mathrm{ml}$ ). $.224 \mathrm{~A}$ recent large multicenter, prospective, RCT of endobronchial valve treatment in patients with heterogeneous emphysema distribution and little to no collateral ventilation, demonstrated significant clinically meaningful benefits over current standard care in lung function, dyspnea, exercise capacity, and quality of life out to at least 12-months post-procedure. $\frac{325}{}$ Consistent with prior studies, $, 24,326$ pneumothorax was seen in $26.6 \%$ of subjects treated with the endobronchial valve usually within the first 72 hours of the procedure (76\%). $\frac{325}{3}$ The occurrence of pneumothorax highlights the need for physicians performing this procedure to have expertise in the management of procedural complications. After the 45 day post-procedural period however, patients treated with the endobronchial valve compared to usual care tended to have a lower number of exacerbations and episodes of respiratory failure. A comparison of treatment benefits and complications associated with 
endobronchial valve placement compared to LVRS demonstrated comparable benefits with endobronchial valve treatment but with fewer complications. Endobronchial valve therapy is now clinically available and approved for treatment in many countries. $\underline{325,327,328}$

In a prospective RCT, targeted thermal vapour ablation of more diseased segments resulted in clinically meaningful and statistically significant improvements in lung function and health status at 6 months. COPD exacerbation was the most common serious adverse event. Durability of these changes was subsequently reported at 12 months follow-up. $2,32,330$ This therapy has limited clinical availability.

Two multicenter trials have examined nitinol coils implanted into the lung compared to usual care on changes in 6-minute walk distance, lung function and health status in patients with advanced homogenous and heterogeneous emphysema. Both studies reported an increase in 6-minute walk distance with coil treatment compared to control and smaller improvements in FEV $\mathrm{V}_{1}$, and quality of life measured by St George's Respiratory Questionnaire. 331,332 Major complications included pneumonia, pneumothorax, hemoptysis and COPD exacerbations occurring more frequently in the coil group. $\frac{332}{2}$ This therapy has limited clinical availability.

Additional data are needed to define the optimal patient population to receive the specific bronchoscopic lung volume technique and to compare the long-term durability of improvements in functional or physiological performance to lung volume reduction surgery relative to side effects. 332

Key points for interventional therapy in stable COPD are summarized in Table 3.11.

\section{INTERVENTIONAL THERAPY IN STABLE COPD}

\section{LUNG VOLUME REDUCTION SURGERY}

- Lung volume reduction surgery improves survival in severe emphysema patients with an upper-lobe emphysema and low post-rehabifitation exercise capacity (Evidence A).

BULLECTOMY

- In selected patients buffectomy is associated with decreased dyspnea, improved lung function and exercise tolerance (Evidence C).

TRANSPLANTATION

- In appropriately selected patients with very severe COPD, lung transplantation has been shown to improve quality of life and functional capacity (Evidence C).

BRONCHOSCOPIC INTERVENTIONS

- In select patients with advanced emphysema, bronchoscopic interventions reduce end-expiratory lung volume and improves exercise tolerance, health status and lung function at 6-12 months following treatment. Endobronchial valves (Evidence B); Lung coils (Evidence B); Vapor ablation (Evidence B). 


\section{REFERENCES}

1. van Eerd EA, van der Meer RM, van Schayck OC, Kotz D. Smoking cessation for people with chronic obstructive pulmonary disease. Cochrane Database Syst Rev 2016; (8): CD010744.

2. Frazer K, Callinan JE, McHugh J, et al. Legislative smoking bans for reducing harms from secondhand smoke exposure, smoking prevalence and tobacco consumption. Cochrane Database Syst Rev 2016; 2: Cd005992.

3. The Tobacco Use and Dependence Clinical Practice Guideline Panel. A clinical practice guideline for treating tobacco use and dependence: A US Public Health Service report. JAMA 2000; 283(24): 324454.

4. van der Meer RM, Wagena EJ, Ostelo RW, Jacobs JE, van Schayck CP. Smoking cessation for chronic obstructive pulmonary disease. Cochrane Database Syst Rev 2003; (2): CD002999.

5. U.S. Public Health Service. A clinical practice guideline for treating tobacco use and dependence: 2008 update. A U.S. Public Health Service report. American journal of preventive medicine 2008; 35(2): 15876.

6. Okuyemi KS, Nollen NL, Ahluwalia JS. Interventions to facilitate smoking cessation. American family physician 2006; 74(2): 262-71.

7. Fiore MC, Bailey WC, Cohen SJ. Smoking Cessation: information for specialists. Rockville, MD; 1996.

8. Lee PN, Fariss MW. A systematic review of possible serious adverse health effects of nicotine replacement therapy. Arch Toxicol 2017; 91(4): 1565-94.

9. McNeill A, Brose LS, Calder R, Hitchman SC. E-cigarettes: an evidence update. A report commissioned by Public Health England.: Public Health England; 2015.

10. McRobbie H, Bullen C, Hartmann-Boyce J, Hajek P. Electronic cigarettes for smoking cessation and reduction. Cochrane Database Syst Rev 2014; 12(12): CD010216.

11. Kalkhoran S, Glantz SA. E-cigarettes and smoking cessation- Authors' reply. The Lancet Respiratory medicine 2016; 4(6): e26-7.

12. Malas M, van der Tempel J, Schwartz R, et al. Electronic Cigarettes for Smoking Cessation: A Systematic Review. Nicotine Tob Res 2016; 18(10): 1926-36.

13. Beard E, West R, Michie S, Brown J. Association between electronic cigarette use and changes in quit attempts, success of quit attempts, use of śmoking cessation pharmacotherapy, and use of stop smoking services in England: time serjes analysis of population trends. Bmj 2016; 354: i4645.

14. Schraufnagel DE, Blasi F, Drummond MB, et al. Electronic cigarettes. A position statement of the forum of international respiratory societies. Am J Respir Crit Care Med 2014; 190(6): 611-8.

15. Reidel B, Radicioni G, Clapp B, et al. E-Cigarette Use Causes a Unique Innate Immune Response in the Lung Involving Increased Neutrophilic Activation and Altered Mucin Secretion. Am J Respir Crit Care Med 2017.

16. Tashkin DP, Rennard S, Hays JT, Ma W, Lawrence D, Lee TC. Effects of varenicline on smoking cessation in patients with mild to moderate COPD: a randomized controlled trial. Chest 2011; 139(3): 591-9.

17. Tashkin D, Kanner R, Bailey W, et al. Smoking cessation in patients with chronic obstructive pulmonary disease: a double-blind, placebo-controlled, randomised trial. Lancet 2001; 357(9268): 1571-5.

18. Cahill K, Stevens S, Perera R, Lancaster T. Pharmacological interventions for smoking cessation: an overview and network meta-analysis. Cochrane Database Syst Rev 2013; 5(5): CD009329.

19. The tobacco use and dependence clinical practice guideline panel s, and consortium representatives, A clinical practice guideline for treating tobacco use and dependence. JAMA 2000; 28: 3244-54.

20. Glynn T, Manley M. How to help your patients stop smoking. A National Cancer Institute manual for physicians. In: U.S. Department of Health and Human Services PHS, National Institutes of Health, National Cancer Institute., editor.; 1990.

21. Stead LF, Buitrago D, Preciado N, Sanchez G, Hartmann-Boyce J, Lancaster T. Physician advice for smoking cessation. Cochrane Database Syst Rev 2013; 5(5): CD000165.

22. Kottke TE, Battista RN, DeFriese GH, Brekke ML. Attributes of successful smoking cessation interventions in medical practice. A meta-analysis of 39 controlled trials. JAMA 1988; 259(19): 2883-9.

23. Katz DA, Muehlenbruch DR, Brown RL, Fiore MC, Baker TB, Group ASCGS. Effectiveness of implementing the agency for healthcare research and quality smoking cessation clinical practice guideline: a randomized, controlled trial. J Natl Cancer Inst 2004; 96(8): 594-603. 
24. Halpern SD, French B, Small DS, et al. Randomized trial of four financial-incentive programs for smoking cessation. N Engl J Med 2015; 372(22): 2108-17.

25. Stead LF, Koilpillai P, Fanshawe TR, Lancaster T. Combined pharmacotherapy and behavioural interventions for smoking cessation. Cochrane Database Syst Rev 2016; 3: CD008286.

26. Wongsurakiat P, Maranetra KN, Wasi C, Kositanont U, Dejsomritrutai W, Charoenratanakul S. Acute respiratory illness in patients with COPD and the effectiveness of influenza vaccination: a randomized controlled study. Chest 2004; 125(6): 2011-20.

27. Poole PJ, Chacko E, Wood-Baker RW, Cates CJ. Influenza vaccine for patients with chronic obstructive pulmonary disease. Cochrane Database Syst Rev 2006; (1): CD002733.

28. Wongsurakiat P, Lertakyamanee J, Maranetra KN, Jongriratanakul S, Sangkaew S. Economic evaluation of influenza vaccination in Thai chronic obstructive pulmonary disease patients. $J$ Med Assoc Thai 2003; 86(6): 497-508.

29. Nichol KL, Margolis KL, Wuorenma J, Von Sternberg T. The efficacy and cost effectiveness of vaccination against influenza among elderly persons living in the community. N Engl J Med 1994; 331(12): 778-84.

30. Fiore AE, Shay DK, Broder K, et al. Prevention and control of seasonal influenza with vaccines: recommendations of the Advisory Committee on Immunization Practices (ACIP), 2009. MMWR Recomm Rep 2009; 58(RR-8): 1-52.

31. Edwards KM, Dupont WD, Westrich MK, Plummer WD, Jr., Palmer PS, Wright PF. A randomized controlled trial of cold-adapted and inactivated vaccines for the prevention of influenza A disease. $J$ Infect Dis 1994; 169(1): 68-76.

32. Hak E, van Essen GA, Buskens E, Stalman W, de Melker RA. Is immunising all patients with chronic lung disease in the community against influenza cost effective? Evidence from a general practice based clinical prospective cohort study in Utrecht, The Netherlands. J Epidemiol Community Health 1998; 52(2): 120-5.

33. Huang CL, Nguyen PA, Kuo PL, Iqbal U, Hsu YH, Jian WS. Influenza vaccination and reduction in risk of ischemic heart disease among chronic obstructive pulmonary elderly. Comput Methods Programs Biomed 2013; 111(2): 507-11.

34. Tomczyk S, Bennett NM, Stoecker C, et al. Use of 13-valent pneumococcal conjugate vaccine and 23valent pneumococcal polysaccharide vaccine among adults aged $>/=65$ years: recommendations of the Advisory Committee on Immunization Practices (ACIP). MMWR Morb Mortal Wkly Rep 2014; 63(37): 822-5.

35. Walters JA, Smith S, Poole P, Granger RH, Wood-Baker R. Injectable vaccines for preventing pneumococcal infection in patients with chronic obstructive pulmonary disease. Cochrane Database Syst Rev 2010; (11): CD001390.

36. Walters JA, Tang JN, Poofe P, Wood-Baker R. Pneumococcal vaccines for preventing pneumonia in chronic obstructive palmonary disease. Cochrane Database Syst Rev 2017; 1: Cd001390.

37. Alfageme I, Vazquez $\mathrm{R}$, Reyes $\mathrm{N}$, et al. Clinical efficacy of anti-pneumococcal vaccination in patients with COPD. Thorax 2006; 61(3): 189-95.

38. Dransfield MT, Harnden S, Burton RL, et al. Long-term comparative immunogenicity of protein conjugate and free polysaccharide pneumococcal vaccines in chronic obstructive pulmonary disease. Clin Infect Dis 2012; 55(5): e35-44.

39. Bonten MJ, Huijts SM, Bolkenbaas M, et al. Polysaccharide conjugate vaccine against pneumococcal pneumonia in adults. N Engl J Med 2015; 372(12): 1114-25.

40. Burge PS, Calverley PM, Jones PW, Spencer S, Anderson JA, Maslen TK. Randomised, double blind, placebo controlled study of fluticasone propionate in patients with moderate to severe chronic obstructive pulmonary disease: the ISOLDE trial. BMJ 2000; 320(7245): 1297-303.

41. Anthonisen NR, Connett JE, Kiley JP, et al. Effects of smoking intervention and the use of an inhaled anticholinergic bronchodilator on the rate of decline of FEV1. The Lung Health Study. JAMA 1994; 272(19): 1497-505.

42. Pauwels RA, LofdahI CG, Laitinen LA, et al. Long-term treatment with inhaled budesonide in persons with mild chronic obstructive pulmonary disease who continue smoking. European Respiratory Society Study on Chronic Obstructive Pulmonary Disease. N Engl J Med 1999; 340(25): 1948-53.

43. Vestbo J, Sorensen $T$, Lange $P$, Brix A, Torre P, Viskum K. Long-term effect of inhaled budesonide in mild and moderate chronic obstructive pulmonary disease: a randomised controlled trial. Lancet 1999; 353(9167): 1819-23. 
44. Tashkin DP, Celli B, Senn S, et al. A 4-year trial of tiotropium in chronic obstructive pulmonary disease. N Engl J Med 2008; 359(15): 1543-54.

45. Decramer M, Celli B, Kesten S, et al. Effect of tiotropium on outcomes in patients with moderate chronic obstructive pulmonary disease (UPLIFT): a prespecified subgroup analysis of a randomised controlled trial. Lancet 2009; 374(9696): 1171-8.

46. Celli BR, Thomas NE, Anderson JA, et al. Effect of pharmacotherapy on rate of decline of lung function in chronic obstructive pulmonary disease: results from the TORCH study. Am J Respir Crit Care Med 2008; 178(4): 332-8.

47. O'Donnell DE, Fluge $T$, Gerken F, et al. Effects of tiotropium on lung hyperinflation, dyspnea and exercise tolerance in COPD. Eur Respir J 2004; 23(6): 832-40.

48. O'Donnell DE, Sciurba F, Celli B, et al. Effect of fluticasone propionate/salmeterol on lung hyperinflation and exercise endurance in COPD. Chest 2006; 130(3): 647-56.

49. Berger R, Smith D. Effect of inhaled metaproterenol on exercise performance in patients with stable "fixed" airway obstruction. Am Rev Respir Dis 1988; 138(3): 624-9.

50. Hay JG, Stone P, Carter J, et al. Bronchodilator reversibility, exercise performance and breathlessness in stable chronic obstructive pulmonary disease. Eur Respir J 1992; 5(6): 659-64.

51. Chrystyn H, Mulley BA, Peake MD. Dose response relation to oral theophylline in severe chronic obstructive airways disease. BMJ 1988; 297(6662): 1506-10.

52. Gross NJ, Petty TL, Friedman M, Skorodin MS, Silvers GW, Donohue JF. Doseresponse to ipratropium as a nebulized solution in patients with chronic obstructive pulmonary disease. A three-center study. Am Rev Respir Dis 1989; 139(5): 1188-91.

53. Higgins BG, Powell RM, Cooper S, Tattersfield AE. Effect of salbutamol and ipratropium bromide on airway calibre and bronchial reactivity in asthma and chronic bronchitis. Eur Respir J 1991; 4(4): 41520.

54. Vathenen AS, Britton JR, Ebden P, Cookson JB, Wharrad HS,Tattersfield AE. High-dose inhaled albuterol in severe chronic airflow limitation. Am Rev Respir Dis 1988; 138(4): 850-5.

55. Donohue JF, Anzueto A, Brooks J, Mehta R, Kalberg C, Crater G. A randomized, double-blind doseranging study of the novel LAMA GSK573719 in patients with COPD. Respir Med 2012; 106(7): 970-9.

56. Donohue JF, Kalberg C, Shah P, et al. Dose response of umeclidinium administered once or twice daily in patients with COPD: a pooled analysis of two randomized, double-blind, placebo-controlled studies. J Clin Pharmacol 2014; 54(11): 1214-20.P

57. Chowdhury BA, Seymour SM, MicheleTM, Durmowicz AG, Liu D, Rosebraugh CJ. The risks and benefits of indacaterol--the FDA's review. N Engl J Med 2011; 365(24): 2247-9.

58. O'Driscoll BR, Kay EA, Taylor RJ, Weatherby H, Chetty MC, Bernstein A. A long-term prospective assessment of home nebulizer treatment. Respir Med 1992; 86(4): 317-25.

59. Jenkins SC, Heaton RW, Fulton TJ, Moxham J. Comparison of domiciliary nebulized salbutamol and salbutamol from a metered-dose inhaler in stable chronic airflow limitation. Chest 1987; 91(6): 804-7.

60. Sestini P, Renzoni E, Robinson S, Poole P, Ram FS. Short-acting beta 2 agonists for stable chronic obstructive pulmonary disease. Cochrane Database Syst Rev 2002; (4): CD001495.

61. Datta D, VitaleA, Lahiri B, ZuWallack R. An evaluation of nebulized levalbuterol in stable COPD. Chest 2003; 124(3): 844-9.

62. Cazzola M, Rogliani P, Ruggeri $P$, et al. Chronic treatment with indacaterol and airway response to salbutamol in stable COPD. Respir Med 2013; 107(6): 848-53.

63. Kew KM, Mavergames C, Walters JA. Long-acting beta2-agonists for chronic obstructive pulmonary disease. Cochrane Database Syst Rev 2013; 10(10): CD010177.

64. Han J, Dai L, Zhong N. Indacaterol on dyspnea in chronic obstructive pulmonary disease: a systematic review and meta-analysis of randomized placebo-controlled trials. BMC Pulm Med 2013; 13: 26.

65. Geake JB, Dabscheck EJ, Wood-Baker R, Cates CJ. Indacaterol, a once-daily beta2-agonist, versus twice-daily beta(2)-agonists or placebo for chronic obstructive pulmonary disease. Cochrane Database Syst Rev 2015; 1: CD010139.

66. Koch A, Pizzichini E, Hamilton A, et al. Lung function efficacy and symptomatic benefit of olodaterol once daily delivered via Respimat(R) versus placebo and formoterol twice daily in patients with GOLD 2-4 COPD: results from two replicate 48-week studies. Int J Chron Obstruct Pulmon Dis 2014; 9: 697714.

67. Kempsford R, Norris V, Siederer S. Vilanterol trifenatate, a novel inhaled long-acting beta2 adrenoceptor agonist, is well tolerated in healthy subjects and demonstrates prolonged bronchodilation in subjects with asthma and COPD. Pulm Pharmacol Ther 2013; 26(2): 256-64. 
68. Lipworth BJ, McDevitt DG, Struthers AD. Hypokalemic and ECG sequelae of combined betaagonist/diuretic therapy. Protection by conventional doses of spironolactone but not triamterene. Chest 1990; 98(4): 811-5.

69. Uren NG, Davies SW, Jordan SL, Lipkin DP. Inhaled bronchodilators increase maximum oxygen consumption in chronic left ventricular failure. Eur Heart J 1993; 14(6): 744-50.

70. Khoukaz G, Gross NJ. Effects of salmeterol on arterial blood gases in patients with stable chronic obstructive pulmonary disease. Comparison with albuterol and ipratropium. Am J Respir Crit Care Med 1999; 160(3): 1028-30.

71. McGarvey L, Niewoehner D, Magder S, et al. One-Year Safety of Olodaterol Once Daily via Respimat(R) in Patients with GOLD 2-4 Chronic Obstructive Pulmonary Disease: Results of a Pre-Specified Pooled Analysis. COPD 2015; 12(5): 484-93.

72. Dahl R, Chung KF, Buhl R, et al. Efficacy of a new once-daily long-acting inhaled beta2-agonist indacaterol versus twice-daily formoterol in COPD. Thorax 2010; 65(6): 473-9.

73. Melani AS. Long-acting muscarinic antagonists. Expert Rev Clin Pharmacol 2015; 8(4): 479-501.

74. Barnes P. Bronchodilators: basic pharmacology. In: Calverley PMA, Pride NB, eds. Chronic obstructive pulmonary disease. London: Chapman and Hall; 1995: 391-417.

75. Appleton $\mathrm{S}$, Jones $\mathrm{T}$, Poole $\mathrm{P}$, et al. Ipratropium bromide versus long-acting beta-2 agonists for stable chronic obstructive pulmonary disease. Cochrane Database Syst Rev 2006; (3):Cd006101.

76. Jones PW, Singh D, Bateman ED, et al. Efficacy and safety of twice-daily aclidinium bromide in COPD patients: the ATTAIN study. Eur Respir J 2012; 40(4): 830-6.

77. Karner C, Chong J, Poole P. Tiotropium versus placebo for chronic obstructive pulmonary disease. Cochrane Database Syst Rev 2014; 7(7): CD009285.

78. Kesten S, Casaburi R, Kukafka D, Cooper CB. Improvement in self-reported exercise participation with the combination of tiotropium and rehabilitative exercise training in COPD patients. Int J Chron Obstruct Pulmon Dis 2008; 3(1): 127-36.

79. Casaburi R, Kukafka D, Cooper CB, Witek TJ, Jr., Kesten S. Improvement in exercise tolerance with the combination of tiotropium and pulmonary rehabilitation in patients with COPD. Chest $2005 ; 127(3)$ : 809-17.

80. Vogelmeier C, Hederer B, Glaab T, et al. Tiotropium versus salmeterol for the prevention of exacerbations of COPD. N Engl J Med 2011;364(12): 1093-103.

81. Decramer ML, Chapman KR, Dahl R, et at. Once-daily indacaterol versus tiotropium for patients with severe chronic obstructive pulmonarydisease (INVIGORATE): a randomised, blinded, parallel-group study. The Lancet Respiratory medicine 2013; 1(7): 524-33.

82. Zhou Y, Zhong NS, Li X, et al. Tiotropium in Early-Stage Chronic Obstructive Pulmonary Disease. N Engl J Med 2017; 377(10): 923-35.

83. Tashkin DP. Long-acting antícholinergic use in chronic obstructive pulmonary disease: efficacy and safety. Curr Opin PulmMed 2010; 16(2): 97-105.

84. Disse B, Speck GA,Rominger KL, Witek TJ, Jr., Hammer R. Tiotropium (Spiriva): mechanistical considerations and clinical profile in obstructive lung disease. Life Sci 1999; 64(6-7): 457-64.

85. Kesten S, Jara M, Wentworth C, Lanes S. Pooled clinical trial analysis of tiotropium safety. Chest 2006; 130(6): 1695-703.

86. Anthonisen NR, Connett JE, Enright PL, Manfreda J, Lung Health Study Research G. Hospitalizations and mortality in the Lung Health Study. Am J Respir Crit Care Med 2002; 166(3): 333-9.

87. Michele TM, Pinheiro S, Iyasu S. The safety of tiotropium--the FDA's conclusions. N Engl J Med 2010; 363(12): 1097-9.

88. Verhamme KM, Afonso A, Romio S, Stricker BC, Brusselle GG, Sturkenboom MC. Use of tiotropium Respimat Soft Mist Inhaler versus HandiHaler and mortality in patients with COPD. Eur Respir J 2013; 42(3): 606-15.

89. Wise RA, Anzueto A, Cotton D, et al. Tiotropium Respimat inhaler and the risk of death in COPD. $N$ Engl J Med 2013; 369(16): 1491-501.

90. Packe GE, Cayton RM, Mashhoudi N. Nebulised ipratropium bromide and salbutamol causing closedangle glaucoma. Lancet 1984; 2(8404): 691.

91. Mulpeter KM, Walsh JB, O'Connor M, O'Connell F, Burke C. Ocular hazards of nebulized bronchodilators. Postgrad Med J 1992; 68(796): 132-3.

92. Hall SK. Acute angle-closure glaucoma as a complication of combined beta-agonist and ipratropium bromide therapy in the emergency department. Ann Emerg Med 1994; 23(4): 884-7.

93. Aubier M. Pharmacotherapy of respiratory muscles. Clin Chest Med 1988; 9(2): 311-24. 
94. McKay SE, Howie CA, Thomson AH, Whiting B, Addis GJ. Value of theophylline treatment in patients handicapped by chronic obstructive lung disease. Thorax 1993; 48(3): 227-32.

95. Moxham J. Aminophylline and the respiratory muscles: an alternative view. Clin Chest Med 1988; 9(2): 325-36.

96. Ram FS, Jones PW, Castro AA, et al. Oral theophylline for chronic obstructive pulmonary disease. Cochrane Database Syst Rev 2002; (4): CD003902.

97. ZuWallack RL, Mahler DA, Reilly D, et al. Salmeterol plus theophylline combination therapy in the treatment of COPD. Chest 2001; 119(6): 1661-70.

98. Zacarias EC, Castro AA, Cendon S. Effect of theophylline associated with short-acting or long-acting inhaled beta2-agonists in patients with stable chronic obstructive pulmonary disease: a systematic review. J Bras Pneumol 2007; 33(2): 152-60.

99. Cosio BG, Shafiek H, Iglesias A, et al. Oral Low-dose Theophylline on Top of Inhaled FluticasoneSalmeterol Does Not Reduce Exacerbations in Patients With Severe COPD: A Pilot Clinical Trial. Chest 2016; 150(1): 123-30.

100. Zhou $Y$, Wang $X$, Zeng $X$, et al. Positive benefits of theophylline in a randomized, double-blind, parallel-group, placebo-controlled study of low-dose, slow-release theophylline in the treatment of COPD for 1 year. Respirology 2006; 11(5): 603-10.

101. Cazzola M, Molimard M. The scientific rationale for combining long-acting beta2-agonists and muscarinic antagonists in COPD. Pulm Pharmacol Ther 2010; 23(4): 257-67.

102. Gross N, Tashkin D, Miller R, Oren J, Coleman W, Linberg S. Inhalation by Aebulization of albuterolipratropium combination (Dey combination) is superior to either agentalone in the treatment of chronic obstructive pulmonary disease. Dey Combination Solution Study Group. Respiration 1998; 65(5): 354-62.

103. Tashkin DP, Pearle J, lezzoni D, Varghese ST. Formoterol and tiotropium compared with tiotropium alone for treatment of COPD. COPD 2009; 6(1): 17-25.

104. Farne HA, Cates CJ. Long-acting beta2-agonist in additi6n to tiotropium versus either tiotropium or long-acting beta2-agonist alone for chronic obstructive pulmonary disease. Cochrane Database Syst Rev 2015; 10(10): CD008989.

105. van der Molen T, Cazzola M. Beyond lung function in COPD management: effectiveness of LABA/LAMA combination therapy on patient-centred outcomes. Prim Care Respir J 2012; 21(1): 101-8.

106. Mahler DA, Decramer M, D'Urzo A, et al Dual bronchodilation with QVA149 reduces patient-reported dyspnea in COPD: the BLAZE study. Eur Respir J 2014; 43(6): 1599-609.

107. Singh D, Ferguson GT, Bolitschek J, et al. Tiotropium + olodaterol shows clinically meaningful improvements in quality of life. Respir Med 2015; 109(10): 1312-9.

108. Bateman ED, Chapman KR, Singh D, et al. Aclidinium bromide and formoterol fumarate as a fixed-dose combination in COPD: pooled analysis of symptoms and exacerbations from two six-month, multicentre, randomised studies (ACLIFORM and AUGMENT). Respir Res 2015; 16: 92.

109. Martinez FJ, FabbriLM, Ferguson GT, et al. Baseline Symptom Score Impact on Benefits of Glycopyrrolate/Formoterol Metered Dose Inhaler in COPD. Chest 2017.

110. Mahler DA, Kerwin E, Ayers T, et al. FLIGHT1 and FLIGHT2: Efficacy and Safety of QVA149 (Indacaterol/Glycopyrrolate) versus Its Monocomponents and Placebo in Patients with Chronic Obstructive Pulmonary Disease. Am J Respir Crit Care Med 2015; 192(9): 1068-79.

111. Bai C, Ichinose $\mathrm{M}$, Lee $\mathrm{SH}$, et al. Lung function and long-term safety of tiotropium/olodaterol in East Asian patients with chronic obstructive pulmonary disease. Int J Chron Obstruct Pulmon Dis 2017; 12: 3329-39.

112. Wedzicha JA, Decramer M, Ficker JH, et al. Analysis of chronic obstructive pulmonary disease exacerbations with the dual bronchodilator QVA149 compared with glycopyrronium and tiotropium (SPARK): a randomised, double-blind, parallel-group study. The Lancet Respiratory medicine 2013; 1(3): 199-209.

113. Calverley PMA, Anzueto AR, Carter K, et al. Tiotropium and olodaterol in the prevention of chronic obstructive pulmonary disease exacerbations (DYNAGITO): a double-blind, randomised, parallelgroup, active-controlled trial. The Lancet Respiratory medicine 2018; 6(5): 337-44.

114. Wedzicha JA, Banerji D, Chapman KR, et al. Indacaterol-Glycopyrronium versus Salmeterol-Fluticasone for COPD. N Engl J Med 2016; 374(23): 2222-34.

115. Lipson DA, Barnhart F, Brealey N, et al. Once-Daily Single-Inhaler Triple versus Dual Therapy in Patients with COPD. N Engl J Med 2018; 378(18): 1671-80. 
116. Barnes PJ. New anti-inflammatory targets for chronic obstructive pulmonary disease. Nature reviews Drug discovery 2013; 12(7): 543-59.

117. Boardman C, Chachi L, Gavrila A, et al. Mechanisms of glucocorticoid action and insensitivity in airways disease. Pulm Pharmacol Ther 2014; 29(2): 129-43.

118. Yang IA, Clarke MS, Sim EH, Fong KM. Inhaled corticosteroids for stable chronic obstructive pulmonary disease. Cochrane Database Syst Rev 2012; 7(7): CD002991.

119. Calverley PM, Anderson JA, Celli B, et al. Salmeterol and fluticasone propionate and survival in chronic obstructive pulmonary disease. N Engl J Med 2007; 356(8): 775-89.

120. Vestbo J, Anderson JA, Brook RD, et al. Fluticasone furoate and vilanterol and survival in chronic obstructive pulmonary disease with heightened cardiovascular risk (SUMMIT): a double-blind randomised controlled trial. Lancet 2016; 387(10030): 1817-26.

121. Calverley PMA, Anderson JA, Brook RD, et al. Fluticasone Furoate, Vilanterol, and Lung Function Decline in Patients with Moderate Chronic Obstructive Pulmonary Disease and Heightened Cardiovascular Risk. Am J Respir Crit Care Med 2018; 197(1): 47-55.

122. Nannini U, Lasserson TJ, Poole P. Combined corticosteroid and long-acting beta(2)-agonist in one inhaler versus long-acting beta(2)-agonists for chronic obstructive pulmonary disease. Cochrane Database Syst Rev 2012; 9(9): CD006829.

123. Nannini U, Poole P, Milan SJ, Kesterton A. Combined corticosteroid and long-acting beta(2)-agonist in one inhaler versus inhaled corticosteroids alone for chronic obstructive pulmonary disease. Cochrane Database Syst Rev 2013; 8(8): CD006826.

124. Vestbo J, Leather D, Diar Bakerly N, et al. Effectiveness of FluticasoneGuroate-Vilanterol for COPD in Clinical Practice. N Engl J Med 2016; 375(13): 1253-60.

125. Bafadhel M, Peterson S, De Blas MA, et al. Predictors of exacerbation risk and response to budesonide in patients with chronic obstructive pulmonary disease: a post-hoc analysis of three randomised trials. The Lancet Respiratory medicine 2018; 6(2): 117-26.

126. Siddiqui SH, Guasconi A, Vestbo J, et al. Blood Eosinophils: A Biomarker of Response to Extrafine Beclomethasone/Formoterol in Chronic Obstructive Pulmonary Disease. Am J Respir Crit Care Med 2015; 192(4): 523-5.

127. Papi A, Vestbo J, Fabbri L, et al. Extrafine inhaled triple therapy versus dual bronchodilator therapy in chronic obstructive pulmonary disease (TRIBUTE): a double-blind, parallel group, randomised controlled trial. Lancet 2018; 391(10125): 1076-84.

128. Pascoe S, Locantore N, Dransfield MT,Barnes NC, Pavord ID. Blood eosinophil counts, exacerbations, and response to the addition of inhaled fluticasone furoate to vilanterol in patients with chronic obstructive pulmonary disease: a secondary analysis of data from two parallel randomised controlled trials. The Lancet Respiratory medicine 2015; 3(6): 435-42.

129. Vestbo J, Papi A, Corradi M, et al. Single inhaler extrafine triple therapy versus long-acting muscarinic antagonist therapy forchronic obstructive pulmonary disea se (TRINITY): a double-blind, parallel group, randomised controlled trial. Lancet 2017; 389(10082): 1919-29.

130. Roche N, Chapman KR, Vogelmeier CF, et al. Blood Eosinophils and Response to Maintenance Chronic Obstructive Pulmonary Disease Treatment. Data from the FLAME Trial. Am J Respir Crit Care Med 2017; 195(9): 1189-97.

131. Watz H, Tetzlaff $\mathrm{K}$, Wouters EF, et al. Blood eosinophil count and exacerbations in severe chronic obstructive pulmonary disease after withdrawal of inhaled corticosteroids: a post-hoc analysis of the WISDOM trial. The Lancet Respiratory medicine 2016; 4(5): 390-8.

132. Calverley PMA, Tetzlaff K, Vogelmeier C, et al. Eosinophilia, Frequent Exacerbations, and Steroid Response in Chronic Obstructive Pulmonary Disease. Am J Respir Crit Care Med 2017; 196(9): 1219-21.

133. Chapman KR, Hurst JR, Frent SM, et al. Long-term Triple Therapy De-escalation to Indacaterol/Glycopyrronium in COPD Patients (SUNSET): a Randomized, Double-Blind, Triple-Dummy Clinical Trial. Am J Respir Crit Care Med 2018.

134. Landis SH, Suruki R, Hilton E, Compton C, Galwey NW. Stability of Blood Eosinophil Count in Patients with COPD in the UK Clinical Practice Research Datalink. Copd 2017; 14(4): 382-8.

135. Oshagbemi OA, Burden AM, Braeken DCW, et al. Stability of Blood Eosinophils in Patients with Chronic Obstructive Pulmonary Disease and in Control Subjects, and the Impact of Sex, Age, Smoking, and Baseline Counts. Am J Respir Crit Care Med 2017; 195(10): 1402-4.

136. Southworth T, Beech G, Foden P, Kolsum U, Singh D. The reproducibility of COPD blood eosinophil counts. Eur Respir J 2018; 52(1). 
137. Casanova C, Celli BR, de-Torres JP, et al. Prevalence of persistent blood eosinophilia: relation to outcomes in patients with COPD. Eur Respir J 2017; 50(5).

138. Vedel-Krogh S, Nielsen SF, Lange P, Vestbo J, Nordestgaard BG. Blood Eosinophils and Exacerbations in Chronic Obstructive Pulmonary Disease. The Copenhagen General Population Study. Am J Respir Crit Care Med 2016; 193(9): 965-74.

139. Yun JH, Lamb A, Chase R, et al. Blood eosinophil count thresholds and exacerbations in patients with chronic obstructive pulmonary disease. J Allergy Clin Immunol 2018; 141(6): 2037-47.e10.

140. Dransfield MT, Bourbeau J, Jones PW, et al. Once-daily inhaled fluticasone furoate and vilanterol versus vilanterol only for prevention of exacerbations of COPD: two replicate double-blind, parallelgroup, randomised controlled trials. The Lancet Respiratory medicine 2013; 1(3): 210-23.

141. Crim C, Dransfield MT, Bourbeau J, et al. Pneumonia risk with inhaled fluticasone furoate and vilanterol compared with vilanterol alone in patients with COPD. Annals of the American Thoracic Society 2015; 12(1): 27-34.

142. Crim C, Calverley PMA, Anderson JA, et al. Pneumonia risk with inhaled fluticasone furoate and vilanterol in COPD patients with moderate airflow limitation: The SUMMIT trial. Respir Med 2017; 131: 27-34.

143. Pavord ID, Lettis S, Anzueto A, Barnes N. Blood eosinophil count and pneumonia risk in patients with chronic obstructive pulmonary disease: a patient-level meta-analysis. The Lancet Respiratory medicine 2016; 4(9): 731-41.

144. Johnell O, Pauwels R, LofdahI CG, et al. Bone mineral density in patients, with chronic obstructive pulmonary disease treated with budesonide Turbuhaler. Eur Respir J 2002; 19(6): 1058-63.

145. Ferguson GT, Calverley PM, Anderson JA, et al. Prevalence and progression of osteoporosis in patients with COPD: results from the TOwards a Revolution in COPD Health study. Chest 2009; 136(6): 145665.

146. Loke YK, Cavallazzi R, Singh S. Risk of fractures with inhaled corticosteroids in COPD: systematic review and meta-analysis of randomised controlled trials and observational studies. Thorax 2011; 66(8): 699-708.

147. Suissa S, Kezouh A, Ernst P. Inhaled corticosteroids and the risks of diabetes onset and progression. Am J Med 2010; 123(11): 1001-6.

148. Wang JJ, Rochtchina E, Tan AG, Cumming RG, Leeder SR, Mitchell P. Use of inhaled and oral corticosteroids and the long-term risk of cataract. Ophthalmology 2009; 116(4): 652-7.

149. Andrejak C, Nielsen R, Thomsen VO, Ouhaut P, Sorensen HT, Thomsen RW. Chronic respiratory disease, inhaled corticosteroids and risk of non-tuberculous mycobacteriosis. Thorax 2013; 68(3): 25662.

150. Dong $\mathrm{YH}$, Chang $\mathrm{CH}$, Lin Wu FL, et al. Use of inhaled corticosteroids in patients with COPD and the risk of TB and influenza: A systematic review and meta-analysis of randomized controlled trials. Chest 2014; 145(6): 1286-97.

151. Lee $\mathrm{CH}$, Kim K, Hyun MK, Jang EJ, Lee NR, Yim JJ. Use of inhaled corticosteroids and the risk of tuberculosis. Thorax 2013; 68(12): 1105-13.

152. Price D, YawnB, Brusselle G, Rossi A. Risk-to-benefit ratio of inhaled corticosteroids in patients with COPD. Prim Care Respir J 2013; 22(1): 92-100.

153. Nadeem NJ, Taylor SJ, Eldridge SM. Withdrawal of inhaled corticosteroids in individuals with COPD--a systematic review and comment on trial methodology. Respir Res 2011; 12: 107.

154. van der Valk P, Monninkhof E, van der Palen J, Zielhuis G, van Herwaarden C. Effect of discontinuation of inhaled corticosteroids in patients with chronic obstructive pulmonary disease: the COPE study. Am J Respir Crit Care Med 2002; 166(10): 1358-63.

155. Wouters EF, Postma DS, Fokkens B, et al. Withdrawal of fluticasone propionate from combined salmeterol/fluticasone treatment in patients with COPD causes immediate and sustained disea se deterioration: a randomised controlled trial. Thorax 2005; 60(6): 480-7.

156. Kunz LI, Postma DS, Klooster K, et al. Relapse in FEV1 Decline After Steroid Withdrawal in COPD. Chest 2015; 148(2): 389-96.

157. Magnussen H, Disse B, Rodriguez-Roisin R, et al. Withdrawal of inhaled glucocorticoids and exacerbations of COPD. N Engl J Med 2014; 371(14): 1285-94.

158. Brusselle G, Price D, Gruffydd-Jones K, et al. The inevitable drift to triple therapy in COPD: an analysis of prescribing pathways in the UK. Int J Chron Obstruct Pulmon Dis 2015; 10: 2207-17. 
159. Welte T, Miravitlles M, Hernandez P, et al. Efficacy and tolerability of budesonide/formoterol added to tiotropium in patients with chronic obstructive pulmonary disease. Am J Respir Crit Care Med 2009; 180(8): 741-50.

160. Singh D, Brooks J, Hagan G, Cahn A, O'Connor BJ. Superiority of "triple" therapy with salmeterol/fluticasone propionate and tiotropium bromide versus individual components in moderate to severe COPD. Thorax 2008; 63(7): 592-8.

161. Jung KS, Park HY, Park SY, et al. Comparison of tiotropium plus fluticasone propionate/salmeterol with tiotropium in COPD: a randomized controlled study. Respir Med 2012; 106(3): 382-9.

162. Hanania NA, Crater GD, Morris AN, Emmett AH, O'Dell DM, Niewoehner DE. Benefits of adding fluticasone propionate/salmeterol to tiotropium in moderate to severe COPD. Respir Med 2012; 106(1): 91-101.

163. Frith PA, Thompson PJ, Ratnavadivel R, et al. Glycopyrronium once-daily significantly improves lung function and health status when combined with salmeterol/fluticasone in patients with COPD: the GLISTEN study, a randomised controlled trial. Thorax 2015; 70(6): 519-27.

164. Siler TM, Kerwin E, Singletary K, Brooks J, Church A. Efficacy and Safety of Umeclidinium Added to Fluticasone Propionate/Salmeterol in Patients with COPD: Results of Two Randomized, Double-Blind Studies. COPD 2016; 13(1): 1-10.

165. Singh D, Papi A, Corradi M, et al. Single inhaler triple therapy versus inhaled corticosteroid plus longacting beta2-agonist therapy for chronic obstructive pulmonary disease (TRHLGY): a double-blind, parallel group, randomised controlled trial. Lancet 2016; 388(10048): 963273.

166. Lipson DA, Barnacle H, Birk R, et al. FULFIL Trial: Once-Daily Triple Therapy for Patients with Chronic Obstructive Pulmonary Disease. Am J Respir Crit Care Med 2017; 196(4): 438-46.

167. Manson SC, Brown RE, Cerulli A, Vidaurre CF. The cumulative burden of oral corticosteroid side effects and the economic implications of steroid use. Respir Med 2009; 103(7): 975-94.

168. Walters JA, Tan DJ, White CJ, Gibson PG, Wood-Baker R, Walters EH. Systemic corticosteroids for acute exacerbations of chronic obstructive pulmonary disease. Cochrane Database Syst Rev 2014; (9): CD001288.

169. Renkema TE, Schouten JP, Koeter GH, Postma DS, Effects of long-term treatment with corticosteroids in COPD. Chest 1996; 109(5): 1156-62.

170. Rice KL, Rubins JB, Lebahn F, et al. Withdrawal of chronic systemic corticosteroids in patients with COPD: a randomized trial. Am J Respir Crit Care Med 2000; 162(1): 174-8.

171. Rabe KF. Update on roflumilast, a phosphodiesterase 4 inhibitor for the treatment of chronic obstructive pulmonary disease. Br X Pharmacol 2011; 163(1): 53-67.

172. Calverley PM, Rabe KF, Goehring UM, et al. Roflumilast in symptomatic chronic obstructive pulmonary disease: two randomised clinical trials. Lancet 2009; 374(9691): 685-94.

173. Fabbri LM, Calverley PM, (zquierdo-Alonso JL, et al. Roflumilast in moderate-to-severe chronic obstructive pulmonary disease treated with longacting bronchodilators: two randomised clinical trials. Lancet 2009; 374(9691): 695-703.

174. Martinez FJ, Catverley PM, Goehring UM, Brose M, Fabbri LM, Rabe KF. Effect of roflumilast on exacerbations in patients with severe chronic obstructive pulmonary disease uncontrolled by combination therapy (REACT): a multicentre randomised controlled trial. Lancet 2015; 385(9971): 857-66.

175. Rabe KF, Calverley PMA, Martinez FJ, Fabbri LM. Effect of roflumilast in patients with severe COPD and a history of hospitalisation. Eur Respir J 2017; 50(1).

176. Han MK, Tayob N, Murray S, et al. Predictors of chronic obstructive pulmonary disease exacerbation reduction in response to daily azithromycin therapy. Am J Respir Crit Care Med 2014; 189(12): 1503-8.

177. Chong J, Leung B, Poole P. Phosphodiesterase 4 inhibitors for chronic obstructive pulmonary disease. Cochrane Database Syst Rev 2013; 11(11): CD002309.

178. Francis RS, May JR, Spicer CC. Chemotherapy of bronchitis. Influence of penicillin and tetracycline administered daily, or intermittently for exacerbations. A report to the Research Committee of the British Tuberculosis Association by its Bronchitis Subcommittee. Br Med J 1961; 2(5258): 979-85.

179. Francis RS, Spicer CC. Chemotherapy in chronic bronchitis. Influence of daily penicillin and tetracycline on exacerbations and their cost. Br Med J 1960; 1(5169): 297-303.

180. Johnston RN, McNeill RS, Smith DH, et al. Five-year winter chemoprophylaxis for chronic bronchitis. BMJ 1969; 4(678): 265-9.

181. Herath SC, Poole P. Prophylactic antibiotic therapy for chronic obstructive pulmonary disease (COPD). Cochrane Database Syst Rev 2013; (11): CD009764. 
182. Ni W, Shao X, Cai X, et al. Prophylactic use of macrolide antibiotics for the prevention of chronic obstructive pulmonary disease exacerbation: a meta-analysis. PloS one 2015; 10(3): e0121257.

183. Seemungal TA, Wilkinson TM, Hurst JR, Perera WR, Sapsford RJ, Wedzicha JA. Long-term erythromycin therapy is associated with decreased chronic obstructive pulmonary disease exacerbations. Am J Respir Crit Care Med 2008; 178(11): 1139-47.

184. Uzun S, Djamin RS, Kluytmans JA, et al. Azithromycin maintenance treatment in patients with frequent exacerbations of chronic obstructive pulmonary disease (COLUMBUS): a randomised, double-blind, placebo-controlled trial. The Lancet Respiratory medicine 2014; 2(5): 361-8.

185. Albert RK, Connett J, Bailey WC, et al. Azithromycin for prevention of exacerbations of COPD. N Engl J Med 2011; 365(8): 689-98.

186. Sethi S, Jones PW, Theron MS, et al. Pulsed moxifloxacin for the prevention of exacerbations of chronic obstructive pulmonary disease: a randomized controlled trial. Respir Res 2010; 11: 10.

187. Cazzola M, Calzetta L, Page $\mathrm{C}$, et al. Influence of $\mathrm{N}$-acetylcysteine on chronic bronchitis or COPD exacerbations: a meta-analysis. Eur Respir Rev 2015; 24(137): 451-61.

188. Poole P, Chong J, Cates CJ. Mucolytic agents versus placebo for chronic bronchitis or chronic obstructive pulmonary disease. Cochrane Database Syst Rev 2015; (7): CD001287.

189. Dal Negro RW, Wedzicha JA, Iversen $M$, et al. Effect of erdosteine on the rate and duration of COPD exacerbations: the RESTORE study. Eur Respir J 2017; 50(4).

190. Collet JP, Shapiro P, Ernst P, Renzi T, Ducruet T, Robinson A. Effects of an immunostimulating agent on acute exacerbations and hospitalizations in patients with chronic obstructive pulmonary disease. The PARI-IS Study Steering Committee and Research Group. Prevention of Acute Respiratory Infection by an Immunostimulant. Am J Respir Crit Care Med 1997; 156(6): 1719-24.

191. Li J, Zheng JP, Yuan JP, Zeng GQ, Zhong NS, Lin CY. Protective effect of a bacterial extract against acute exacerbation in patients with chronic bronchitis accompanied by chronic obstructive pulmonary disease. Chin MedJ (Engl) 2004; 117(6): 828-34.

192. Lee JH, Kim HJ, Kim YH. The Effectiveness of Anti-leukotriene Agents in Patients with COPD: A Systemic Review and Meta-analysis. Lung 2015; 193(4): 477-86.

193. Liu L, Wang JL, Xu XY, Feng M, Hou Y, Chen L. Leukotriene receptor antagonists do not improve lung function decline in COPD: a meta-analysis. EurRev Med Pharmacol Sci 2018; 22(3): 829-34.

194. Rennard SI, Fogarty C, Kelsen S, et al. The safety and efficacy of infliximab in moderate to severe chronic obstructive pulmonary disease. Am J Respir Crit Care Med 2007; 175(9): 926-34.

195. Criner GJ, Connett JE, Aaron SD, et al. Simvastatin for the prevention of exacerbations in moderate-tosevere COPD. N Engl J Med 2014; 370(23): 2201-10.

196. Ingebrigtsen TS, Marott JL, Nordestgaard BG, Lange P, Hallas J, Vestbo J. Statin use and exacerbations in individuals with chronic obstructive pulmonary disease. Thorax 2015; 70(1): 33-40.

197. Lehouck A, Mathieu C, Carremans C, et al. High doses of vitamin D to reduce exacerbations in chronic obstructive pulmonary disease: a randomized trial. Ann Intern Med 2012; 156(2): 105-14.

198. Laube BL, Janssens HM, de Jongh FH, et al. What the pulmonary specialist should know about the new inhalation therapies. Eur Respir J 2011; 37(6): 1308-31.

199. Souza ML, Meneghini AC, Ferraz E, Vianna EO, Borges MC. Knowledge of and technique for using inhalation devices among asthma patients and COPD patients. J Bras Pneumol 2009; 35(9): 824-31.

200. Melani AS, Bonavia M, Cilenti V, et al. Inhaler mishandling remains common in real life and is associated with reduced disease control. Respir Med 2011; 105(6): 930-8.

201. Sanchis J. Has patient technique improved over time? Chest 2016; 150: 394.

202. Sulaiman I, Cushen B, Greene G, et al. Objective Assessment of Adherence to Inhalers by Patients with Chronic Obstructive Pulmonary Disease. Am J Respir Crit Care Med 2017; 195(10): 1333-43.

203. Rootmensen GN, van Keimpema AR, Jansen HM, de Haan RJ. Predictors of incorrect inhalation technique in patients with asthma or COPD: a study using a validated videotaped scoring method. $J$ Aerosol Med Pulm Drug Deliv 2010; 23(5): 323-8.

204. Dantic DE. A critical review of the effectiveness of "teach-back" technique in teaching COPD patients self-management using respiratory inhalers. Health Educ J 2014; 73: 41-50.

205. van der Palen J, Klein JJ, Schildkamp AM. Comparison of a new multidose powder inhaler (Diskus/Accuhaler) and the Turbuhaler regarding preference and ea se of use. J Asthma 1998; 35(2): 147-52.

206. van der Palen J, van der Valk P, Goosens M, Groothuis-Oudshoorn K, Brusse-Keizer M. A randomised cross-over trial investigating the ease of use and preference of two dry powder inhalers in patients 
with asthma or chronic obstructive pulmonary disease. Expert opinion on drug delivery 2013; 10(9): 1171-8.

207. van der Palen J, Eijsvogel MM, Kuipers BF, Schipper M, Vermue NA. Comparison of the Diskus inhaler and the Handihaler regarding preference and ease of use. J Aerosol Med 2007; 20(1): 38-44.

208. van der Palen J, Klein JJ, Kerkhoff AH, van Herwaarden CL. Evaluation of the effectiveness of four different inhalers in patients with chronic obstructive pulmonary disease. Thorax 1995; 50(11): 11837.

209. van der Palen J, Ginko T, Kroker A, et al. Preference, satisfaction and errors with two dry powder inhalers in patients with COPD. Expert opinion on drug delivery 2013; 10(8): 1023-31.

210. Pascual S, Feimer J, De Soyza A, et al. Preference, satisfaction and critical errors with Genuair and Breezhaler inhalers in patients with COPD: a randomised, cross-over, multicentre study. NPJ Prim Care Respir Med 2015; 25: 15018.

211. Yawn BP, Colice GL, Hodder R. Practical aspects of inhaler use in the management of chronic obstructive pulmonary disease in the primary care setting. Int J Chron Obstruct Pulmon Dis 2012; 7: 495-502.

212. Dekhuijzen PN, Vincken W, Virchow JC, et al. Prescription of inhalers in asthma and COPD: towards a rational, rapid and effective approach. Respir Med 2013; 107(12): 1817-21.

213. Chapman KR, Stockley RA, Dawkins C, Wilkes MM, Navickis RJ. Augmentation therapy for alpha1 antitrypsin deficiency: a meta-analysis. Copd 2009; 6(3): 177-84.

214. The Alpha-1-Antitrypsin Deficiency Registry Study Group. Survival and FEV1 decline in individuals with severe deficiency of alpha1-antitrypsin. Am J Respir Crit Care Med 1998; 158(1): 49-59.

215. Dirksen A, Dijkman JH, Madsen F, et al. A randomized clinical trial of alpha(1)-antitrypsin augmentation therapy. Am J Respir Crit Care Med 1999; 160(5 Pf 1): 1468-72.

216. Dirksen A, Piitulainen E, Parr DG, et al. Exploring the role of CT densitometry: a randomised study of augmentation therapy in alpha1-antitrypsin deficiency. EurRespir J 2009; 33(6): 1345-53.

217. McElvaney NG, Burdon J, Holmes M, et al. Long-term efficacy and safety of alpha1 proteinase inhibitor treatment for emphysema caused by severe alpha1 antitrypsin deficiency: an open-label extension trial (RAPID-OLE). The Lancet Respiratory medicine 2017; 5(1): 51-60.

218. Stockley RA, Edgar RG, Pillai A, Turner AM. Individualized lung function trends in alpha-1-antitrypsin deficiency: a need for patience in order to provide patient centered management? Int J Chron Obstruct Pulmon Dis 2016; 11: 1745-56. P

219. Stoller JK, Aboussouan LS. A review of alpha1-antitrypsin deficiency. Am J Respir Crit Care Med 2012; 185(3): 246-59.

220. Sandhaus R, Turino G, Brantly M. The diagnosis and management of alpha-1 antitrypsin deficiency in the adult. J COPD F 2016; 3(3): 668-82.

221. Schildmann EK, Remi C, Bausewein C. Levodropropizine in the management of cough associated with cancer or nonmalignant chronic disease--a systematic review. J Pain Palliat Care Pharmacother 2011; 25(3): 209-18.

222. Barbera JA, Roger N, Roca J, Rovira I, Higenbottam TW, Rodriguez-Roisin R. Worsening of pulmonary gas exchange with nitric oxide inhalation in chronic obstructive pulmonary disease. Lancet 1996; 347(8999): 436-40.

223. Blanco I, Santos S, Gea J, et al. Sildenafil to improve respiratory rehabilitation outcomes in COPD: a controlled trial. Eur Respir J 2013; 42(4): 982-92.

224. Goudie AR, Lipworth BJ, Hopkinson PJ, Wei L, Struthers AD. Tadalafil in patients with chronic obstructive pulmonary disease: a randomised, double-blind, parallel-group, placebo-controlled trial. The Lancet Respiratory medicine 2014; 2(4): 293-300.

225. Spruit MA, Singh SJ, Garvey C, et al. An official American Thoracic Society/European Respiratory Society statement: key concepts and advances in pulmonary rehabilitation. Am J Respir Crit Care Med 2013; 188(8): e13-64.

226. Vogiatzis I, Rochester CL, Spruit MA, Troosters T, Clini EM, American Thoracic Society/European Respiratory Society Task Force on Policy in Pulmonary Rehabilitation. Increasing implementation and delivery of pulmonary rehabilitation: key messages from the new ATS/ERS policy statement. Eur Respir J 2016; 47(5): 1336-41.

227. Garvey C, Bayles MP, Hamm LF, et al. Pulmonary Rehabilitation Exercise Prescription in Chronic Obstructive Pulmonary Disease: Review of Selected Guidelines: An official statement from the American Association of Cardiovascular and Pulmonary Rehabilitation J Cardiopulm Rehabil Prev 2016; 36(2): 75-83. 
228. Alison JA, McKeough ZJ, Johnston K, et al. Australian and New Zealand Pulmonary Rehabilitation Guidelines. Respirology 2017; 22(4): 800-19.

229. McCarthy B, Casey D, Devane D, Murphy K, Murphy E, Lacasse Y. Pulmonary rehabilitation for chronic obstructive pulmonary disease. Cochrane Database Syst Rev 2015; 2(2): CD003793.

230. Sahin H, Naz I, Varol Y, Aksel N, Tuksavul F, Ozsoz A. Is a pulmonary rehabilitation program effective in COPD patients with chronic hypercapnic failure? Expert Rev Respir Med 2016; 10(5): 593-8.

231. Puhan MA, Gimeno-Santos E, Cates CJ, Troosters T. Pulmonary rehabilitation following exacerbations of chronic obstructive pulmonary disease. Cochrane Database Syst Rev 2016; 12: Cd005305.

232. Greening NJ, Williams JE, Hussain SF, et al. An early rehabilitation intervention to enhance recovery during hospital admission for an exacerbation of chronic respiratory disease: randomised controlled trial. BMJ 2014; 349: g4315.

233. Coultas DB, Jackson BE, Russo R, et al. Home-based Physical Activity Coaching, Physical Activity, and Health Care Utilization in Chronic Obstructive Pulmonary Disease. Chronic Obstructive Pulmonary Disease Self-Management Activation Research Trial Secondary Outcomes. Annals of the American Thoracic Society 2018; 15(4): 470-8.

234. Rochester CL, Vogiatzis I, Holland AE, et al. An Official American Thoracic Society/European Respiratory Society Policy Statement: Enhancing Implementation, Use, and Delivery of Pulmonary Rehabilitation. Am J Respir Crit Care Med 2015; 192(11): 1373-86.

235. Han MK, Martinez $\mathrm{CH}, \mathrm{Au} \mathrm{DH}$, et al. Meeting the challenge of COPD care detivery in the USA: a multiprovider perspective. The Lancet Respiratory medicine 2016; 4(6): 473-526.

236. Holland AE, Mahal A, Hill CJ, et al. Home-based rehabilitation for COPDusing minimal resources: a randomised, controlled equivalence trial. Thorax 2017; 72(1): 57-65.

237. Maltais F, Bourbeau J, Shapiro S, et al. Effects of home-based pulmonary rehabilitation in patients with chronic obstructive pulmonary disease: a randomized trial. Ann Intern Med 2008; 149(12): 86978.

238. Bourne $S$, DeVos R, North $M$, et al. Online versus face-to-face pulmonary rehabilitation for patients with chronic obstructive pulmonary disease: randomised controlled trial. BMJ Open 2017; 7(7): e014580.

239. Horton EJ, Mitchell KE, Johnson-Warrington V,et al. Comparison of a structured home-based rehabilitation programme with conventional supervised pulmonary rehabilitation: a randomised noninferiority trial. Thorax 2018; 73(1): 29-36.

240. Guell MR, Cejudo P, Ortega F, et al. Benefits of Long-Term Pulmonary Rehabilitation Maintenance Program in Patients with Severe Chronic Obstructive Pulmonary Disease. Three-Year Follow-up. Am J Respir Crit Care Med 2017; 195(5): 622-9.

241. Effing TW, Vercoulen JH, Bourbeau J, et al. Definition of a COPD self-management intervention: International Expert Group consensus. Eur Respir J 2016; 48(1): 46-54.

242. Lenferink A, Brusse-Keizer M, van der Valk PD, et al. Self-management interventions including action plans for exacerbations versus usual care in patients with chronic obstructive pulmonary disease. Cochrane Database Syst Rev 2017; 8: Cd011682.

243. Fan VS, Gaziano JM, Lew R, et al. A comprehensive care management program to prevent chronic obstructive pulmonary disease hospitalizations: a randomized, controlled trial. Ann Intern Med 2012; 156(10): 673-83.

244. Peytremann-Bridevaux I, Taffe P, Burnand B, Bridevaux PO, Puhan MA. Mortality of patients with COPD participating in chronic disease management programmes: a happy end? Thorax 2014; 69(9): 865-6.

245. Zwerink M, Brusse-Keizer M, van der Valk PD, et al. Self management for patients with chronic obstructive pulmonary disease. Cochrane Database Syst Rev 2014; 3(3): CD002990.

246. Kessler R, Casan-Clara P, Koehler D, et al. COMET: a multicomponent home-based diseasemanagement programme versus routine care in severe COPD. Eur Respir J 2018; 51(1).

247. Rose L, Istanboulian L, Carriere L, et al. Program of Integrated Care for Patients with Chronic Obstructive Pulmonary Disease and Multiple Comorbidities (PIC COPD(+)): a randomised controlled trial. Eur Respir J 2018; 51(1).

248. Kruis AL, Smidt N, Assendelft WJ, et al. Integrated disease management interventions for patients with chronic obstructive pulmonary disease. Cochrane Database Syst Rev 2013; 10(10): CD009437.

249. Kruis AL, Boland MR, Assendelft WJ, et al. Effectiveness of integrated disease management for primary care chronic obstructive pulmonary disease patients: results of cluster randomised trial. $B M J$ 2014; 349: g5392. 
250. Gregersen TL, Green A, Frausing E, Ringbaek T, Brondum E, Suppli Ulrik C. Do telemedical interventions improve quality of life in patients with COPD? A systematic review. Int J Chron Obstruct Pulmon Dis 2016; 11: 809-22.

251. Cartwright M, Hirani SP, Rixon L, et al. Effect of telehealth on quality of life and psychological outcomes over 12 months (Whole Systems Demonstrator telehealth questionnaire study): nested study of patient reported outcomes in a pragmatic, cluster randomised controlled trial. BMJ 2013; 346: f653.

252. American Academy of Hospice and Palliative Medicine Center to Advance Palliative Care Hospice and Palliative Nurses Association Last Acts Partnership National Hospice and Palliative Care Organization. National Consensus Project for Quality Palliative Care: Clinical Practice Guidelines for quality palliative care, executive summary. Journal of palliative medicine 2004; 7(5): 611-27.

253. Au DH, Udris EM, Fihn SD, McDonell MB, Curtis JR. Differences in health care utilization at the end of life among patients with chronic obstructive pulmonary disease and patients with lung cancer. Arch Intern Med 2006; 166(3): 326-31.

254. Levy MH, Adolph MD, Back A, et al. Palliative care. J Natl Compr Canc Netw 2012; 10(10): 1284-309.

255. Morrison RS, Maroney-Galin C, Kralovec PD, Meier DE. The growth of palliative care programs in United States hospitals. Journal of palliative medicine 2005; 8(6): 1127-34.

256. Ekstrom M, Nilsson F, Abernethy AA, Currow DC. Effects of opioids on breathlesshess and exercise capacity in chronic obstructive pulmonary disease. A systematic review. Annats of the American Thoracic Society 2015; 12(7): 1079-92.

257. Rocker GM, Simpson AC, Joanne Young B, et al. Opioid therapy for refractory dyspnea in patients with advanced chronic obstructive pulmonary disease: patients' experiences and outcomes. CMAJ Open 2013; 1(1): E27-36.

258. Marciniuk DD, Goodridge D, Hernandez P, et al. Managing dyssnea in patients with advanced chronic obstructive pulmonary disease: a Canadian Thoracic Society clinical practice guideline. Can Respir J 2011; 18(2): 69-78.

259. Vieira PJ, Chiappa AM, Cipriano G, Jr., Umpierre D, Arena R, Chiappa GR. Neuromuscular electrical stimulation improves clinical and physiological function in COPD patients. Respir Med 2014; 108(4): 609-20.

260. Galbraith S, Fagan P, Perkins P, Lynch A, Booth S. Does the use of a handheld fan improve chron ic dyspnea? A randomized, controlled, crossover trial. J Pain Symptom Manage 2010; 39(5): 831-8.

261. Marchetti N, Lammi MR, Travaline JM, Ciccolella D, Civic B, Criner GJ. Air Current Applied to the Face Improves Exercise Performance in Ratients with COPD. Lung 2015; 193(5): 725-31.

262. Abdallah SJ, Wilkinson-Maitland C, Saad N, et al. Effect of morphine on breathlessness and exercise endurance in advanced COPD: a randomised crossover trial. Eur Respir J 2017; 50(4).

263. Uronis HE, Ekstrom MP, Currow DC, McCrory DC, Samsa GP, Abernethy AP. Oxygen for relief of dyspnea in people with chronic obstructive pulmonary disease who would not qualify for home oxygen: a systematic review and meta-analysis. Thorax 2015; 70(5): 492-4.

264. Higginson IJ, Bausewein C, Reilly CC, et al. An integrated palliative and respiratory care service for patients with advanced disease and refractory breathlessness: a randomised controlled trial. The Lancet Respiratory medicine 2014; 2(12): 979-87.

265. Simon ST, Higginson IJ, Booth S, Harding R, Bausewein C. Benzodiazepines for the relief of breathlessness in advanced malignant and non-malignant diseases in adults. Cochrane Database Syst Rev 2010; (1): CD007354.

266. Bausewein C, Booth S, Gysels M, Higginson I. Non-pharmacological interventions for breathlessness in advanced stages of malignant and non-malignant diseases. Cochrane Database Syst Rev 2008; (2): CD005623.

267. Guo Y, Zhang T, Wang Z, et al. Body mass index and mortality in chronic obstructive pulmonary disease: A dose-response meta-analysis. Medicine (Baltimore) 2016; 95(28): e4225.

268. Ferreira IM, Brooks D, White J, Goldstein R. Nutritional supplementation for stable chronic obstructive pulmonary disease. Cochrane Database Syst Rev 2012; 12: CD000998.

269. Yohannes AM, Alexopoulos GS. Depression and anxiety in patients with COPD. Eur Respir Rev 2014; 23(133): 345-9.

270. Farver-Vestergaard I, Jacobsen D, Zachariae R. Efficacy of psychosocial interventions on psychological and physical health outcomes in chronic obstructive pulmonary disease: a systematic review and meta-analysis. Psychother Psychosom 2015; 84(1): 37-50. 
271. Payne C, Wiffen PJ, Martin S. Interventions for fatigue and weight loss in adults with advanced progressive illness. Cochrane Database Syst Rev 2012; 1: CD008427.

272. Murray SA, Kendall M, Boyd K, Sheikh A. Illness trajectories and palliative care. BMJ 2005; 330(7498): 1007-11.

273. Eriksen N, Vestbo J. Management and survival of patients admitted with an exacerbation of COPD: comparison of two Danish patient cohorts. Clin Respir J 2010; 4(4): 208-14.

274. Groenewegen KH, Schols AM, Wouters EF. Mortality and mortality-related factors after hospitalization for acute exacerbation of COPD. Chest 2003; 124(2): 459-67.

275. Gudmundsson G, Ulrik CS, Gislason T, et al. Long-term survival in patients hospitalized for chronic obstructive pulmonary disease: a prospective observational study in the Nordic countries. Int J Chron Obstruct Pulmon Dis 2012; 7: 571-6.

276. Disler RT, Green A, Luckett T, et al. Experience of advanced chronic obstructive pulmonary disease: metasynthesis of qualitative research. J Pain Symptom Manage 2014; 48(6): 1182-99.

277. Halpin DMG, Seamark DA, Seamark CJ. Palliative and end-of-life care for patients with respiratory diseases. Eur Respir Monograph 2009; 43: 327-53.

278. Patel K, Janssen DJ, Curtis JR. Advance care planning in COPD. Respirology 2012; 17(1): 72-8.

279. Pinnock H, Kendall M, Murray SA, et al. Living and dying with severe chronic obstructive pulmonary disease: multi-perspective longitudinal qualitative study. BMJ 2011; 342: d142.

280. Weber C, Stirnemann J, Herrmann FR, Pautex S, Janssens JP. Can early introduction of specialized palliative care limit intensive care, emergency and hospital admissions inpatients with severe and very severe COPD? a randomized study. BMC Palliat Care 2014; 13: $4 \mathrm{~T}$.

281. Ek K, Andershed B, Sahlberg-Blom E, Ternestedt BM. "The unpredictable death"-The last year of life for patients with advanced COPD: Relatives' stories. Palliat Support Care 2015; 13(5): 1213-22.

282. National Hospice and Palliative Care Organization. Web Pagel http://www.nhpco.org (accessed 14 October 2018).

283. Cranston JM, Crockett AJ, Moss JR, Alpers JH. Domiciliary oxygen for chronic obstructive pulmonary disease. Cochrane Database Syst Rev 2005; (4): CD001744.

284. Long-term Oxygen Treatment Trial Research Group. A randomized trial of long-term oxygen for COPD with moderate desaturation. NEJM 2016; 375(17): 1617.

285. Ekstrom M, Ahmadi Z, Bornefalk-Hermansson A, Abernethy A, Currow D. Oxygen for breathlessness in patients with chronic obstructive pulmopary disease who do not qualify for home oxygen therapy. Cochrane Database Syst Rev 2016; 11.Cd006429.

286. Ahmedzai S, Balfour-Lynn IM, Bewick T, et al. Managing passengers with stable respiratory disease planning air travel: British Thoracic Society recommendations. Thorax 2011; 66 Suppl 1: i1-30.

287. Berg BW, Dillard TA, Rajagopal KR, Mehm WJ. Oxygen supplementation during air travel in patients with chronic obstructivelung disease. Chest 1992; 101(3): 638-41.

288. Edvardsen A, Akero A, Christensen CC, Ryg M, Skjonsberg OH. Air travel and chronic obstructive pulmonary disease: a new algorithm for pre-flight evaluation. Thorax 2012; 67(11): 964-9.

289. Christensen CC, Ryg M, Refvem OK, Skjonsberg OH. Development of severe hypoxaemia in chronic obstructive pulmonary disease patients at 2,438 m (8,000 ft) altitude. Eur Respir J 2000; 15(4): 635-9.

290. Elliott MW, Nava S. Noninvasive ventilation for acute exacerbations of chronic obstructive pulmonary disease: "Don't think twice, it's alright!". Am J Respir Crit Care Med 2012; 185(2): 121-3.

291. Chandra D, Stamm JA, Taylor B, et al. Outcomes of noninvasive ventilation for acute exacerbations of chronic obstructive pulmonary disease in the United States, 1998-2008. Am J Respir Crit Care Med 2012; 185(2): 152-9.

292. Lindenauer PK, Stefan MS, Shieh MS, Pekow PS, Rothberg MB, Hill NS. Outcomes associated with invasive and noninvasive ventilation among patients hospitalized with exacerbations of chronic obstructive pulmonary disease. JAMA Intern Med 2014; 174(12): 1982-93.

293. Marin JM, Soriano JB, Carrizo SJ, Boldova A, Celli BR. Outcomes in patients with chronic obstructive pulmonary disease and obstructive sleep apnea: the overlap syndrome. Am J Respir Crit Care Med 2010; 182(3): 325-31.

294. Murphy PB, Rehal S, Arbane G, et al. Effect of Home Noninvasive Ventilation With Oxygen Therapy vs Oxygen Therapy Alone on Hospital Readmission or Death After an Acute COPD Exacerbation: A Randomized Clinical Trial. Jama 2017; 317(21): 2177-86.

295. Galli JA, Krahnke JS, James Mamary A, Shenoy K, Zhao H, Criner GJ. Home non-invasive ventilation use following acute hypercapnic respiratory failure in COPD. Respir Med 2014; 108(5): 722-8. 
296. Coughlin S, Liang WE, Parthasarathy S. Retrospective Assessment of Home Ventilation to Reduce Rehospitalization in Chronic Obstructive Pulmonary Disease. Journal of clinical sleep medicine : JCSM : official publication of the American Academy of Sleep Medicine 2015; 11(6): 663-70.

297. Clini E, Sturani C, Rossi A, et al. The Italian multicentre study on noninvasive ventilation in chronic obstructive pulmonary disease patients. Eur Respir J 2002; 20(3): 529-38.

298. Kohnlein T, Windisch W, Kohler D, et al. Non-invasive positive pressure ventilation for the treatment of severe stable chronic obstructive pulmonary disease: a prospective, multicentre, randomised, controlled clinical trial. The Lancet Respiratory medicine 2014; 2(9): 698-705.

299. Struik FM, Sprooten RT, Kerstjens HA, et al. Nocturnal non-invasive ventilation in COPD patients with prolonged hypercapnia after ventilatory support for acute respiratory failure: a randomised, controlled, parallel-group study. Thorax 2014; 69(9): 826-34.

300. Casanova C, Celli BR, Tost L, et al. Long-term controlled trial of nocturnal nasal positive pressure ventilation in patients with severe COPD. Chest 2000; 118(6): 1582-90.

301. White DP, Criner GJ, Dreher M, et al. The role of noninvasive ventilation in the management and mitigation of exacerbations and hospital admissions/readmissions for the patient with moderate to severe COPD. Chest 2015; 147(6): 1704-5.

302. Lightowler JV, Wedzicha JA, Elliott MW, Ram FS. Non-invasive positive pressure yentilation to treat respiratory failure resulting from exacerbations of chronic obstructive pulmonary disease: Cochrane systematic review and meta-analysis. BMJ 2003; 326(7382): 185.

303. Kolodziej MA, Jensen L, Rowe B, Sin D. Systematic review of noninvasive positive pressure ventilation in severe stable COPD. Eur Respir J 2007; 30(2): 293-306.

304. Cooper JD, Trulock EP, Triantafillou AN, et al. Bilateral pneumectomy (volume reduction) for chronic obstructive pulmonary disease. J Thorac Cardiovasc Surg 1995; 109(1): 106-16; discussion 16-9.

305. Criner G, Cordova FC, Leyenson V, et al. Effect of lung volume reduction surgery on diaphragm strength. Am J Respir Crit Care Med 1998; 157(5 Pt 1): 1578-85.

306. Martinez FJ, de Oca MM, Whyte RI, Stetz J, Gay SE, Celli BR. Lung-volume reduction improves dyspnea, dynamic hyperinflation, and respiratory muscle function. Am J Respir Crit Care Med 1997; 155(6): 1984-90.

307. Fessler HE, Permutt S. Lung volume reduction surgery and airflow limitation. Am J Respir Crit Care Med 1998; 157(3 Pt 1): 715-22.

308. Washko GR, Fan VS, Ramsey SD, et al. The effect of lung volume reduction surgery on chronic obstructive pulmonary disease exacerbations. Am J Respir Crit Care Med 2008; 177(2): 164-9.

309. Fishman A, Martinez F, Naunheim K, et al. A randomized trial comparing lung-volume-reduction surgery with medical therapy for severe emphysema. N Engl J Med 2003; 348(21): 2059-73.

310. National Emphysema Treatment Trial Research Group. Patients at high risk of death after lungvolume-reduction surgery. W Engl J Med 2001; 345(15): 1075-83.

311. Ramsey SD, Berry K, Etzioni R, et al. Cost effectiveness of lung-volume-reduction surgery for patients with severe emphysema. N Engl J Med 2003; 348(21): 2092-102.

312. Marchetti N, Criner GJ. Surgical Approaches to Treating Emphysema: Lung Volume Reduction Surgery, Bullectomy, and Lung Transplantation. Semin Respir Crit Care Med 2015; 36(4): 592-608.

313. Christie JD, Edwards LB, Kucheryavaya AY, et al. The Registry of the International Society for Heart and Lung Transplantation: 29th adult lung and heart-lung transplant report-2012. J Heart Lung Transplant 2012; 31(10): 1073-86.

314. Stavem K, Bjortuft O, Borgan O, Geiran O, Boe J. Lung transplantation in patients with chronic obstructive pulmonary disease in a national cohort is without obvious survival benefit. J Heart Lung Transplant 2006; 25(1): 75-84.

315. ISHLT: The International Society for Heart \& Lung Transplantation [Internet]. Slide Sets - Overall Lung Transplantation Statistics. Available from: https://ishltregistries.org/registries/slides.asp (accessed 14 October 2018).

316. Thabut G, Christie JD, Ravaud P, et al. Survival after bilateral versus single lung transplantation for patients with chronic obstructive pulmonary disease: a retrospective analysis of registry data. Lancet 2008; 371(9614): 744-51.

317. Theodore J, Lewiston N. Lung transplantation comes of age. N Engl J Med 1990; 322(11): 772-4.

318. Criner GJ, Cordova F, Sternberg AL, Martinez FJ. The National Emphysema Treatment Trial (NETT) Part II: Lessons learned about lung volume reduction surgery. Am J Respir Crit Care Med 2011; 184(8): 88193. 
319. Shah PL, Slebos DJ, Cardoso PF, et al. Bronchoscopic lung-volume reduction with Exhale airway stents for emphysema (EASE trial): randomised, sham-controlled, multicentre trial. Lancet 2011; 378(9795): 997-1005.

320. Come CE, Kramer MR, Dransfield MT, et al. A randomised trial of lung sealant versus medical therapy for advanced emphysema. Eur Respir J 2015; 46(3): 651-62.

321. Sciurba FC, Ernst A, Herth FJ, et al. A randomized study of endobronchial valves for advanced emphysema. N Engl J Med 2010; 363(13): 1233-44.

322. Davey C, Zoumot Z, Jordan S, et al. Bronchoscopic lung volume reduction with endobronchial valves for patients with heterogeneous emphysema and intact interlobar fissures (the BeLieVeR-HIFi trial): study design and rationale. Thorax 2015; 70(3): 288-90.

323. Klooster K, ten Hacken NH, Hartman JE, Kerstjens HA, van Rikxoort EM, Slebos DJ. Endobronchial Valves for Emphysema without Interlobar Collateral Ventilation. N Engl J Med 2015; 373(24): 2325-35

324. Valipour A, Slebos DJ, Herth F, et al. Endobronchial Valve Therapy in Patients with Homogeneous Emphysema. Results from the IMPACT Study. Am J Respir Crit Care Med 2016; 194(9): 1073-82.

325. Criner GJ, Sue R, Wright S, et al. A Multicenter RCT of Zephyr(R) Endobronchial Valve Treatment in Heterogeneous Emphysema (LIBERATE). Am J Respir Crit Care Med 2018.

326. Kemp SV, Slebos DJ, Kirk A, et al. A Multicenter Randomized Controlled Trial of Zephyr Endobronchial Valve Treatment in Heterogeneous Emphysema (TRANSFORM). Am J Respir Crit Care Med 2017; 196(12): 1535-43.

327. Naunheim KS, Wood DE, Mohsenifar Z, et al. Long-term follow-up of patients receiving lung-volumereduction surgery versus medical therapy for severe emphysema by the National Emphysema Treatment Trial Research Group. Ann Thorac Surg 2006; 82(2): 431-43.

328. DeCamp MM, Blackstone EH, Naunheim KS, et al. Patient and surgical factors influencing air leak after lung volume reduction surgery: lessons learned from the National Emphysema Treatment Trial. Ann Thorac Surg 2006; 82(1): 197-206; discussion -7.

329. Shah PL, Gompelmann D, Valipour A, et al. Thermal va four ablation to reduce segmental volume in patients with severe emphysema: STEP-UP 12 month results. The Lancet Respiratory medicine 2016; 4(9): e44-e5.

330. Herth FJ, Valipour A, Shah PL, et al. Segmentalvolume reduction using thermal vapour ablation in patients with severe emphysema: 6 -month results of the multicentre, parallel-group, open-label, randomised controlled STEP-UP trial. The Lancet Respiratory medicine 2016; 4(3): 185-93.

331. Deslee G, Mal H, Dutau H, et al. Lung Volume Reduction Coil Treatment vs Usual Care in Patients With Severe Emphysema: The REVOLENS Randomized Clinical Trial. JAMA 2016; 315(2): 175-84.

332. Sciurba FC, Criner GJ, Strange C, et al. Effect of Endobronchial Coils vs Usual Care on Exercise Tolerance in Patients With Severe Emphysema: The RENEW Randomized Clinical Trial. JAMA 2016; 315(20): 2178-89. 


\section{CHAPTER 4: MANAGEMENT OF STABLE COPD}

\section{OVERALL KEY POINTS:}

- The management strategy for stable COPD should be predominantly based on the individualized assessment of symptoms and future risk of exacerbations.

- All individuals who smoke should be strongly encouraged and supported to quit.

- The main treatment goals are reduction of symptoms and future risk of exacerbations.

- Management strategies are not limited to pharmacological treatments and should be complemented by appropriate non-pharmacological interventions.

\section{INTRODUCTION}

Once COPD has been diagnosed, effective management should be based on an individualized assessment to reduce both current symptoms and future risks of exacerbations (Table 4.1).

The individualized assessment is summarized in Chapter $\mathbf{2}$.

\section{GOALS FOR TREATMANT OF STABLE COPD}

- Relieve Symptơms

- Improve Exercise Tolerance

- Improve Health Status

and

- Prevent Disease Progression

- Prevent and Treat Exacerbations

TABLE 4.1
REDUCE SYMPTOMS

REDUCE RISK

We propose a personalized approach to initiate and escalate/de-escalate a patient's treatment based on their level of symptoms and risk for exacerbations. The basis for these recommendations, which propose an organized approach to treatment, is partially derived from evidence generated from randomized controlled trials. These recommendations are intended to support clinician decisionmaking and therefore also incorporate expert advice based on clinical experience.

It is crucial for patients with COPD to understand the nature of the disease, risk factors for its progression, and the role that they and their healthcare workers must play in order to achieve optimal 
management and health outcomes. In addition, patients should receive general advice on healthy living, including diet, and that physical exercise is safe and encouraged for people with COPD. Ongoing monitoring should include continuous evaluation of exposure to risk factors and monitoring of disease progression, the effect of treatment and possible adverse effects, exacerbation history, and comorbidities.

\section{IDENTIFY AND REDUCE EXPOSURE TO RISK FACTORS}

Identification and reduction of exposure to risk factors is important in the treatment and prevention of COPD. Cigarette smoking is the most commonly encountered and easily identifiable risk factor for COPD, and smoking cessation should be continually encouraged for all individuals who smoke. Reduction of total personal exposure to occupational dusts, fumes, and gases, and to indoor and outdoor air pollutants, should also be addressed.

\section{Tobacco smoke}

Smoking cessation is a key intervention for all COPD patients who continue to smoke. Healthcare providers are pivotal in delivering smoking cessation messages and interventions to patients, and should encourage patients to quit at every available opportunity.

TREATING TOBACCO USE AND DEPENDENCE:

A CLINICAL PRACTICE GUIDELINE - MAJOR FINDINGS \& RECOMMENDATIONS

- Tobacco dependence is a chronic condition that warranstrepeated treatment until long-term or permanent abstinence is achieved.

- Effective treatments for tobacco dependence exist and all tobacco users should be offered these treatments.

- Clinicians and health care delivery systerms must operationalize the consistent identification, documentation, and treatment of every tobacco user at every visit.

- Brief smoking cessation counseling is effective and every tobacco usershould be offered such advice at every contact with health care providers.

- There is a strong dose-response relation between the intensity of tobacco dependence counseling and its effectiveness.

- Three types of counseling have been found to be especially effective: practical counseling, social support of family and friends as part of treatment, and social support arranged outside of treatment.

- First-line pharmacotherapies for tobacco dependence - varenicline, bupropion sustained release, nicotine gum, nicotine inhaler, nicotine nasal spray, and nicotine patch-are effective and at least one of these medications should be prescribed in the absence of contraindications.

- Financial incentive programs for smoking cessation may facilitate smoking cessation.

- Tobacco dependence treatments are cost effective interventions.

TABLE 4.2

Smokers should be provided with counseling when attempting to quit. When possible, the patient should be referred to a comprehensive smoking cessation program that incorporates behavior change techniques that enhance patient motivation and confidence, patient education, and pharmacological 
and non-pharmacological interventions. Recommendations for treating tobacco use and dependence are summarized in Table 4.2. ${ }^{1}$

\section{Indoor and outdoor air pollution}

Reducing exposure to indoor and outdoor air pollution requires a combination of public policy, local and national resources, cultural changes, and protective steps taken by individual patients. Reduction of exposure to smoke from biomass fuel is a crucial goal to reduce the prevalence of COPD worldwide. Efficient ventilation, non-polluting cooking stoves and similar interventions are feasible and should be recommended..,$\underline{3}$

\section{IDENTIFY \& REDUCE RISK FACTOR EXPOSURE}

- Smoking cessation interventions should be actively pursued in all COPD patients (Evidence A).

- Efficient ventilation, non-polluting cooking stoves and similar interventions should be recommended (Evidence B).

- Clinicians should advise patients to avoid continued exposures to potential ir(itants, if possible (Evidence D).

TABLE 4.3

\section{Occupational exposures}

There are no studies that demonstrate whether inferventions that reduce occupational exposures also reduce the burden of COPD, but it seems logical to advise patients to avoid ongoing exposures to potential irritants if possible. Measures toreduce risk factor exposure are summarized in Table 4.3. 


\section{TREATMENT OF STABLE COPD: PHARMACOLOGICAL TREATMENT}

Pharmacological therapies can reduce symptoms, and the risk and severity of exacerbations, as well as improve the health status and exercise tolerance of patients with COPD.

The classes of medications commonly used to treat COPD are shown in Table $\mathbf{3 . 3}$ and a detailed description of the effects of these medications is given in Chapter 3. The choice within each class depends on the availability of medication and the patient's responses and preferences.

Most of the drugs are inhaled so proper inhaler technique is highly relevant. Key points for the inhalation of drugs are given in Table 4.4. Key points for bronchodilator use are given in Table 4.5. Key points for the use of anti-inflammatory agents are summarized in Table 4.6. Key points for the use of pharmacological treatments are summarized in Table 4.7.

\section{KEY POINTS FOR INHALATION OF DRWGS}

- The choice of inhaler device has to be individually tailored and will depend on access, cost, prescriber, and most importantly, patient's ability and preference.

- It is essential to provide instructions and to demonstrate theproper inhalation technique when prescribing a device, to ensure that inhaler technique is adequate andre-check at each visit that patients continue to use their inhaler correctly.

- Inhaler technique (and adherence to therapy) should be assessed before concluding that the current therapy requires modification.

TABLE 4.4

\section{KEY POINדS FOR THE USE OF BRONCHODILATORS}

- LABAs and LAMAs are preferred over short-acting agents except for patients with only occasional dyspnea (Evidence A), and for immediate relief of symptoms in patients already on long-acting bronchodilators for maintenance therapy.

- Patients may be started on single long-acting bronchodilator therapy or dual long-acting bronchodilator therapy. In patients with persistent dyspnea on one bronchodilator treatment should be escalated to two (Evidence A).

- Inhaled bronchodilators are recommended over oral bronchodilators (Evidence A).

- Theophylline is not recommended unless other long-term treatment bronchodilators are unavailable or unaffordable (Evidence B).

TABLE 4.5 
- Long-term monotherapy with ICS is not recommended (Evidence A).

- Long-term treatment with ICS may be considered in association with LABAs for patients with a history of exacerbations despite appropriate treatment with long-acting bronchodilators (Evidence A).

- Long-term therapy with oral corticosteroids is not recommended (Evidence A).

- In patients with exacerbations despite LABA/ICS or LABA/LAMA/ICS, chronic bronchitis and severe to very severe airflow obstruction, the addition of a PDE4 inhibitor can be considered (Evidence B).

- In former smokers with exacerbations despite appropriate therapy, macrolides, in particular azithromycin, can be considered (Evidence B).

- Statin therapy is not recommended for prevention of exacerbations (Evidence A).

- Antioxidant mucolytics are recommended only in selected patients (Evidence A).

TABLE 4.6

KEY POINTS FOR THE USE OF OTHER PHARMACOLOGICAL TREATMENTS

- Patients with severe hereditary alpha-1 antitrypsin deficien@yand established emphysema may be candidates for alpha-1 antitrypsin augmentation therapy (Evidence-B)!

- Antitussives cannot be recommended (Evidence C).

- Drugs approved for primary pulmonary hypertension are not recommended for patients with a pulmonary hypertension secondary to COPD (EvidenceB).

- Low-dose long acting oral and parenteral opioids may be considered for treating dyspnea in COPD patients with severe disease (Evidence Bl.

TABLE 4.7

\section{Algorithms for the assessment, initiation and follow-up management of pharmacological treatment}

A model for the INITIATION of pharmacological management of COPD according to the individualized assessment of symptoms and exacerbation risk following the $A B C D$ assessment scheme is shown in Figure 4.1. There is a lack of high-quality evidence supporting initial pharmacological treatment strategies in newly diagnosed COPD patients. Figure 4.1 is an attempt to provide clinical guidance using the best available evidence. 


\section{INITIAL PHARMACOLOGICAL TREATMENT}

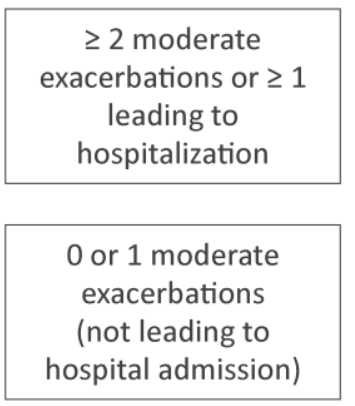

FIGURE 4.1
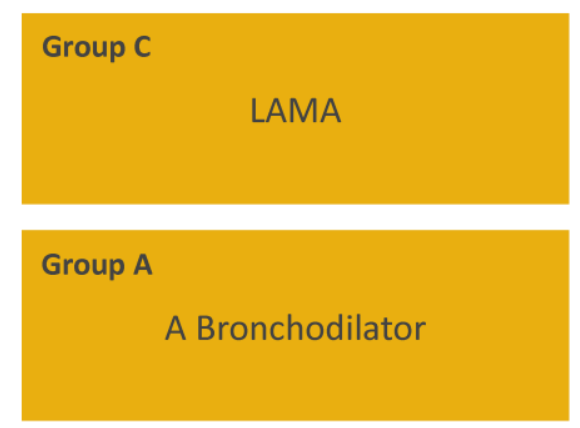

mMRC 0-1 CAT $<10$

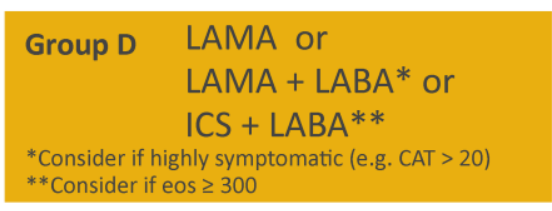

Group B

A Long Acting Bronchodilator (LABA or LAMA)

$\mathrm{mMRC} \geq 2 \mathrm{CAT} \geq 10$

Definition of abbreviations: eos: blood eosinophil count in cells per microliter; mMRC: modified Medical Research Council dyspnea questionnaire; CAT ${ }^{\mathrm{TM}}$ : COPD Assessment $\mathrm{T}^{\mathrm{T}} \mathrm{st}^{\mathrm{TM}}{ }^{\mathrm{m}}$.

Following implementation of therapy, patients should be reassessedfor attainment of treatment goals and identification of any barriers for successful treatment (Figure 4.2). Following review of the patient response to treatment initiation, adjustments in pharmacological treatment may be needed.

\section{MANAGEMENT CYCLE}

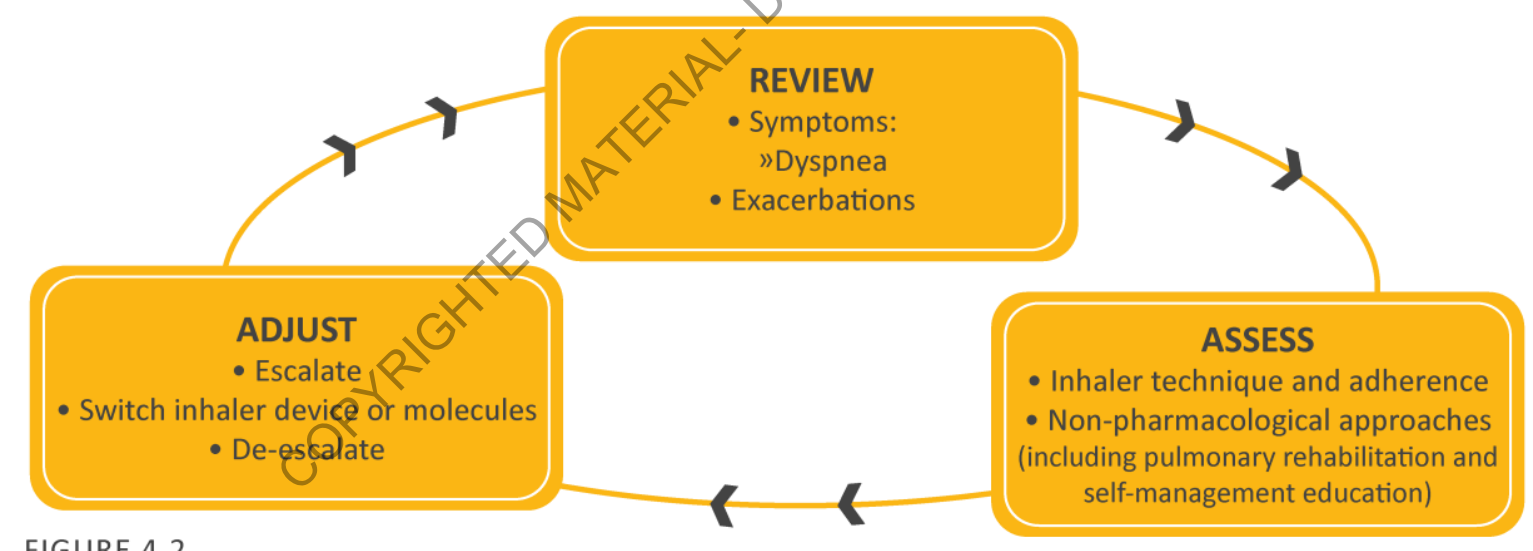

FIGURE 4.2

A separate algorithm is provided for FOLLOW-UP treatment, where the management is still based on symptoms and exacerbations, but the recommendations do not depend on the patient's GOLD group at diagnosis (Figure 4.3). These follow-up recommendations are designed to facilitate management of patients taking maintenance treatment(s), whether early after initial treatment or after years of follow-up. These recommendations incorporate recent evidence from clinical trials and the use of peripheral blood eosinophil counts as a biomarker to guide the use of ICS therapy for exacerbation prevention (see more detailed information regarding blood eosinophil counts as a predictor of ICS effects in Chapter 3 ). 


\section{FOLLOW-UP PHARMACOLOGICAL TREATMENT}

1. IF RESPONSE TO INITIAL TREATMENT IS APPROPRIATE, MAINTAIN IT.

2. IF NOT: $\checkmark$ Consider the predominant treatable trait to target (dyspnea or exacerbations)

- Use exacerbation pathway if both exacerbations and dyspnea need to be targeted

$\checkmark$ Place patient in box corresponding to current treatment \& follow indications

$\checkmark$ Assess response, adjust and review

$\checkmark$ These recommendations do not depend on the ABCD assessment at diagnosis

- DYSPNEA •

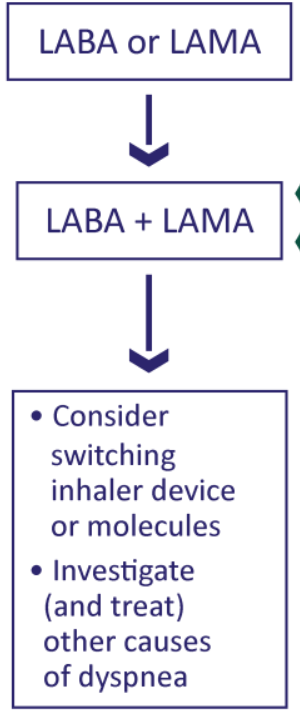

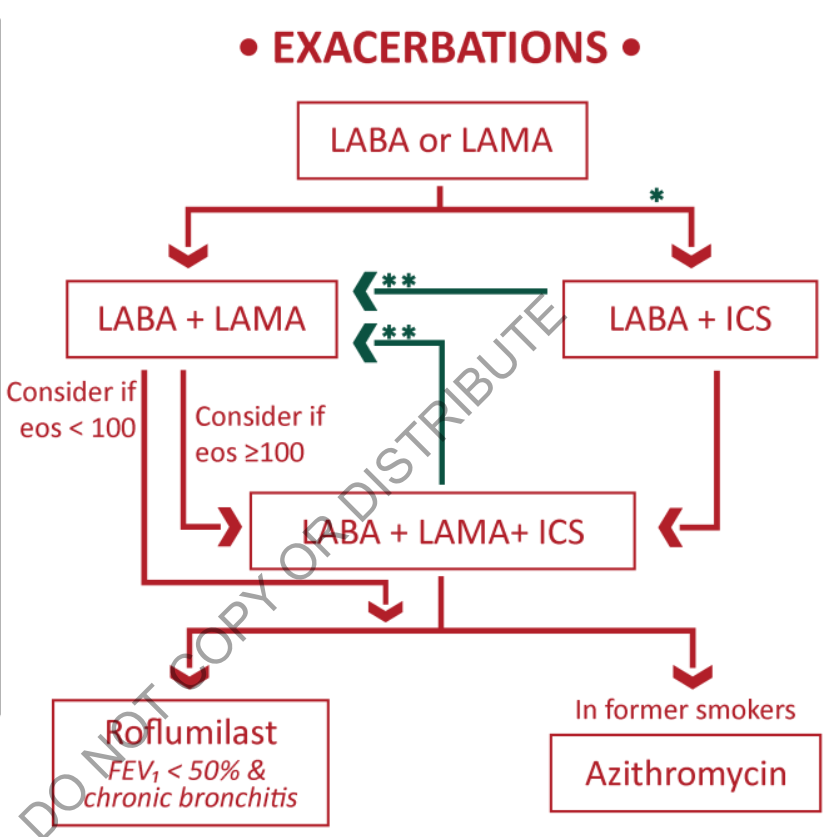

eos = blood eosinophil count (cells $/ \mu L)$

* Consider if eos $\geq 300$ or eos $\geq 100$ AND $\geq 2$ moderate exacerbations / 1 hospitalization

** Consider de-escalation of ICS or switch if aneumonia, inappropriate original indication or lack of response to ICS

FIGURE 4.3

Figure 4.3 suggests escalation and de-escalation strategies based on available efficacy as well as safety data. The response to treatment escalation should always be reviewed, and de-escalation should be considered if there is a lack of clinical benefit and/or side effects occur. De-escalation may also be considered in COPD patients receiving treatment who return with resolution of some symptoms that subsequently may require less therapy. Patients, in whom treatment modification is considered, in particular de-escalation, should be undertaken under close medical supervision. We are fully aware that treatment escalation has not been systematically tested; trials of de-escalation are also limited and only include ICS. 


\section{Initial pharmacological management}

Rescue short-acting bronchodilators should be prescribed to all patients for immediate symptom relief.

\section{Group A}

All Group A patients should be offered bronchodilator treatment based on its effect on breathlessness. This can be either a short- or a long-acting bronchodilator.

This should be continued if benefit is documented.

\section{Group B}

Initial therapy should consist of a long acting bronchodilator. Long-acting inhaled bronchodilators are superior to short-acting bronchodilators taken as needed i.e., pro re nata (prn) and are therefore recommended.., 5

There is no evidence to recommend one class of long-acting bronchodilators over another for initial relief of symptoms in this group of patients. In the individual patient, the ghoice should depend on the patient's perception of symptom relief.

For patients with severe breathlessness initial therapy with two bronchodilators may be considered. $\underline{6}$

Group B patients are likely to have comorbidities that may add to their symptomatology and impact their prognosis, and these possibilities should be investigated..,$\underline{\text { s }}$

\section{Group C}

Initial therapy should consist of a single long acting bronchodilator. In two head-to-head comparisons $=\underline{910}$ the tested LAMACwas superior to the LABA regarding exacerbation prevention (for details see Chapter $\mathbf{3}$ ) therefore we recommend starting therapy with a LAMA in this group.

\section{Group D}

In general, therapy can be started with a LAMA as it has effects on both breathlessness and exacerbations (see Chapter 3).

For patients with more severe symptoms (order of magnitude of CAT $T^{\mathrm{TM}} \geq 20$ ), especially driven by greater dyspnea and / or exercise limitation, LAMA/LABA may be chosen as initial treatment based on studies with patient reported outcomes as the primary endpoint where LABA/LAMA combinations showed superior results compared to the single substances (see Chapter 3). An advantage of LABA/LAMA over LAMA for exacerbation prevention has not been consistently demonstrated, so the decision to use LABA/LAMA as initial treatment should be guided by the level of symptoms.

In some patients, initial therapy with LABA/ICS may be the first choice; this treatment has the greatest likelihood of reducing exacerbations in patients with blood eosinophil counts $\geq 300$ cells $/ \mu \mathrm{L}$. LABA/ICS may also be first choice in COPD patients with a history of asthma. 
ICS may cause side effects such as pneumonia,,$\underline{911}$ so should be used as initial therapy only after the possible clinical benefits versus risks have been considered.

\section{Follow-up pharmacological management}

The follow-up pharmacological treatment algorithm (Figure 4.3) can be applied to any patient who is already taking maintenance treatment(s) irrespective of the GOLD group allocated at treatment initiation. The need to treat primarily dyspnea/exercise limitation or prevent exacerbations further should be evaluated. If a change in treatment is considered necessary then select the corresponding algorithm for dyspnea (Figure 4.3 left column) or exacerbations (Figure 4.3 right column); the exacerbation algorithm should also be used for patients who require a change in treatment for both dyspnea and exacerbations. Identify which box corresponds to the patient's the current treatment.

Follow up pharmacological management should be guided by the principles of first review and assess, then adjust if needed:

\section{Review}

- Review symptoms (dyspnea) and exacerbation risk.

\section{Assess}

- Assess inhaler technique and adherence, and the role of non-pharmacological approaches (covered later in this chapter).

\section{Adjust}

- Adjust pharmacological treatment, including escalation or de-escalation. Switching inhaler device or molecules within the same class (e.g. using a different long acting bronchodilator) may be considered as appropriate. Any change in treatment requires a subsequent review of the clinical response, including side effects.

\section{Dyspnea}

For patients with persistent breathlessness or exercise limitation on long acting bronchodilator monotherapy, $\underline{12}$ the use of two bronchodilators is recommended.

- If the addition of a second long acting bronchodilator does not improve symptoms, we suggest the treatment could be stepped down again to monotherapy. Switching inhaler device or molecules can also be considered.

For patients with persistent breathlessness or exercise limitation on LABA/ICS treatment, LAMA can be added to escalate to triple therapy.

- Alternatively, switching from LABA/ICS to LABA/LAMA should be considered if the original indication for ICS was inappropriate (e.g., an ICS was used to treat symptoms in the absence of a history of exacerbations), or there has been a lack of response to ICS treatment, or if ICS side effects warrant discontinuation.

At all stages, dyspnea due to other causes (not COPD) should be investigated and treated appropriately. Inhaler technique and adherence should be considered as causes of inadequate 
treatment response.

\section{Exacerbations}

For patients with persistent exacerbations on long acting bronchodilator monotherapy, escalation to either LABA/LAMA or LABA/ICS is recommended. LABA/ICS may be preferred for patients with a history or findings suggestive of asthma. Blood eosinophil counts may identify patients with a greater likelihood of a beneficial response to ICS. For patients with one exacerbation per year, a peripheral blood level $\geq 300$ eosinophils/ $\mu \mathrm{L}$ identifies patients more likely to respond to LABA/ICS treatment. $\underline{13,14}$ For patients with $\geq 2$ moderate exacerbations per year or at least one severe exacerbation requiring hospitalization in the prior year, LABA/ICS treatment can be considered at blood eosinophil counts $\geq$ 100 cells $/ \mu \mathrm{L}$, as ICS effects are more pronounced in patients with greater exacerbation frequency and/or severity. $\underline{15}$

In patients who develop further exacerbations on LABA/LAMA therapy we syggest two alternative pathways. Blood eosinophil counts $<100$ cells $/ \mu \mathrm{L}$ can be used to predict a low likelihood of a beneficial ICS response:

- Escalation to LABA/LAMA/ICS. A beneficial response after the addition of ICS may be observed at blood eosinophil counts $\geq 100$ cells $/ \mu \mathrm{L}$, with a) greater magnitude of response more likely with higher eosinophil counts.

- Add roflumilast or azithromycin (see below) if blood eosinophils $<100$ cells $/ \mu \mathrm{L}$.

In patients who develop further exacerbations on LABA/ICS therapy, we recommend escalation to triple therapy by adding a LAMA. $\underline{15}, \underline{16}$ Alternatively, treatment can be switched to LABA/LAMA if there has been a lack of response to ICS treatment, or if ICS side effects warrant discontinuation.

If patients treated with LABA/LAMA/ICS who still have exacerbations the following options may be considered:

- Add roflumilast. This may be considered in patients with an $\mathrm{FEV}_{1}<50 \%$ predicted and chronic bronchitis, $1-$ particularly if they have experienced at least one hospitalization for an exacerbation in the previous year. $\underline{18,19}$

- Add a macrolide. The best available evidence exists for the use of azithromycin, especially in those who are not current smokers. $\underline{20}, 21$ Consideration to the development of resistant organisms should be factored into decision-making.

- Stopping ICS. This can be considered if there are adverse effects (such as pneumonia) or a reported lack of efficacy. However, a blood eosinophil count $\geq 300$ cells $/ \mu \mathrm{L}$ identifies patients with the greatest likelihood of experiencing more exacerbations after ICS withdrawal and who subsequently should be followed closely for relapse of exacerbations. $\underline{2}, \underline{23}$ 


\section{TREATMENT OF STABLE COPD: NON- PHARMACOLOGICAL TREATMENT}

\section{Education and self-management}

Self-management education and coaching by healthcare professionals should be a major component of the "Chronic Care Model" within the context of the healthcare delivery system.

The aim of self-management interventions is to motivate, engage and coach the patients to positively adapt their health behavior(s) and develop skills to better manage their disease on a day-to-day basis. $\underline{24}$

Physicians and healthcare providers need to go beyond pure education/advice-giving (didactic) approaches to help patients learn and adopt sustainable self-management skills. In addition to addressing behavioral risk factors (i.e., smoking, diet, exercise), self-management should involve patients in monitoring and managing the signs and symptoms of their disease, being adherent to treatment (including to medications and other medical advice), maintaining regular contact with healthcare providers, and managing the psychosocial consequences of their condition.

The individual patient's evaluation and risk assessment with respect to exacerbations, patient's needs, preferences, and personal goals should inform the personalized design of the self-management education plan.

Based on GOLD groups, personalized design coúld include:

- Groups A, B, C \& D - addressing behavioral risk factors, including smoking cessation, maintaining or increasing physical activity, and ensuring adequate sleep and a healthy diet.

- Groups B \& D - learning to self-manage breathlessness, energy conservation techniques, and stress management strategies.

- Groups C \& D - avoiding aggravating factors, monitoring and managing worsening symptoms, having a written action plan and maintaining regular contact/communication with a healthcare professional.

- Group D - discussing with their healthcare providers palliative strategies and advance care directives.

Some relevant non-pharmacological measures for patient groups $A$ to $D$ are summarized in Table 4.8. 


\begin{tabular}{clcc}
\hline NON-PHARMACOLOGIC MANAGENENT OF COPD \\
$\begin{array}{clc}\text { PATIENT } \\
\text { GROUP }\end{array}$ & ESSENTIAL & RECOMMENDED & $\begin{array}{c}\text { DEPENDING ON LOCAL } \\
\text { GUIDELINES }\end{array}$ \\
\hline $\mathbf{A}$ & $\begin{array}{l}\text { Smoking Cessation } \\
\text { (can include pharmacologic } \\
\text { treatment) }\end{array}$ & Physical Activity & Flu Vaccination \\
\hline B-D & $\begin{array}{l}\text { Smoking Cessation } \\
\text { (can include pharmacologic } \\
\text { treatment) }\end{array}$ & Physical Activity & Flu Vaccination \\
\hline
\end{tabular}

TABLE 4.8

\section{Physical activity}

Pulmonary rehabilitation, including community and home-based, is an approach with clear evidence of benefits. However, the challenge is promoting physical activity and maintaining it. There is evidence that physical activity is decreased in COPD patients. $\underline{25}$ This leads to a downward spiral of inactivity which predisposes patients to reduced quality of life, increased rates of hospitalization and mortality. $\frac{26-28}{2}$ As such, there has been tremendous interest in implementing behavior-targeted interventions with the aim of improving physical activity $\underline{29}$ and these should be encouraged. $\underline{26}$ However, most published studies to date provide little guidance, being inconsistent in the techniques, and lacking the necessary details (e.g., type, quantity, timing and method of delivery; tools used; quality-assurance methods) to replicate the study or adapt the interventions for clinical care.

\section{Pulmonary rehabilitation gêgrams}

Patients with high symptom burden and risk of exacerbations (Groups B, C and D), should be encouraged to take part in formal rehabilitation program that includes setting patient goals and is designed and delivered in a structured manner, taking into account the individual's COPD characteristics and-comorbidities. $\underline{30-32}$

Key time points when it may be appropriate to consider referral are: (a) at diagnosis; (b) at discharge following hospitalization for an exacerbation; and (c) when symptoms are found to be progressively deteriorating. These could relate to each patient at different time points of the disease trajectory.

Because benefits diminish over time if activity and other positively adaptive behaviors are not continued, patients should be offered a maintenance program, or at least supported sufficiently to increase and maintain physical activity in daily living. If deterioration is noted in physical or functional health status a year or more after improvement from an initial pulmonary rehabilitation program, it may be feasible to refer the patient for additional rehabilitation.

The components of pulmonary rehabilitation may vary but evidence-based best practice for program delivery includes: structured and supervised exercise training, smoking cessation, nutrition 
counseling, and self-management education. Further details and recommendations on the components of pulmonary rehabilitation, the program organization (duration and structure) and evaluation are presented in Chapter 3. $\cdot 30$

\section{Exercise training}

A meta-analysis of RCTs found that exercise training alone, or with the addition of activity counseling, significantly improved physical activity levels in COPD patients. $\frac{33}{} \mathrm{~A}$ combination of constant load or interval training with strength training provides better outcomes than either method alone. ${ }^{34}$

Where possible, endurance exercise training to $60-80 \%$ of the symptom-limited maximum work or heart rate is preferred, ${ }^{35}$ or to a Borg-rated dyspnea or fatigue score of 4 to 6 (moderate to severe). $\frac{36}{6}$ Endurance training can be accomplished through either continuous or interval exercise programs. The latter involves the patient doing the same total work but divided into briefer periods of high-intensity exercise, a useful strategy when performance is limited by other comorbidities,, $3 z$

Exercise training can be enhanced by optimizing bronchodilators, $\underline{39}$ since both LAMA and LABA have shown reduced resting and dynamic hyperinflation. These changes contribute to better training effects. ${ }^{40,41}$ Adding strength training to aerobic training is effective in improving strength, but does not improve health status or exercise tolerance. $\stackrel{42}{ }$ Upper extremities exercise training improves arm strength and endurance, and results in improved functiona capacity for upper extremity activities. $\frac{43}{3}$ Exercise capacity may also be improved by whole-body Vibration training. 44

Inspiratory muscle training increases strength of inspiratory muscles,,$\underline{45}$ but this not consistently translate to better performance, reduced dysṕnea or improved health related quality of life when added to a comprehensive pulmonary rehabilitation program. $\underline{46,47,48}$

Assessment and follow-up. Baseline and outcome assessments of each participant in a pulmonary rehabilitation program should be made to specify individual maladaptive behaviors (including motivation), physical and mental health impediments to training, goals, barriers and capabilities and to quantify gains and to target areas for improvement.

Assessments should include:

1. Detailed history and physical examination.

2. Measurement of post-bronchodilator spirometry.

3. Assessment of exercise capacity.

4. Measurement of health status and impact of breathlessness.

5. Assessment of inspiratory and expiratory muscle strength and lower limb strength in patients who suffer from muscle wasting.

6. Discussion about individual patient goals and expectations

The first two assessments are important for establishing entry suitability and baseline status but are not used in outcome assessment. 
Exercise tolerance can be assessed by cycle ergometry or treadmill exercise with the measurement of a number of physiological variables, including maximum oxygen consumption, maximum heart rate, and maximum work performed. Standardized self-paced, timed walking tests (e.g., 6-minute walking distance) are useful in clinical practice as they require minimal facilities and are relevant to routine functioning. Shuttle walking tests provide more complete information than an entirely self-paced test, and are simpler to perform than a treadmill test. ${ }^{49}$ Walking tests do require at least one practice session before data can be interpreted.

It is important not to limit assessment only to these outcome measures but gather information on each patient's ultimate goal (relevant or valued outcomes), such as their desired achievements in work, home and leisure by the end of the program.

Several detailed questionnaires for assessing health status are available, including some specifically designed for patients with respiratory disease. Health status can also be assessed by generic instruments, although these are less sensitive to change than the disease specific questionnaires such as the CAT ${ }^{\mathrm{TM}}, \mathrm{CRQ}$ or SGRQ. The Hospital Anxiety and Depression Scale (HADS) $\underline{50}$ and the Primary Care Evaluation of Mental Disorders (PRIME-MD) Patient Questionnaire 51 Dave been used to improve identification and treatment of anxious and depressed patients.

\section{Self-management intervention}

The basis of enabling patients to become active partners in their ongoing care is to build knowledge and skills. Topics considered appropriate for an education program include: smoking cessation; basic information about COPD; general approach to therapy and specific aspects of medical treatment (respiratory medications and inhalation devices); strategies to help minimize dyspnea; advice about when to seek help; decision-making during exacerbations; and advance directives and end-of-life issues. The intensity and content of these educational messages will vary depending on the severity of the patient's disease, although the specific contributions of education to the improvements seen

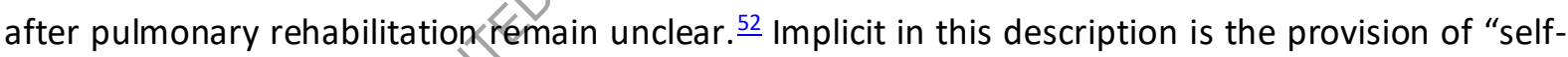
management support/coaching", which refers to the strategies, techniques and skills used by healthcare providers to arm patients with the knowledge, confidence and skills required to selfmanage their disease effectively.

It is important to recognize that patient education alone does not itself change behavior or even motivate patients, and it has had no impact on improving exercise performance or lung function, $\underline{53,54}$ but it can play a role in improving skills, ability to cope with illness, and health status. $\frac{30}{\text { Patients may }}$ have individual and/or group education sessions. During group sessions, patients engage in active, participatory-based learning of program content. During one-on-one interactions, a motivational communication style should be used, as this approach empowers patients to take greater responsibility for their health and well-being, where physicians and other healthcare professionals only serve as guides in the behavior change process. 


\section{End-of-life and palliative care}

The goal of palliative care is to relieve the suffering of patients and their families by the comprehensive assessment and treatment of physical, psychosocial, and spiritual symptoms experienced by patients. Patients with a chronic life-limiting illness like COPD should be informed that, should they become critically ill, they or their family members may be in a position where they would need to decide whether a course of intensive care is likely to achieve their personal goals of care, and they are willing to accept the burdens of such treatment.

Clinicians should develop and implement methods to help patients and their families to make informed choices that are consistent with patients' values. Simple, structured approaches to facilitate these conversations may help to improve the occurrence and quality of communication from the patients' perspective. $\frac{55}{}$

\section{Nutritional support}

For malnourished patients with COPD nutritional supplementation is recommended. This is based on systematic review findings of positive effects on body weight, fat mass and fat-free mass when nutritional supplementation is provided alone to COPD patients (especially if malnourished) and when used as an adjunct to exercise training. The optimal amount and duration of supplementation are not clearly established. $\underline{56}$ Patients receiving nutritional supplementation demonstrated significant improvements compared to baseline for 6 -minute walk test, respiratory muscle strength and health status (only in malnourished patients). $\underline{56}$

\section{Vaccination}

Influenza vaccination is recommended førall patients with COPD..$\underline{7}$

Pneumococcal vaccinations, PCV13 and PPSV23, are recommended for all patients $>65$ years of age. The PPSV23 is also recommended for younger COPD patients with significant comorbid conditions including chronic heart or lang disease. $\underline{58}$

\section{Oxygen therapy?}

Long-term oxygen therapy is indicated for stable patients who have:

- $\mathrm{PaO}_{2}$ at or below $7.3 \mathrm{kPa}(55 \mathrm{mmHg})$ or $\mathrm{SaO}_{2}$ at or below $88 \%$, with or without hypercapnia confirmed twice over a three-week period; or

- $\mathrm{PaO}_{2}$ between $7.3 \mathrm{kPa}\left(55 \mathrm{mmHg}\right.$ ) and $8.0 \mathrm{kPa}(60 \mathrm{mmHg})$, or $\mathrm{SaO}_{2}$ of $88 \%$, if there is evidence of pulmonary hypertension, peripheral edema suggesting congestive cardiac failure, or polycythemia (hematocrit $>55 \%$ ).

Once placed on long-term oxygen therapy (LTOT) the patient should be re-evaluated after 60 to 90 days with repeat arterial blood gas ( $A B G$ ) or oxygen saturation while inspiring the same level of oxygen or room air to determine if oxygen is therapeutic and still indicated, respectively. An appropriate algorithm for the prescription of oxygen to COPD patients is shown in Figure 4.4. 
Arterial hypoxemia defined as:

$\mathrm{PaO}_{2}<55 \mathrm{mmHg}(8 \mathrm{kPa})$ or $\mathrm{SaO}_{2}<88 \%$

or

$\mathrm{PaO}_{2}>55$ but $<60 \mathrm{mmHg}$ ( $>7.3 \mathrm{kPa}$ but $\left.<8 \mathrm{kPa}\right)$

with right heart failure or erythrocytosis

FIGURE 4.4

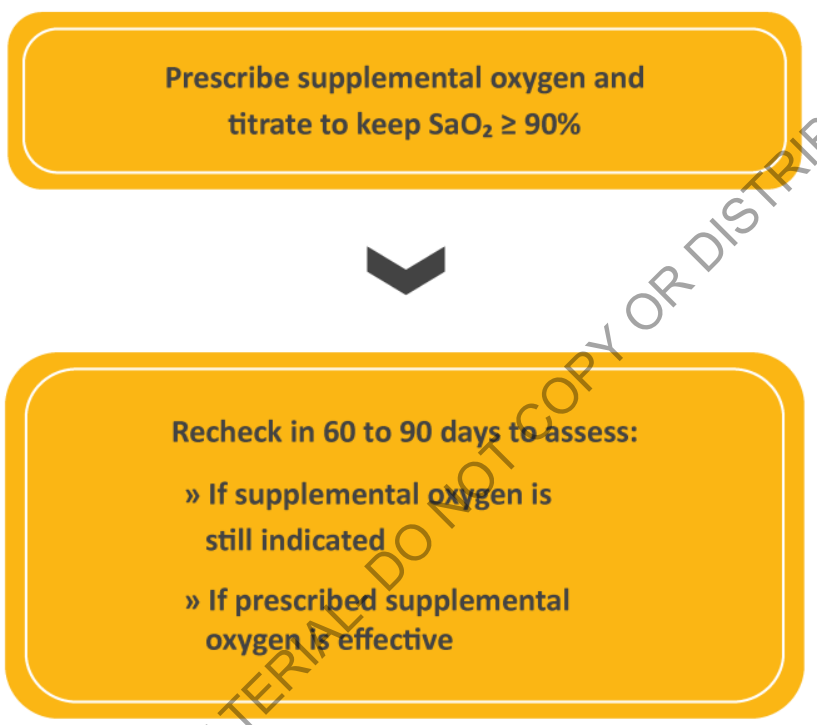

\section{Ventilatory support}

NIV is occasionally used in patients with stable very severe COPD. NIV may be considered of some use in a selected group of patients, particularly in those with pronounced daytime hypercapnia and recent hospitalization, although systematic review is unable to support or refute this. $\frac{59}{}$ However, in patients with both COPD and obstructive sleep apnea there are clear indications for continuous positive airway pressure (CPAP). $\underline{60}$

\section{Interventional bronchoscopy and surgery}

- In selected patients with heterogeneous or homogenous emphysema and significant hyperinflation refractory to optimized medical care, surgical or bronchoscopic modes of lung volume reduction (e.g., endobronchial one-way valves, lung coils or thermal ablation) may be considered..$\underline{61}$ Some of these therapies (vapor ablation and lung coils) are not widely available for clinical care in many countries.

- In selected patients with a large bulla, surgical bullectomy may be considered.

- In selected patients with very severe COPD and without relevant contraindications, lung transplantation may be considered. 
Choosing bronchoscopic lung reduction (endobronchial valve, coil placement or thermal ablation) or surgical resection (lung volume reduction surgery, LVRS) to treat hyperinflation in an emphysematous patient depends on a number of factors. These include: the extent and pattern of emphysema identified on $\mathrm{HRCT}$; the presence of interlobar collateral ventilation measured by fissure integrity on HRCT or physiological assessment (endoscopic balloon occlusion and flow assessment); regional availability of the various therapies for clinical care, local proficiency in the performance of the procedures; and patient and provider preferences. Vapor ablation therapy is the only lung reduction therapy that has been reported to be successfully performed at the segmental rather than lobar level. $\underline{62}$

INTERVENTIONAL BRONCHOSCOPIC AND SURGICAL TREATMENTS FOR COPD

Overview of various therapies used to treat patients with COPD and emphysema worldwide. Note that all therapies are not approved for clinical care in all countries. Additionally, the effects of BLVR on survival or other long term outcomes or comparison to LVRS are unknown.

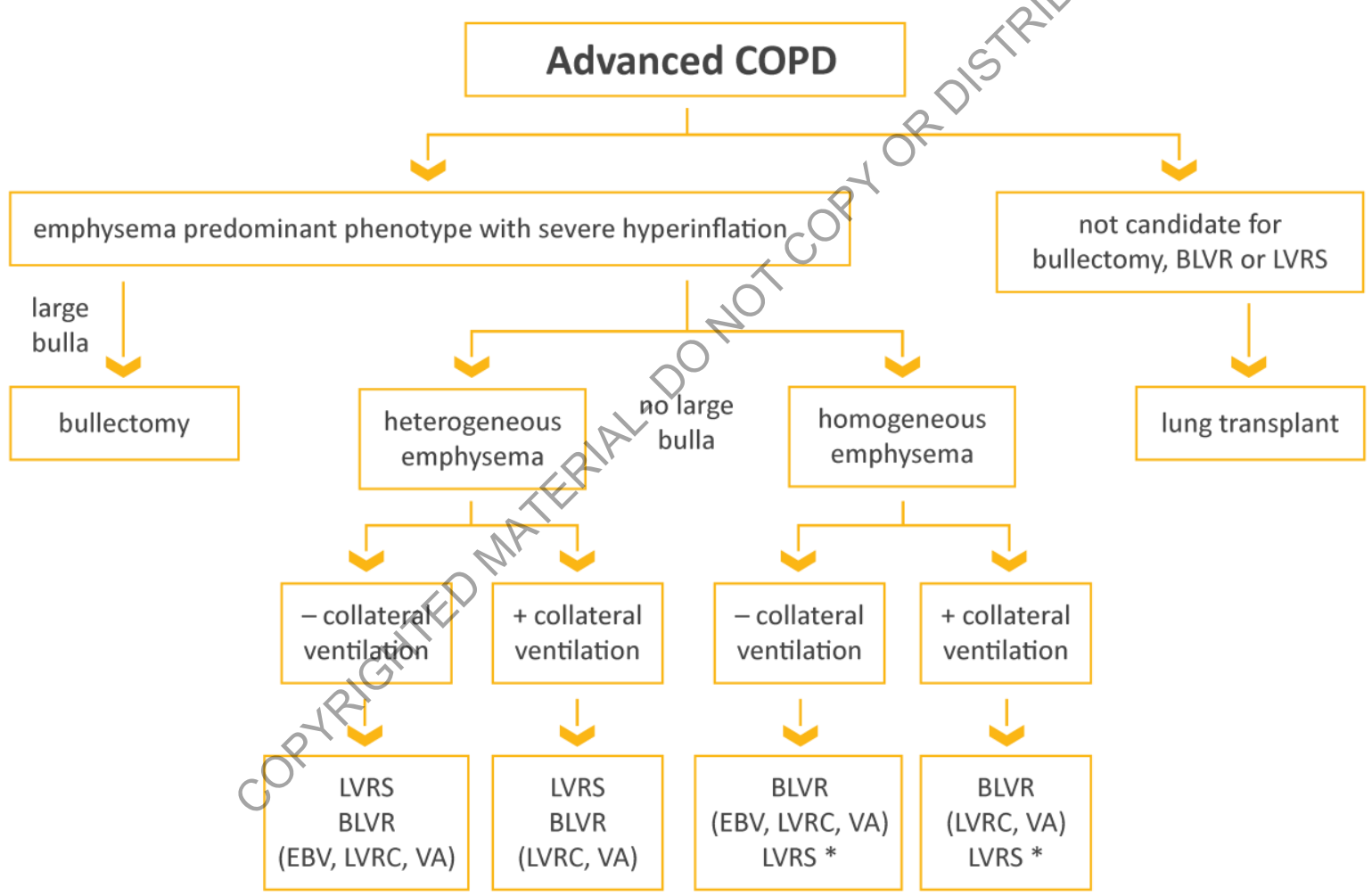

Definition of Abbreviations: BLVR, Bronchoscopic Lung Volume Reduction, EBV, endobronchial Valve, LVRS, Lung volume reduction surgery, LVRC, Lung volume reduction coil, VA, Vapor ablation

*at some but not all centers

FIGURE 4.5

In patients with fissure integrity or lack of interlobar collateral ventilation based on physiologic assessment, endobronchial valve, lung coil treatment, vapor ablation therapy or LVRS could all be useful. In patients with lack of fissure integrity or interlobar collateral ventilation, vapor ablation, lung coil therapy or LVRS may be performed but endobronchial valve therapy is not useful. Patients with heterogeneous upper lobe predominant emphysema may be candidates for either LVRS or bronchoscopic lung reduction approaches. The presence of interlobar collateral ventilation would 
exclude the use of endobronchial valve therapy but lung coil or vapor ablation therapies could be considered along with LVRS. Patients with homogenous emphysema are not routinely considered candidates for LVRS at most centers, however, bronchoscopic lung reduction can be successful using endobronchial valve, vapor ablation or coil therapies. Again the presence of interlobar collateral ventilation is important in selecting endobronchial valve as the intervention of choice. An algorithm depicting an overview of various interventions is shown in Figure 4.5.

Criteria for referral for lung transplantation include COPD with progressive disease, not a candidate for endoscopic or surgical lung volume reduction, $\mathrm{BODE}$ index of 5 to $6, \mathrm{PCO}_{2}>50 \mathrm{~mm} \mathrm{Hg}$ or $6.6 \mathrm{kPa}$ and/or $\mathrm{PaO}_{2}<60 \mathrm{mmHg}$ or $8 \mathrm{kPa}$, and $\mathrm{FEV}_{1}<25 \%$ predicted. $\underline{63}$ Recommended criteria for listing include one of the following: BODE index $>7, \mathrm{FEV}_{1}<15-20 \%$ predicted, three or more severe exacerbations during the preceding year, one severe exacerbation with acute hypercapnic respiratory failure, or moderate to severe pulmonary hypertension. $\underline{63, \underline{64}}$

Key points for the use of non-pharmacological treatments are given in Table 4.9. 
KEY POINTS FOR THE USE OF NON-PHARMACOLOGICAL TREATMENTS

\section{EDUCATION, SELF-MANAGEMENT AND PULMONARY REHABILITATION}

- Education is needed to change patient's knowledge but there is no evidence that used alone it will change patient behavior.

- Education self-management with the support of a case manager with or without the use of a written action plan is recommended for the prevention of exacerbation complications such as hospital admissions (Evidence B).

- Rehabilitation is indicated in all patients with relevant symptoms and/or a high risk for exacerbation (Evidence A).

- Physical activity is a strong predictor of mortality (Evidence A). Patients should be encouraged to increase the level of physical activity although we still don't know how to best insure the likelihood of success.

\section{VACCINATION}

- Influenza vaccination is recommended for all patients with COPD (Evidence A).

- Pneumococcal vaccination: the PCV13 and PPSV23 are recommended for all patients> 65 years of age, and in younger patients with significant comorbid conditions including chronic heart or lung disease (Evidence B).

\section{NUTRITION}

- Nutritional supplementation should be considered in malnourished patients with CQPD (Evidence B).

\section{END OF LIFE AND PALLIATIVE CARE}

- All clinicians managing patients with COPD should be aware of the effectiveness of palliative approaches to symptom control and use these in their practice (Evidence D).

- End of life care should include discussions with patients and their amilies about their views on resuscitation, advance directives and place of death preferences (Evidence D).

TREATMENT OF HYPOXEMIA

- In patients with severe resting hypoxemia long-term Qyygen therapy is indicated (Evidence A).

- In patients with stable COPD and resting or exercisé-induced moderate desaturation, long term oxygen treatment should not be routinely prescribed. However, individual patient factors may be considered when evaluating the patient's needs for supplemental oxygen (Evidence A).

- Resting oxygenation at sea level does nof exclude the development of severe hypoxemia when travelling by air (Evidence $\mathrm{C}$ ).

TREATMENT OF HYPERCAPNIA

- In patients with severe chronic hypercapnia and a history of hospitalization for acute respiratory failure, long term noninvasive ventilation may be considered (Evidence B).

\section{INTERVENTION BRONCHOSCOPY AND SURGERY}

- Lung volume reduction surgery should be considered in selected patients with upper-lobe emphysema (Evidence A).

- Bronchoscopic lung volume reduction interventions may be considered in selected patients with advanced emphysema (Evidence B).

- In selected patients with a large bulla surgical bullectomy may be considered (Evidence C).

- In patients with very severe COPD (progressive disease, BODE score of 7 to 10 , and not candidate for lung volume reduction) lung transplantation may be considered for referral with at least one of the following: (1) history of hospitalization for exacerbation associated with acute hypercapnia $\left(\mathrm{PcO}_{2}>50 \mathrm{~mm} \mathrm{Hg}\right)$; (2) pulmonary hypertension and/or cor pulmonale, despite oxyqen therapy; or (3) $\mathrm{FEV}_{1}<20 \%$ and either DLCO $<20 \%$ or homogenous distribution of emphysema (Evidence C).

TABLE 4.9 


\section{MONITORING AND FOLLOW-UP}

Routine follow-up of COPD patients is essential. Lung function may worsen over time, even with the best available care. Symptoms, exacerbations and objective measures of airflow limitation should be monitored to determine when to modify management and to identify any complications and/or comorbidities that may develop. Based on current literature, comprehensive self-management or routine monitoring has not shown long-term benefits in terms of health status over usual care alone for COPD patients in general practice. $\underline{65}$

\section{Monitoring disease progression and development of complications and/or}

\section{comorbidities}

Measurements. Decline in $\mathrm{FEV}_{1}$ can be tracked by spirometry performed at least once a year to identify patients who are declining quickly, although other lung function parameters reflecting hyperinflation and gas transfer may also be informative.

Functional capacity as measured by a timed walking test (6-minute walking distance or shuttle-walking test) provides additional information regarding prognosis. $\underline{66}, 67$ Measurement of oxygenation at rest in an arterial blood gas sample may help identify patients who will benefit from supplemental oxygen to improve both symptoms and survival in those with severe resting hypoxemia.

Symptoms. At each visit, information on symptoms since the last visit should be collected, including cough and sputum, breathlessness, fatigue, activitylimitation, and sleep disturbances. Questionnaires such as the COPD Assessment Test (CAT $\left.{ }^{\mathrm{TM}}\right)^{\underline{68}}$ can be used; trends and changes are more valuable than single measurements.

Exacerbations. The frequency, severity, type and likely causes of all exacerbations ${ }^{69}$ should be monitored. Sputum volume and presence or absence of sputum purulence should be noted. Specific inquiry into response to prexious treatment, unscheduled visits to providers, telephone calls for assistance, and use of urgeht or emergency care facilities is important. Hospitalizations should be documented, including the facility, duration of stay, and any use of critical care or mechanical ventilatory support.

Imaging. If there is a clear worsening of symptoms, imaging may be indicated. When exacerbations are repeatedly characterized by purulent sputum, patients should be investigated for bronchiectasis.

Smoking status. At each visit, the current smoking status and smoke exposure should be determined followed by appropriate action.

\section{Pharmacotherapy and other medical treatment}

In order to adjust therapy appropriately as the disease progresses, each follow-up visit should include a discussion of the current therapeutic regimen. Monitoring should focus on:

- Dosages of prescribed medications.

- Adherence to the regimen. 
- Inhaler technique.

- Effectiveness of the current regime.

- Side effects.

Treatment modifications should be recommended (Figure 4.1).

\section{Comorbidities}

Those symptoms that may indicate the worsening or development of another comorbid condition such as obstructive sleep apnea, congestive heart failure, ischemic heart disease, etc. should be recorded and an approach to their evaluation and treatment enacted. Therefore, monitoring is recommended for conditions including heart failure, ischemic heart disease, arrhythmias, osteoporosis, depression/anxiety, and lung cancer (see also Chapter 6).

\section{Surgery in the COPD patient}

General. Postoperative pulmonary complications are as important and common as postoperative cardiac complications and, consequently, are a key component of the increased risk posed by surgery in COPD patients. ${ }^{70}$ The key factors that can contribute to the risk include smoking, poor general health status, age, obesity, and COPD severity. A comprehensive definition of postoperative pulmonary complications should include only major pulmonary respiratory complications, namely lung infections, atelectasis and/or increased airflow limitation, which allpotentially result in acute respiratory failure and aggravation of COPD. $\underline{71-73}$

Increased risk of postoperative pulmonary complications in COPD patients may vary with the severity of COPD, although the surgical site is the most important predictor and risk increases as the incision approaches the diaphragm. $\underline{-3}$ Most reports conclude that epidural or spinal anesthesia have a lower risk than general anesthesia, although the results are not totally uniform. Some studies conducted in patients undergoing sham bronchoscopic procedures have reported acute exacerbation rates as high

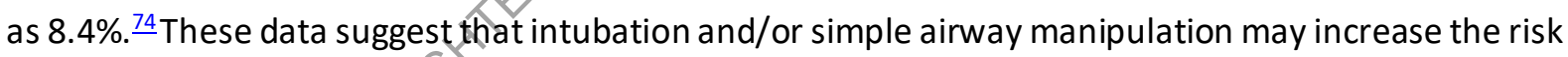
of exacerbation in select CQQPD patients.

To prevent postoperative pulmonary complications, stable COPD patients clinically symptomatic and/or with limited exercise capacity should be treated medically intensively before surgery, with all the measures already well established for stable COPD patients who are not about to have surgery. The presence of comorbid conditions, especially cardiac abnormalities, should be systemically assessed and treated before any major surgical intervention.

Lung resection. For lung resection, the individual patient's risk factors should be identified by careful history taking including physical examination, chest radiography, and pulmonary function tests. Although the value of pulmonary function tests remains contentious, there is consensus that all COPD candidates for lung resection should undergo a complete battery of tests, including spirometry with bronchodilator response, static lung volumes, diffusing capacity, and arterial blood gases at rest. $.75, \underline{76}$ COPD patients at high risk for surgical complications due to poor lung function should undergo

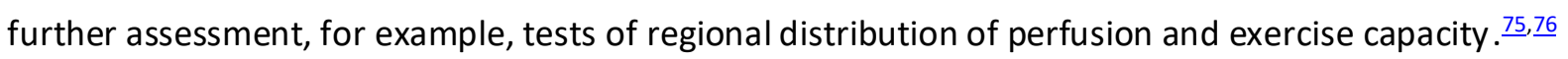


The risk of postoperative complications from lung resection appears to be increased in patients with decreased predicted postoperative pulmonary function ( $\mathrm{FEV}_{1}$ or DLCO $<30-40 \%$ predicted) or exercise capacity (peak $\mathrm{VO}_{2}<10 \mathrm{ml} / \mathrm{kg} / \mathrm{min}$ or $35 \%$ predicted). The final decision to pursue surgery should be made after discussion with the surgeon, pulmonary specialist, primary clinician, and the patient. Surgery should be postponed if an exacerbation is present.

\section{REFERENCES}

1. The Tobacco Use and Dependence Clinical Practice Guideline Panel. A clinical practice guideline for treating tobacco use and dependence: A US Public Health Service report. JAMA 2000; 283(24): 324454.

2. Romieu I, Riojas-Rodriguez H, Marron-Mares AT, Schilmann A, Perez-Padilla R, Masera O. Improved biomass stove intervention in rural Mexico: impact on the respiratory health of women. Am J Respir Crit Care Med 2009; 180(7): 649-56.

3. Liu S, Zhou Y, Wang X, et al. Biomass fuels are the probable risk factor for chronic obstructive pulmonary disease in rural South China. Thorax 2007; 62(10): 889-97.

4. Appleton S, Poole P, Smith B, Veale A, Lasserson TJ, Chan MM. Long-acting beta2-agonists for poorly reversible chronic obstructive pulmonary disease. Cochrane database of systematic reviews 2006; 3(3): CD001104.

5. Barr RG, Bourbeau J, Camargo CA, Ram FS. Inhaled tiotropium forstable chronic obstructive pulmonary disease. Cochrane Database Syst Rev 2005; (2): CD002876.

6. Martinez FJ, Fabbri LM, Ferguson GT, et al. Baseline Symptom Score Impact on Benefits of Glycopyrrolate/Formoterol Metered Dose Inhaler in COPD. Chest 2017.

7. Lange P, Marott JL, Vestbo J, et al. Prediction of the clinical course of chronic obstructive pulmonary disease, using the new GOLD classification: a study of the general population. Am J Respir Crit Care Med 2012; 186(10): 975-81.

8. Agusti A, Edwards LD, Celli B, et al. Characteristics, stability and outcomes of the 2011 GOLD COPD groups in the ECLIPSE cohort. Eur Respir 12013; 42(3): 636-46.

9. Vogelmeier C, Hederer B, Glaab T, et al. Tiotropium versus salmeterol for the prevention of exacerbations of COPD. N Engl J Med 2011; 364(12): 1093-103.

10. Decramer ML, Chapman KR, DahlR, et al. Once-daily indacaterol versus tiotropium for patients with severe chronic obstructive pulmonary disease (INVIGORATE): a randomised, blinded, parallel-group study. The Lancet Respiratory medicine 2013; 1(7): 524-33.

11. Crim C, Dransfield MT,Bourbeau J, et al. Pneumonia risk with inhaled fluticasone furoate and vilanterol compared with vilanterol alone in patients with COPD. Annals of the American Thoracic Society 2015; 12(1): 27-34.

12. Karner C, Cates CJ. Long-acting beta(2)-agonist in addition to tiotropium versus either tiotropium or long-acting beta(2)-agonist alone for chronic obstructive pulmonary disease. Cochrane Database Syst Rev 2012; (4): Cd008989.

13. Siddiqui SH, Guasconi A, Vestbo J, et al. Blood Eosinophils: A Biomarker of Response to Extrafine Beclomethasone/Formoterol in Chronic Obstructive Pulmonary Disease. Am J Respir Crit Care Med 2015; 192(4): 523-5.

14. Bafadhel M, Peterson S, De Blas MA, et al. Predictors of exacerbation risk and response to budesonide in patients with chronic obstructive pulmonary disease: a post-hoc analysis of three randomised trials.

The Lancet Respiratory medicine 2018; 6(2): 117-26.

15. Lipson DA, Barnhart F, Brealey N, et al. Once-Daily Single-Inhaler Triple versus Dual Therapy in Patients with COPD. N Engl J Med 2018; 378(18): 1671-80.

16. Singh D, Papi A, Corradi M, et al. Single inhaler triple therapy versus inhaled corticosteroid plus longacting beta2-agonist therapy for chronic obstructive pulmonary disease (TRILOGY): a double-blind, parallel group, randomised controlled trial. Lancet 2016; 388(10048): 963-73.

17. Martinez FJ, Calverley PM, Goehring UM, Brose M, Fabbri LM, Rabe KF. Effect of roflumilast on exacerbations in patients with severe chronic obstructive pulmonary disease uncontrolled by combination therapy (REACT): a multicentre randomised controlled trial. Lancet 2015; 385(9971): 857-66. 
18. Martinez FJ, Rabe KF, Sethi S, et al. Effect of Roflumilast and Inhaled Corticosteroid/Long-Acting Beta2-Agonist on Chronic Obstructive Pulmonary Disease Exacerbations (RE2SPOND) A Randomized Clinical Trial. Am J Respir Crit Care Med 2016; 194(5): 559-67.

19. Rabe KF, Calverley PMA, Martinez FJ, Fabbri LM. Effect of roflumilast in patients with severe COPD and a history of hospitalisation. Eur Respir J 2017; 50(1).

20. Albert RK, Connett J, Bailey WC, et al. Azithromycin for prevention of exacerbations of COPD. N Engl J Med 2011; 365(8): 689-98.

21. Han MK, Tayob N, Murray S, et al. Predictors of chronic obstructive pulmonary disease exacerbation reduction in response to daily azithromycin therapy. Am J Respir Crit Care Med 2014; 189(12): 1503-8.

22. Chapman KR, Hurst JR, Frent SM, et al. Long-term Triple Therapy De-escalation to Indacaterol/Glycopyrronium in COPD Patients (SUNSET): a Randomized, Double-Blind, Triple-Dummy Clinical Trial. Am J Respir Crit Care Med 2018.

23. Calverley PMA, Tetzlaff K, Vogelmeier C, et al. Eosinophilia, Frequent Exacerbations, and Steroid Response in Chronic Obstructive Pulmonary Disease. Am J Respir Crit Care Med 2017; 196(9): 1219-21.

24. Effing TW, Vercoulen JH, Bourbeau J, et al. Definition of a COPD self-management intervention: International Expert Group consensus. Eur Respir J 2016; 48(1): 46-54.

25. Pitta F, Troosters T, Spruit MA, Probst VS, Decramer M, Gosselink R. Characteristics of physical activities in daily life in chronic obstructive pulmonary disease. Am J Respir Crit Care Med 2005; 171(9): 972-7.

26. Watz H, Pitta F, Rochester CL, et al. An official European Respiratory Society statement on physical activity in COPD. Eur Respir J 2014; 44(6): 1521-37.

27. Garcia-Aymerich J, Lange P, Benet M, Schnohr P, Anto JM. Regular physical activity reduces hospital admission and mortality in chronic obstructive pulmonary disease: a population based cohort study. Thorax 2006; 61(9): 772-8.

28. Yohannes AM, Baldwin RC, Connolly M. Mortality predictors in disabling chronic obstructive pulmonary disease in old age. Age Ageing 2002; 31(2):137-40.

29. Mantoani LC, Rubio N, McKinstry B, MacNee W, Rabinovich RA. Interventions to modify physical activity in patients with COPD: a systematic review. Eur Respir J 2016; 48(1): 69-81.

30. Spruit MA, Singh SJ, Garvey C, et al. An officia/American Thoracic Society/European Respiratory Society statement: key concepts and advances in pulmonary rehabilitation. Am J Respir Crit Care Med 2013; 188(8): e13-64.

31. Vogiatzis I, Rochester CL, Spruit MA, Troosters T, Clini EM, American Tho racic Society/European Respiratory Society Task Force on Policy in Pulmonary Rehabilitation. Increasing implementation and delivery of pulmonary rehabilitation: key messages from the new ATS/ERS policy statement. Eur Respir J 2016; 47(5): 1336-41.

32. Garvey C, Bayles MP, Hamm LF, et al. Pulmonary Rehabilitation Exercise Prescription in Chronic Obstructive Pulmonary Disease: Review of Selected Guidelines: An official statement from the American Association of Cardiovascular and Pulmonary Rehabilitation J Cardiopulm Rehabil Prev 2016; 36(2): 75-83.

33. Lahham A, MCDonald CF, Holland AE. Exercise training alone or with the addition of activity counseling improves physical activity levels in COPD: a systematic review and meta-analysis of randomized controlled trials. Int J Chron Obstruct Pulmon Dis 2016; 11: 3121-36.

34. Ortega F, Toral J, Cejudo P, et al. Comparison of effects of strength and endurance training in patients with chronic obstructive pulmonary disease. Am J Respir Crit Care Med 2002; 166(5): 669-74.

35. Garber CE, Blissmer B, Deschenes MR, et al. American College of Sports Medicine position stand. Quantity and quality of exercise for developing and maintaining cardiorespiratory, musculoskeletal, and neuromotor fitness in apparently healthy adults: guidance for prescribing exercise. Med Sci Sports Exerc 2011; 43(7): 1334-59.

36. Horowitz MB, Littenberg B, Mahler DA. Dyspnea ratings for prescribing exercise intensity in patients with COPD. Chest 1996; 109(5): 1169-75.

37. Puhan MA, Busching G, Schunemann HJ, VanOort E, Zaugg C, Frey M. Interval versus continuous highintensity exercise in chronic obstructive pulmonary disease: a randomized trial. Ann Intern Med 2006; 145(11): 816-25.

38. Vogiatzis I, Nanas S, Roussos C. Interval training as an alternative modality to continuous exercise in patients with COPD. Eur Respir J 2002; 20(1): 12-9. 
39. Casaburi R, Kukafka D, Cooper CB, Witek TJ, Jr., Kesten S. Improvement in exercise tolerance with the combination of tiotropium and pulmonary rehabilitation in patients with COPD. Chest 2005; 127(3): 809-17.

40. Ramirez-Venegas A, Ward J, Lentine T, Mahler DA. Salmeterol reduces dyspnea and improves lung function in patients with COPD. Chest 1997; 112(2): 336-40.

41. O'Donnell DE, Fluge T, Gerken F, et al. Effects of tiotropium on lung hyperinflation, dyspnea and exercise tolerance in COPD. Eur Respir J 2004; 23(6): 832-40.

42. Bernard $S$, Whittom $F$, Leblanc $P$, et al. Aerobic and strength training in patients with chronic obstructive pulmonary disease. Am J Respir Crit Care Med 1999; 159(3): 896-901.

43. Velloso M, do Nascimento NH, Gazzotti MR, Jardim JR. Evaluation of effects of shoulder girdle training on strength and performance of activities of daily living in patients with chronic obstructive pulmonary disease. Int J Chron Obstruct Pulmon Dis 2013; 8: 187-92.

44. Cardim AB, Marinho PE, Nascimento JF, Jr., Fuzari HK, Dornelas de Andrade A. Does Whole-Body Vibration Improve the Functional Exercise Capacity of Subjects With COPD? A Meta-Analysis. Respir Care 2016; 61(11): 1552-9.

45. Beaumont $M$, Forget $P$, Couturaud $F$, Reychler $G$. Effects of inspiratory muscle training in COPD patients: A systematic review and meta-analysis. Clin Respir J 2018; 12(7): 2178-88.

46. Charususin N, Gosselink R, Decramer M, et al. Randomised controlled trial of adjunctive inspira tory muscle training for patients with COPD. Thorax 2018.

47. Chuang HY, Chang HY, Fang YY, Guo SE. The effects of threshold inspiratory muscle training in patients with chronic obstructive pulmonary disease: A randomised experimental study. J Clin Nurs 2017; 26(23-24): 4830-8.

48. Beaumont $\mathrm{M}$, Mialon $\mathrm{P}$, Le Ber $\mathrm{C}$, et al. Effects of inspiratory muscle training on dyspnea in severe COPD patients during pulmonary rehabilitation: controlled randomised trial. Eur Respir J 2018; 51(1).

49. Singh SJ, Morgan MD, Scott S, Walters D, Hardman AE. Development of a shuttle walking test of disability in patients with chronic airways obstruction. Thorax 1992; 47(12): 1019-24.

50. Dowson C, Laing R, Barraclough R, et al. The use of the Hospital Anxiety and Depression Scale (HADS) in patients with chronic obstructive pulmonary disease: a pilot study. N Z Med J 2001; 114(1141): 4479.

51. Kunik ME, Veazey C, Cully JA, et al. COPD education and cognitive behavioral therapy group treatment for clinically significant symptoms of depression and anxiety in COPD patients: a randomized controlled trial. Psychol Med 2008; 38(3): 385-96.

52. Blackstock FC, Webster KE, McDonald CF, Hill CJ. Comparable improvements achieved in chronic obstructive pulmonary disease through pulmonary rehabilitation with and without a structured educational intervention: a randomized controlled trial. Respirology 2014; 19(2): 193-202.

53. Ashikaga T, Vacek PM, Lewis SO. Evaluation of a community-based education program for individuals with chronic obstructive pulmonary disease. J Rehabil 1980; 46(2): 23-7.

54. Janelli LM, Scherer XK, Schmieder LE. Can a pulmonary health teaching program alter patients' ability to cope with COPD? Rehabil Nurs 1991; 16(4): 199-202.

55. Au DH, UdrisEM, Engelberg RA, et al. A randomized trial to improve communication about end-of-life care among patients with COPD. Chest 2012; 141(3): 726-35.

56. Ferreira IM, Brooks D, White J, Goldstein R. Nutritional supplementation for stable chronic obstructive pulmonary disease. Cochrane Database Syst Rev 2012; 12: CD000998.

57. Bekkat-Berkani $R$, Wilkinson $T$, Buchy $P$, et al. Seasonal influenza vaccination in patients with COPD: a systematic literature review. BMC Pulm Med 2017; 17(1): 79.

58. Tomczyk S, Bennett NM, Stoecker C, et al. Use of 13-valent pneumococcal conjugate vaccine and 23valent pneumococcal polysaccharide vaccine among adults aged $>/=65$ years: recommendations of the Advisory Committee on Immunization Practices (ACIP). MMWR Morb Mortal Wkly Rep 2014; 63(37): 822-5.

59. Struik FM, Lacasse Y, Goldstein R, Kerstjens HM, Wijkstra PJ. Nocturnal non-invasive positive pressure ventilation for stable chronic obstructive pulmonary disease. Cochrane Database Syst Rev 2013; (6): Cd002878.

60. Marin JM, Soriano JB, Carrizo SJ, Boldova A, Celli BR. Outcomes in patients with chronic obstructive pulmonary disease and obstructive sleep apnea: the overlap syndrome. Am J Respir Crit Care Med 2010; 182(3): 325-31.

61. Tiong LU, Davies R, Gibson PG, et al. Lung volume reduction surgery for diffuse emp hysema. Cochrane Database Syst Rev 2006; (4): Cd001001. 
62. Herth FJ, Valipour A, Shah PL, et al. Segmental volume reduction using thermal vapour ablation in patients with severe emphysema: 6-month results of the multicentre, parallel-group, open-label, randomised controlled STEP-UP trial. The Lancet Respiratory medicine 2016; 4(3): 185-93.

63. Weill D, Benden C, Corris PA, et al. A consensus document for the selection of lung transplant candidates: 2014--an update from the Pulmonary Transplantation Council of the International Society for Heart and Lung Transplantation. J Heart Lung Transplant 2015; 34(1): 1-15.

64. ISHLT: The International Society for Heart \& Lung Transplantation [Internet]. Slide Sets - Overall Lung Transplantation Statistics. Available from: https://ishltregistries.org/registries/slides.asp (accessed 14 October 2018).

65. Bischoff EW, Akkermans R, Bourbeau J, van Weel C, Vercoulen JH, Schermer TR. Comprehensive self management and routine monitoring in chronic obstructive pulmonary disease patients in general practice: randomised controlled trial. BMJ 2012; 345: e7642.

66. Johnson-Warrington V, Mitchell KE, Singh SJ. Is a practice incremental shuttle walk test needed for patients with chronic obstructive pulmonary disease admitted to hospital for an acute exacerbation? Respiration 2015; 90(3): 206-10.

67. Rochester CL, Vogiatzis I, Holland AE, et al. An Official American Thoracic Society/European Respiratory Society Policy Statement: Enhancing Implementation, Use, and Delivery of Pulmonary Rehabilitation. Am J Respir Crit Care Med 2015; 192(11): 1373-86.

68. Jones PW, Harding G, Berry P, Wiklund I, Chen WH, Kline Leidy N. Development and first validation of the COPD Assessment Test. Eur Respir J 2009; 34(3): 648-54.

69. Kessler R, Stahl E, Vogelmeier C, et al. Patient understanding, detection and experience of COPD exacerbations: an observational, interview-based study. Chest 2006; 130(1): 133-42.

70. Mazzone PJ. Preoperative evaluation of the lung cancer resection candidate. Expert Rev Respir Med 2010; 4(1): 97-113.

71. Celli BR, MacNee W, ATS ERS Task Force. Standards for the diagnosis and treatment of patients with COPD: a summary of the ATS/ERS position paper. Eur Respir J 2004; 23(6): 932-46.

72. Schuurmans MM, Diacon AH, Bolliger CT. Functionafevaluation before lung resection. Clin Chest Med 2002; 23(1): 159-72.

73. Smetana GW. Preoperative pulmonary evaluation. N Engl J Med 1999; 340(12): 937-44.

74. Shah PL, Slebos DJ, Cardoso PF, et al. Bronchoscopic lung-volume reduction with Exhale airway stents for emphysema (EASE trial): randomised, sham-controlled, multicentre trial. Lancet 2011; 378(9795): 997-1005.

75. Brunelli A, Charloux A, Bolliger CT, et al. ERS/ESTS clinical guidelines on fitness for radical therapy in lung cancer patients (surgery and chemo-radiotherapy). Eur Respir J 2009; 34(1): 17-41.

76. Colice GL, Shafazand S, Griffin JP, Keenan R, Bolliger CT, American College of Chest P. Physiologic evaluation of the patient with lung cancer being considered for resectional surgery: ACCP evidencedbased clinical practice guidelines (2nd edition). Chest 2007; 132(3 Suppl): 161S-77S. 


\section{CHAPTER 5: MANAGEMENT OF EXACERBATIONS}

\section{OVERALL KEY POINTS:}

- An exacerbation of COPD is defined as an acute worsening of respiratory symptoms that results in additional therapy.

- Exacerbations of COPD can be precipitated by several factors. The most common causes are respiratory tract infections.

- The goal for treatment of COPD exacerbations is to minimize the negative impact of the current exacerbation and to prevent subsequent events.

- Short-acting inhaled beta-agonists, with or without short-acting anticholinergics, are recommended as the initial bronchodilators to treat andcute exacerbation.

- Maintenance therapy with long-acting bronchodilators should be initiated as soon as possible before hospital discharge.

- Systemic corticosteroids can improve lung function (FEV 1 ), oxygenation and shorten recovery time and hospitalization duration. Duration of therapy should not be more than 5-7 days.

- Antibiotics, when indicated, can shorten recovery time, reduce the risk of early relapse, treatment failure, and hospitalization duration. Duration of therapy should be 5-7 days.

- Methylxanthines are not recommended due to increased side effect profiles.

- Non-invasive mechanical ventilation should be the first mode of ventilation used in COPD patients with acute respiratory failure who have no absolute contraindication because it improves gas exchange, reduces work of breathing and theneed for intubation, decreases hospitalization duration and improves survival.

- Following an exacerbation, appropriate measures for exacerbation prevention should be initiated (see Chapter 3 and Chapter 4). 
Exacerbations of chronic obstructive pulmonary disease (COPD) are important events in the management of COPD because they negatively impact health status, rates of hospitalization and readmission, and disease progression. ${ }^{12}$ COPD exacerbations are complex events usually associated with increased airway inflammation, increased mucus production and marked gas trapping. These changes contribute to increased dyspnea that is the key symptom of an exacerbation. Other symptoms include increased sputum purulence and volume, together with increased cough and wheeze. ${ }^{3}$ As comorbidities are common in COPD patients, exacerbations must be differentiated clinically from other events such as acute coronary syndrome, worsening congestive heart failure, pulmonary embolism and pneumonia.

COPD exacerbations are defined as an acute worsening of respiratory symptoms that result in additional therapy. $\frac{1,2}{2}$

They are classified as:

- Mild (treated with short acting bronchodilators only, SABDSt

- Moderate (treated with SABDs plus antibiotics and/or oral corticosteroids) or

- Severe (patient requires hospitalization or visits the emergency room). Severe exacerbations may also be associated with acute respiratory failure.

It is now recognized that many exacerbations are-rot reported to healthcare professionals for therapy and yet these events, although often shorter in duration, also have a significant impact on health status.., 5 Thus COPD patients need to receive education about the importance of understanding exacerbation symptoms and when to seek professional healthcare.

Exacerbations are mainly triggered by respiratory viral infections although bacterial infections and environmental factors such as pollution and ambient temperature may also initiate and/or amplify these events. ${ }^{6}$ Short-term exposure to fine particulate matter (PM2.5) is associated with increased hospitalizations for acute exacerbations and increased mortality of COPD. $\underline{7}, \underline{\underline{8}}$ The most common virus isolated is human (rhinovirus (the cause of the common cold) and can be detected for up to a week after an exacerbation onset. 6,9 When associated with viral infections, exacerbations are often more severe, last longer and precipitate more hospitalizations, as seen during winter.

Exacerbations can be associated with increased sputum production and, if purulent, there are studies that demonstrated increased bacteria in the sputum $-, 9,10$ There is reasonable evidence to support the concept that eosinophils are increased in the airways, lung, and blood in a significant proportion of patients with COPD. Furthermore, eosinophil numbers increase together with neutrophils and other inflammatory cells during exacerbations in a proportion of subjects with COPD exacerbations. $11-13$ The presence of sputum eosinophilia has been related to susceptibility to viral infection. $\frac{10}{}$ It has been suggested that exacerbations associated with an increase in sputum or blood eosinophils may be more responsive to systemic steroids $\frac{14}{4}$ although more prospective trials are needed to test this hypothesis. $\frac{14}{}$ During a COPD exacerbation, symptoms usually last between 7 to 10 days, but some events may last longer. At 8 weeks, $20 \%$ of patients have not recovered to their pre-exacerbation state. $\frac{15}{}$ It is well 
established that COPD exacerbations contribute to disease progression. $\underline{16}$ Disease progression is even more likely if recovery from exacerbations is slow. ${ }^{17}$ Exacerbations can also cluster in time and once a COPD patient experiences an exacerbation, they will show increased susceptibility to another event $\underline{18,19}$ (see Chapter 2).

Some COPD patients are particularly susceptible to frequent exacerbations (defined as two or more exacerbations per year), and these patients have been shown to have worse health status and morbidity than patients with less frequent exacerbations. ${ }^{2}$ Patients at high risk of frequent exacerbations can be recognized across all disease severity groups. The exact reason for an individual's increased susceptibility to exacerbation symptoms remains largely unknown. However, the perception of breathlessness is greater in frequent exacerbators than infrequent exacerbators, $\underline{20}$ suggesting that a perception of breathing difficulty may contribute to precipitating the respiratory symptoms of an exacerbation rather than solely physiological, or causative factors. The strongest predictor of a patient's future exacerbation frequency remains the number of exacerbations they have had in the prior year. $\frac{18}{}$ It is recognized that these patients form a moderately stable phenotype, although some studies have shown that a significant proportion of patientschange their exacerbation frequency especially with worsening $\mathrm{FEV}_{1} \cdot \underline{21}$

Other factors that have been associated with an increased risk of acute exacerbations and/or severity of exacerbations include an increase in the ratio of the pufmonary artery to aorta cross sectional dimension (i.e., ratio $>1$ ), $\underline{22}$ a greater percentage of emphysema or airway wall thickness $\underline{23}$ measured by chest $\mathrm{CT}$ imaging and the presence of chronic bronchitis. 24,25

\section{TREATMENT OPTIONS}

\section{Treatment setting}

The goals of treatment for COP exacerbations are to minimize the negative impact of the current exacerbation and prevent the development of subsequent events. ${ }^{26}$ Depending on the severity of an exacerbation and/or the severity of the underlying disease, an exacerbation can be managed in either the outpatient or inpatient setting. More than $80 \%$ of exacerbations are managed on an outpatient basis with pharmacological therapies including bronchodilators, corticosteroids, and antibiotics. $\underline{15}, \underline{23}, \underline{24}$

The indications for assessing the need for hospitalization during a COPD exacerbation are shown in Table 5.1. When patients with a COPD exacerbation come to the emergency department, they should be provided with supplemental oxygen and undergo assessment to determine whether the exacerbation is life-threatening and if increased work of breathing or impaired gas exchange requires consideration for non-invasive ventilation. If so, healthcare providers should consider admission to the respiratory or intensive care unit of the hospital. Otherwise, the patient may be managed in the emergency department or hospital ward unit. In addition to pharmacological therapy, hospital management of exacerbations includes respiratory support (oxygen therapy, ventilation). The management of severe, but not life threatening, exacerbations is outlined in Table $\mathbf{5 . 2}$ 


\section{POTENTIAL INDICATIONS FOR HOSPITALIZATION ASSESSMENT*}

- Severe symptoms such as sudden worsening of resting dyspnea, high respiratory rate, decreased oxygen saturation, confusion, drowsiness.

- Acute respiratory failure.

- Onset of new physical signs (e.g., cyanosis, peripheral edema).

- Failure of an exacerbation to respond to initial medical management.

- Presence of serious comorbidities (e.g., heart failure, newly occurring arrhythmias, etc.).

- Insufficient home support.

*Local resources need to be considered.

TABLE 5.1

MANAGEMENT OF SEVERE BUT NOT LIFE-THREATENING EXACERBATIONS*

- Assess severity of symptoms, blood gases, chest radiograph.

- Administer supplemental oxygen therapy, obtain serial arterial blood gas, venous blood gas and pulse oximetry measurements.

- Bronchodilators:

"Increase doses and/or frequency of short-acting bronchodilators.

»Combine short-acting beta 2-agopists and anticholinergics.

»Consider use of long-active branchodilators when patient becomes stable.

» Use spacers or air-driven nebulizers when appropriate.

- Consider oral corticosteroids.

- Consider antibiotics (oral) when signs of bacterial infection are present.

- Consider noninvasive mechanical ventilation (NIV).

- At all times:

» Monitor fluid balance.

» Consider subcutaneous heparin or low molecular weight heparin for thromboembolism prophylaxis.

»Identify and treat associated conditions (e.g., heart failure, arrhythmias, pulmonary embolism etc.).

*Local resources need to be considered.

TABLE 5.2

The clinical presentation of COPD exacerbation is heterogeneous, thus we recommend that in hospitalized patients the severity of the exacerbation should be based on the patient's clinical signs and recommend the following classification. $\underline{27}$ 
No respiratory failure: Respiratory rate: 20-30 breaths per minute; no use of accessory respiratory muscles; no changes in mental status; hypoxemia improved with supplemental oxygen given via Venturi mask $28-35 \%$ inspired oxygen $\left(\mathrm{FiO}_{2}\right)$; no increase in $\mathrm{PaCO}_{2}$.

Acute respiratory failure - non-life-threatening: Respiratory rate: > 30 breaths per minute; using accessory respiratory muscles; no change in mental status; hypoxemia improved with supplemental oxygen via Venturi mask $25-30 \% \mathrm{FiO}_{2}$; hypercarbia i.e., $\mathrm{PaCO}_{2}$ increased compared with baseline or elevated $50-60 \mathrm{mmHg}$.

Acute respiratory failure - life-threatening: Respiratory rate: > 30 breaths per minute; using accessory respiratory muscles; acute changes in mental status; hypoxemia not improved with supplemental oxygen via Venturi mask or requiring $\mathrm{FiO}_{2}>40 \%$; hypercarbia i.e., $\mathrm{PaCO}_{2}$ increased compared with baseline or elevated $>60 \mathrm{mmHg}$ or the presence of acidosis $(\mathrm{pH} \leq 7.25)$.

Long-term prognosis following hospitalization for COPD exacerbation is poor, with a five-year mortality rate of about $50 \%$. 28 Factors independently associated with poor $0 u t c o m e$ include older age, lower BMI, comorbidities (e.g., cardiovascular disease or lung cancer), previous hospitalizations for COPD exacerbations, clinical severity of the index exacerbation and need for long-term oxygen therapy at discharge. $\frac{29-31}{}$ Patients characterized by a higher prevalence and severity of respiratory symptoms, poorer quality of life, worse lung function, lower exercise capacity, lower lung density and thickened bronchial walls on CT-scan are also at increased risk for a higher mortality following an acute COPD exacerbation. $\underline{32}$

A recent updated Cochrane review concluded that the use of COPD exacerbation action plans with a single short educational component, in conjunction with ongoing support, reduced in-hospital healthcare utilization. Such educational interventions were also found to increase the treatment of COPD exacerbations with corticosterolds and antibiotics. $\frac{33}{3}$

Key points for the management of all exacerbations are given in Table 5.3.

\section{KEY POINTSFOR THE MANAGEMENT OF EXACERBATIONS}

- Short-acting inhaled beta ${ }_{2}$-agonists, with or without short-acting anticholinergics, are recommended as the initial bronchodilators to treat an acute exacerbation (Evidence C).

- Systemic corticosteroids can improve lung function $\left(\mathrm{FEV}_{1}\right)$, oxygenation and shorten recovery time and hospitalization duration. Duration of therapy should not be more than 5-7 days (Evidence A).

- Antibiotics, when indicated, can shorten recovery time, reduce the risk of early relapse, treatment failure, and hospitalization duration. Duration of therapy should be 5-7 days (Evidence B).

- Methylxanthines are not recommended due to increased side effect profiles (Evidence B).

- Non-invasive mechanical ventilation should be the first mode of ventilation used in COPD patients with acute respiratory failure who have no absolute contraindication because it improves gas exchange, reduces work of breathing and the need for intubation, decreases hospitalization duration and improves survival (Evidence A). 


\section{Pharmacological treatment}

The three classes of medications most commonly used for COPD exacerbations are bronchodilators, corticosteroids, and antibiotics.

Bronchodilators. Although there is no high-quality evidence from RCTs, it is recommended that short-acting inhaled beta ${ }_{2}$-agonists, with or without short-acting anticholinergics, are the initial bronchodilators for acute treatment of a COPD exacerbation. $\stackrel{34}{35} \mathrm{~A}$ systematic review of the route of delivery of short-acting bronchodilators found no significant differences in FEV ${ }_{1}$ between using metered dose inhalers (MDI) (with or without a spacer device) or nebulizers to deliver the agent, $\underline{36}, 37$ although the latter may be an easier delivery method for sicker patients. It is recommended that patients do not received continuous nebulization, but use the MDI inhaler one puff every one hour for two or three doses and then every 2-4 hours based on the patient's response. Although, there are no clinical studies that have evaluated the use of inhaled long-acting bronchodilators (either beta $2^{-}$ agonists or anticholinergics or combinations) with or without inhaled corticosteroids during an exacerbation, we recommend continuing these treatments during the exacerbation or to start these medications as soon as possible before hospital discharge. Intravenous methylxanthines (theophylline or aminophylline) are not recommended to use in these patients due to significant side effects. $\frac{38,39}{39}$

Glucocorticoids. Data from studies indicate that systemicglucocorticoids in COPD exacerbations shorten recovery time and improve lung function $\left(\mathrm{FEV}_{1}\right)$. They also improve oxygenation, $\frac{40-43}{\text { the risk }}$ of early relapse, treatment failure, $\underline{\underline{4}}$ and the length of hospitalization. $\underline{40,42,45}$ A dose of $40 \mathrm{mg}$ prednisone per day for 5 days is recommended. $\frac{46}{6}$ Therapy with oral prednisolone is equally effective to intravenous administration. $\underline{47}$ Nebulized budesonide alone may be a suitable alternative for treatment of exacerbations in some patients, $\underline{41,48,49}$ and provides similar benefits to intravenous methylprednisolone, although the choice between these options may depend on local cost issues. $\underline{50}$ Intensified combination therapy with VES/LABA for 10 days at URTI onset could be associated with a reduction of exacerbations, particularly in patients with severe disease. $\frac{51}{1}$ Recent studies suggest that glucocorticoids may be less efficácious to treat acute COPD exacerbations in patients with lower levels of blood eosinophils. $\underline{11}, \underline{14}, 18 \mathrm{C}$

Antibiotics. Although the infectious agents in COPD exacerbations can be viral or bacterial, -52 the use of antibiotics in exacerbations remains controversial. $\frac{53-55}{2}$ The uncertainties originate from studies that did not differentiate between bronchitis (acute or chronic) and COPD exacerbations, studies without placebo-control, and/or studies without chest X-rays that do not exclude that patients may have had underlying pneumonia. There is evidence supporting the use of antibiotics in exacerbations when patients have clinical signs of a bacterial infection e.g., increased sputum purulence..$\underline{5,55}$

A systematic review of placebo-controlled studies has shown that antibiotics reduce the risk of shortterm mortality by $77 \%$, treatment failure by $53 \%$ and sputum purulence by $44 \%$. $\frac{56}{6}$ The review provides evidence to treat moderately or severely ill patients with COPD exacerbations and increased cough and sputum purulence with antibiotics. $\frac{56,57}{}$ These data are supported by more recent RCTs in patients with diagnoses of moderate COPD..$\underline{58}$ In a recent RCT, the addition of doxycycline to oral corticosteroid an outpatient setting did not prolong time to next exacerbation. $\frac{59}{\text { In }}$ the outpatient setting, sputum cultures are not feasible as they take at least two days and frequently do not give reliable results for 
technical reasons. Several biomarkers of airway infection are being studied in exacerbations of COPD that have a better diagnostic profile. Studies of C-reactive protein (CRP) have reported contradictory findings; CRP has been reported to be elevated in both bacterial and viral infections, therefore its use in this condition is not recommended. 60,61 Another biomarker that has been investigated is procalcitonin, a marker that is more specific for bacterial infections and that may be of value in the decision to use antibiotics, $\underline{62}$ but this test is expensive and not readily available. Several studies have suggested that procalcitonin-guided antibiotic treatment reduces antibiotic exposure and side effects with the same clinical efficacy. $\frac{63-65}{A}$ A recent meta-analysis of available clinical studies suggests that procalcitonin-based protocols to trigger antibiotic use are associated with significantly decreased antibiotic prescription and total antibiotic exposure, without affecting clinical outcomes (e.g., rate of treatment failure, length of hospital stay, mortality). However, the quality of this evidence is low to moderate, because of methodological limitations and smaller overall study populations. Procalcitoninbased protocols may be clinically effective; however, confirmatory trials with rigorous methodology

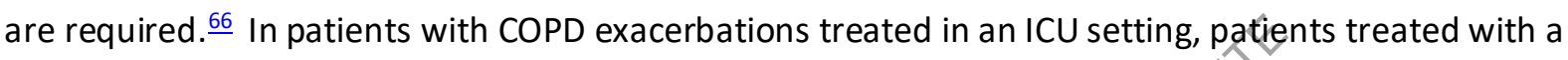
procalcitonin based algorithm for initiating or stopping antibiotics had a highercate of mortality when compared to those receiving standard antibiotic regimens. $\frac{67}{}$

In summary, antibiotics should be given to patients with exacerbations of COPD who have three cardinal symptoms: increase in dyspnea, sputum volume, and sputum purulence; have two of the cardinal symptoms, if increased purulence of sputum is one of the two symptoms; or require mechanical ventilation (invasive or noninvasive). ${ }^{3,6}$ The recommended length of antibiotic therapy is 5-7 days..$\underline{6}$

The choice of the antibiotic should be based on the local bacterial resistance pattern. Usually initial empirical treatment is an aminopenicillin with clavulanic acid, macrolide, or tetracycline. In patients with frequent exacerbations, severe airf 6 w limitation, $\underline{69}, 70$ and/or exacerbations requiring mechanical ventilation,, 11 cultures from sputum or other materials from the lung should be performed, as gramnegative bacteria (e.g., Pseudomonas species) or resistant pathogens that are not sensitive to the above-mentioned antibiotics may be present. The route of administration (oral or intravenous) depends on the patient's ability to eat and the pharmacokinetics of the antibiotic, although it is preferable that antibiotics be given orally. Improvements in dyspnea and sputum purulence suggest clinical success.

Adjunct Therapies. Depending on the clinical condition of the patient, an appropriate fluid balance, use of diuretics when clinically indicated, anticoagulants, treatment of comorbidities and nutritional aspects should be considered. At all times, healthcare providers should strongly enforce the need for smoking cessation. Given that patients hospitalized with COPD exacerbations are at increased risk of deep vein thrombosis and pulmonary proca, $, 2, \underline{73}$ prophylactic measures for thromboembolism should be instituted. $\underline{74}, 7 \underline{75}$

\section{Respiratory support}

Oxygen therapy. This is a key component of hospital treatment of an exacerbation. Supplemental oxygen should be titrated to improve the patient's hypoxemia with a target saturation of $88-92 \% . \underline{76}$ Once oxygen is started, blood gases should be checked frequently to ensure satisfactory oxygenation 
without carbon dioxide retention and/or worsening acidosis. A recent study demonstrated that venous blood gas to assess bicarbonate levels and $\mathrm{pH}$ is accurate when compared with arterial blood gas assessment..$\underline{77}$ Additional data are needed to clarify the utility of venous blood gas sampling to make clinical decisions in scenarios of acute respiratory failure; most patients included had a $\mathrm{pH}>7.30$ on presentation, $\mathrm{PCO}_{2}$ levels were dissimilar when measured by venous compared to arterial blood samples and the severity of airflow limitation was not reported. $\underline{-17}$ Venturi masks (high-flow devices) offer more accurate and controlled delivery of oxygen than do nasal prongs. $\underline{35}$

High-flow oxygen therapy by nasal cannula. In patients with acute hypoxemic respiratory failure, high-flow oxygen therapy by nasal cannula (HFNC) may be an alternative to standard oxygen therapy or noninvasive positive pressure ventilation; some studies have shown that HFNC can reduce the need for intubation or mortality in patients with acute hypoxemic respiratory failure (ARF). $\underline{78}$ Studies to date were performed in COPD patients with very severe underlying disease that required supplemental oxygen; a randomized cross-over trial demonstrated that HFNC improved oxygenation and ventilation, and decreased hypercarbia. ${ }^{79}$ A systematic review of RCTs in patients with acute hypoxemic respiratory failure suggests that HFNC tends to reduce intubation rate, but did not meet statistical significance compared with conventional oxygen therapy of NIV, and had no effect on mortality. .80 However, the meta-analysis included no studies of patients with acute respiratory failure due to a COPD exacerbation. A small pilot RCT $(n=29)$ reported that six weeks of high-flow nasal cannula oxygen therapy reduced hypercapnia and improved health-related quality of life in patients with stable hypercapnic COPD. $\stackrel{81}{ }$ There is a need for well-designed, randomized, multicenter trials to study the effects of HFNC in acute hypoxemic/hypercarbic respiratory failure in COPD patients.

Ventilatory Support. Some patients need immediate admission to the respiratory care or intensive care unit (ICU) (Table 5.4). Admission of patients with severe exacerbations to intermediate or special respiratory care units may be appropriaté if adequate personnel skills and equipment exist to identify and manage acute respiratory failure Ventilatory support in an exacerbation can be provided by either noninvasive (nasal or facial mask) or invasive (oro-tracheal tube or tracheostomy) ventilation. Respiratory stimulants are notrecommended for acute respiratory failure. $\underline{34}$

INDICATIONS FOR RESPIRATORY OR

MEDICAL INFENSIVE CARE UNIT ADMISSION*

- Severe dyspnea that responds inadequately to initial emergency therapy.

- Changes in mental status (confusion, lethargy, coma).

- Persistent or worsening hypoxemia ( $\mathrm{PaO} 2<5.3 \mathrm{kPa}$ or $40 \mathrm{mmHg}$ ) and/or severe/worsening respiratory acidosis $(\mathrm{pH}<7.25)$ despite supplemental oxygen and noninvasive ventilation.

- Need for invasive mechanical ventilation.

- Hemodynamic instability - need for vasopressors.

* Local resources need to be considered.

TABLE 5.4 
Noninvasive mechanical ventilation. The use of noninvasive mechanical ventilation (NIV) is preferred over invasive ventilation (intubation and positive pressure ventilation) as the initial mode of ventilation to treat acute respiratory failure in patients hospitalized for acute exacerbations of COPD. NIV has been studied in RCTs showing a success rate of 80-85\%.82-86 NIV has been shown to improve oxygenation and acute respiratory acidosis i.e., NIV increases $\mathrm{pH}$ and decreases $\mathrm{PaCO}_{2}$. NIV also decreases respiratory rate, work of breathing and the severity of breathlessness but also decreases complications such as ventilator associated pneumonia, and length of hospital stay. More importantly, mortality and intubation rates are reduced by this intervention. $\underline{83,87-89}$ Once patients improve and can tolerate at least 4 hours of unassisted breathing, NIV can be directly discontinued without any need for a "weaning" period. $\stackrel{90}{ }$ The indications for NIV $\underline{86}$ are summarized in Table 5.5.

\section{INDICATIONS FOR NONINVASIVE MECHANICAL VENTILATION (NIV)}

At least one of the following:

- Respiratory acidosis $\left(\mathrm{PaCO}_{2} \geq 6.0 \mathrm{kPa}\right.$ or $45 \mathrm{mmHg}$ and arterial $\left.\mathrm{pH} \leq 7.35\right)$.

- Severe dyspnea with clinical signs suggestive of respiratory muscle fatigue, increased work of breathing, or both, such as use of respiratory accessory muscles, paradoxical motion of the abdomen, or retraction of the intercostal spaces.

- Persistent hypoxemia despite supplemental oxygen therapy.

\section{INDICATIONS FOR INVASIVE ME'ĆHANICAL VENTILATION}

- Unable to tolerate NIV or NIV failure.

- Status post - respiratory or cardiac orrest.

- Diminished consciousness, psychomotor agitation inadequately controlled by sedation.

- Massive aspiration or persistent vomiting.

- Persistent inabilit to remove respiratory secretions.

- Severe hemodynamic instability without response to fluids and vasoactive drugs.

- Severe ventricular or supraventricular arrhythmias.

- Life-threatening hypoxemia in patients unable to tolerate NIV.

TABLE 5.6

Invasive mechanical ventilation. The indications for initiating invasive mechanical ventilation during an exacerbation are shown in Table 5.6, and include failure of an initial trial of NIV. .1 As experience is gained with the generalized clinical use of NIV in COPD, a number of indications for invasive mechanical ventilation are being successfully treated with NIV, thus eliminating invasive mechanical ventilation as first line treatment of acute respiratory failure during hospitalization for COPD exacerbation. $\frac{91}{}$ In patients who fail non-invasive ventilation as initial therapy and receive 
invasive ventilation as subsequent rescue therapy, morbidity, hospital length of stay and mortality are greater. .44 The use of invasive ventilation in patients with very severe COPD is influenced by the likely reversibility of the precipitating event, the patient's wishes, and the availability of intensive care

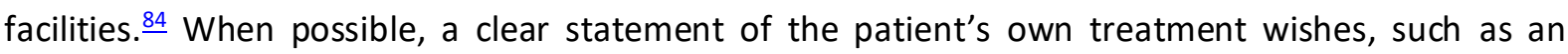
advance directive or "living will", makes these difficult decisions easier to resolve. Major hazards include the risk of ventilator-acquired pneumonia (especially when multi-resistant organisms are prevalent), barotrauma and volutrauma, and the risk of tracheostomy and consequential prolonged ventilation.

Acute mortality among COPD patients with respiratory failure is lower than mortality among patients ventilated for non-COPD causes. $\underline{\text {. }}$ Despite this, there is evidence that patients who might otherwise survive are frequently denied admission to intensive care for intubation because of unwarranted prognostic pessimism. $\frac{93}{}$ A large study of COPD patients with acute respiratory failure reported inhospital mortality of $17-49 \% .{ }^{94}$ Further deaths were reported over the next 12 months, particularly among those patients who had poor lung function before invasive ventilation ( $E E V_{1}<30 \%$ predicted), had a non-respiratory comorbidity, or were housebound. Patients who did not have a previously diagnosed comorbidity, had respiratory failure due to a potentially reversible cause (such as an infection), or were relatively mobile and not using long-term oxygen, did well after ventilator support.

\section{Hospital discharge and follow-up}

The cause, severity, impact, treatment and time course offexacerbations varies from patient to patient and facilities in the community, and healthcare systems, differ from country to country. Accordingly, there are no standards that can be applied to the timing and nature of discharge. However, it is recognized that recurrent exacerbations leading to short-term readmission and increased all-cause mortality are associated with the initiar hospitalization for an acute episode of deterioration. Consequently, the clinical practice and management of the acute hospitalization have been studied extensively and the introduction of factors thought to be beneficial has been investigated increasingly in recent years. When features related to re-hospitalization and mortality have been studied, defects in perceived optimal management have been identified including spirometric assessment and arterial

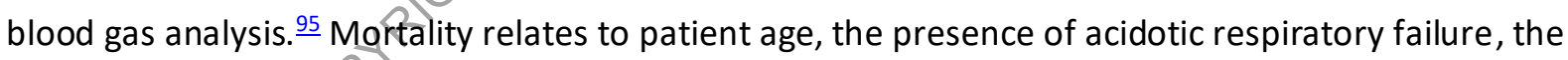
need for ventilatorysupport and comorbidities including anxiety and depression. $\underline{96}$

The introduction of care bundles at hospital discharge to include education, optimization of medication, supervision and correction of inhaler technique, assessment and optimal management of comorbidities, early rehabilitation, telemonitoring and continued patient contact have all been investigated to address these issues (Table 5.7). ${ }^{97}$ While these measures all seem sensible there is insufficient data that they influence either readmission rates or short-term mortality $\underline{95}, \underline{96}, \underline{98,99}$ and there is little evidence of cost-effectiveness. $\frac{96}{}$ One recent RCT showed that telemonitoring did not change hospitalization or exacerbation rates in patients with COPD. $\frac{100}{1}$ Nevertheless, it remains good clinical practice to cover these issues before discharge and their effectiveness on health status and readmission rates may be increased if they are delivered with an approach that includes motivational interview-based health coaching. $\frac{101}{1}$ The only possible exception is early rehabilitation as there is some evidence that this factor is associated with increased mortality, although the reasons remain unknown. $\frac{99}{}$ However, other data suggest that early rehabilitation post hospital discharge (i.e., $<4$ 
weeks) may be associated with improved survival. $\underline{102}$

Early follow-up (within one month) following discharge should be undertaken when possible and has been related to less exacerbation-related readmissions. 103 There are many patient issues that prevent early follow-up; those not attending early follow-up have increased 90 -day mortality. This may reflect both patient compliance, limited access to medical care, poor social support, and/or the presence of more severe disease.

Nevertheless, early follow-up permits a careful review of discharge therapy (and especially any remaining need for long-term oxygen treatment by assessment of both oxygen saturation and arterial blood gases) and an opportunity to make any needed changes in therapy (antibiotic and steroid therapy review).

Additional follow-up at three months is recommended to ensure return to a stable clinical state and permit a review of the patient's symptoms, lung function (by spirometry), and where possible the assessment of prognosis using multiple scoring systems such as BODE. $\frac{104}{2}$ a d dition, arterial oxygen saturation and blood gas assessment will determine the need for longterm oxygen therapy more accurately at prolonged follow-up compared to shortly after discharge. CT assessment to determine the presence of bronchiectasis and emphysema should be done in patients with recurrent exacerbations/ and or hospitalizations. 105,106 A further detailed assessment of the presence and management of comorbidities should also be undertaken (Table 5.7). $\frac{86}{}$

\section{Prevention of exacerbations}

After an acute exacerbation, appropriate measúres for prevention of further exacerbations should be initiated (Table 5.3 and Table 5.8). For the following treatment modalities significant effects on exacerbation risk/frequency could be shown in clinical trials. For details and references refer to Chapter 3 and Chapter 4. 


\section{DISCHARGE CRITERIA AND RECOMMENDATIONS FOR FOLLOW-UP}

- Full review of all clinical and laboratory data.

- Check maintenance therapy and understanding.

- Reassess inhaler technique.

- Ensure understanding of withdrawal of acute medications (steroids and/or antibiotics).

- Assess need for continuing any oxygen therapy.

- Provide management plan for comorbidities and follow-up.

- Ensure follow-up arrangements: early follow-up $<4$ weeks, and late follow-up $<12$ weeks as indicated.

- All clinical or investigational abnormalities have been identified.

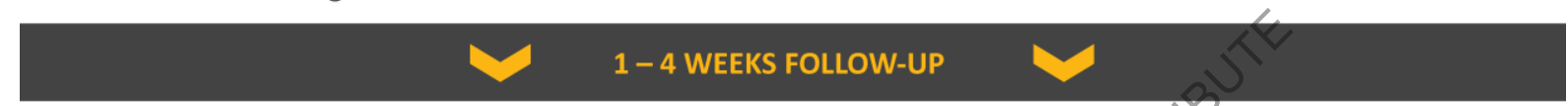

- Evaluate ability to cope in his/her usual environment.

- Review and understanding treatment regimen.

- Reassessment of inhaler techniques.

- Reassess need for long-term oxygen.

- Document the capacity to do physical activity and activities daily living.

- Document symptoms: CAT or mMRC.

- Determine status of comorbidities.

\section{2 - 16 WEEKS FOLLOW-UP}

- Evaluate ability to cope in his/her usyal environment.

- Review understanding treatment regimen.

- Reassessment of inhalen techniques.

- Reassess need forlong-term oxygen.

- Document the capacity to do physical activity and activities of daily living.

- Measure spirometry: FEV

- Document symptoms: CAT or mMRC.

- Determine status of comorbidities.

TABLE 5.7 


Mucoregulators

Mucoregulators $\mathrm{N}$-acetylcysteine
Carboøysteine

Smoking Cessation

Rehabilitation

Lung Volume Reduction

\section{REFERENCES}

1. Wedzicha JA, Seemungal TA. COPD exacerbations: defining their cause and prevention. Lancet 2007; 370(9589): 786-96.

2. Seemungal TA, Donaldson GC, Paul EA, Bestall JC, Jeffries DJ, Wedzicha JA. Effect of exacerbation on quality of life in patients with chronic obstructive pulmonary disease. Am J Respir Crit Care Med 1998; 157(5 Pt 1): 1418-22.

3. Anthonisen NR, Manfreda J, Warren CP, Hershfield ES, Harding GK, Nelson NA. Antibiotic therapy in exacerbations of chronic obstructive pulmonary disease. Ann Intern Med 1987; 106(2): 196-204.

4. Wilkinson TM, Donaldson GC, Hurst JR, Seemungal TA, Wedzicha JA. Early therapy improves outcomes of exacerbations of chronic obstructive pulmonary disease. Am J Respir Crit Care Med 2004; 169(12): 1298-303.

5. Vijayasaratha K, Stockley RA. Reported and unreported exacerbations of COPD: analysis by diary cards. Chest 2008; 133(1): 34-41.

6. Woodhead M, Blasi F, Ewig S, et al. Guidelines for the management of adult lower respiratory tract infections. Eur Respir J 2005; 26(6): 1138-80.

7. Li MH, Fan LC, Mao B, et al. Short-term Exposure to Ambient Fine Particulate Matter Increases Hospitalizations and Mortality in COPD: A Systematic Review and Meta-analysis. Chest 2016; 149(2): 447-58.

8. Liu S, Zhou Y, Liu S, et al. Association between exposure to ambient particulate matter and chronic obstructive pulmonary disease: results from a cross-sectional study in China. Thorax 2017; 72(9): 78895. 
9. White AJ, Gompertz S, Stockley RA. Chronic obstructive pulmonary disease . 6: The aetiology of exacerbations of chronic obstructive pulmonary disease. Thorax 2003; 58(1): 73-80.

10. Papi A, Bellettato CM, Braccioni $F$, et al. Infections and airway inflammation in chronic obstructive pulmonary disease severe exacerbations. Am J Respir Crit Care Med 2006; 173(10): 1114-21.

11. Bafadhel M, McKenna S, Terry S, et al. Acute exacerbations of chronic obstructive pulmonary disease: identification of biologic clusters and their biomarkers. Am J Respir Crit Care Med 2011; 184(6): 66271.

12. Baines KJ, Pavord ID, Gibson PG. The role of biomarkers in the management of airways disease. Int J Tuberc Lung Dis 2014; 18(11): 1264-8.

13. Groenke L, Disse B. Blood eosinophil counts as markers of response to inhaled corticosteroids in COPD? The Lancet Respiratory medicine 2015; 3(8): e26.

14. Bafadhel M, McKenna S, Terry S, et al. Blood eosinophils to direct corticosteroid treatment of exacerbations of chronic obstructive pulmonary disease: a randomized placebo-controlled trial. $\mathrm{Am} \mathrm{J}$ Respir Crit Care Med 2012; 186(1): 48-55.

15. Seemungal TA, Donaldson GC, Bhowmik A, Jeffries DJ, Wedzicha JA. Time course and recovery of exacerbations in patients with chronic obstructive pulmonary disease. Am J Respir Crit Care Med 2000; 161(5): 1608-13.

16. Halpin DMG, Birk R, Brealey N, et al. Single-inhaler triple therapy in symptomatic COPD patients: FULFIL subgroup analyses. ERJ open research 2018; 4(2).

17. Donaldson GC, Law M, Kowlessar B, et al. Impact of Prolonged Exacerbation Recovery in Chronic Obstructive Pulmonary Disease. Am J Respir Crit Care Med 2015; 192(8): 943-50.

18. Hurst JR, Vestbo J, Anzueto A, et al. Susceptibility to exacerbation inchronic obstructive pulmonary disease. N Engl J Med 2010; 363(12): 1128-38.

19. Hurst JR, Donaldson GC, Quint JK, Goldring JJ, Baghai-Ravary R, Wedzicha JA. Temporal clustering of exacerbations in chronic obstructive pulmonary disease. Am J Respir Crit Care Med 2009; 179(5): 36974.

20. Scioscia G, Blanco I, Arismendi E, et al. Different dyspnea perception in COPD patients with frequent and infrequent exacerbations. Thorax 2017; 72(2):-117-21.

21. Donaldson GC, Mullerova $\mathrm{H}$, Locantore $\mathrm{N}$, et al.Factors associated with change in exacerbation frequency in COPD. Respir Res 2013; 14: 79.

22. Wells JM, Washko GR, Han MK, et al. Pútmonary arterial enlargement and acute exacerbations of COPD. N Engl J Med 2012; 367(10): 913-21.

23. Han MK, Kazerooni EA, Lynch DA, et al. Chronic obstructive pulmonary disease exacerbations in the COPDGene study: associated radiologic phenotypes. Radiology 2011; 261(1): 274-82.

24. Kim V, Han MK, Vance GB, et al. The chronic bronchitic phenotype of COPD: an analysis of the COPDGene Study. Chest 2011; 140(3): 626-33.

25. Burgel PR, Nesme-Meyer $P$, Chanez $P$, et al. Cough and sputum production are associated with frequent exacerbations and hospitalizations in COPD subjects. Chest 2009; 135(4): 975-82.

26. Martinez FJ, Han MK, Flaherty K, Curtis J. Role of infection and antimicrobial therapy in acute exacerbations of chronic obstructive pulmonary disease. Expert Rev Anti Infect Ther 2006; 4(1): 101 24.

27. Celli BR, Barnes PJ. Exacerbations of chronic obstructive pulmonary disease. Eur Respir J 2007; 29(6): 1224-38.

28. Hoogendoorn M, Hoogenveen RT, Rutten-van Molken MP, Vestbo J, Feenstra TL. Case fatality of COPD exacerbations: a meta-analysis and statistical modelling approach. Eur Respir J 2011; 37(3): 50815.

29. Piquet J, Chavaillon JM, David $P$, et al. High-risk patients following hospitalisation for an acute exacerbation of COPD. Eur Respir J 2013; 42(4): 946-55.

30. Singanayagam A, Schembri S, Chalmers JD. Predictors of mortality in hospitalized adults with acute exacerbation of chronic obstructive pulmonary disease. Annals of the American Thoracic Society 2013; 10(2): 81-9.

31. Guo Y, Zhang T, Wang Z, et al. Body mass index and mortality in chronic obstructive pulmonary disease: A dose-response meta-analysis. Medicine (Baltimore) 2016; 95(28): e4225.

32. Garcia-Aymerich J, Serra Pons I, Mannino DM, Maas AK, Miller DP, Davis KJ. Lung function impairment, COPD hospitalisations and subsequent mortality. Thorax 2011; 66(7): 585-90. 
33. Howcroft M, Walters EH, Wood-Baker R, Walters JA. Action plans with brief patient education for exacerbations in chronic obstructive pulmonary disease. Cochrane Database Syst Rev 2016; 12: Cd005074.

34. National Institute for Health and Care Excellence. Chronic obstructive pulmonary disease in over 16s: diagnosis and management. 2010. https://www.nice.org.uk/guidance/CG101 (accessed 14 October 2018).

35. Celli BR, MacNee W, ATS ERS Task Force. Standards for the diagnosis and treatment of patients with COPD: a summary of the ATS/ERS position paper. Eur Respir J 2004; 23(6): 932-46.

36. van Geffen WH, Douma WR, Slebos DJ, Kerstjens HA. Bronchodilators delivered by nebuliser versus pMDI with spacer or DPI for exacerbations of COPD. Cochrane Database Syst Rev 2016; (8): Cd011826.

37. van Eerd EA, van der Meer RM, van Schayck OC, Kotz D. Smoking cessation for people with chronic obstructive pulmonary disease. Cochrane Database Syst Rev 2016; (8): Cd010744.

38. Barr RG, Rowe BH, Camargo CA, Jr. Methylxanthines for exacerbations of chronic obstructive pulmonary disease: meta-analysis of randomised trials. BMJ 2003; 327(7416): 643.

39. Duffy N, Walker P, Diamantea F, Calverley PM, Davies L. Intravenous aminophylline in patients admitted to hospital with non-acidotic exacerbations of chronic obstructive pulmonary disease: a prospective randomised controlled trial. Thorax 2005; 60(9): 713-7.

40. Davies L, Angus RM, Calverley PM. Oral corticosteroids in patients admitted to hospital with exacerbations of chronic obstructive pulmonary disease: a prospective randomised controlled trial. Lancet 1999; 354(9177): 456-60.

41. Maltais F, Ostinelli J, Bourbeau J, et al. Comparison of nebulized budesonide and oral prednisolone with placebo in the treatment of acute exacerbations of chronic obstructive pulmonary disease: a randomized controlled trial. Am J Respir Crit Care Med 2002; 165(5): 698-703.

42. Niewoehner DE, Erbland ML, Deupree RH, et al. Effect of systemic glucocorticoids on exacerbations of chronic obstructive pulmonary disease. Department of Veferans Affairs Cooperative Study Group. $N$ Engl J Med 1999; 340(25): 1941-7.

43. Thompson WH, Nielson CP, Carvalho P, Charan NB, Growley JJ. Controlled trial of oral prednisone in outpatients with acute COPD exacerbation. Am JRespir Crit Care Med 1996; 154(2 Pt 1): 407-12.

44. Alia I, de la Cal MA, Esteban A, et al. Efficacy of corticosteroid therapy in patients with an acute exacerbation of chronic obstructive pulmonary disease receiving ventilatory support. Arch Intern Med 2011; 171(21): 1939-46.

45. Aaron SD, Vandemheen KL, Hebert $P$, et al. Outpatient oral prednisone after emergency treatment of chronic obstructive pulmonary disease. N Engl J Med 2003; 348(26): 2618-25.

46. Leuppi JD, Schuetz $P$, Bingisser $B$, et al. Short-term vs conventional glucocorticoid therapy in acute exacerbations of chronic obstructive pulmonary disease: the REDUCE randomized clinical trial. JAMA 2013; 309(21): 2223-31.

47. de Jong YP, Uil SM, Grotjohan HP, Postma DS, Kerstjens HA, van den Berg JW. Oral or IV prednisolone in the treatment of COPD exacerbations: a randomized, controlled, double-blind study. Chest 2007; 132(6): 1741-7?

48. Gunen H, Hacievliyagil SS, Yetkin O, Gulbas G, Mutlu LC, In E. The role of nebulised budesonide in the treatment of exacerbations of COPD. Eur Respir J 2007; 29(4): 660-7.

49. Stallberg B, Selroos O, Vogelmeier C, Andersson E, Ekstrom T, Larsson K. Budesonide/formoterol as effective as prednisolone plus formoterol in acute exacerbations of COPD. A double-blind, randomised, non-inferiority, parallel-group, multicentre study. Respir Res 2009; 10: 11.

50. Ding Z, Li X, Lu Y, et al. A randomized, controlled multicentric study of inhaled budesonide and intravenous methylprednisolone in the treatment on acute exacerbation of chronic obstructive pulmonary disease. Respir Med 2016; 121: 39-47.

51. Stolz D, Hirsch HH, Schilter D, et al. Intensified Therapy with Inhaled Corticosteroids and Long-Acting beta2-Agonists at the Onset of Upper Respiratory Tract Infection to Prevent Chronic Obstructive Pulmonary Disease Exacerbations. A Multicenter, Randomized, Double-Blind, Placebo-controlled Trial. Am J Respir Crit Care Med 2018; 197(9): 1136-46.

52. Seemungal T, Harper-Owen R, Bhowmik A, et al. Respiratory viruses, symptoms, and inflammatory markers in acute exacerbations and stable chronic obstructive pulmonary disease. Am J Respir Crit Care Med 2001; 164(9): 1618-23.

53. Vollenweider DJ, Jarrett H, Steurer-Stey CA, Garcia-Aymerich J, Puhan MA. Antibiotics for exacerbations of chronic obstructive pulmonary disease. Cochrane Database Syst Rev 2012; 12: cd010257. 
54. Miravitlles M, Kruesmann F, Haverstock D, Perroncel R, Choudhri SH, Arvis P. Sputum colour and bacteria in chronic bronchitis exacerbations: a pooled analysis. Eur Respir J 2012; 39(6): 1354-60.

55. Stockley RA, O'Brien C, Pye A, Hill SL. Relationship of sputum color to nature and outpatient management of acute exacerbations of COPD. Chest 2000; 117(6): 1638-45.

56. Ram FS, Rodriguez-Roisin R, Granados-Navarrete A, Garcia-Aymerich J, Barnes NC. Antibiotics for exacerbations of chronic obstructive pulmonary disease. Cochrane Database Syst Rev 2006; (2): CD004403.

57. Quon BS, Gan WQ, Sin DD. Contemporary management of acute exacerbations of COPD: a systematic review and metaanalysis. Chest 2008; 133(3): 756-66.

58. Wilson R, Anzueto A, Miravitlles M, et al. Moxifloxacin versus amoxicillin/clavulanic acid in outpatient acute exacerbations of COPD: MAESTRAL results. Eur Respir J 2012; 40(1): 17-27.

59. van Velzen P, Ter Riet G, Bresser P, et al. Doxycycline for outpatient-treated acute exacerbations of COPD: a randomised double-blind placebo-controlled trial. The Lancet Respiratory medicine 2017; 5(6): 492-9.

60. Clark TW, Medina MJ, Batham S, Curran MD, Parmar S, Nicholson KG. C-reactive protein level and microbial aetiology in patients hospitalised with acute exacerbation of COPD. Eur Respir J 2015; 45(1): 76-86.

61. Peng C, Tian C, Zhang Y, Yang X, Feng Y, Fan H. C-reactive protein levels predict ba Cterial exacerbation in patients with chronic obstructive pulmonary disease. The American journal of the medical sciences 2013; 345(3): 190-4.

62. Christ-Crain M, Jaccard-Stolz D, Bingisser R, et al. Effect of procalcitonin-guided treatment on antibiotic use and outcome in lower respiratory tract infections: cluster-randomised, single-blinded intervention trial. Lancet 2004; 363(9409): 600-7.

63. Schuetz $\mathrm{P}$, Christ-Crain $\mathrm{M}$, Thomann $\mathrm{R}$, et al. Effect of procalcitonin-based guidelines vs standard guidelines on antibiotic use in lower respiratory tract infections: the ProHOSP randomized controlled trial. Jama 2009; 302(10): 1059-66.

64. Schuetz P, Muller B, Christ-Crain M, et al. Procalcitonin to initiate or discontinue antibiotics in acute respiratory tract infections. Cochrane Database Syst Rev 2012; (9): Cd007498.

65. Wang JX, Zhang SM, Li XH, Zhang Y, Xu ZY, CaoB. Acute exacerbations of chronic obstructive pulmonary disease with low serum procalcitonin values do not benefit from antibiotic treatment: a prospective randomized controlled trial. International journal of infectious diseases : IJID : official publication of the International Society for Infectious Diseases 2016; 48: 40-5.

66. Mathioudakis AG, Chatzimavridou-Grigoriadou V, Corlateanu A, Vestbo J. Procalcitonin to guide antibiotic administration in COPD exacerbations: a meta-analysis. Eur Respir Rev 2017; 26(143).

67. Daubin $C$, Valette $X$, Thiolliere $F$, et al. Procalcitonin algorithm to guide initial antibiotic therapy in acute exacerbations of CQPD admitted to the ICU: a randomized multicenter study. Intensive Care Med 2018; 44(4): 428-37.

68. Masterton RG, Burfey CJ. Randomized, double-blind study comparing 5- and 7-day regimens of oral levofloxacin in patients with acute exacerbation of chronic bronchitis. Int J Antimicrob Agents 2001; 18(6): 503-12.

69. Adams S, J. M, Luther M. Antibiotics are associated with lower relapse rates in outpatients with acute exacerbations of chronic obstructive pulmonary disease. Chest 2000; 117: 1345-52.

70. Miravitlles M, Espinosa C, Fernandez-Laso E, Martos JA, Maldonado JA, Gallego M. Relationship between bacterial flora in sputum and functional impairment in patients with acute exacerbations of COPD. Study Group of Bacterial Infection in COPD. Chest 1999; 116(1): 40-6.

71. Soler N, Torres A, Ewig S, et al. Bronchial microbial patterns in severe exacerbations of chronic obstructive pulmonary disease (COPD) requiring mechanical ventilation. Am J Respir Crit Care Med 1998; 157(5 Pt 1): 1498-505.

72. Rizkallah J, Man SF, Sin DD. Prevalence of pulmonary embolism in acute exacerbations of COPD: a systematic review and metaanalysis. Chest 2009; 135(3): 786-93.

73. Gunen H, Gulbas G, In E, Yetkin O, Hacievliyagil SS. Venous thromboemboli and exacerbations of COPD. Eur Respir J 2010; 35(6): 1243-8.

74. Bertoletti L, Quenet S, Laporte S, et al. Pulmonary embolism and 3-month outcomes in 4036 patients with venous thromboembolism and chronic obstructive pulmonary disease: data from the RIETE registry. Respir Res 2013; 14: 75. 
75. Kahn S, Lim W, Dunn A, et al. American College of Chest Physicians. Prevention of VTE in nonsurgical patients: Antithrombotic Therapy and Prevention of Thrombosis, 9th ed: American College of Chest Physicians Evidence-Based Pracice Guidelines. Chest 2012; 141((2 Suppl)): e195S-226S.

76. Austin MA, Wills KE, Blizzard L, Walters EH, Wood-Baker R. Effect of high flow oxygen on mortality in chronic obstructive pulmonary disease patients in prehospital setting: randomised controlled trial. BMJ 2010; 341: c5462.

77. McKeever TM, Hearson G, Housley G, et al. Using venous blood gas analysis in the assessment of COPD exacerbations: a prospective cohort study. Thorax 2016; 71(3): 210-5.

78. Frat JP, Coudroy R, Marjanovic N, Thille AW. High-flow nasal oxygen therapy and noninvasive ventilation in the management of acute hypoxemic respiratory failure. Annals of translational medicine 2017; 5(14): 297.

79. Fraser JF, Spooner AJ, Dunster KR, Anstey CM, Corley A. Nasal high flow oxygen therapy in patients with COPD reduces respiratory rate and tissue carbon dioxide while increasing tidal and endexpiratory lung volumes: a randomised crossover trial. Thorax 2016; 71(8): 759-61.

80. Lin SM, Liu KX, Lin ZH, Lin PH. Does high-flow nasal cannula oxygen improve outcome in acute hypoxemic respiratory failure? A systematic review and meta-analysis. Respir Med 2017; 131: 58-64.

81. Nagata K, Kikuchi T, Horie T, et al. Domiciliary High-Flow Nasal Cannula Oxygen Therapy for Patients with Stable Hypercapnic Chronic Obstructive Pulmonary Disease. A Multicenter Randomized Crossover Trial. Annals of the American Thoracic Society 2018; 15(4): 432-9.8

82. Osadnik CR, Tee VS, Carson-Chahhoud KV, Picot J, Wedzicha JA, Smith BJ.Non-invasive ventilation for the management of acute hypercapnic respiratory failure due to exacerbation of chronic obstructive pulmonary disease. Cochrane Database Syst Rev 2017; 7: Cd004104.)

83. Brochard L, Mancebo J, Wysocki M, et al. Noninvasive ventilation for acute exacerbations of chronic obstructive pulmonary disease. N Engl J Med 1995; 333(13): 817-22.

84. Chandra D, Stamm JA, Taylor B, et al. Outcomes of noninvasive ventilation for acute exacerbation s of chronic obstructive pulmonary disease in the United States, 1998-2008. Am J Respir Crit Care Med 2012; 185(2): 152-9.

85. Meyer TJ, Hill NS. Noninvasive positive pressure ventilation to treat respiratory failure. Ann Intern Med 1994; 120(9): 760-70.

86. Consensus development conference committee. Clinical indications for noninvasive positive pressure ventilation in chronic respiratory failure due to restrictive lung disease, COPD, and nocturnal hypoventilation--a consensus conference report. Chest 1999; 116(2): 521-34.

87. Bott J, Carroll MP, Conway JH, et al. Randomised controlled trial of nasal ventilation in acute ventilatory failure due to chronic obstructive airways disease. Lancet 1993; 341(8860): 1555-7.

88. Kramer N, Meyer TJ, Meharg J, Cece RD, Hill NS. Randomized, prospective trial of noninvasive positive pressure ventilation in acute respiratory failure. Am J Respir Crit Care Med 1995; 151(6): 1799-806.

89. Plant PK, Owen JL, Elliott MW. Early use of non-invasive ventilation for acute exacerbations of chronic obstructive pulmopary disease on general respiratory wards: a multicentre randomised controlled trial. Lancet 2000; 355(9219): 1931-5.

90. Sellares J, Ferrer M, Anton A, et al. Discontinuing noninvasive ventilation in severe chronic obstructive pulmonary disease exacerbations: a randomised controlled trial. Eur Respir J 2017; 50(1).

91. Conti G, Antonelli M, Navalesi P, et al. Noninvasive vs. conventional mechanical ventilation in patients with chronic obstructive pulmonary disease after failure of medical treatment in the ward: a randomized trial. Intensive Care Med 2002; 28(12): 1701-7.

92. Esteban A, Anzueto A, Frutos F, et al. Characteristics and outcomes in adult patients receiving mechanical ventilation: a 28-day international study. JAMA 2002; 287(3): 345-55.

93. Wildman MJ, Sanderson C, Groves J, et al. Implications of prognostic pessimism in patients with chronic obstructive pulmonary disease (COPD) or asthma admitted to intensive care in the UK within the COPD and asthma outcome study (CAOS): multicentre observational cohort study. BMJ 2007; 335(7630): 1132.

94. Gunen H, Hacievliyagil SS, Kosar F, et al. Factors affecting survival of hospitalised patients with COPD. Eur Respir J 2005; 26(2): 234-41.

95. Jennings JH, Thavarajah K, Mendez MP, Eichenhorn M, Kvale P, Yessayan L. Predischarge bundle for patients with acute exacerbations of COPD to reduce readmissions and ED visits: a randomized controlled trial. Chest 2015; 147(5): 1227-34.

96. Singh G, Zhang W, Kuo YF, Sharma G. Association of Psychological Disorders With 30-Day Readmission Rates in Patients With COPD. Chest 2016; 149(4): 905-15. 
97. Ringbaek T, Green A, Laursen LC, Frausing E, Brondum E, Ulrik CS. Effect of tele health care on exacerbations and hospital admissions in patients with chronic obstructive pulmonary disease: a randomized clinical trial. Int J Chron Obstruct Pulmon Dis 2015; 10: 1801-8.

98. Hartl S, Lopez-Campos JL, Pozo-Rodriguez F, et al. Risk of death and readmission of hospital-admitted COPD exacerbations: European COPD Audit. Eur Respir J 2016; 47(1): 113-21.

99. Jordan RE, Majothi S, Heneghan NR, et al. Supported self-management for patients with moderate to severe chronic obstructive pulmonary disease (COPD): an evidence synthesis and economic analysis. Health technology assessment (Winchester, England) 2015; 19(36): 1-516.

100. Walker PP, Pompilio PP, Zanaboni P, et al. Telemonitoring in COPD: The CHROMED Study, a Randomized Clinical Trial. Am J Respir Crit Care Med 2018.

101. Benzo R, Vickers K, Novotny PJ, et al. Health Coaching and Chronic Obstructive Pulmonary Disease Rehospitalization. A Randomized Study. Am J Respir Crit Care Med 2016; 194(6): 672-80.

102. Puhan MA, Gimeno-Santos E, Scharplatz M, Troosters T, Walters EH, Steurer J. Pulmonary rehabilitation following exacerbations of chronic obstructive pulmonary disease. Cochrane Database Syst Rev 2011; (10): CD005305.

103. Gavish R, Levy A, Dekel OK, Karp E, Maimon N. The Association Between Hospital Readmission and Pulmonologist Follow-up Visits in Patients With COPD. Chest 2015; 148(2): 375-81.

104. Oga T, Tsukino M, Hajiro T, Ikeda A, Nishimura K. Predictive properties of different multidimensional staging systems in patients with chronic obstructive pulmonary disease. Int JChron Obstruct Pulmon Dis 2011; 6: 521-6.

105. Haruna A, Muro S, Nakano Y, et al. CT scan findings of emphysema predict mortality in COPD. Chest 2010; 138(3): 635-40.

106. Martinez-Garcia MA, de la Rosa Carrillo D, Soler-Cataluna JJ, et aRrognostic value of bronchiectasis in patients with moderate-to-severe chronic obstructive pulmonary disease. Am J Respir Crit Care Med 2013; 187(8): 823-31. 


\section{CHAPTER 6: COPD AND COMORBIDITIES}

OVERALL KEY POINTS:

- COPD often coexists with other diseases (comorbidities) that may have a significant impact on disease course.

- In general, the presence of comorbidities should not alter COPD treatment and comorbidities should be treated per usual standards regardless of the presence of COPD.

- Lung cancer is frequently seen in patients with COPD and is a maincause of death.

- Cardiovascular diseases are common and important comorbidities in COPD.

- Osteoporosis and depression/anxiety are frequent, \mportant comorbidities in COPD, are often under-diagnosed, and are associated with poor health status and prognosis.

- Gastroesophageal reflux (GERD) is associated with an increased risk of exacerbations and poorer health status.

- When COPD is part of a multimorbidity care plan, attention should be directed to ensure simplicity of treatment and to minimize polypharmacy.

\section{INTRODUCTION}

COPD often coexisfs with other diseases (comorbidities) that may have a significant impact on prognosis. $\stackrel{1-8}{-1}$ Some of these arise independently of COPD whereas others may be causally related, either with shared risk factors or by one disease increasing the risk or compounding the severity of the other. It is possible that features of COPD, are shared with other diseases and as such this mechanism represents a link between COPD and some of its comorbidities. $\underline{9}$ This risk of comorbid disease can be increased by the sequelae of COPD e.g., reduced physical activity or continued smoking. Whether or not COPD and comorbid diseases are related, management of the COPD patient must include identification and treatment of its comorbidities. Importantly, comorbidities with symptoms also associated with COPD may be overlooked e.g., heart failure and lung cancer (breathlessness) or depression (fatigue and reduced physical activity).

Comorbidities are common at any severity of COPD $\underline{10}$ and the differential diagnosis can often be difficult. For example, in a patient with both COPD and heart failure, an exacerbation of COPD may be accompanied by worsening of heart failure or vice versa. Although COPD is negatively impacted by 
multiple comorbid diseases, COPD itself is one of the most important comorbid conditions that adversely affects outcome of other disorders. For example, patients hospitalized with congestive heart failure or undergoing cardiac procedures such as coronary artery bypass grafting have greater morbidity and mortality when COPD is present compared to when it is absent. $\underline{11-13}$

Below is a brief guide to the management of some common comorbidities occurring in patients with COPD with stable disease. The recommendations may be insufficient for the management of all COPD patients and are not a substitute for the use of guidelines for the management of each individual comorbid condition.

\section{Cardiovascular disease (CVD)}

CVD is a frequent and important comorbidity in COPD. 2.9 Five separate entities within CVD will be considered: ischemic heart disease, heart failure, arrhythmias, peripheral vascular disease, and hypertension.

\section{Heart failure}

The prevalence of systolic or diastolic heart failure in COPD patients ranges from 20 to $70 \%, \underline{14}$ and its annual incidence between 3-4\%. Incident heart failure is a significant and independent predictor of all-cause mortality.

Unrecognized heart failure may mimic or accompany acute COPD; $40 \%$ of COPD patients that are mechanically ventilated because of hypercapnic respiratory failure have evidence of left ventricular dysfunction. $\underline{\underline{15}, \underline{16}}$

There is no evidence that chronic heart failure should be treated differently in the presence of COPD. Treatment with $ß_{1}$-blockers improves survival in heart failure and is recommended. However, $\beta_{1}$-blockers are often not prescribed in COPD despite available evidence showing that their use in COPD is safe. Selective $\beta_{1}$-blockers should be used. $\underline{17}^{17}$

Acute heart failure-should be treated according to usual heart failure guidelines since there is no evidence to support an alternative management strategy. Noninvasive ventilation added to conventional therapy improves outcomes for patients with either hypercapnic respiratory failure due to an exacerbation of COPD as well as heart failure with acute pulmonary edema. $\underline{18}$

\section{Ischaemic heart disease (IHD)}

Ischaemic heart disease should be considered in all COPD patients depending on their risk factor profile. The cardiovascular risk may be assessed by the global risk calculator, which can be found on the US National Heart Blood Lung Institute website $\underline{\underline{19}}$ and treatment initiated based on the current recommendations.

During and for at least 30 days after acute COPD exacerbations, there is an increased risk of myocardial damage in patients with concomitant ischemic heart disease. 20 Patients who demonstrate abnormal cardiac troponins in isolation are at increased risk of adverse outcomes including short-term (30 day) and long-term mortality. $\underline{21}$ 
The treatment of ischaemic heart disease should be according to guidelines irrespective of the presence of COPD and vice versa.

\section{Arrhythmias}

Cardiac arrhythmias are common in COPD and vice versa. Atrial fibrillation is frequent and directly associated with $\mathrm{FEV}_{1} . \underline{22}$

In COPD patients presenting with severe worsening dyspnea, associated atrial fibrillation is frequently documented, and it may be either a trigger or a consequence of an acute exacerbation episode. $\underline{23}$

The presence of atrial fibrillation does not alter the treatment of COPD. Bronchodilators have been previously described as potentially pro-arrhythmic agents $\underline{24}, \underline{25}$; however, available evidence suggests an overall acceptable safety profile for long-acting beta ${ }_{2}$-agonists,, anticholinergic drugs (and inhaled corticosteroids)..$\underline{27-34}$ Nevertheless, caution is advised when using short-acting beta 2 -agonists $\underline{26}, \underline{35}$ and theophylline, which may precipitate atrial fibrillation and make controt of the ventricular response rate difficult. $\frac{36-38}{6}$

\section{Peripheral vascular disease}

Peripheral artery disease (PAD) is an atherosclerotic process that refers to the occlusion of the arteries in the lower limbs; PAD is commonly associafed with atherosclerotic heart disease and may have significant implications for functional activity as well as quality of life in patients with COPD. $\frac{39}{}$

In a large cohort of patients with COPD of all degrees of severity, $8.8 \%$ were diagnosed with PAD that was higher than the prevalence in non-COPD controls (1.8\%).

COPD patients with PAD reported a worse functional capacity and worse health status compared to those without PAD. Clinicians should consider PAD in patients with COPD to those at risk for vascular events and to fully understand their functional impairments.

\section{Hypertension}

Hypertension is likely to be the most frequently occurring comorbidity in COPD and may have implications for prognosis. .90 Diastolic dysfunction as a result of optimally treated hypertension may be associated with exercise intolerance and mimic symptoms associated with an acute exacerbation thereby provoking hospitalization in COPD. $\underline{14}$ These data stress the importance of optimal blood pressure control in COPD patients with underlying hypertension. $.11,42$

Hypertension should be treated according to usual guidelines. There is no evidence that hypertension should be treated differently in the presence of COPD. The role of treatment with selective beta-blockers is less prominent in recent hypertension guidelines and there is no evidence that in patients with COPD and increased cardiovascular risk beta-blockers either reduce the benefits of treatment with LABA or increase cardiovascular risk. $\underline{43}$

COPD should be treated as usual as there is no direct evidence that COPD should be treated 
differently in the presence of hypertension.

\section{Osteoporosis}

Osteoporosis is a major comorbidity $-9,9$ which is often under-diagnosed $\underline{44}$ and associated with poor health status and prognosis.

Osteoporosis is often associated with emphysema,,$\underline{45}$ decreased body mass index $\underline{46}$ and low fat-free mass. ${ }^{47}$ Low bone mineral density and fractures are commonly in COPD patients even after adjustment for steroid use, age, pack-years of smoking, current smoking, and exacerbations. $\stackrel{48,49}{9}$

Osteoporosis should be treated according to usual guidelines.

COPD should be treated as usual despite the presence of osteoporosis. An association between inhaled corticosteroids and fractures has been found in pharmaco- epidemiologícall studies; however, these studies have not fully taken severity of COPD or exacerbations and theirtreatment into account.

Systemic corticosteroids significantly increase the risk of osteoporosis and repeated courses for COPD exacerbations should be avoided if possible

\section{Anxiety and depression}

Anxiety and depression are important comorbidities in COPD ${ }^{50-53}$ and both are associated with a poor prognosis, $\underline{52,54}$ younger age, female sex, smoking, lower FEV ${ }_{1}$, cough, higher SGRQ score, and a history of cardiovascular disease. $\underline{50,53,55}$

There is no evidence that anxiety and depression should be treated differently in the presence of COPD.

COPD should be treated as usual. The potential impact of pulmonary rehabilitation should be stressed as studies have found that physical exercise has a beneficial effect on depression in general. $\frac{5,57}{57}$

COPD is very common in patients with other psychiatric illnesses, often under-diagnosed and treated. $\underline{58,59}$

\section{COPD and lung cancer}

There is ample evidence of an association between COPD and lung cancer. $4,9,60-62$ The association between emphysema and lung cancer is stronger than between airflow limitation and lung cancer. $\underline{63-}$ 65 The greatest risk is observed in subjects with both findings. Increased age and greater smoking history further increases risk. $\frac{66}{6}$

As for COPD, the best prevention for lung cancer is smoking cessation. $\underline{67,68}$

Two studies of low-dose chest computed tomography (LDCT) screening have shown improved survival in subjects aged 55-74 years, current smokers or those who quit within the previous 15 years, 
with a smoking history of at least 30 pack-years..$\underline{60}$ LDCT is now recommended in the US for patients meeting these demographics. However, this is not a worldwide practice. The reasons are: concerns regarding avoidance of over-diagnosis; greater morbidity and mortality with needless diagnostic procedures for benign abnormalities; anxiety; and incomplete follow-up.

\section{Metabolic syndrome and diabetes}

Studies have shown that metabolic syndrome and manifest diabetes are more frequent in COPD and the latter is likely to affect prognosis. . $^{-}$

The prevalence of metabolic syndrome has been estimated to be more than $30 \% . \underline{71}$

Diabetes should be treated according to usual guidelines for diabetes. COPD should be treated as usual.

\section{Gastroesophageal reflux (GERD)}

GERD is an independent risk factor for exacerbations and is associated with worse health status. $\frac{72-}{2}$ 74 The mechanisms responsible for increased risk of exacerbations are not yet fully established.

Proton pump inhibitors are often used for treatment of GERD. One small, single-blind study suggested these agents decrease the risk of exacerbation, remains controversial most effective treatment for this condition in COPD has yet to be established. $\underline{76, \underline{7}, \underline{7}}$

\section{Bronchiectasis}

With increasing use of computed tomography in the assessment of patients with COPD, the presence of previously unrecognized bronchiectasis is being identified. $\underline{78}$

Whether this diagnosis bassed on radiological criteria has the same impact as a clinical diagnosis of bronchiectasis remains unknown at present, although it is associated with longer exacerbations $\underline{79}$ and increased mortality.

Bronchiectasis should be treated according to usual guidelines.

Regarding COPD treatment, some patients may need more aggressive and prolonged antibiotic therapy. Inhaled corticosteroids may not be indicated in patients with bacterial colonization or recurrent lower respiratory tract infections.

\section{Obstructive sleep apnea}

COPD has an estimated prevalence in U.S. adults of $13.9 \%$ 1, 82 and obstructive sleep apnea (OSA), a sleep disorder hallmarked by repeated episodes of upper airway closure, affects $9 \%$ to $26 \%$ of the U.S. adult population. $\underline{\underline{8}}$

The term "overlap syndrome" has been used to describe the association of both conditions in a 


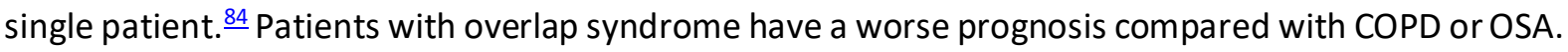
During sleep, patients with both COPD and OSA suffer more frequent episodes of oxygen desaturation and have more total sleep time with hypoxemia and hypercapnia than OSA patients without COPD. $\underline{85}$

The apneic events in patients with combined OSA and COPD have more profound hypoxemia and more cardiac arrhythmias. ${ }^{86}$ Additionally, patients with combined COPD and OSA are more likely to develop daytime pulmonary hypertension ${ }^{87,88}$ than patients with just OSA or COPD alone.

\section{COPD as part of multimorbidity}

An increasing number of people in any aging population will suffer from multi-morbidity, defined as the presence of two or more chronic conditions, and COPD is present in the majority of multimorbid patients.

Multi-morbid patients have symptoms from multiple diseases and thus symptoms and signs are complex and most often attributable to several causes in the chronic state as well as during acute events.

There is no evidence that COPD should be treated differently when part of multi-morbidity; however, it should be kept in mind that most evidence comesfrom trials in patients with COPD as the only significant disease. $\frac{89}{}$

Treatments should be kept simple in the light of the unbearable polypharmacy that these patients are often exposed to.

\section{REFERENCES}

1. Barnes PJ, Celli BR. Systemi manifestations and comorbidities of COPD. Eur Respir J 2009; 33(5): 1165-85.

2. Soriano JB, Visick GT, Muellerova H, Payvandi N, Hansell AL. Patterns of comorbidities in newly diagnosed COPD and asthma in primary care. Chest 2005; 128(4): 2099-107.

3. Mannino DM, Thorn D, Swensen A, Holguin F. Prevalence and outcomes of diabetes, hypertension and cardiovascular disease in COPD. Eur Respir J 2008; 32(4): 962-9.

4. Sin DD, Anthonisen NR, Soriano JB, Agusti AG. Mortality in COPD: Role of comorbidities. Eur Respir J 2006; 28(6): 1245-57.

5. Iversen KK, Kjaergaard J, Akkan D, et al. The prognostic importance of lung function in patients admitted with heart failure. Eur J Heart Fail 2010; 12(7): 685-91.

6. Almagro P, Soriano JB, Cabrera FJ, et al. Short- and medium-term prognosis in patients hospitalized for COPD exacerbation: the CODEX index. Chest 2014; 145(5): 972-80.

7. Miller J, Edwards LD, Agusti A, et al. Comorbidity, systemic inflammation and outcomes in the ECLIPSE cohort. Respir Med 2013; 107(9): 1376-84.

8. Campo G, Napoli N, Serenelli C, Tebaldi M, Ferrari R. Impact of a recent hospitalization on treatment and prognosis of ST-segment elevation myocardial infarction. Int J Cardiol 2013; 167(1): 296-7.

9. Fabbri LM, Luppi F, Beghe B, Rabe KF. Complex chronic comorbidities of COPD. Eur Respir J 2008; 31(1): 204-12.

10. Agusti A, Calverley PM, Celli B, et al. Characterisation of COPD heterogeneity in the ECLIPSE cohort. Respir Res 2010; 11: 122.

11. Krahnke JS, Abraham WT, Adamson PB, et al. Heart failure and respiratory hospitalizations are reduced in patients with heart failure and chronic obstructive pulmonary disease with the use of an implantable pulmonary artery pressure monitoring device. J Card Fail 2015; 21(3): 240-9. 
12. Leavitt BJ, Ross CS, Spence B, et al. Long-term survival of patients with chronic obstructive pulmonary disease undergoing coronary artery bypass surgery. Circulation 2006; 114(1 Suppl): 1430-4.

13. Mascarenhas J, Lourenco P, Lopes R, Azevedo A, Bettencourt P. Chronic obstructive pulmonary disease in heart failure. Prevalence, therapeutic and prognostic implications. American heart journal 2008; 155(3): 521-5.

14. Bhatt SP, Dransfield MT. Chronic obstructive pulmonary disease and cardiovascular disease. Trans/ Res 2013; 162(4): 237-51.

15. Matamis D, Tsagourias M, Papathanasiou A, et al. Targeting occult heart failure in intensive care unit patients with acute chronic obstructive pulmonary disease exacerbation: effect on outcome and quality of life. J Crit Care 2014; 29(2): 315.e7-14.

16. MacDonald MI, Shafuddin E, King PT, Chang CL, Bardin PG, Hancox RJ. Cardiac dysfunction during exacerbations of chronic obstructive pulmonary disease. The Lancet Respiratory medicine 2016; 4(2): 138-48.

17. Lipworth B, Wedzicha J, Devereux G, Vestbo J, Dransfield MT. Beta-blockers in COPD: time for reappraisal. Eur Respir J 2016; 48(3): 880-8.

18. Masa JF, Utrabo I, Gomez de Terreros J, et al. Noninvasive ventilation for severely acidotic patients in respiratory intermediate care units : Precision medicine in intermediate care units. BMC Pulm Med 2016; 16(1): 97.

19. National Heart Lung \& Blood Institute. Risk Assessment Tool for Estimating Xour 10-year Risk of Having a Heart Attack 2016. http://cvdrisk.nhlbi.nih.gov/ (accessed 14 October 2018).

20. Kunisaki KM, Dransfield MT, Anderson JA, et al. Exacerbations of Chronic Obstructive Pulmonary Disease and Cardiac Events. A Post Hoc Cohort Analysis from the SUMMIT Randomized Clinical Trial. Am J Respir Crit Care Med 2018; 198(1): 51-7.

21. Hoiseth AD, Neukamm A, Karlsson BD, Omland T, Brekke PH, Soyseth V. Elevated high-sensitivity cardiac troponin $\mathrm{T}$ is associated with increased mortality after acute exacerbation of chronic obstructive pulmonary disease. Thorax 2011; 66(9): 775-81.

22. Buch $\mathrm{P}$, Friberg J, Scharling $\mathrm{H}$, Lange $\mathrm{P}$, Prescott $\mathrm{E}$. Reduced lung function and risk of atrial fibrillation in the Copenhagen City Heart Study. Eur Respir J2003; 21(6): 1012-6.

23. Terzano C, Romani S, Conti V, Paone G, Oriolo E, Vitarelli A. Atrial fibrillation in the acute, hypercapnic exacerbations of COPD. Eur Rev Med Pharmacol Sci 2014; 18(19): 2908-17.

24. Singh S, Loke YK, Enright P, Furberg CD. Pro-arrhythmic and pro-ischaemic effects of inhaled anticholinergic medications. Thorax 2013; 68(1): 114-6.

25. Wilchesky M, Ernst P, Brophy JM, Platt RW, Suissa S. Bronchodilator use and the risk of arrhythmia in COPD: part 2: reassessment in the larger Quebec cohort. Chest 2012; 142(2): 305-11.

26. Salpeter SR, Ormiston TM, Salpeter EE. Cardiovascular effects of beta-agonists in patients with asthma and COPD: a meta-analysis. Chest 2004; 125(6): 2309-21.

27. Wise RA, Anzueto A, Cotton D, et al. Tiotropium Respimat inhaler and the risk of death in COPD. $N$ Engl J Med 2013; 369(16): 1491-501.

28. Tashkin DP, Celli B, Senn S, et al. A 4-year trial of tiotropium in chronic obstructive pulmonary disease. N Engl J Med 2008; 359(15): 1543-54.

29. Tashkin DP, Fabbri LM. Long-acting beta-agonists in the management of chronic obstructive pulmonary disease: current and future agents. Respir Res 2010; 11: 149.

30. Calverley P, Pauwels R, Vestbo J, et al. Combined salmeterol and fluticasone in the treatment of chronic obstructive pulmonary disease: a randomised controlled trial. Lancet 2003; 361(9356): 44956.

31. Szafranski W, Cukier A, Ramirez A, et al. Efficacy and safety of budesonide/formoterol in the management of chronic obstructive pulmonary disease. Eur Respir J 2003; 21(1): 74-81.

32. Calverley PM, Boonsawat W, Cseke Z, Zhong N, Peterson S, Olsson H. Maintenance therapy with budesonide and formoterol in chronic obstructive pulmonary disease. Eur Respir J 2003; 22(6): 912-9.

33. Calverley PM, Anderson JA, Celli B, et al. Cardiovascular events in patients with COPD: TORCH study results. Thorax 2010; 65(8): 719-25.

34. Vestbo J, Anderson JA, Brook RD, et al. Fluticasone furoate and vilanterol and survival in chronic obstructive pulmonary disease with heightened cardiovascular risk (SUMMIT): a double-blind randomised controlled trial. Lancet 2016; 387(10030): 1817-26.

35. Wilchesky M, Ernst P, Brophy JM, Platt RW, Suissa S. Bronchodilator use and the risk of arrhythmia in COPD: part 1: Saskatchewan cohort study. Chest 2012; 142(2): 298-304. 
36. January CT, Wann LS, Alpert JS, et al. 2014 AHA/ACC/HRS guideline for the management of patients with atrial fibrillation: a report of the American College of Cardiology/American Heart Association Task Force on practice guidelines and the Heart Rhythm Society. Circulation 2014; 130(23): e199-267.

37. Ohta K, Fukuchi Y, Grouse L, et al. A prospective clinical study of theophylline safety in 3810 elderly with asthma or COPD. Respir Med 2004; 98(10): 1016-24.

38. Sessler CN, Cohen MD. Cardiac arrhythmias during theophylline toxicity. A prospective continuous electrocardiographic study. Chest 1990; 98(3): 672-8.

39. Houben-Wilke S, Jorres RA, Bals R, et al. Peripheral Artery Disease and Its Clinical Relevance in Patients with Chronic Obstructive Pulmonary Disease in the COPD and Systemic ConsequencesComorbidities Network Study. Am J Respir Crit Care Med 2017; 195(2): 189-97.

40. Divo $\mathrm{M}$, Cote $\mathrm{C}$, de Torres JP, et al. Comorbidities and risk of mortality in patients with chronic obstructive pulmonary disease. Am J Respir Crit Care Med 2012; 186(2): 155-61.

41. Abusaid GH, Barbagelata A, Tuero E, Mahmood A, Sharma G. Diastolic dysfunction and COPD exacerbation. Postgraduate medicine 2009; 121(4): 76-81.

42. Lopez-Sanchez M, Munoz-Esquerre M, Huertas D, et al. High Prevalence of Left Ventricle Diastolic Dysfunction in Severe COPD Associated with A Low Exercise Capacity: A Cross-Sectional Study. PloS one 2013; 8(6): e68034.

43. Dransfield MT, McAllister DA, Anderson JA, et al. beta-Blocker Therapy and Clinical Outcomes in Patients with Moderate Chronic Obstructive Pulmonary Disease and Heightened Cardiovascular Risk. An Observational Substudy of SUMMIT. Annals of the American Thoracic Society 2018; 15(5): 608-14.

44. Madsen $\mathrm{H}$, Brixen K, Hallas J. Screening, prevention and treatment of OSteoporosis in patients with chronic obstructive pulmonary disease - a population-based database study. Clin Respir J 2010; 4(1): 22-9.

45. Bon J, Fuhrman CR, Weissfeld JL, et al. Radiographic emphysema predicts low bone mineral density in a tobacco-exposed cohort. Am J Respir Crit Care Med 2011,183(7): 885-90.

46. Bolton $\mathrm{CE}$, Cannings-John R, Edwards $\mathrm{PH}$, et al. What community measurements can be used to predict bone disease in patients with COPD? Respir-Med 2008; 102(5): 651-7.

47. Bolton CE, Ionescu AA, Shiels KM, et al. Associated loss of fat-free mass and bone mineral density in chronic obstructive pulmonary disease. Am JRespir Crit Care Med 2004; 170(12): 1286-93.

48. Jaramillo JD, Wilson C, Stinson DS, et al. Reduced Bone Density and Vertebral Fractures in Smokers. Men and COPD Patients at Increased Risk. Annals of the American Thoracic Society 2015; 12(5): 648 56.

49. Jaramillo J, Wilson C, Stinson D, et al. Erratum: reduced bone density and vertebral fractures in smokers. men and COPD patients at increased risk. Annals of the American Thoracic Society 2015; 12(7): 1112.

50. Hanania NA, Mullerova H, Locantore NW, et al. Determinants of depression in the ECLIPSE chronic obstructive pulmonary disease cohort. Am J Respir Crit Care Med 2011; 183(5): 604-11.

51. Kunik ME, Roundy $K$, Veazey $C$, et al. Surprisingly high prevalence of anxiety and depression in chronic breathing disorders. Chest 2005; 127(4): 1205-11.

52. Ng TP, Niti M, Tan WC, Cao Z, Ong KC, Eng P. Depressive symptoms and chronic obstructive pulmonary disease: effect on mortality, hospital readmission, symptom burden, functional status, and quality of life. Arch Intern Med 2007; 167(1): 60-7.

53. Maurer J, Rebbapragada V, Borson S, et al. Anxiety and depression in COPD: current understanding, unanswered questions, and research needs. Chest 2008; 134(4 Suppl): 43S-56S.

54. Eisner MD, Blanc PD, Yelin EH, et al. Influence of anxiety on health outcomes in COPD. Thorax 2010; 65(3): 229-34.

55. Chen W, Thomas J, Sadatsafavi M, FitzGerald JM. Risk of cardiovascular comorbidity in patients with chronic obstructive pulmonary disease: a systematic review and meta-analysis. The Lancet Respiratory medicine 2015; 3(8): 631-9.

56. Bolton CE, Bevan-Smith EF, Blakey JD, et al. British Thoracic Society guideline on pulmonary rehabilitation in adults. Thorax 2013; 68 Suppl 2: ii1-30.

57. Coventry PA, Bower P, Keyworth C, et al. The effect of complex interventions on depression and anxiety in chronic obstructive pulmonary disease: systematic review and meta-analysis. PloS one 2013; 8(4): e60532.

58. Himelhoch S, Lehman A, Kreyenbuhl J, Daumit G, Brown C, Dixon L. Prevalence of chronic obstructive pulmonary disease among those with serious mental illness. The American journal of psychiatry 2004; 161(12): 2317-9. 
59. Jones DR, Macias C, Barreira PJ, Fisher WH, Hargreaves WA, Harding CM. Prevalence, severity, and cooccurrence of chronic physical health problems of persons with serious mental illness. Psychiatric services (Washington, DC) 2004; 55(11): 1250-7.

60. McGarvey LP, Magder S, Burkhart D, et al. Cause-specific mortality adjudication in the UPLIFT(R) COPD trial: findings and recommendations. Respir Med 2012; 106(4): 515-21.

61. Lange P, Nyboe J, Appleyard M, Jensen G, Schnohr P. Ventilatory function and chronic mucus hypersecretion as predictors of death from lung cancer. Am Rev Respir Dis 1990; 141(3): 613-7.

62. Tockman MS, Anthonisen NR, Wright EC, Donithan MG. Airways obstruction and the risk for lung cancer. Ann Intern Med 1987; 106(4): 512-8.

63. de Torres JP, Bastarrika G, Wisnivesky JP, et al. Assessing the relationship between lung cancer risk and emphysema detected on low-dose CT of the chest. Chest 2007; 132(6): 1932-8.

64. Wilson DO, Leader JK, Fuhrman CR, Reilly JJ, Sciurba FC, Weissfeld JL. Quantitative computed tomography analysis, airflow obstruction, and lung cancer in the pittsburgh lung screening study. J Thorac Oncol 2011; 6(7): 1200-5.

65. Wilson DO, Weissfeld JL, Balkan A, et al. Association of radiographic emphysema and airflow obstruction with lung cancer. Am J Respir Crit Care Med 2008; 178(7): 738-44.

66. de-Torres JP, Wilson DO, Sanchez-Salcedo P, et al. Lung cancer in patients with chronic obstructive pulmonary disease. Development and validation of the COPD Lung Cancer Screening Score. Am J Respir Crit Care Med 2015; 191(3): 285-91.

67. Oelsner EC, Carr JJ, Enright PL, et al. Per cent emphysema is associated with respiratory and lung cancer mortality in the general population: a cohort study. Thorax 2016; 71(7): 624-32.

68. Zulueta JJ, Wisnivesky JP, Henschke $\mathrm{Cl}$, et al. Emphysema scores predict death from COPD and lung cancer. Chest 2012; 141(5): 1216-23.

69. Aberle DR, Adams AM, Berg CD, et al. Reduced lung-cancer mortality with low-dose computed tomographic screening. N Engl J Med 2011; 365(5): 395-409.

70. Infante M, Cavuto S, Lutman FR, et al. Long-Term Follow-up Results of the DANTE Trial, a Randomized Study of Lung Cancer Screening with Spiral Computed Tomography. Am J Respir Crit Care Med 2015; 191(10): 1166-75.

71. Cebron Lipovec N, Beijers RJ, van den Borst B, Doehner W, Lainscak M, Schols AM. The Prevalence of Metabolic Syndrome In Chronic Obstructive Pulmonary Disease: A Systematic Review. Copd 2016; 13(3): 399-406.

72. Hurst JR, Vestbo J, Anzueto A, et al. Susceptibility to exacerbation in chronic obstructive pulmonary disease. N Engl J Med 2010; 363(12): 1128-38.

73. Martinez $\mathrm{CH}$, Okajima Y, Murray S, et al. Impact of self-reported gastroesophageal reflux disease in subjects from COPDGene cohort. Respir Res 2014; 15: 62.

74. Ingebrigtsen TS, Marott $\mathcal{L}$, Vestbo J, Nordestgaard BG, Hallas J, Lange P. Gastro-esophageal reflux disease and exacerbations in chronic obstructive pulmonary disease. Respirology 2015; 20(1): 101-7.

75. Sasaki T, Nakayama K, Yasuda $\mathrm{H}$, et al. A randomized, single-blind study of lansoprazole for the prevention of exacerbations of chronic obstructive pulmonary disease in older patients. J Am Geriatr Soc 2009; $57(8):$ 1453-7.

76. Baumeler L, Papakonstantinou E, Milenkovic B, et al. Therapy with proton-pump inhibitors for gastroesophageal reflux disease does not reduce the risk for severe exacerbations in COPD. Respirology 2016; 21(5): 883-90.

77. Benson VS, Mullerova H, Vestbo J, Wedzicha JA, Patel A, Hurst JR. Associations between gastrooesophageal reflux, its management and exacerbations of chronic obstructive pulmonary disease. Respir Med 2015; 109(9): 1147-54.

78. O'Brien C, Guest PJ, Hill SL, Stockley RA. Physiological and radiological characterisation of patients diagnosed with chronic obstructive pulmonary disease in primary care. Thorax 2000; 55(8): 635-42.

79. Patel IS, Vlahos I, Wilkinson TM, et al. Bronchiectasis, exacerbation indices, and inflammation in chronic obstructive pulmonary disease. Am J Respir Crit Care Med 2004; 170(4): 400-7.

80. Martinez-Garcia MA, de la Rosa Carrillo D, Soler-Cataluna JJ, et al. Prognostic value of bronchiectasis in patients with moderate-to-severe chronic obstructive pulmonary disease. Am J Respir Crit Care Med 2013; 187(8): 823-31.

81. Jemal A, Ward E, Hao Y, Thun M. Trends in the leading causes of death in the United States, 19702002. JAMA 2005; 294(10): 1255-9. 
82. Mannino DM, Gagnon RC, Petty TL, Lydick E. Obstructive lung disease and low lung function in adults in the United States: data from the National Health and Nutrition Examination Survey, 1988-1994. Arch Intern Med 2000; 160(11): 1683-9.

83. Young T, Palta M, Dempsey J, Skatrud J, Weber S, Badr S. The occurrence of sleep-disordered breathing among middle-aged adults. N Engl J Med 1993; 328(17): 1230-5.

84. Flenley DC. Sleep in chronic obstructive lung disease. Clin Chest Med 1985; 6(4): 651-61.

85. Chaouat A, Weitzenblum E, Krieger J, Ifoundza T, Oswald M, Kessler R. Association of chronic obstructive pulmonary disease and sleep apnea syndrome. Am J Respir Crit Care Med 1995; 151(1): 82-6.

86. Shepard JW, Jr., Garrison MW, Grither DA, Evans R, Schweitzer PK. Relationship of ventricular ectopy to nocturnal oxygen desaturation in patients with chronic obstructive pulmonary disease. Am J Med 1985; 78(1): 28-34.

87. Bradley TD, Rutherford R, Grossman RF, et al. Role of daytime hypoxemia in the pathogenesis of right heart failure in the obstructive sleep apnea syndrome. Am Rev Respir Dis 1985; 131(6): 835-9.

88. Weitzenblum E, Krieger J, Apprill M, et al. Daytime pulmonary hypertension in patients with obstructive sleep apnea syndrome. Am Rev Respir Dis 1988; 138(2): 345-9.

89. National Institute for Health and Care Excellence. Multimorbidity: clinical assessment and management, in press. 2016. https://www.nice.org.uk/guidance/indevelopment/gidcgwave0704/documents (accessed 14 October 2018). 


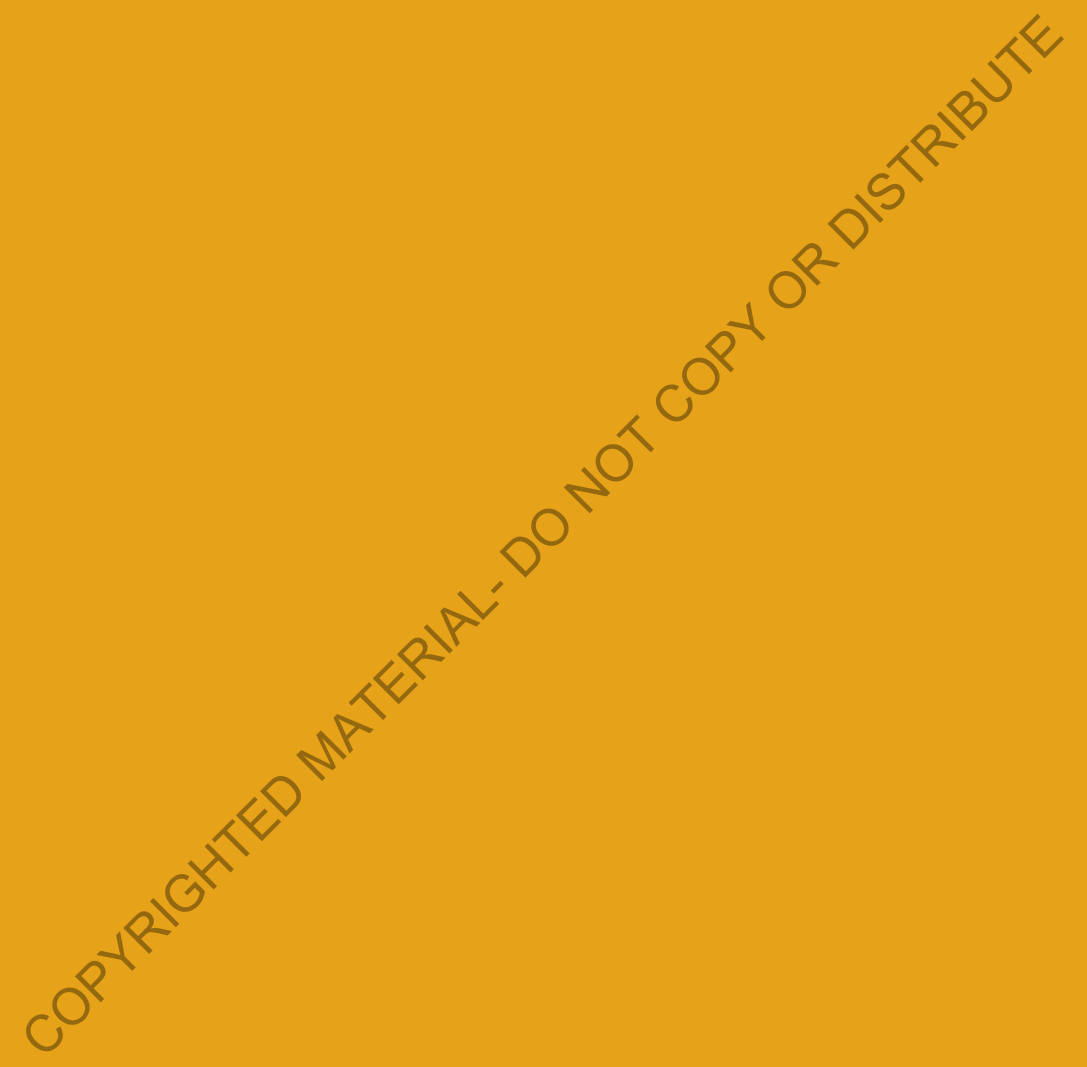

Visit the GOLD website at www.goldcopd.org (C) 2019 Global Initiative for Chronic Obstructive Lung Disease 